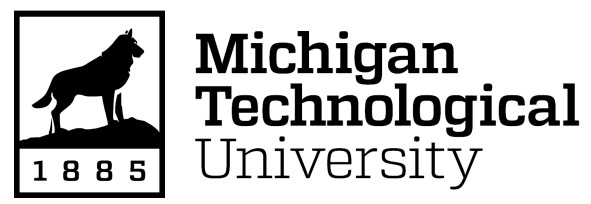

Michigan Technological University Digital Commons @ Michigan Tech

Dissertations, Master's Theses and Master's Reports

2021

\title{
A TRANSDISCIPLINARY ANALYSIS OF JUST TRANSITION PATHWAYS TO 100\% RENEWABLE ELECTRICITY
}

Adewale Aremu Adesanya

Michigan Technological University, adesanya@mtu.edu

Copyright 2021 Adewale Aremu Adesanya

\section{Recommended Citation}

Adesanya, Adewale Aremu, "A TRANSDISCIPLINARY ANALYSIS OF JUST TRANSITION PATHWAYS TO 100\% RENEWABLE ELECTRICITY", Open Access Dissertation, Michigan Technological University, 2021. https://doi.org/10.37099/mtu.dc.etdr/1184

Follow this and additional works at: https://digitalcommons.mtu.edu/etdr

Part of the Data Science Commons, Design of Experiments and Sample Surveys Commons, Energy Policy Commons, Environmental Policy Commons, Environmental Studies Commons, Infrastructure Commons, Multivariate Analysis Commons, Operational Research Commons, Other Operations Research, Systems Engineering and Industrial Engineering Commons, Power and Energy Commons, Public Policy Commons, Social Justice Commons, and the Statistical Models Commons 


\title{
A TRANSDISCIPLINARY ANALYSIS OF JUST TRANSITION PATHWAYS TO $100 \%$ RENEWABLE ELECTRICITY
}

\author{
By \\ Adewale A. Adesanya \\ A DISSERTATION \\ Submitted in partial fulfillment of the requirements for the degree of \\ DOCTOR OF PHILOSOPHY \\ In Environmental and Energy Policy \\ MICHIGAN TECHNOLOGICAL UNIVERSITY \\ 2021 \\ (C) 2021 Adewale A. Adesanya
}


This dissertation has been approved in partial fulfillment of the requirements for the Degree of DOCTOR OF PHILOSOPHY in Environmental and Energy Policy.

\title{
Department of Social Sciences
}

\author{
Dissertation Co-Advisor: Chelsea L. Schelly (Ph.D.) \\ Dissertation Co-Advisor: Roman V. Sidortsov (Ph.D.) \\ Committee Member: $\quad$ Angela Carter (Ph.D.) \\ Committee Member: Joshua M. Pearce (Ph.D.)
}

Department Chair: Hugh Gorman (Ph.D.) 


\section{Table of Contents}

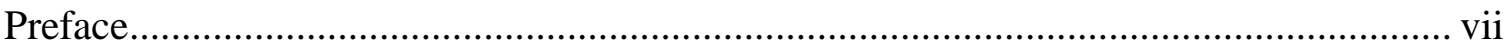

Acknowledgements ................................................................................................. ix

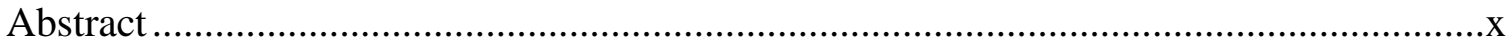

Dissertation Snapshot Table .................................................................................... xi

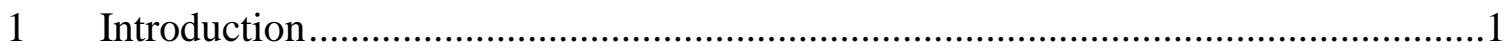

1.1 The Scholarship: just energy transition, energy transitions as a sociotechnical system transition (STST), STST and the intergenerational justice nexus ...................

1.1.1 Just Energy Transition ................................................................

1.1.2 Energy Transitions as Sociotechnical System Transitions (STST) ....5

1.1.3 STST and Intergenerational Justice Nexus .........................................6

1.2 Overarching Dissertation Question and Objective .........................................

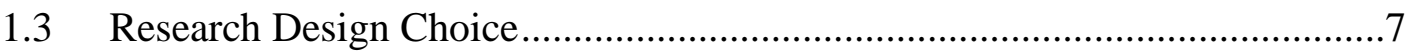

1.3.1 Methodology and Rationale ..........................................................

1.3.2 Transdisciplinary Research Approach ...............................................8

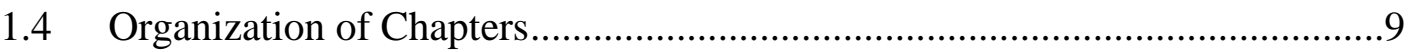

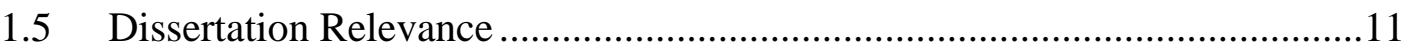

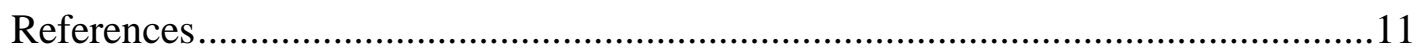

2 Act Locally, Transition Globally: Grassroots Resilience, Local Politics, and Five Municipalities in the United States with 100\% Renewable Electricity ............................16

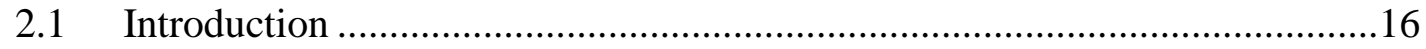

2.1.1 Research Problem ..................................................................... 18

2.1.2 Research Objectives........................................................................18

2.2 Conceptual Lens: Energy Transitions and the MLP ....................................19

2.2.1 Re-introducing and operationalizing the MLP in energy transition .20

2.2.2 100\% Renewable Electricity and Transition Typologies...................22

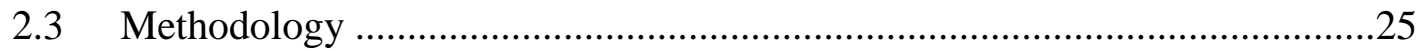

2.3.1 Qualitative Comparative Analysis of Data...........................................26

2.4 Results: Review of transition drivers in the five municipalities ...................27

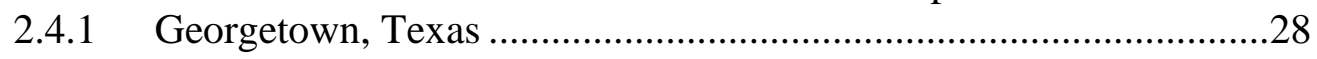

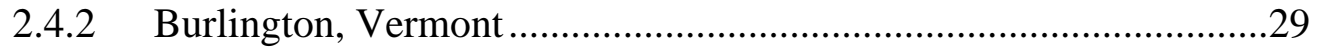

2.4.3 Aspen, Colorado ………………………...................................

2.4.4 Rock Port, Missouri ........................................................................

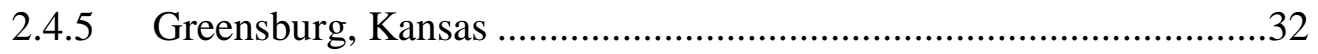


2.5 Discussion

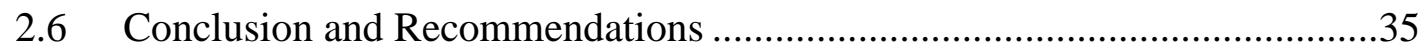

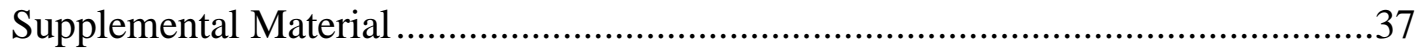

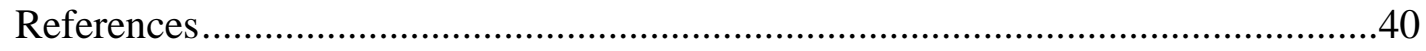

3 Achieving 100\% Renewable and Self-Sufficient Electricity in Impoverished, Rural, Northern Climates: Case Studies from Western Upper Michigan, USA .........................47

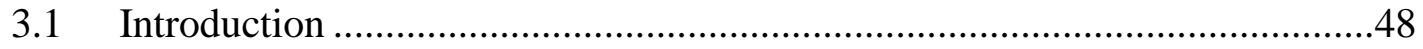

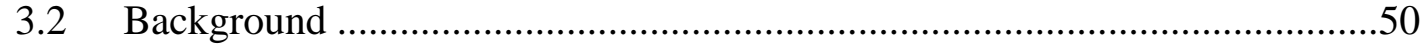

3.2.1 100\% RE Transition and Concerns for Unlikely Places ...................50

3.2.2 100\% RE Transitions and Energy Justice Concern .........................51

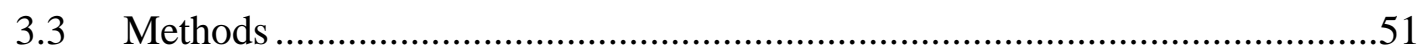

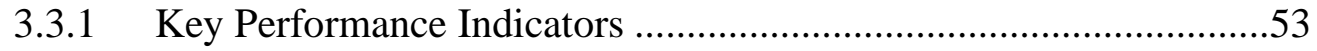

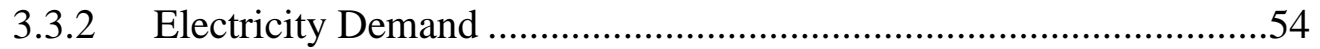

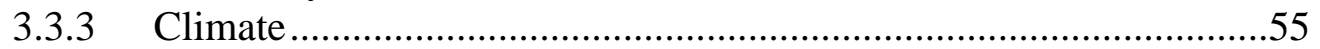

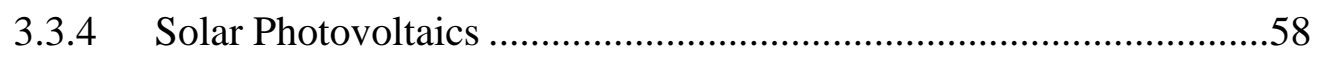

3.3.5 Wind Turbines ....................................................................59

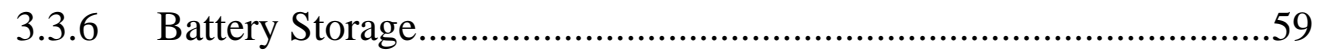

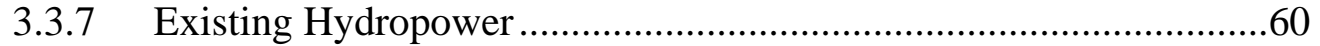

3.3.8 Grid Connection......................................................................6

3.3.9 Energy Efficiency ................................................................62

3.3.10 System Level Parameters .............................................................62

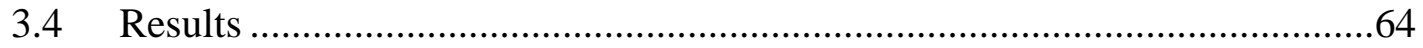

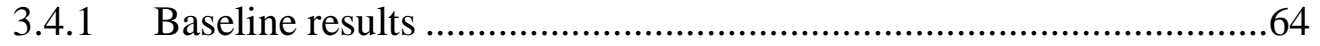

3.4.2 PV tilt angle .......................................................................66

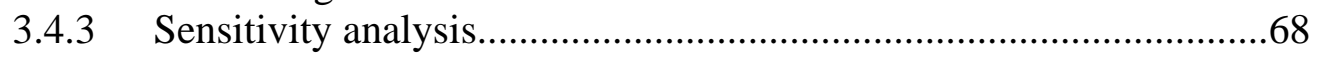

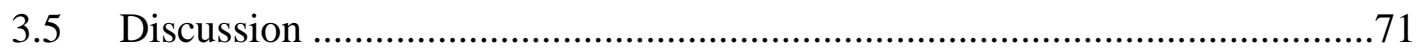

3.5.1 Feasibility and Economic Justification of 100\% RE Transition.......71

3.5.2 Policy Implications and Future Work ..........................................73

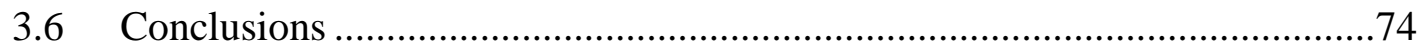

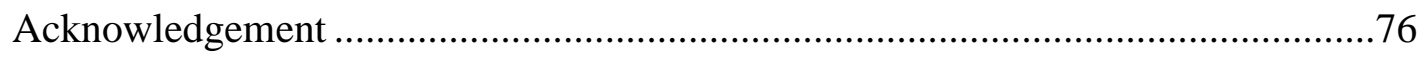

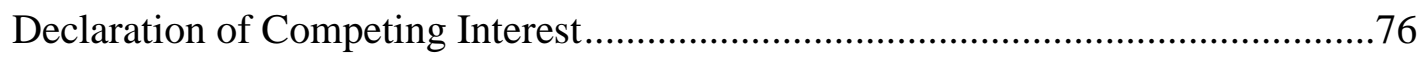

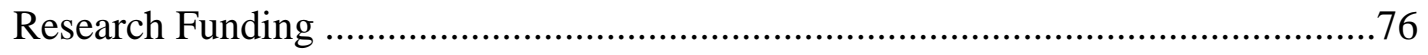

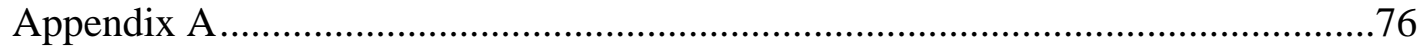

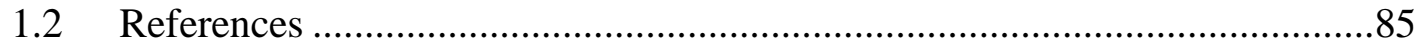


4 Can Michigan's Upper Peninsula Achieve Justice in Transitioning to 100\%

Renewable Electricity? Survey of public perceptions in Sociotechnical Change .............96

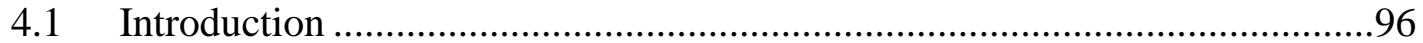

4.1.1 Opinion of Public in Energy Transition as STST ..............................97

4.2 Public Perception in 100\% Renewable Electricity in the U.S.......................98

4.2.1 Energy Consumption Behavior and RE Transition ...........................99

4.2.2 Electricity Price and Environmental Concern in the Case of

Michigan's Western Upper Peninsula (WUP) ..............................................100

4.2.3 Method and Survey Design...........................................................100

4.2.3.1 Sampling Frame ............................................................102

4.3 Results Analysis ....................................................................................104

4.3.1 Descriptive Statistics of Results.....................................................104

4.3.1.1 Knowledge of RE Technologies in WUP .....................104

4.3.1.2 Demographic Analysis of Respondents .......................107

4.3.1.3 Installation, Finance, and Benefit Preferences...............108

4.3.1.4 Summary of Descriptive Statistics of Survey ................114

4.3.2 Regression Analysis of Factors Influencing Support.......................115

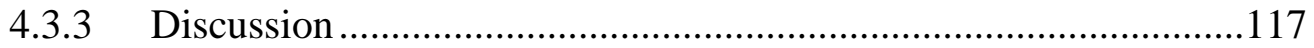

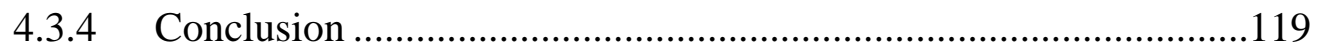

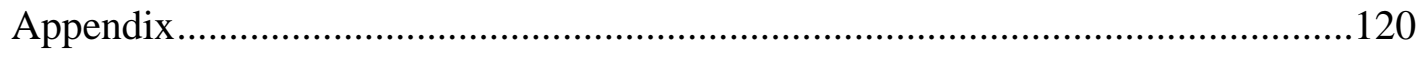

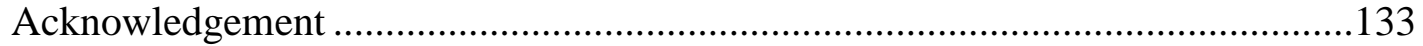

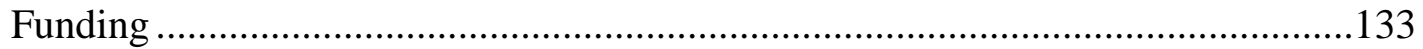

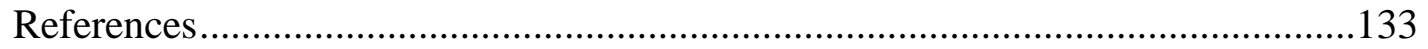

$5 \quad$ Promoting Policies for Renewable Electrification....................................................138

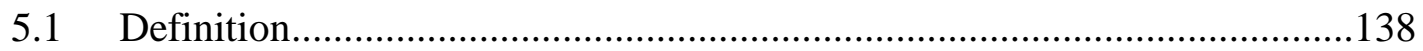

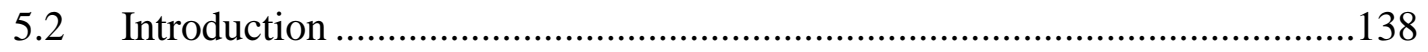

5.3 Sustainable Development and Renewable Electrification.............................139

5.4 Sustainable Electrification and Energy Justice Nexus ..................................140

5.5 Most Effective Renewable Energy Policies ...................................................141

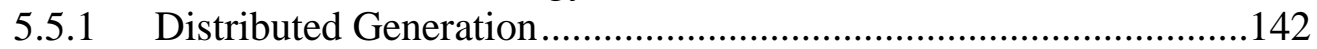

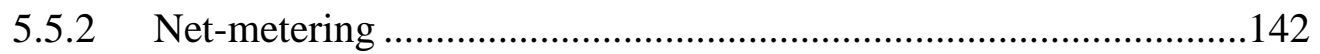

5.5.3 Feed-in Tariff ................................................................................143

5.5.4 Renewable Portfolio Standards (RPS) ...........................................144

5.5.5 Renewable Energy Credits..........................................................145

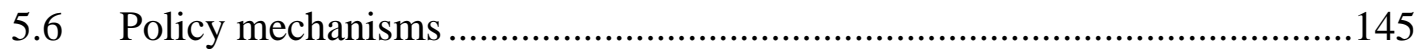

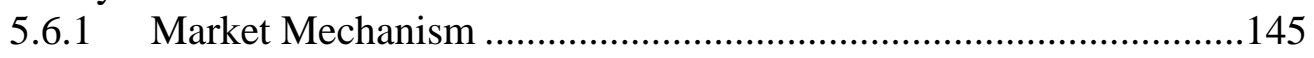

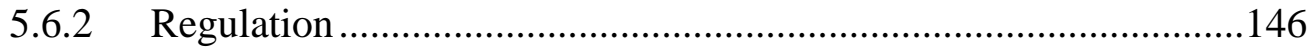

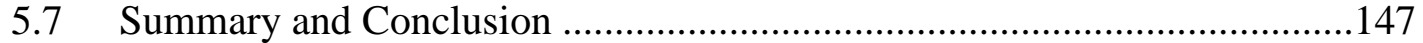




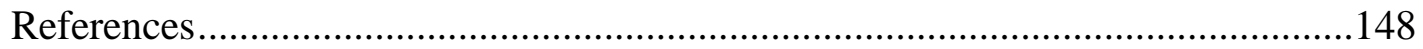

$6 \quad$ Overall Research Conclusion and Contribution ...................................................152

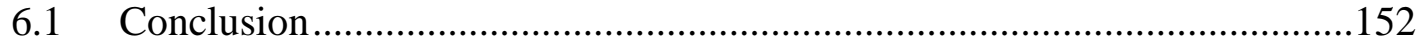

6.1.1 Positionality and Trust in Research Design ....................................152

6.1.2 Conclusion Based on Research Results ............................................154

6.1.2.1 Minimum Renewable Energy Resources.......................154

6.1.2.2 People and Community Centered Energy Transition ...155

6.1.3 Just Energy Transition Factors..........................................................155

6.1.4 Policy Implications and Future Work ………………………….....156

6.1.4.1 Policy on Municipalization of Utility ............................156

6.1.4.2 Future Work on Community Engagement.....................158

6.1.4.3 Future Work on Regional Wide 100\% RE Feasibility

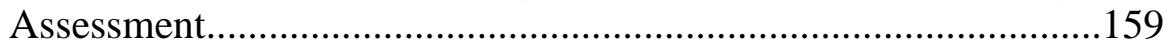

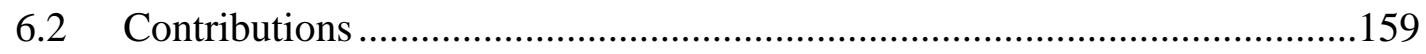

6.2.1 STST and MLP Expansion to Just 100\% RE Context.....................159

6.2.2 Transdisciplinary Approach to Just 100\% RE Transition.................160

6.2.3 Process Flowchart for Transdisciplinary Energy Transition ...........160

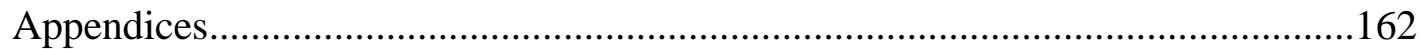

1. One-page summary: Achieving 100\% Renewable and Self-Sufficient

Electricity in Impoverished, Rural, Northern Climates: Case Studies from

Upper Michigan, USA

2. One-page summary: How can Michigan's Western UP Achieve Just transition to $100 \%$ Renewable Electricity? Survey of public perception in Sociotechnical Change ............................................................................163

Reference .164 


\section{Preface}

This dissertation is composed of four core chapters, and the embedded research and core chapters herein were carried out with the supervision and guidance of Dr. Chelsea Schelly and Dr. Roman Sidortsov in the Environmental and Energy Policy Program, Department of Social Sciences, Michigan Technological University, between September 2018 December 2020. The first and the last chapters of the dissertation provide an introduction and conclusion, respectively, and the middle four chapters are research work either published or under review for publication. The majority (3 out of 4) of the research work in this dissertation was created as a product of collaboration with other researchers.

Chapter two: Research was conducted by gathering, reviewing, and analyzing data of five municipalities in the U.S. that have achieved their goals of $100 \%$ renewable electricity (RE). The chapter serves as the foundation on which others are built. As the lead author of this research, my contributions include research idea conceptualization, data collection and analysis, and preparing the initial drafts of all the sections of the paper. Further, I was responsible for identifying the appropriate journal for submission and also acted as the correspondence for the publication. This chapter is published in Energy Research and Social Science (ERSS).

Chapter three focuses on a technical pre-feasibility study of $100 \%$ renewably sourced electricity in the Western Upper Peninsula (WUP), Michigan, U.S. The feasibility targets the possibility of achieving $100 \%$ RE by the year 2030. As the lead author, the contributions that I made to this research include idea conceptualization, data sourcing, development and receipt of the memorandum of understanding with external stakeholders for data access, data collection, and preparation of paper draft. System modelling and simulations, result analysis, final manuscript was shared with co-authors. I was also responsible for identifying and submitting the research paper to an appropriate journal. I also serve as the correspondence for this paper. The research is under review in Renewable Energy and is co-authored by Joshua Pearce and Nelson Sommerfeldt.

Chapter four adapts an existing survey questionnaire of Long Island residents regarding perception of non-residential solar to investigate public perceptions and social acceptance of $100 \%$ renewable electricity in the WUP. The research involves quantitative analysis of opinions provided via survey response on the potential for a renewable energy transition in the WUP. Unlike chapters two and three, this research is solely authored. Work done includes idea conceptualization, survey design, survey distribution, data collection, analysis, and writing. This research was submitted to Sustainability and has been accepted for publication. The research was partially funded with a grant award from Great Lakes Research Center (GLRC) of Michigan Technological University (MTU).

Chapter five is a review of existing and future policies to promote renewable electrification. In this paper, which is co-authored, my contribution includes structuring of research ideas and preparation of the initial draft of the paper. Research idea conceptualization and final draft of manuscript was jointly shared with co-author. The work 
is published: Adesanya, A., and Schelly, C. "Promoting Policies" in Encyclopedia of the UN Sustainable Development Goals: Affordable and Clean Energy, edited by Prof. Walter Leal Filho, Amanda Lange Salvia, Dr. Anabela Marisa Azul, Prof. Luciana Londero Brandli, and Prof. Tony Wall. Published by Springer Nature.

Adewale A. Adesanya, December 2020 


\section{Acknowledgements}

I would first like to thank my advisors, Dr. Chelsea Schelly and Dr. Roman Sidortsov for their immense support and guidance throughout my time as a $\mathrm{PhD}$ student. The work in this dissertation would not have been possible without the unwavering support of these two advisors. In addition, Dr. Schelly's dedication to seeing my academic success and professional development has been second to none. I am very grateful to you both for your patient, encouragement, and support to my academic world and my life outside academia.

I would like to thank my committee members Dr. Joshua Pearce and Dr. Angie Carter for providing support and several opportunities to engage in collaborative research work throughout my time at Michigan Technological University. They have been very instrumental to the success of this degree.

Thank you to Michigan Public Service Commission (MPSC) for allowing me to intern in their commission, learning so much about energy policy and regulation in the state of Michigan. The knowledge gained at MPSC has been very valuable to my research. Thank you to Great Lakes Research Center (GLRC) and Michigan Indigenous Community and Anishinaabe Renewable Sovereignty (MICARES) research group for partly funding my research.

I want to thank my family for standing by me all through this very demanding journey. The love and support they have shown me have kept me going through the thick and thin of my doctoral degree program. I especially want to thank my wife, Olufunmilayo Adesanya for always being by my side and providing all the moral support and encouragement whenever the going gets tough. Thank you for sacrificing your career for these years of my academic journey all through to completing this dissertation. Thank you to my kids, Jenelle, Jeffrey, and Jewel for always giving me a reason to laugh even in difficult periods of this work. Last but ultimately, I thank God for giving me the life and health to start and complete this against all odds. 


\section{Abstract}

The transition to using clean, affordable, and reliable electrical energy is critical for enhancing human opportunities and capabilities. In the United States, many states and localities are engaging in this transition despite the lack of ambitious federal policy support. This research builds on the theoretical framework of the multilevel perspective (MLP) of sociotechnical transitions as well as the concept of energy justice to investigate potential pathways to 100 percent renewable energy (RE) for electricity provision in the U.S. This research seeks to answer the question: what are the technical, policy, and perceptual pathways, barriers, and opportunities for just transition to $100 \%$ renewable electricity in the U.S., at a state and local levels? In this dissertation, an analysis of factors contributing to RE transition in communities across the country is developed. Results from this are used to make further analysis and recommendations to research undertaken specifically in the context of Michigan's Western Upper Peninsula (WUP). This dissertation demonstrates that research on achieving a just energy transition requires transdisciplinary approaches that integrate social sciences, engineering, and natural sciences and multiple ways of knowing from scientists, practitioners, and diverse community perspectives. This research provides tools for decision makers at all levels of government, local stakeholders, citizens, and the academic world in understanding what matters for success in a just transition to $100 \%$ RE in the U.S. 


\section{Dissertation Snapshot Table}

Dissertation Research Question: what are the technical, policy, and perceptual pathways, barriers and opportunities for just transition to $100 \%$ renewable electricity in the U.S., at states and local level?

\begin{tabular}{|c|c|c|c|}
\hline Chapter 2 & Chapter 3 & Chapter 4 & Chapter 5 \\
\hline $\begin{array}{l}\text { Title: Act Locally, } \\
\text { Transition Globally: } \\
\text { Grassroots } \\
\text { Resilience, Local } \\
\text { Politics, and Five } \\
\text { Municipalities in the } \\
\text { United States with } \\
\text { 100\% Renewable } \\
\text { Electricity }\end{array}$ & $\begin{array}{l}\text { Title: Technical } \\
\text { Pre-feasibility } \\
\text { Studies of } 100 \% \\
\text { Renewably Sourced } \\
\text { Electricity in the } \\
\text { Western Upper } \\
\text { Peninsula, } \\
\text { Michigan, U.S. }\end{array}$ & $\begin{array}{l}\text { Title: How can } \\
\text { Michigan Western } \\
\text { UP Achieve Just } \\
\text { transition to } 100 \% \\
\text { Renewable } \\
\text { Electricity? An } \\
\text { Assessment of } \\
\text { Regime Actors }\end{array}$ & $\begin{array}{l}\text { Title: Promoting } \\
\text { policies for } \\
\text { renewable } \\
\text { electrification }\end{array}$ \\
\hline $\begin{array}{l}\text { Research Question: } \\
\text { 1. What are the } \\
\text { contributing factors } \\
\text { to } 100 \% \text { RE } \\
\text { transition in the } \\
\text { U.S.? } \\
\text { 2. What are the } \\
\text { various pathways to } \\
100 \% \text { RE transition? }\end{array}$ & $\begin{array}{l}\text { Research } \\
\text { Question: } \\
\text { 1. How technically } \\
\text { feasible is } 100 \% \mathrm{RE} \\
\text { transition in the } \\
\text { Western UP? } \\
\text { 2. What is the } \\
\text { economic viability } \\
\text { of this transition? }\end{array}$ & $\begin{array}{l}\text { Research } \\
\text { Question: } \\
\text { 1. What are the } \\
\text { perceptions of } \\
\text { residents and } \\
\text { stakeholders on RE } \\
\text { transition? } \\
\text { 2. What are the } \\
\text { potential barriers to } \\
\text { RE transition? }\end{array}$ & $\begin{array}{l}\text { Research } \\
\text { Question: } \\
\text { 1. What are the } \\
\text { existing policies } \\
\text { to promote } \\
\text { renewable } \\
\text { electrification? } \\
\text { 2. What are the } \\
\text { future policies } \\
\text { that can } \\
\text { facilitate } \\
\text { renewable } \\
\text { electrification }\end{array}$ \\
\hline $\begin{array}{l}\text { Unit of Analysis: } \\
\text { Five municipalities } \\
\text { in the U.S. }\end{array}$ & $\begin{array}{l}\text { Unit of Analysis: } \\
\text { Nine counties of the } \\
\text { Western UP, MI, } \\
\text { U.S. }\end{array}$ & $\begin{array}{l}\text { Unit of Analysis: } \\
\text { Residents from the } \\
\text { nine counties of the } \\
\text { Western UP, MI, } \\
\text { U.S. }\end{array}$ & $\begin{array}{l}\text { Unit of } \\
\text { Analysis: } \\
\text { Global policies }\end{array}$ \\
\hline
\end{tabular}




\begin{tabular}{|c|c|c|c|}
\hline $\begin{array}{l}\text { Co-Authors: } \\
\text { Adewale A. } \\
\text { Adesanya, Roman } \\
\text { Sidortsov and } \\
\text { Chelsea Schelly }\end{array}$ & $\begin{array}{l}\text { Co-Authors: } \\
\text { Adewale A. } \\
\text { Adesanya, Nelson } \\
\text { Sommerfeldt, and } \\
\text { Joshua Pearce }\end{array}$ & $\begin{array}{l}\text { Authors: } \\
\text { Adewale A. } \\
\text { Adesanya }\end{array}$ & $\begin{array}{l}\text { Co-Authors: } \\
\text { Adewale A. } \\
\text { Adesanya and } \\
\text { Chelsea Schelly }\end{array}$ \\
\hline $\begin{array}{l}\text { Published in Energy } \\
\text { Research and Social } \\
\text { Science (ERSS) }\end{array}$ & $\begin{array}{l}\text { Submitted for } \\
\text { publication in } \\
\text { Renewable Energy }\end{array}$ & $\begin{array}{l}\text { Submitted to } \\
\text { Sustainability and } \\
\text { has been accepted } \\
\text { for publication }\end{array}$ & $\begin{array}{l}\text { Published in } \\
\text { Encyclopaedia } \\
\text { of UN } \\
\text { Sustainable } \\
\text { Development, } \\
\text { published by } \\
\text { Springer Nature }\end{array}$ \\
\hline \multicolumn{4}{|c|}{ Dissertation Contribution } \\
\hline $\begin{array}{l}\text { 1. Contribution t } \\
\text { 2. Understanding } \\
\text { 3. Bringing justi } \\
\text { 4. Developing tr } \\
\text { justice in tran } \\
\text { 5. The criteria c } \\
\text { transition proj }\end{array}$ & $\begin{array}{l}\text { the MLP framework } \\
\text { the framework in the } \\
\text { e to MLP (technical } \mathrm{f} \\
\text { nsdisciplinary approa } \\
\text { tion through SDGs ( } \\
\text { n serve as checklist } \\
\text { cts }\end{array}$ & $\begin{array}{l}\text { empirical and theor } \\
\text { empricasibility) }\end{array}$ & $\begin{array}{l}\mathrm{n} \text { as a criterion for } \\
\text { cal just } 100 \% \mathrm{RE}\end{array}$ \\
\hline
\end{tabular}




\section{Introduction}

A transition to clean, affordable, and reliable sources of electrical energy is irrefutably necessary. This is especially true considering how critical energy is in enhancing human opportunities and capabilities (McCauley et al., 2019). Renewable energy is energy from resources such as solar, wind, hydro, geothermal, tidal waves, etc. Renewable energy (RE) is receiving increasing global attention (Thompson et al., 2017) with the current scientific projections that 2030 is the temporal threshold facing humans to limit global warming below 2 degrees Celsius to avert impending climate catastrophe. Climatic change is resulting from emission of gaseous substances from the combustion of fossil fuel such as coal, oil, and natural gas.

In the U.S., substantial emissions of these gases, also known as greenhouse gases (GHGs), comes from electricity; the electricity sector accounts for $28 \%$ of the GHG emissions in the U.S., which is just $1 \%$ behind the transportation sector, which has the highest share (Central Climate, 2020). The current electrical energy regime is dominated by fossil fuels, with substantial associated carbon dioxide emissions. This situation is facilitated by previous massive investment and strong policies to sustain current energy infrastructure and economic growth.

Further, the U.S. energy intensity ranks high due to consumption level and path dependency. Path dependency is a phenomenon describing a situation of lock-in and strong inertia to changes (Goldthau \& Sovacool, 2012). It is a situation that creates strong reliance on a system, with little cognizance of alternatives. One of the examples of path dependence is carbon lock-in. Carbon lock-in is defined as a special case of path dependency caused by inertia of carbon emission due to mutually reinforcing economic, social, and physical constraints (Unruh, 2000; Seto et al., 2016). Carbon lock-in is due to interconnected socioeconomic, technological, and political policies that are built around heavy consumption of fossil fuel such as, coal, oil, and natural gas. Across this policy spectrum are different lessons regarding path dependency.

Since the 1970s and until recently, the U.S. energy policy was premised heavily on capital investment in domestic oil production to reduce threats of energy insecurity in the face of Arab Oil Embargo (Klass \& Wiseman 2016). The investment on fossil fuel is fostered by the U.S. capitalist system driven by policies to sustain growth in the consumption of energy and strengthening oil independence (Lovins, 1977). The resulting effect on electricity infrastructure is immense proliferation of oil, gas, and coal-fired power plants. Situations like this have created policy failures against successful transition to and diffusion of alternatives such as renewable energy Unruh (Unruh, 2002).

According to the World Economic Forum data, the U.S. ranks relatively low in the energy transition index score (Figure 1). The energy transition index (ETI) is measured as an average of two key performances: 1) system performance score, which is based on a country's environmental sustainability, energy security and access, and economic 
development and growth 2) transition readiness, which measures a country's outlook on a combination of its capital and investment, energy systems structure, regulation and political commitment, institution and governance, infrastructure and innovative business environment, as well as human capital and consumer participation (World Economic Forum, 2019). The U.S. lags the top 10 countries in pursuing the energy transition, including countries in Europe such as France, United Kingdom, Ireland, Sweden as well as Uruguay, New Zealand, and Japan. The country is also historically among the highest carbon emitters (Sovacool et al., 2016). Currently, it is the third largest carbon-dioxide $\left(\mathrm{CO}_{2}\right)$ emitter in the world, with $14 \%$ of total global emission (Union of Concerned Scientists, 2020). While this is currently the case, the U.S. has the potential to lead the global transition through introduction of more REs in its electricity sector at national, state, and municipal levels. For instance, the U.S. ranks higher than many other countries in transition index performance, with a range of $70-80 \%$.

In response to this possibility, there are growing interests in the U.S. at state and local levels on transitioning to RE. A bipartisan coalition of governors from 25 states in the country have joined the U.S. Climate Alliance, which has the goal of pursuing the Paris Agreement (State of Michigan, 2020). If these states and local actions in the U.S. will experience the expected success, the right pathways must be followed to ensure that the energy transition is just, inclusive, and sustainable. 


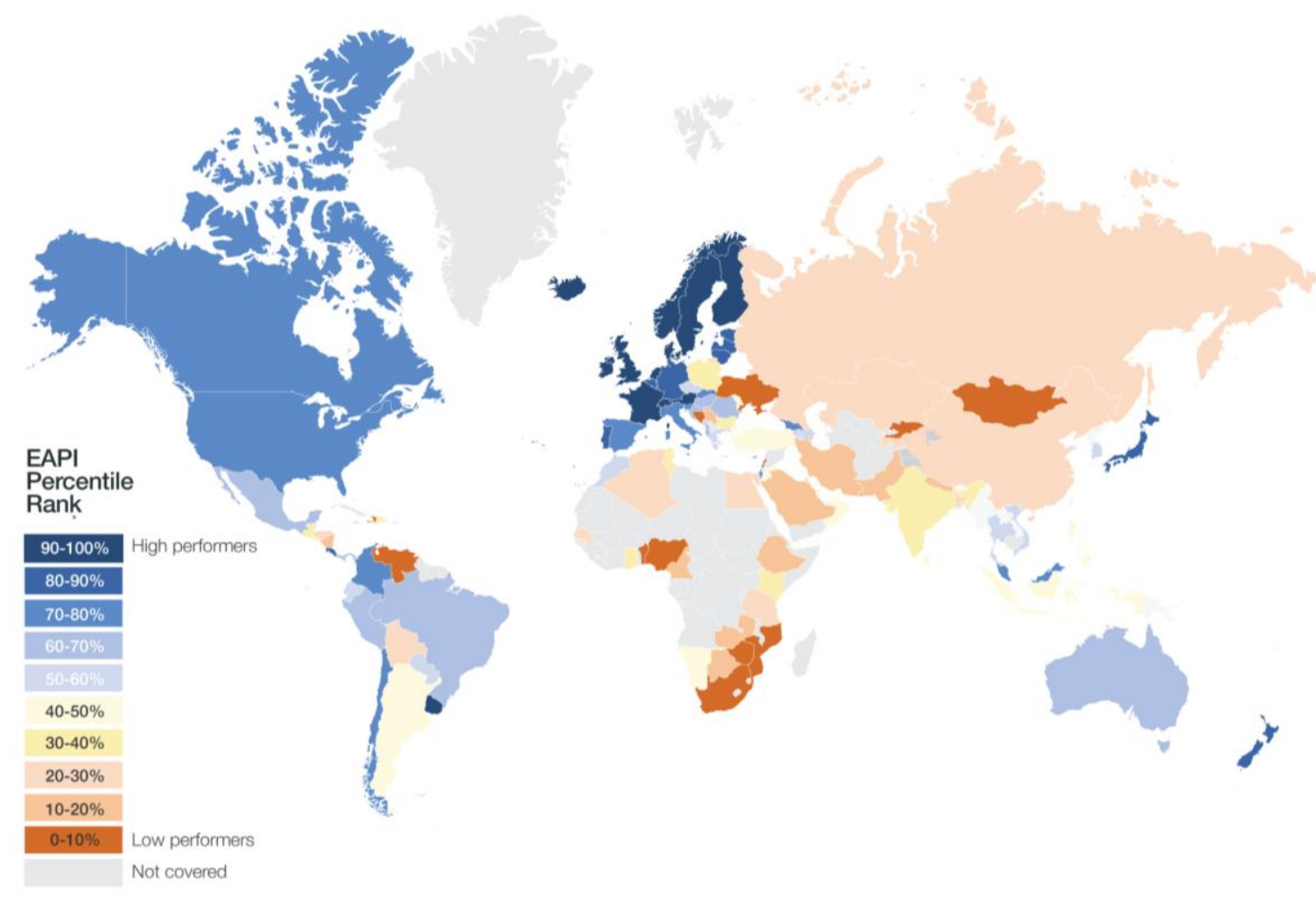

Figure 1: World Map of energy transition index, 2019 (Vijay, 2019)

\subsection{The Scholarship: just energy transition, energy transitions as a sociotechnical system transition (STST), STST and the intergenerational justice nexus}

The term 'transition' refers to deep structural changes in systems, involving strategic and intertwined reconfigurations of landscapes, regime, and technologies (Geels, 2018; Newell et al., 2013; Geels \& Schot, 2007; Geels, 2004). The discourse on using renewable energy for electrical energy transitions may be viewed as involving issues related only to technology, because it requires a shift from one technology to another. However, such a shift is also a social issue because the use of technology is contingent on its users. Technology artefacts are created and shaped by society (Winner, 1980). Thus, studying transitions requires attention to both the technologies at play and the ways they will impact and will be impacted by their users.

\subsubsection{Just Energy Transition}

A just energy transition can be defined as a change or evolution in the socio-technological systems providing humans access to energy that enhances just processes and outcomes within that system (McCauley \& Heffron, 2018; Healy \& Barry, 2017). Just process means 
ensuring access to participation, inclusion in decision making, and recognition of diverse views and priorities in the decision-making process (Newell et al., 2013). This means that people are able to participate regardless of their current access to various forms of capital including financial, social, human, and cultural (Flora and Flora, 2013). Just outcomes would also mean ensuring that negative impacts from energy development are managed to avoid inequitable distribution of those negative impacts across social groups but also across ecological systems and temporally across multiple generations (Jakob \& Steckel, 2016).

A just energy transition serves as a foundation for energy justice in society, while also escaping the current carbon lock-in through government mediation. (Newell et al., 2013). The concept of a 'just transition' from one of its earliest formations by U.S. trade unions was developed in the 1980s as a response to new regulation against industrial air and water pollution (Newell et al., 2013). The multidimensional requirements for transitioning to clean energy across the world include strong financing, changes in technology, and institutional and policy-process reforms (Newell et al., 2013).

Research, dating from the 1980s such as (Winner, 1980) and post 2000s such as McCauley et al. (2019) and Galvin, (2020), demonstrates that energy technologies can be used in just or unjust manners. In the same vein, RE technologies are not by themselves capable of averting injustice, despite being environmentally more benign than incumbent fossil fuels (Banerjee et al., 2017). For example, RE project planning in some Indigenous communities in the U.S. has occurred without fully aligning with community values and expectations in the initial stages, an example of injustice in process or procedure (Krupa et al., 2015). To ensure that such approaches do not continue, it is important to begin a shift in paradigm on $\mathrm{RE}$ research and project planning to incorporate various interests and or concerns of the people. This should also apply to every other community where the RE project is planned.

An approach to energy transition planning that includes involvement of and partnership with individuals, communities, and stakeholders can improve justice in terms of both processes and outcomes. In this dissertation, the pathway to a $100 \%$ renewable electricity in the U.S. is viewed through the lens of energy justice to consider the potential for a sustainable and just energy transition. There is a pluralistic view used in defining the concept of energy justice.

By pluralistic, reference is made to various dimensions of viewing the concept of energy justice. One dimension is the system approach, while another dimension is the foundational approach to energy justice. In the system approach, energy justice is defined as one of the cross-cutting agendas in social science, which strives to perpetuate justice principles in energy systems, policymaking, planning, production consumption, security, climate change as well as activism (Sidortsov et al., 2019). It is also defined as that which requires equitable distribution of energy services in meeting basic goods of life as an individual's entitlement (Heffron et al., 2015; Sovacool et al., 2014; Sovacool \& Dworkin, 2015). 
Energy justice spans ethics concerns across the energy value chain which include energy development, production, transportation, processing, and use (Sovacool et al., 2014). The work of Sidortsov et al. (2019) approaches energy justice with energy as a prerequisite to other basic needs or goods, based on the interrelated principles of Prohibitive and Affirmative. The prohibitive principle assumes energy service provision should not interfere an individual's ability to meet other basic goods. The affirmative principle views energy service is seen as a derivative right to entitlement of the minimum of basic goods. This dissertation does not attempt to be bound by a single view but use each as applicable. The reason is because there is convergence of these approaches, which is the articulation of ethical consideration in the use of energy resources and technology for societal benefit.

Part of this dissertation deploys the foundational approach. This is done by assessing and modelling the feasibility of less costly, clean, and sustainable electricity generation as an alternative in meeting the energy needs of Michigan Western Upper Peninsula (WUP) residents as a basic need. More so, this dissertation is used to analyze the ethicality for the region to embark on $100 \% \mathrm{RE}$ transition in the face of high disparity in retail price of electricity relative to average price in the U.S. Consideration of how the public perceives their energy systems and their perspectives on a potential RE transition is used as an applied form of procedural justice. This survey of factors that would make WUP residents more or less supportive of a transition to $100 \%$ RE is used as a preliminary stage in following due process, illustrating how procedural justice can begin with a process that allows for community input from those who will be impacted by this transition.

\subsubsection{Energy Transitions as Sociotechnical System Transitions (STST)}

Energy transitions are characterized by significant strategic changes or transformation in energy landscape and usage (Prehoda et al., 2019). They involve changes across the value chain in energy provisions. The value chain can be described as all the processes and technologies that are involved providing energy services. For instance, for the provision of electricity, this value chain includes the generation, transmission, and distribution systems. While generation is used interchangeably with production of energy, transmission and distribution are often used to depict its transportation from one place to another (Klass \& Wiseman, 2016).

Technological changes will be facilitated by the development of technology as well as market breakthroughs, while institutional change is mainly driven by social movements and other informal institutions, as precedence to changes in the formal institutions (Seto et al., 2016; Unruh, 2002). This also applies to changes in energy technologies and resources. The understanding of alignments and the co-evolution of the society and technology requires moving beyond an isolated focus on singular politics, economy, consumption, culture, or business aspects of sociotechnical systems (Geels, 2018). This is to facilitate convergence in knowledge of the complexities that are inherent in the system, by bringing various disciplines into the discussion. 
Smith \& Stirling (2010) argue that evolution of technological occurs through subjection of the protected incumbent technological regime under pressure. In the case of socio-technical system transitions in energy, the fossil fuel energy system represents the incumbent, while $\mathrm{RE}$ is the evolving and emerging technology. Geels' theoretical framework, the multi-level perspective (MLP), provides analysis of various factors and elements involved in sociotechnological system transitions (STST) (Geels \& Schot, 2007; Geels, 2020). The MLP stipulates that transition occurs through the interactions among various factors and actors across different levels. Scholars of MLP argue that beyond technological innovation, changes also include consumer practices, policies, infrastructures, business strategies and cultural meanings (Geels \& Schot, 2007; Markard et al., 2012; Bayulgen, 2020). By implication, understanding changes along technological innovation requires consideration of different perspectives involving users, institutions, existing landscapes, and the technology itself. The social components (users, institutions, policies, etc.) and material components (tangible and intangible artefacts, landscape, etc.) are all part of the STST. Examining their individual roles and interactions and the effects of such interactions is required to fully understand the context of a potential energy transition.

\subsubsection{STST and Intergenerational Justice Nexus}

STST and energy justice are two conceptual tools that present the basis for just actions towards meeting intergenerational needs STST, especially management of such, involves attentiveness to the connection to sustainability. To analyze the role of policies in STST, this dissertation tangentially addresses issues of sustainability. Defining sustainability, (Kuhlman \& Farrington, 2010) postulate that it is humanity's ability to meet the needs of the present without compromising the ability of future generations to replicate the same. Implicitly, sustainability draws on just intergenerational actions towards meeting the fundamental needs of every human. With this definition, the connection of STST management to sustainability presents another conceptual tool for understanding what a sustainable and just energy should ideally achieve - justice and fairness across social groups and across space and time.

The United Nations in the year 2015 highlighted 17 sustainable development goals (or popularly known as SDGs) that must be considered by nation states in the pursuit of development (United Nations, -a: United Nations, -b). Among these 17 goals is the SDG 7 , which is affordable, reliable, sustainable, and modern energy for all. SDG 7 closely aligns with the Affirmative Principle of energy justice that states: "If any of the basic goods to which every person is justly entitled can only be secured by means of energy services, then in that case there is also a derivative right to the energy service" (Sovacool et al., 2014). The goal stipulates that energy provision must not only be environmentally or socially sustainable, but also comes at a price that will not impede the ability of meeting other needs. This is the premise of the Prohibitive Principle of energy justice, which states: "Energy systems must be designed and constructed in such a way that they do not unduly interfere with the ability of any person to acquire those basic goods to which he or she is 
justly entitled" (Sidortsov \& Sovacool, 2015). The SDG 7 thus represent an applied side of energy justice, which is being deployed in this research through the context of RE energy transitions in the U.S. (Chapter 2) and specifically in the WUP (Chapters 3 and 4), with insight applicable at global scales (Chapter 5). As such, this dissertation also considers energy justice through the lens of SDGs.

\subsection{Overarching Dissertation Question and Objective}

The overarching question that this dissertation seeks to answer is: "What are the technical, policy, and perceptual pathways, barriers and opportunities for just to $100 \% \mathrm{RE}$ transitions in the U.S., at states and local level?" This question embodies four broader areas of inquiries on RE transitions. The working assumption from the four areas is that a successful and just $100 \% \mathrm{RE}$ transition depends on progressive activities at multiple levels of society. Thus, these are the following objectives that this dissertation aimed to achieve:

1. To investigate pathways that can lead to sociotechnical $100 \% \mathrm{RE}$ transition

2. To assess if Michigan's Western Upper Peninsula, U.S. can achieve just transition to $100 \% \mathrm{RE}$ along technical and social perceptual dimensions

3. To review policy pathways for promoting a just RE

\subsection{Research Design Choice}

\subsubsection{Methodology and Rationale}

The methodology for this dissertation is a mixed research method (MRM). By MRM, this dissertation refers to the use of multiple methods involved in answering specific disciplinary questions within the overarching research question. MRM is a popular approach that combines qualitative and quantitative research paradigm to obtain a broader and complete overview of research endeavors (Morgan, 2017; Manzoor, 2020; Turner, 2007). It is an approach to scientific knowledge accumulation that considers multiple perspectives, standpoints, viewpoints, and positions in seeking a workable solution for research problems of interest (Turner, 2007). MRM is perceived as an effective dialectic that considers divergent but complementary stances in building a holistic analysis towards a solution to a research problem (Hopper \& Hoque, 2006). A research design choice that involves mixed methods can therefore facilitate knowledge convergence necessary for a complex STST on renewable electricity.

This dissertation engages mixed research methods through qualitative study of existing policy and institutional structures involved in the RE transition and through technical and quantitative modelling of energy transition feasibility. In addition, technical and quantitative modelling is deployed for feasibility assessment of energy transition. 
Qualitative method of systematic literature review and analysis of data are utilized in analysis of MLP and its value for identifying important factors in the 100\% RE transition and in the review of policies to promote RE. Quantitative methods are used in modelling and simulation of $100 \%$ RE transition in the WUP using load data of case study, and statistical analysis was deployed in investigating public perceptions of the potential for a $100 \%$ RE transition in the WUP.

\subsubsection{Transdisciplinary Research Approach}

This dissertation is transdisciplinary in its approach to the research questions because it applies knowledge from social sciences, engineering, and experiential data from stakeholder in understanding pathways to $100 \% \mathrm{RE}$ transition. Technological changes in general are facilitated by innovation development and market breakthroughs, while drivers of institutional changes include social movements and social change (Unruh, 2002). Further, Geels (2018) posits that understanding alignments and co-evolution of the society and technology requires moving beyond an isolated focus on single politics, economy, consumption, culture, or business aspects of sociotechnical systems. This is to facilitate convergence in knowledge of complexities that are inherent in the system, by bringing various disciplines into the discussion (Halvorsen et al., 2019). STST involve a web of technology, institutions, and society (Unruh, 2000; Geels, 2018), and untangling this web requires an analysis that is integrated and that transcends multiple individual disciplines.

Research on achieving a just energy transition requires a transdisciplinary approach across social sciences, engineering, and natural sciences, underpinned by scientific and experimental data (McCauley et al., 2019). An example of such a transdisciplinary approach in research is that of Great Lakes fish consumption advisories' (Gorman et al., 2019), which involved collaborative input of different academic disciplines and partnerships with external stakeholders.

Transdisciplinary approaches to energy research are gaining traction in empirical community based renewable energy research (Halvorsen et al., 2019; Yánez et al., 2017). This approach has been adopted in investigating how low-to-medium income households could benefit from community solar in L'Anse, Michigan (Barnett et al., 2019). The project engaged social scientists but also experts from other disciplines and community stakeholders. The approach led to the formation of a transdisciplinary team named the Upper Peninsula Solar Technical Assistance and Resource Team (UPSTART).

There are various reasons for the increasing use of transdisciplinary research in assessing societal problems and potential solutions. First, social science disciplines are central in studying social change, including studying contemporary issues such as climate change and energy transitions (Shove, 2010). Second, although technological innovations are needed in STST, the social dimension is essential to understanding relations of power, dimensions of inclusion and exclusion, historical and contemporary conditions of injustice and oppression, entrenchment of regime actors who resist change, and other facets of social 
life and social institutions and structures shaping the possibilities for change. The reason is because despite the complementing input of natural sciences and engineering in ushering innovation for human use, how those technologies and innovations are developed and deployed in a way that is just is a primary area of inquiry in social science disciplines. Thus, without allowing for this convergence in various disciplines, facilitating balanced and just solutions to societal problems may be very hard to achieve.

\subsection{Organization of Chapters}

In this dissertation, four chapters are presented to study the multidimensional pathways for a just transition to $100 \%$ renewable electricity. The applicability of these prerequisites covers all scales including local, state, regional, national, and global. The following is an overview of each of the main chapters.

Chapter two - This research builds on the multilevel perspective (MLP) theory of transitions, taking holistic consideration of the factors contingent to achieving $100 \% \mathrm{RE}$ technology in five municipalities around the U.S.A. The MLP theory argues that technological transitions occur through interactions at three levels, which are innovation niche, sociotechnical regime, and sociotechnical landscape of the society (Geels \& Schot, 2007). The chapter covers a comparative analysis of the five municipalities in the U.S. that have achieved a $100 \%$ RE transition.

In this research, secondary data on the five municipalities was collected and analyzed to understand different factors that contributed to the process of achieving the energy transition. These factors lay a foundation for assessing energy transition potentials in other places in the U.S. The data include utility structure, supporting energy policy, renewable energy resource availability, partisanship of local leadership, and public participation, among other factors. Qualitative comparative analysis (QCA) was carried out to understand how these places were able to achieve the target.

The comparative study also serves as a springboard for further investigation of transition typologies in the U.S., as there is no clear indication if $100 \%$ RE transition in the five municipalities occurred in a just and fair manner. For instance, it cannot be ascertained if in the transition in the five municipalities, installed energy infrastructure interferes with some community member's right or if there was public consensus on trade-off between cost and convenience was reached. The concept of justice in $100 \%$ renewable electricity in future study can, therefore, add another layer to the discourse of sociotechnical transition and the MLP framework. This research is published in Energy Research and Social Science (ERSS) as "Act Locally, Transition Globally: Grassroots Resilience, Local Politics, and Five Municipalities in the United States with 100\% Renewable Electricity" (Adesanya et al., 2020)

Chapter three - This chapter focuses on the Western Upper Peninsula (WUP) region of the state of Michigan as a case study on the feasibility of transitioning to $100 \%$ RE for 
electricity in the next ten years. The scope of this research is limited to electrical energy supply from RE resources including solar PV, wind, hydro, biogas, and battery storage systems. This research involves modelling the energy systems of different municipalities and counties in the WUP.

The technical feasibility research results serve as a complement in the study of the sociotechnical regime perspectives on $100 \% \mathrm{RE}$ transition. The results from this study informed the development of the survey questionnaires for residents in WUP. Within this research is also the aspect of justice in 100\% RE transition discourse, especially with the possibility of lower energy cost with RE compared to the currently fossil fuel predominant system. This research is undergoing review in Renewable Energy and titled "Achieving 100\% Renewable and Self-Sufficient Electricity in Impoverished, Rural, Northern Climates: Case Studies from Upper Michigan, USA" (Adesanya et al., in review)

The fourth chapter - This chapter considers the perspectives of residents in the WUP. This research seeks to answer a broad question: What are the social perspectives of the feasibility and factors that could contribute to a just transition to $100 \%$ RE for electricity in the region? This research can help researchers, governments at all levels, local stakeholders, and citizens of the WUP understand what may matter for either success or failure of transitioning to $100 \% \mathrm{RE}$ for electricity. This research is under review for publication in Sustainability and titled "Can Michigan's Upper Peninsula Achieve a Just Transition to 100\% Renewable Electricity? Survey of public perceptions in Sociotechnical Change" (Adesanya, 2020).

Chapter five - The rationale for this paper is that beyond technical feasibility and public perspectives within the existing energy regime, policy plays a crucial role in the transition process. The research analyzes current and prospective policies that can facilitate renewable electrification while promoting affordable and clean energy. The research is published as a book chapter in Encyclopedia of the UN Sustainable Development Goals: Affordable and Clean Energy, as "Promoting Policies for Renewable Electricity" (Adesanya and Schelly, 2020)

Each of the four core chapters are complementary in examining various factors in the STST transition process that can influence the possibilities for RE to contribute to a just energy transition. While Chapter Two forms a foundation by identifying different factors that contribute to achieving $100 \%$ RE in five U.S. municipalities, the remaining papers consider these factors in Michigan municipalities as empirical case studies. In Chapter Two, technical feasibility of RE through resource availability was one of the observed factors of the transition process. Other factors include participation of residents in the municipalities and enabling policies applicable to each of the five municipalities. Chapter Three investigates the technical feasibility of this transition with available and existing energy resources in Michigan's WUP. Policy implications and policy development, also factors in the MLP of STST, are discussed in Chapter Three as ways to ensure the feasibility. Chapter Four involves investigation of public perception as another necessary factor in STST. 
Beliefs and perceptions of WUP residents are investigated. As policies and regulations are critical in the MLP for STST, Chapter Five revisits current and future policies to achieve $100 \%$ RE, thinking beyond municipal scales and even U.S. contexts to bring a global perspective. Policy is presented here as a bridging platform for facilitating technological changes in the society at different scales. Thus, the chapters allow for holistic perspectives regarding the potential for and the factors contributing to a just energy transition.

\subsection{Dissertation Relevance}

This dissertation will be relevant for future researchers as well as policy decision makers at national, state, and local levels of leadership in the U.S. Municipal and community leaders in the U.S., in particular those intending to transition to $100 \% \mathrm{RE}$, will be able to explore the results of this research on pathways to achieving such a goal while also attending to issues of justice. Further, community leaders and utilities will be able to use information from the research in making local decisions on the feasibility of transitions to RE for electricity generation, specifically in the WUP. For instance, Western Upper Peninsula Planning and Development Region (WUPPDR) can use some of the results from this dissertation and directly integrate them into their own planning and goal making for the region's energy outlook.

Lastly, the results presented in this dissertation and the information contained in the published articles will contribute to the body of knowledge in energy and environmental policy at a global scale. The results can be adapted as criteria for general investigation of a just energy transition in other contexts. These criteria can serve as a checklist in empirical and theoretical explorations of the potential for just 100\% RE transition projects, especially for electricity supply at local, regional, and state scale. A process flow chart to potentially replicate this type of empirical research in other social contexts is provided in the concluding chapter of this dissertation.

\section{References}

Banerjee, A., Prehoda, E., Sidortsov, R., \& Schelly, C. (2017). Renewable, ethical? Assessing the energy justice potential of renewable electricity. AIMS Energy, 5(5), 768-797. https://doi.org/10.3934/energy.2017.5.768

Barnett, B., Prehoda, E. W., Kantamneni, A., Winkler, R. L., \& Schelly, C. (2019). Applying transdisciplinary research to enhance low-to-moderate income households' access to community solar. In A Research Agenda for Environmental Management. Edward Elgar Publishing.

Bayulgen, O. (2020). Localizing the energy transition: Town-level political and socioeconomic drivers of clean energy in the United States. Energy Research and Social Science, 62(January 2019), 101376. https://doi.org/10.1016/j.erss.2019.101376 
Central Climate (2019). Emissions Sources (2020). Retrieved May 12, 2020, from https://www.climatecentral.org/gallery/graphics/emissions-sources-2020

Flora, C. B., \& Flora, J. L. (2013). Rural Communities: Legacy and change. Boulder, CO: Westview Press.

Galvin, R. (2020). Economic inequality, energy justice and the meaning of life. In In Inequality and Energy (pp. 75-96). Academic Press.

Geels, F. W. (2004). From sectoral systems of innovation to socio-technical systems: Insights about dynamics and change from sociology and institutional theory. Research Policy, 33(6-7), 897-920. https://doi.org/10.1016/j.respol.2004.01.015

Geels, F. W. (2018). Energy Research \& Social Science Disruption and low-carbon system transformation : Progress and new challenges in socio-technical transitions research and the Multi-Level Perspective. Energy Research \& Social Science, 37(September 2017), 224-231. https://doi.org/10.1016/j.erss.2017.10.010

Geels, F. W. (2020). Technological Forecasting \& Social Change Micro-foundations of the multi-level perspective on socio-technical transitions : Developing a multidimensional model of agency through crossovers between social constructivism , evolutionary economics and neo- i. Technological Forecasting \& Social Change, 152(October 2018), 119894. https://doi.org/10.1016/j.techfore.2019.119894

Geels, F. W., \& Schot, J. (2007). Typology of sociotechnical transition pathways. Research Policy, 36(3), 399-417. https://doi.org/10.1016/j.respol.2007.01.003

Goldthau, Andreas, and Sovacool, Benjamin K. (2012). "The uniqueness of the energy security, justice, and governance problem." Energy Policy, 41, 232-240.

Gorman, Hugh S., Valoree S. Gagnon, Amanda Giang, Judith A. Perlinger, and N. R. U. (2019). Policy, science and transdisciplinary research: when will it be safe to eat as much fish as desired?. In In A Research Agenda for Environmental Management. Edward Elgar Publishing.

Halvorsen, K. E., Knowlton, J. L., Handler, R. M., Schelly, C., \& Pischke, E. C. (2019). (2019). Integrating across sectors and disciplines: transdisciplinary teamwork challenges and strategies. In In A Research Agenda for Environmental Management. Edward Elgar Publishing.

Healy, N., \& Barry, J. (2017). Politicizing energy justice and energy system transitions: Fossil fuel divestment and a "just transition". Energy Policy, 108, 451-459.

Heffron, R. J., McCauley, D., \& Sovacool, B. K. (2015). Resolving society's energy trilemma through the Energy Justice Metric. Energy Policy, 87, 168-176. 
https://doi.org/10.1016/j.enpol.2015.08.033

Hopper, T., \& Hoque, Z. (2006). Triangulation Approaches to Accounting Research. Methodological Issues in Accounting Research: Theories, Methods and Issues, 477486.

Jakob, M., \& Steckel, J. C. (2016). The Just Energy Transition. 1-21. http://awsassets.wwfit.panda.org/downloads/jakobsteckel_2016_jet.pdf

Klass, Alexandra, and Wiseman, H. (2016). Energy Law. West Academic.

Krupa, Joel, Lindsay Galbraith, and S. B. (2015). "Participatory and multi-level governance: applications to Aboriginal renewable energy projects." Local Environment, 20(1), 81-101.

Kuhlman, T., \& Farrington, J. (2010). What is sustainability? Sustainability, 2(11), 34363448. https://doi.org/10.3390/su2113436

Lovins, A. B. (1977). Energy Strategy: The Road Not Taken? Friends of the Earth's Not Man Apart, 6(20).

Manzoor, A. (2020). Designs of Mixed Method Research." In Cognitive Analytics: Concepts, Methodologies, Tools, and Applications. IGI Global, 95-121.

Markard, J., Raven, R., \& Truffer, B. (2012). Sustainability transitions: An emerging field of research and its prospects. Research Policy, 41(6), 955-967. https://doi.org/10.1016/j.respol.2012.02.013

McCauley, D., \& Heffron, R. (2018). Just transition: Integrating climate, energy and environmental justice. Energy Policy, 119, 1-7.

McCauley, D., Ramasar, V., Heffron, R. J., Sovacool, B. K., Mebratu, D., \& Mundaca, L. (2019). Energy justice in the transition to low carbon energy systems: Exploring key themes in interdisciplinary research. Applied Energy, 234, 916-921. https://doi.org/10.1016/j.apenergy.2018.10.005

Morgan, D. L. (2017). Mixed methods research. The Cambridge Handbook of Sociology, 1, 153-161. https://doi.org/10.1017/9781316418376.015

Newell, P., Mulvaney, D., \& Bn, B. (2013). The political economy of the ' just transition $\therefore$ The Geographical Journal, 179(2), 132-140. https://doi.org/10.1111/geoj.12008

Prehoda, E., Pearce, J. M., \& Schelly, C. (2019). Policies to overcome barriers for renewable energy distributed generation: A case study of utility structure and regulatory regimes in Michigan. Energies, 12(4). 
https://doi.org/10.3390/en12040674

Seto, K. C., Davis, S. J., Mitchell, R. B., Stokes, E. C., Unruh, G., \& Ürge-Vorsatz, D. (2016). Carbon Lock-In: Types, Causes, and Policy Implications. Annual Review of Environment and Resources, 41, 425-452. https://doi.org/10.1146/annurev-environ110615-085934

Shove, E. (2010). Beyond the ABC: Climate change policy and theories of social change. Environment and Planning A, 42(6), 1273-1285. https://doi.org/10.1068/a42282

Sidortsov, R., Heffron, R.J., Mose, T.M., Schelly, C. and Tarekegne, B. (2019). In search of common ground: energy justice perspectives in global fossil fuel extraction. In $A$ Research Agenda for Environmental Management. Edward Elgar Publishing.

Sidortsov, R., \& Sovacool, B. (2015). Left out in the cold: energy justice and Arctic energy research. Journal of Environmental Studies and Sciences, 5(3), 302-307. https://doi.org/10.1007/s13412-015-0241-0

Smith, A., \& Stirling, A. (2010). The politics of social-ecological resilience and sustainable socio-technical transitions. Ecology and Society, 15(1). https://doi.org/10.5751/ES-03218-150111

Sovacool, B. K., \& Dworkin, M. H. (2015). Energy justice : Conceptual insights and practical applications. Applied Energy, 142, 435-444.

https://doi.org/10.1016/j.apenergy.2015.01.002

Sovacool, B. K., Heffron, R. J., McCauley, D., \& Goldthau, A. (2016). Energy decisions reframed as justice and ethical concerns. Nature Energy, l(May). https://doi.org/10.1038/nenergy.2016.24

Sovacool, B. K., Sidortsov, R. V, \& Jones, B. R. (2014). Energy Security , Equality, and Justice. Routledge.

State of Michigan. (2020). State of Michigan Executive Directive; No.2020-10; Re: Building a Carbon Neutral Michigan.

Thompson, M., Beston, J. A., Etterson, M., Diffendorfer, J. E., \& Loss, S. R. (2017). Factors associated with bat mortality at wind energy facilities in the United States. Biological Conservation, 215(May), 241-245. https://doi.org/10.1016/j.biocon.2017.09.014

Turner, R. B. J. A. J. L. A. (2007). Toward a Definition of Mixed Methods Research. Journal of Mixed Method Research, 1(2), 112-133.

Union of Concerned Scientists (2020). Each Country's Share of CO2 Emissions. 
Retrieved April 17, 2020, from https://www.ucsusa.org/resources/each-countrysshare-co2-emissions

United Nations. (n.d.-a). Ensure access to affordable, reliable, sustainable and modern energy for all. Retrieved April 17, 2020, from https://sdgs.un.org/goals/goal7

United Nations. (n.d.-b). THE 17 GOALS. https://sustainabledevelopment.un.org/sdgs

Unruh, G. C. (2000). Understanding carbon lock-in. Energy Policy, 28.

Unruh, G. C. (2002). Escaping carbon lock-in. Energy Policy, 30, 317-325.

Vijay, H. (2019). The countries most ready for the global energy transition | World Economic Forum. World Economic Forum.

https://www.weforum.org/agenda/2019/03/the-countries-most-ready-for-the-globalenergy-transition/

Winner, L. (1980). Do Artifacts Have Politics? The MIT Press on Behalf of American Academy of Arts \& Sciences, 109(1), 121-136.

World Economic Forum. (2019). Insight Report: Fostering Effective Energy Transition 2019 edition (Issue March).

Yánez, G. A., Halvorsen, K., \& Ohira, M. (2017). TRANSDISCIPLINARY

APPROACHES TO INTEGRATING POLICY AND SCIENCE FOR

SUSTAINABILITY.

http://www.birs.ca/workshops/2017/17w2688/report17w2688.pdf 


\title{
2 Act Locally, Transition Globally: Grassroots Resilience, Local Politics, and Five Municipalities in the United States with $100 \%$ Renewable Electricity
}

\author{
Adewale A. Adesanya ${ }^{1 *}$, Roman V. Sidortsov ${ }^{1}$ and Chelsea Schelly ${ }^{1}$ \\ 1. Department of Social Sciences, Michigan Technological University, Houghton, MI, \\ U.S.A. \\ *Correspondence: adesanya@mtu.edu
}

\begin{abstract}
This paper examines five communities in the United States (U.S.) that have transitioned to $100 \%$ use of renewable resources for electricity. The paper describes and compares social, political, and economic similarities and differences among these communities to improve understanding of the factors that support successful renewable energy (RE) transitions. The analysis builds on Geels' multi-level perspective theory in assessing sustainable energy transitions and the energy transition process based on these five case studies. Main variables of interest considered for $100 \%$ renewable energy transition in these municipalities are renewable energy resource availability (solar, wind, and hydro), utility ownership, partisanship of municipal leadership, population size, and supporting energy legislation at state level renewable portfolio standard (RPS). Findings from this paper show that utility ownership appears to play a critical role in the transition process, as most of the municipalities have municipally owned utilities. State RPS programs are also prominent among all the states in which these municipalities are located, indicating the importance of state legislation. Further, RE resource availability may not be required, as possibilities for hybridization of energy technologies are evident in the studied places. The most common pathway typology in these $100 \%$ RE transitions is reconfiguration. This typology results from technological innovations fueled by development in RE technologies and stakeholder advocacy. Identified drivers from this research provide helpful parameters of consideration for energy transitions in other places in the U.S. and beyond.
\end{abstract}

Keywords: $100 \%$ RE transition, municipalities; United States; multi-level perspective; driver matrix.

\subsection{Introduction}

It is no longer news that renewable energy (RE), specifically electricity generated from renewable sources, is becoming more appealing globally. At local levels, municipalities are already benefiting from lower energy costs associated with RE resources such as solar, 
wind, and hydro [1], [2], [3], while also achieving GHG reduction, better air quality, and new job opportunities [4], [5], [6]. RE is also appealing because of the degree of financial security it offers due to the non-volatility of prices relative to fossil fuels [4], [7]. This is especially advantageous to community members who are retired or are for other reasons supported by a fixed income [4]. The economics of RE compared to conventional fossil fuel resources make RE a better investment choice for electricity production at a local level [8], [9].RE is becoming increasingly popular in the United States (U.S.). Data from the U.S. Energy Information Administration reveals a gradual and steady increase in the penetration of RE, at $17 \%$ in 2017, ranking 4th among other sources for electrical power generation in U.S. electrical power mix [10]. EIA forecasts also show that by 2050, RE will rank second highest, reaching about $31 \%$ behind natural gas with 39\% [10]. This RE transition will likely be propelled by the development in renewable technologies, especially through the deployment of storage to balance the intermittencies of solar and wind power plants, as well as the continuous decline in costs and improvement in performance of RE technologies [10]. Simultaneously, use of coal and nuclear sources are expected to experience corresponding decline. The International Renewable Energy Agency (IRENA) appears to be more optimistic regarding the country's potential for RE adoption, predicting that RE will comprise $78 \%$ of U.S. electricity generation by 2050 [11].

If all current assumptions regarding geophysical and technological variables such as increase in efficiency of solar, wind, etc. remain constant, the U.S. is capable of meeting $80 \%$ of current nationwide electricity demand with solar and/or wind at any given time [12]. This implies that as far as technical feasibility is concerned, 100\% RE transition for electricity production in many places in the U.S. is beyond just an ambition. Furthermore, [12] argue that the country has $100 \%$ RE transition capability with the right storage technology, policy, and planning. In the face of grid parity, price performance, market competition, and cost-benefit analyses of RE electric generation technologies, different energy agencies or regime actors in the energy sector can easily exhibit a trajectory of transition [12].

Another important trend is people's perceptions and increasing interest in RE [2]. In one national survey, $90 \%$ of respondents support government intervention to encourage the development of RE [4]. Various coalitions of cities, including the Global Covenant of Mayors for Climate and Energy, C40 Cities Climate Leadership Group, and ICLEI Local Governments for Sustainability, are moving toward 100\% RE targets, with over 250 US Mayors showing strong commitments [2], [4]. These reveals growing grassroots commitments on climate and energy issues [14] despite the current U.S. federal administration's announcement to withdraw from the Paris Agreement [4] [15]. At the state level, at least five municipalities in U.S states have achieved their 100\% RE goals by May 2019 [16]. This is an indication of small but growing interest in transitioning from dominant incumbent energy sources.

Sierra Club is a U.S. based environmental advocacy organization that has created its own campaign for government commitments to $100 \%$ electricity from RE. This study 
draws on Sierra Club's campaign and focuses on five U.S. municipalities that have already achieved this goal: Burlington, Vermont; Aspen, Colorado; Greensburg, Kansas; Georgetown, Texas; and Rock Port, Missouri [2]. ${ }^{1}$ This study examines 100\% RE transitions with attentiveness to the role of various actors and their interactions at different levels in these five pioneering municipalities. This analysis utilizes the Multi-level Perspective (MLP) of sociotechnical transitions [13] as well as drawing from existing literature on energy transitions to examine the successful energy transitions in these five municipalities.

\subsubsection{Research Problem}

Prior research on $100 \%$ RE in the five municipalities [2], [4], [16], [17] approaches the topic from different perspectives, with little framework that could be replicated by other U.S. municipalities. As municipalities and their mayors that have pledged their commitment to transitioning prepare to achieve this feat, there is a need for a framework of what to learn from. This is especially true for other municipalities within the same state of those five municipalities; Georgetown, Burlington, Aspen, Rock Port and Greensburg, who have achieved the 100\% RE transition. Although the five cases appear to be small sample sizes to generalize for the thousands of municipalities in the U.S., they equally provide geographical diversity as well as social, economic, and political diversity based on states where they are located. For instance, Aspen, CO, possesses residents with higher income and population than Rock Port, MO. As such, having a transition framework that can be useful for other U.S. grassroots and communities who are interested in low-carbon electricity to consider is needed.

Another shortcoming with existing literature is limited reference to how the driving factors interact in such transition processes. The knowledge of various interactions of driving factors in the transition process can inform typologies in those places and allows for better understanding of the MLP. As the MLP has gained much attention among scholars of sociotechnical transition, there is still limited work that operationalizes the various typologies, especially in $100 \%$ renewable electricity context. This is perhaps since not so many of such transitions to zero carbon electricity has been achieved globally.

\subsubsection{Research Objectives}

This paper aims to develop a framework of factors that should be considered while assessing the socio-technical feasibility of $100 \% \mathrm{RE}$ transitions at the local level in the U.S. In this paper, a comparative analysis is carried out on contributing factors at the three levels of socio-technical transition. The levels based on MLP are the niche innovations,

${ }^{1}$ For the purposes of this article, any references to $100 \%$ commitment to RE means commitment to electricity from $100 \%$ renewable sources. 
socio-technical landscape, and socio-technical regime. Qualitative Comparative Analysis (QCA) is used to develop a driver matrix of observed factors and their role in these five municipalities.

Further, we aim to provide a descriptive analysis of the energy transitions and observed typologies in each of the five communities that are being powered by $100 \%$ RE. With this, we strive to identify some of the important factors to consider through the multilevel perspective (MLP) as a framework in researching transition to 100\% RE in other U.S. municipalities. This paper contributes to bridging the gap in existing literature, which is currently lacking detailed and comparative accounts on pathways for $100 \% \mathrm{RE}$ transition in U.S. municipalities. Developing a framework for understanding RE transitions through a comparative analysis of successful case studies is intended to contribute to both further refinement of MLP as a conceptual model and to developing practical guidance for communities seeking to move toward $100 \%$ RE.

\subsection{Conceptual Lens: Energy Transitions and the MLP}

The use of energy for meeting human needs has involved several evolutions in sources, from the use of human power to the adoption of animals like oxen and then the development of machinery for productivity improvement with steam engines produced by wood and coal, and then by liquid fossil fuels [18]. Markard et al. [19] highlight a need for future empirical research to elaborate and specify such conceptual frameworks like the MLP. This is because there is limited research on transitions in practice and everyday life [19], [20]. This is the aim of this work - to deploy a conceptual framework in a comparative analysis of the empirical realities of energy transitions at the municipal level in order to refine the framework and provide enhanced understandings of transitions in practice.

Based on the MLP of sociotechnical transition, energy transitions are presumed to be dependent on the interactions and process alignment of three levels: niche innovation, socio-technical regimes, and socio-technical landscapes [13], [21], [22]. This analysis revealed what previous research found as drivers to RE transitions in the U.S. in addition to the MLP theoretical framework. Other research recently found that the clean energy transition in the local town of Connecticut, hangs on government-society synergy [23]. Regime actors appear to be the main drivers analyzed in the paper. The research was done using a combination of public documents (secondary data) and semi-structured interviews (primary data).

In similar research by Lee et al. [24], regime level policies (state RPS) and nichelevel actions are found to contribute significantly to Hawaii's transition. Other drivers include energy resource endowment [4], [25], energy cost, and experience of climate change effects [4]. Public engagement through environmental organizations and community advocacy in the planning process has been critical in establishment of some documented 100\% RE goals [17], especially in Lake City, Park City, and Moab, Utah [25]. 


\subsubsection{Re-introducing and operationalizing the MLP in energy transition}

The socio-technical regime involves structural and social agencies including markets, users and their preferences, policy makers, scientists and industry actors that dictate the how, when, and what of energy systems and their transitions [13]. The MLP argues that every form of technological transition is strongly influenced by overlapping activities in two or all three levels at different times [13], [20], [21], [26]. Figure 1 presents the MLP transition curve, showing the interplay among processes in bringing about technological transitions. Transitions take place through the interaction of multiple scales, within and across hybrid agencies, and based on rational, interpretative, routine, and power-based actions [13]. The MLP as a global model takes into consideration the activities of different actors as transitions occur through contests and struggles [13].

In other words, in energy transitions, the dynamics surrounding the interactions of multiple entities such as consumers, policy makers, utility structures, and technological novelty as well as the multilevel interactions among various actors are critical prerequisites. Energy systems are characterized as socio-technical systems involving several elements fulfilling societal energy functions [27]. Because the MLP discusses socio-technical transitions in general, it is expedient to operationalize it in the context of energy transition in the U.S. This paper attempts to match the actors involved in energy transitions in the U.S. to those described in general in the MLP framework and to document characteristics and interactions that correspond to successful RE transitions in municipal settings.

The socio-technical landscape also includes external factors (e.g. climate change) beyond control of regime members, affecting the development of the energy system [27]. From the MLP transition typology curve, form of ownership and structure of the electricity provider, resource availability, and other external factors can be assumed to operate at the level of the sociotechnical landscape. Also, central to achieving such trajectory as in the case of the U.S., is the type and role of electricity provider. By electricity provider, this analysis refers to electric utilities. including investor owned utilities (IOUs), cooperatively owned utilities (co-ops) or municipally owned utilities (MOUs) [28], [29], [30]. IOUs are required to maintain a certain level of electricity service to their customers while maximizing profit for their shareholders. In contrast, MOUs and co-ops are supposed to serve in the best interest of their customer-residents and customer-members, respectively. [8], [28]. In the U.S., most customers are served by a small number of IOUs [30]. Communities that are served by IOUs are reported to experience higher resistance to $100 \%$ RE transition goals [17]. Understanding the role utilities play in successful transitions is therefore necessary.

Scientists, public authorities such policy makers and energy regulators at all levels, consumers, energy markets, civil and special interest groups such as the Sierra Club, Greenpeace, and the media [31] all contribute to the patterning of technological development, and they constitute part of the sociotechnical regime [21]. Within the MLP, they represent various techno-institution complexes like that which is described by Unruh 
[32], [33]. The complexity of formal and informal institutions in this web include preferences and identities of individuals, community, leadership, and policy makers. An example is the role of partisanship in energy technology choices. Previous research examining the relationship between political affiliation of Americans and their perception towards alternative energy development has resulted in conflicting findings.

Mildenberger et al. [34] provide a background for understanding the effect of partisanship on the perception of climate change and corresponding degree of heterogeneity in policy preferences. Their research establishes that among the members of the Republican Party, there are heterogeneous climate policy preferences including renewable energy funding and carbon controls. In addition, political ideology proved insignificant in terms of support for solar energy development in the U.S., meaning that there may be differences in views on climate and energy policies within the same political party [35]. However, other work finds that local policy actors who identify as Republicans were less likely to support the Clean Power Plan, a signature initiative of the Obama Democrat administration [36], [37]. It is thus unclear how individual, or community level political affiliation identities may affect support and ultimate achievement of $100 \% \mathrm{RE}$ transitions.

The niche innovation level is the point where technology is developed and introduced to the market for price or performance improvements [21]; the evolution of technologies and innovations usually bring about a shift via adoption. Niche-innovations describe various energy technologies such as solar, wind, hydro, and fossil fuels (coal, oil and natural gas), available to the U.S. market. Geels [22] defines them as social or technological innovations with sharp contrast from prevailing socio-technical systems and regimes. They are also the level that accounts for preferences regarding one technology or another for the purpose of power generation. At this level, the contest is between wellestablished incumbent fossil fuel and the renewables for electricity generation. However, most adoption decision activities lie at the socio-technical regime and the socio-technical landscape levels (also referred to as the incumbents). 


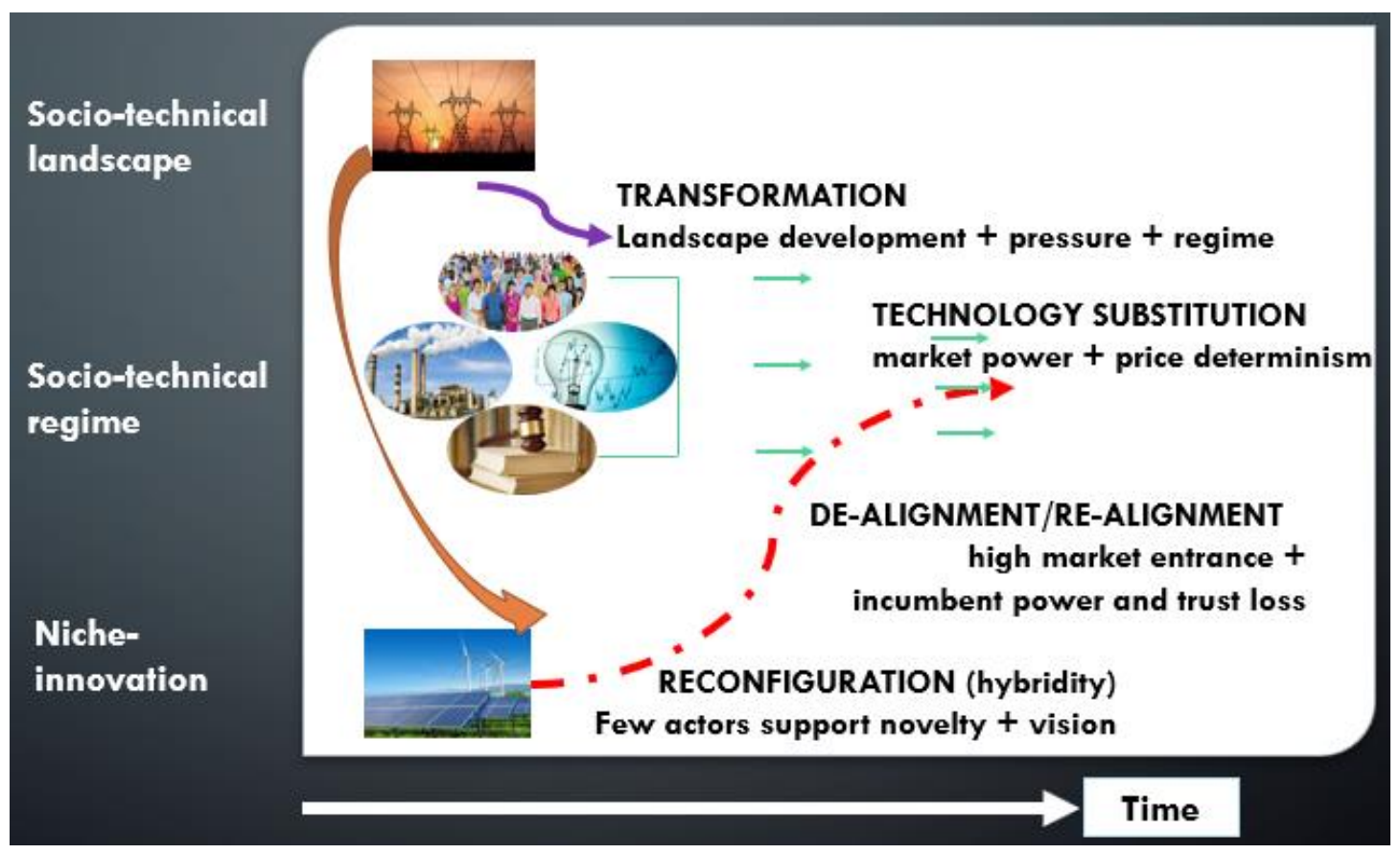

Figure 2-1: MLP on socio-technical transition and main actors and interactions in each pathway (adapted by authors from Geels and Schot 2007)

\subsubsection{0\% Renewable Electricity and Transition Typologies}

The MLP organizes transitions into typologies depending on the types of interactions. Geels and Schot [13] describe four different transition pathways, based on the interaction of actors in the MLP curve: 1) Transformation, 2) Technological Substitution, 3) Reconfiguration and Dealignment, and 4) Re-alignment. The major difference between these pathways is the level of involvement of main actors, leading to such transition. In other words, all of these pathways have common elements and agencies who play roles in various degrees. So, in this section, efforts are made to give a clearer view of each pathway with respect to transition to low-carbon electricity.

In the Transformation pathway, main actors involve actions and voices of players such as policy makers, policy regulators (e.g. public service commissions), customers, researchers, special interest groups (e.g. Sierra Club), and other stakeholders. These regimes and niche actors lead to the creation of new plans or goals for innovation [13]. Specifically, instability and changes in the socio-technical regime precipitate adoption of new solutions. Current 100\% RE goals, adoption and implementation of low carbon electricity in many places fall into this category.

Technological Substitution is described as a situation of technological push sequel to the emergence of radical innovations in the niche and simultaneous landscape pressure 
on existing regimes [31]. In other words, as changes begin to occur via technological innovation, demand for better solutions compels a change in the market, consumer behavior, user culture as well as in policy. Unlike in the transformation with stakeholders, some of which may be external to the community, cultural adjustment of internal stakeholders and market power tussle play key roles in technological substitution. However, this takes time before the pressure yields substantial change in a dynamically stable regime.

Reconfiguration involves hybridization and interaction across multiple innovations [22]. The key concept here is co-existence of technologies leading to hybridization to foster the learning process and gradual development of new goals and visions. Transition in electricity to low-carbon technologies in many places such as The Netherlands [27] has been achieved through hybrid energy technologies of coal, gas, nuclear, and renewables as well as social interactions while the incumbent regime experiences gradual weakening or phasing out [21]. Reconfiguration often involves formal pressures in the landscape and regime level that create niche level innovation.

In the Dealignment and Realignment typology, increased niche momentum facilitates multiple innovations, allowing one dominant design to stabilize. In other words, the peculiarity of this transition typology is based on loss of confidence in the existing regime and landscape levels (energy resources, structures, technologies, policies, etc.), due to the emergence of a new paradigm. This may lead to a shift to decentralized technologies and management [14].

As the MLP is a generalized broad framework for different socio-technical transitions, it is necessary to place it in juxtaposition with existing energy contexts. This research intends to identify the specific transition pathway typology involved in each of the five municipalities that have achieved $100 \% \mathrm{RE}$ and account for the factors that contributed to these successful energy transitions. This is necessary for further recognition of dependent variables that must be considered in other municipalities and cities for possible replication of achieving $100 \%$ RE transitions.

To put the MLP pathways typology in the context of $100 \%$ RE transitions in the U.S., Table 1 below was created by extrapolating descriptions from [13]. As demonstrated in the table, each pathway involves a transition with main actors, interactions, and concepts that vary. This table also signals the key features this paper interrogates in each municipal case study in order to conduct the comparative analysis of successful transitions. 
Table 1: Main actors and interactions in MLP transition typology (Source: Author based on interpretation of [13])

\begin{tabular}{|c|c|c|c|}
\hline Transition pathways & Main Actors & $\begin{array}{c}\text { Types of } \\
\text { (inter)actions }\end{array}$ & Key Concepts \\
\hline 1. Transformation & $\begin{array}{l}\text { Scientists, policy } \\
\text { makers and state } \\
\text { legislation (RPS), } \\
\text { resource availability, } \\
\text { utility structure, } \\
\text { special interest } \\
\text { groups (Sierra club, } \\
\text { etc.) }\end{array}$ & $\begin{array}{l}\text { Criticism leading to } \\
\text { formation of new } \\
\text { goals and plans }\end{array}$ & $\begin{array}{l}\text { External energy } \\
\text { advocacy, Mayor } \\
\text { negotiations, rule } \\
\text { adjustment, and } \\
\text { statutory formation, } \\
\text { changes in structure } \\
\text { or landscape }\end{array}$ \\
\hline $\begin{array}{l}\text { 2. Technological } \\
\text { substitution }\end{array}$ & $\begin{array}{l}\text { Conventional and RE } \\
\text { producers and } \\
\text { suppliers, (utilities } \\
\text { and power generating } \\
\text { firms), political } \\
\text { affiliation of mayors, } \\
\text { consumers, electricity } \\
\text { prices, interest group, } \\
\text { state legislation etc. }\end{array}$ & $\begin{array}{l}\text { Novel RE solutions } \\
\text { that compete with } \\
\text { current fossil fuel- } \\
\text { based energy } \\
\text { producers }\end{array}$ & $\begin{array}{l}\text { Price determinism, } \\
\text { rationalism, market } \\
\text { power tussles } \\
\text { between the old and } \\
\text { new energy } \\
\text { producers. High } \\
\text { market entrance of } \\
\text { new technologies, } \\
\text { retirements of old, re- } \\
\text { establishment of new } \\
\text { winner. }\end{array}$ \\
\hline 3. Reconfiguration & $\begin{array}{l}\text { Niche-innovation } \\
\text { entrants and energy } \\
\text { resources (RE), small } \\
\text { regime actors such as } \\
\text { utility, policy makers, } \\
\text { community members, } \\
\text { institutions etc }\end{array}$ & $\begin{array}{l}\text { Energy technology } \\
\text { adoption by small } \\
\text { regime actors, } \\
\text { changes in utility } \\
\text { structure leading to } \\
\text { new energy plans and } \\
\text { goals. Interplay of } \\
\text { regime actors with } \\
\text { energy technology } \\
\text { and suppliers }\end{array}$ & $\begin{array}{l}\text { Co-existence of } \\
\text { technologies leading } \\
\text { to hybridization to } \\
\text { foster the learning } \\
\text { process. Gradual } \\
\text { development of new } \\
\text { goals and visions. }\end{array}$ \\
\hline $\begin{array}{l}\text { 4. Dealignment and } \\
\text { Realignment }\end{array}$ & $\begin{array}{l}\text { A segment of } \\
\text { industries and small } \\
\text { users of RE and EE } \\
\text { technologies, } \\
\text { incumbent } \\
\text { technologies e.g. coal } \\
\text { and their actors }\end{array}$ & $\begin{array}{l}\text { Energy technological } \\
\text { innovations poses } \\
\text { pressure on regime, } \\
\text { incumbents lose } \\
\text { power, giving way } \\
\text { for new technologies }\end{array}$ & $\begin{array}{l}\text { Market competition } \\
\text { and new versus old } \\
\text { firm power struggles, } \\
\text { culture change etc. } \\
\text { Gradual loss of trust } \\
\text { in incumbent }\end{array}$ \\
\hline
\end{tabular}




\subsection{Methodology}

This study is based on qualitative systematic review of peer-reviewed academic literature, online documentation such as relevant information from webpage of the case study communities, and variable data regarding the energy transition in the five municipalities. The approach in analysis of these data is qualitative comparative analysis, described further in section 2.3.1 below. In the absence of enough previous research that systematically accounts for $100 \%$ RE transition in these five municipalities, it is pertinent to seek direct information from these places. Each municipality's website divulges useful information for investigating factors leading to the transition. Data from Sierra Club on advocacy for RE is used as foundation to this research. This advocacy comes in three different forms. Sierra Club distinguishes three types of calls for RE adoption: 100\% RE Campaign, 100\% RE Commitment, and 100\% RE Powered. The ready for 100\% RE Campaign indicates interest and calling for achieving 100\% RE but without specific temporal commitments to targets. Because these pledges do not usually come in the form of legislative acts, they are susceptible to being discarded with changes in mayoral or municipal leadership.

The $100 \%$ RE Commitment involves pledges made by municipal leaders, which are made for ambitious targets. In the U.S., the main municipal governments forms include Mayor-Council, Commission, Council-Manager, Town Meeting, and Representative Town Meeting [38], [39]. The two prevalent forms are Council Manager and Mayor-Council [39]. While the first three mentioned forms involve election of the local government leaders in the municipalities, Town Meeting and Representative Town Meeting officials are selected by voting citizens [39]. A mayor is a common elected official at the municipal level, charged with overseeing and managing affairs in cities, towns, and other sovereign units [40], [41]. Mayors also have capability to veto ordinances passed by a city council, which serves as the legislative body [39], [41].

In total, mayors from 121 different cities have indicated their committed to reaching RE targets by a specific year [2]. States with the most mayors making such commitments to $100 \%$ RE are California, Colorado, and New Mexico, with fifteen, seven and six municipalities respectively [4]. Of these 121 mayoral level commitments, five municipalities have already achieved 100\% RE Powered. The five municipalities Rock Port, Burlington, Greensburg, Georgetown, and Aspen are the members of this category, and they are the objects of this study. These commitments and actions have been accumulating at the same time as the U.S. announced its withdrawal from the 2015 Paris Agreement [2], [42]. In addition, the current administration under President Trump is showing more interest in supporting fossil fuels and their use in electricity generation U.S. [42].

Although this analysis of factors involved in these sociotechnical transitions are built through the MLP framework, we also incorporate more literature review by using search term "100 percent renewable energy in U.S." on various search engines such as google 
scholar, to strengthen the analysis with the MLP. The variables of the study are RE technology utilization, RE resource availability (solar, wind and hydro), utility ownership and supply source, supporting energy legislation at state level (renewable portfolio standard, RPS), municipality size (population), partisanship of municipal leadership, time to reach accomplishment sequel to initial decision, and other unique corresponding factors including municipal energy programs and stakeholder involvement in the process. While RE technology relates to development of niche innovation on the MLP, population, leadership partisanship, supporting legislation and stakeholder involvement pertains to activities in the socio-technical regime. Socio-technical landscape thus involves RE resource availability outlook and utility ownership. The varying interactions of these variables yield four different pathways to the energy transition based on the MLP.

Data on the different combinations of RE technology utilized in each municipality and utility ownership in each municipality were checked from their webpages and other published data. In the U.S., three forms of utility ownership generally exist; investor owned utilities (IOU) are a profit-making corporation, municipal utilities are controlled by the municipality as the name suggests, and rural electric cooperative utilities are owned by utility ratepayers. National Renewable Energy Laboratory (NREL) data was used to assess RE potential in the municipalities that have achieved $100 \%$ RE. For solar potential, NREL's published National Solar Radiation Database map (Appendix 1-1) was used. Wind potential was assessed using Land-base and Offshore Annual Average Wind Speed at 100 meter above ground level, also published online by NREL (Appendix 1-2). The U.S. National Hydropower Map of Oak Ridge National Laboratory provided the information of operational hydro plants in the country (Appendix 1-3).

NCSL data was used to obtain supporting energy legislation, specifically state RPS. RPS is a statutory requirement on utilities to ensure a certain percentage of the electricity sold by them comes from RE resources [43], [44]. Previous research has shown that there is a significant and positive relationship between state RPS and adoption of renewable energy [45]. Data on municipality size, partisanship of mayors, and time of accomplishment were gathered from Sierra Club and other published information. The MLP transition typology [13] was used to identify what variables may matter for successful energy transitions and the kinds of transitions identified in each case based on the associated variables in each municipality.

\subsubsection{Qualitative Comparative Analysis of Data}

Each of the variables in this study - energy technologies, resource mix, utility ownership, municipality size, mayor's political affiliation and state legislation exists in one or more of the multi-levels, that is the innovation niche, socio-technical regime, and socio technical landscape. From data collected on these variables, a qualitative comparative analysis (QCA) on the RE transition was carried on the five municipalities. QCA is one of the most suitable and widely used research strategies in social sciences for multiple case studies, designed to address small- $N$ and intermediate- $N$ research situations [46]. In doing 
this, a matrix table (Table 2) was created for the description of results of the research. QCA is also gaining ground as a method in investigating and uncovering complex patterns like the MLP [20].

Table 2: Driver Matrix

\begin{tabular}{|l|c|c|c|c|}
\hline $\begin{array}{l}\text { Municipality, } \\
\text { Transition } \\
\text { Typology and } \\
\text { Year }\end{array}$ & $\begin{array}{c}\text { Renewable } \\
\text { Energy Mix }\end{array}$ & $\begin{array}{c}\text { Utility } \\
\text { Ownership \& } \\
\text { Supply } \\
\text { Source }\end{array}$ & $\begin{array}{c}\text { City size \& } \\
\text { Mayor's } \\
\text { Affiliation }\end{array}$ & $\begin{array}{c}\text { State } \\
\text { Legislation } \\
\text { on RE (RPS) }\end{array}$ \\
\hline Georgetown, TX & & & & \\
\hline Burlington, VT & & & & \\
\hline Aspen, CO & & & & \\
\hline Rock Port, MO & & & & \\
\hline Greensburg, KS & & & & \\
\hline
\end{tabular}

\subsection{Results: Review of transition drivers in the five municipalities}

There are a diverse set of motivations for the RE transition among the five municipalities. In accounting for these drivers, this section serves as a checklist in assessing some prominent factors of each energy transition based on the driver matrix provided in section 3. It also interprets the transition pathway typology that is evident in each municipality based on key actors, levels, and their interactions. The three prominent RE resources that are common to these municipalities for electricity generation are hydro, solar and wind. However, achieving $100 \%$ electricity delivery from RE sources is possible even without resource availability either within the municipality or others in proximity. Factors other than resource availability that appear to drive these successful municipal RE transitions are identified. A summary of all the identified driving factors is presented in Figure 2 of the driver matrix at the end of this section. 


\subsubsection{Georgetown, Texas}

In 2018, Georgetown achieved its goal of $100 \%$ powered by RE resources. The municipality's energy mix comprises $150 \mathrm{MW}$ solar with NGR Energy Inc. (a renewable energy company) and 144 MW wind with Électricité de France (EDF) RE, serving its municipally owned utility, Georgetown Utility System (GUS) [47], [48]. Resulting generation mix shows approximately 50\% solar and 50\% wind resources, imported from power stations located about 500 miles away from the municipality. The utility, GUS, is municipally owned and not for profit. Georgetown and its utility are developing solutions to long transmission distance (500 miles) from its solar and wind power sources in Fort Stockton and Amarillo respectively despite locally available resources.

Georgetown has the highest population among the examined five municipalities, with 54,898 residents [2]. The local government is headed by an elected mayor, who is a Democrat [49], [50]. On RE resource availability, global horizontal solar irradiance in this place is higher than average in the US, within the range of $5.00-5.25 \mathrm{kWh} / \mathrm{m}^{2} /$ day based on NREL data map (supplemental material 1). Further, at 100 meters above ground level the wind speed in Georgetown is about $7 \mathrm{~m} / \mathrm{s}$ (supplemental material 2), while the hydrography shows average annual run off approximately $250 \mathrm{~mm} / \mathrm{year}$ of hydropower potential (supplemental material 3). This shows an indication of locally available renewable energy resources that can support the community's RE transition goal.

Furthermore, the state of Texas is well endowed both in conventional sources and renewable energy resources (Long et al. 2018). The state of Texas had its RPS legislation first enacted in 1999 [51] and currently has a renewable generation requirement of $10 \mathrm{GW}$ RE capacity target by 2025 [52]. As the RE usage in Georgetown is counted as part of the state's RPS, the legislation is considered another support for achieving 100\% RE transition in the city. Texas also leads the nation in RE installed capacity of over $23 \mathrm{GW}$ from combined solar and wind [49]. To support transmission infrastructure for RE, Texas state has shown significant support by investing \$7 billion in a competitive Renewable Energy Zone program [2].

GUS engages community members, energy partners, and stakeholders in the development of distributed generation such as rooftop solar and batteries, which reduce the technical and economic challenges of using centralized systems to meet the $100 \%$ RE target [53]. The attempt is also geared towards harnessing local resources to continuously meet demand without interruption. This public engagement is increasing perception and willingness of the people, especially homeowners to participate in the rooftop solar power project if approached. This is also very instrumental to Georgetown winning a \$1 million grant from Bloomberg Philanthropies in the U.S. Mayors Challenge in 2018 to install 400 solar panels on about 15 city rooftops [54].

Environmental reasons such as drought, as well as the falling prices of RE are among main drivers in Georgetown [2]. The drivers of 100\% RE in Georgetown are long-term 
contracts with fixed energy prices and financial and regulatory risk mitigation [2], [47]. Thus, a pathway typology observed in this place is dealignment and realignment, with the regime level spearheading the energy transition due to loss of faith in the incumbent system (refer to Figure 1 and Table 1). This is partly due to fuel price volatility leading to electricity costs unpredictability, scientific consensus on climate change and a match in resources to meet electricity supply from renewables [49].

\subsubsection{Burlington, Vermont}

Burlington, under the leadership of a democratic mayor [55], achieved the $100 \%$ RE goal in 2014. Its energy mix consists of 50\% hydro, 30\% wood chip (biomass) and 20\% for combined solar, wind, and landfill methane [2]. Its municipal utility, Burlington electric department (BED) [14], also outsources part of its supply from renewable electricity retailers such as NextEra Energy Power Marketing, Sheffield Wind, Georgia Mountain Community Wind, New York Power Authority (NYPA), Hydro Quebec, Vermont Electric Power Producers Inc., Vermont Standard Offer, ISO-NE Exchange and Hancock Wind [56]. The net metering available in Burlington allows for distributed generation of electricity from solar and wind resources by privately owned systems to feed into the grid.

The city of Burlington in Vermont has been acknowledged internationally as being the first U.S. city to transition to $100 \%$ RE [14]. Among the list of these five municipalities, Burlington is the second biggest in terms of population, with 42,282 people [2]. The city's GHI is among the lowest in the country, ranging between $4.00-4.25 \mathrm{kWh} / \mathrm{m} 2 /$ day and wind speed of $6.0 \mathrm{~m} / \mathrm{s}$ (supplemental materials 1 and 2). However, it also ranks among the highest on hydro power potential and resources (supplemental material 3). The average annual runoff is about $2800 \mathrm{~mm} / \mathrm{year}$.

The state of Vermont also has a renewable energy standard (RES) of 75\% RE by 2032 , which is enforceable on investor, municipal and cooperative utilities as well as retail suppliers [52]. Under title 30 V.S.A. § 8004 on Vermont's RES, no electricity retailer in the state shall sell or provide electricity without enough RE capacity or tradeable RE credits [57]. The public-private partnership (PPA) in place encourages community solar [52]. However, the state's RPS was first enacted in 2015 [51], a year after Burlington's $100 \%$ RE achievement. Vermont also exemplifies citizens involvement and activism for transition [58] in the energy planning process due to the state's commitment to RE through participatory approaches [2]. This includes a town energy committee set up in over 100 communities, various community solar projects developments, and establishment of energy action networks (EAN), among others [2].

Here, the transition pathway corresponds to the technological substitution typology, due to price determinism and market power tussles existing between energy producers. However, [2] in previous research interpret the transition typology in this place as being dealignment and realignment. On the one hand, the eventual interplay of regimes led the way to a democratically accepted paradigm shift to the deployed energy source. On the 
other hand, the root cause is laden in technological innovation. Innovation in renewable energy technologies resulted in low LCOE opened room to demand for more affordable and just energy systems. This is also coupled with the net metering and energy efficiency programs in the region. The utility company influenced this transition as a socio-technical regime actor. It may also suffice to say, if the main actors in these two typologies evolved simultaneously, then this is a combined typology, as there is thin line differentiating them (refer to table 1).

\subsubsection{Aspen, Colorado}

In 2004, the city of Aspen began to embark on the journey of 100\% RE transition, which was achieved in the year 2015 [59], [60], [61]. The electricity mix in Aspen now is approximately $53 \%$ wind, $46 \%$ hydropower, and $1 \%$ land-fill gas through COA-utilities [62]. A review of the RE resources in this location shows that the city has average solar irradiance between $4.75-5.00 \mathrm{kWh} / \mathrm{m} 2 /$ day, low wind speed of $4.0 \mathrm{~m} / \mathrm{s} 100$ meters above ground level, and average annual runoff rivers around $250 \mathrm{~mm} /$ year (supplemental material 1-3). COA-utilities is a municipal utility that provides electric and water services to the residents of Aspen. One of the core missions of this utility company is to deliver safe, reliable and $100 \%$ RE electricity to customers [62]. These must have played a key role in the transitioning of the city to $100 \%$ RE. The driver that seemed most important for Aspen is the environmental factor, because of the historical mining activities in the region [4]. Within a decade (2004-2014), the city had reduced emissions by as much as $42 \%$ and had developed a future goal of 30\% reduction by 2030 (2004 benchmark) and $80 \%$ reduction by 2050 for the same reference [2].

Aspen is a small city with a total population of 6,658 under the governance of the elected city council [60], headed by a mayor politically affiliated to the Libertarian party. The city established the "Canary Initiative" in 2005 in acknowledgement of the impact of climate change on the city, prioritizing sustainability with quality of life [62]. The Canary Action Plan was a collaborative work of the City of Aspen utilities (COA-utilities), Global Warming Alliance, city and county staff, and other stakeholders. From the Canary Action Plan, policy decisions and education at all levels of government prioritized significant reductions in GHG emissions. This represents a form of legislative commitment support to RE. To meet its $100 \%$ RE target in the face of deficient local renewable resources, Aspen entered a PPA with wind energy producers in neighboring states - the Municipal Energy Agency of Nebraska and South Dakota [2]. The city also utilizes its hydro resources for power generation based on available run of rivers (Supplemental material 3), having two generating hydro power plants of $5 \mathrm{MW}$ and $0.5 \mathrm{MW}$ [2]. Furthermore, Holy Cross Energy (HCE), a cooperatively owned utility company in Colorado, is collaborating with COAutilities to serve 70\% of energy demand in Aspen to achieve 100\% RE goal [2], [60], [62]. These, together with the state of Colorado's RPS under Act Colo. Rev. Stat. §40-2-124 (supplemental material 4 ) of up to $20 \%$ by 2020 , which applies to all utilities (investor, 
cooperative and municipal) [52], is considered to have facilitated the achievement of the clean energy goal.

The observed energy transition pathway typology in this city is reconfiguration, where regime actors (here city council) interplay with energy technology suppliers (COAutilities, HCE). These actors played principal roles in the process and achievement of the target. It should also be noted that the time difference between when the decision or plan for $100 \%$ RE target was made and when it was achieved is within 11 years. This shows that time is a factor for maturity, as planning processes in this municipality were required to experience a successful energy transition. As indicated in the MLP analysis (Figure 1), the adjustment that occurred in the socio-technical regime of the City of Aspen led to the breakthrough of new technology. Also, in line with this is the fact that RE went through tremendous development in efficiency, component costs, and research between 2004 and 2015.

\subsubsection{Rock Port, Missouri}

Located in the state of Missouri, Rock Port is the first community in the U.S. to be $100 \%$ wind powered, achieving 100\% RE in the year 2008 [63], [64]. The small town generates $125 \%$ of its energy demand through public-private partnerships [65] from a total installed capacity of $5 \mathrm{MW}$ [66]. It has its power generating wind farm financed through partnership with Wind Capital Group and John Deere. Due to generation excess, the community is also able to sell electricity, serving as a means of income.

The energy resource maps show a very high wind and average solar resources of $10 \mathrm{~m} / \mathrm{s}$ and $4.25-5.00 \mathrm{kWh} / \mathrm{m} 2 /$ day respectively in this area (supplementary material $1-2$ ). The amount of energy generated from wind resources shows how much the resource availability contributes to the transition process. Recounting the transition, resource availability and technological innovation in wind power inspired one of the community members, which resulted in further research [66], [67]. With the wind turbines supplying electricity, Rock Port enjoys lower annual energy costs per capita compared to others, with an average of $\$ 3000$ per household [68]. Another economic benefit considered in transitioning to 100\% $\mathrm{RE}$ is that it fosters stakeholder-ship in the communities, as in the case of Rock Port, where landowners can lease their properties for renewable infrastructures [2], [63].

Rock Port is a small community with a total population of 1300 [63], [64], [66] and under the leadership of a nonpartisan mayor. The state of Missouri has an RPS established in 2007 to achieve 15\% RE share by 2021 [52]. Furthermore, this small town is the only one among the list of five communities served by an investor owned utility [52]. The profit driven nature of such a type of utility did not however deter the city from achieving this target amidst stiff challenges from the incumbent regime and technology. According to the narrative of how this community transitioned, one of its residents, Eric Chamberlain who was the brainchild of this transition, saw a wind turbine in a nearby town and thereafter made a case for its consideration by the community [66]. This narrative provides two 
learning points, first is the importance of knowledge and information about the capabilities of various energy technologies, and second is the role of small group individuals and local leaders in the community who are willing to share their knowledge for community benefits [69]. The reconfiguration pathway typology is evident in this town's transition process, seeing the interplay between small regime actors, community leadership, energy suppliers and investors for energy transition.

\subsubsection{Greensburg, Kansas}

In 2013, Greensburg achieved transitioning to 100\% RE amidst different socioeconomic challenges it was facing. The challenges include natural disasters of tornado in May 2007 that killed 25 residents $^{2}$ and its associated impact on economic situations in the municipality. The city houses the $12.5 \mathrm{MW}$ Greensburg Wind Farm, which produces a $66 \%$ of energy demand, which is sold back for Renewable Energy Credits [2]. One of the ways Greensburg is achieving its goal is by having a contractual private partnership agreement (PPA) with Kansas Power Pool [4]. The whole city of Greensburg's electricity comes from wind energy [70]. Greenburg also created a Sustainable Comprehensive Master Plan as a means of keeping the city's vision for their socio-technical landscape in transition [2].

Greenburg has the smallest population among the studied municipalities with a population of 778 [71] and is under the leadership of a republican mayor and city council executives [70]. Greensburg was affected by the massive tornado in May 2007 [72], [73], leading to outmigration and a population reduction from 1400 to 785 [2]. Mayor Bob Dixson argued the environment got over-politicized and his administration decided to put an end to it while rebuilding Greensburg [74]. Reviewing minutes of the Greensburg council from December 2007, the impacts of regime actors in the city's energy transition is evident. Records show Mid-Kansas Electric Corporation (MKEC) instigating the city council into greening Greensburg and their support for it during the executive session meeting in December 17, 2007 executive session [75]. MKEC is a cooperative owned utility in the generation and transmission of electricity in Kansas [76]. The proposal submitted during this meeting by MKEC was greeted by unanimous support by all executives in attendance with a 4-0 motion passed under the leadership of Mayor John Janssen and city administrator Steve Hewitt. This marks the beginning of the city's journey to transitioning into $100 \%$ RE.

On resource availability, map shows very high speed of $9.0 \mathrm{~m} / \mathrm{s}$ at $100 \mathrm{~m}$ height above ground level and good solar irradiation ranging between 5.25 to $5.0 \mathrm{kWh} / \mathrm{m}^{2} /$ day (supplementary document 1-2). The state of Kansas does not have RPS, but a renewable

\footnotetext{
${ }^{2}$ Reported in various media including The Washington Post here in this link https://www.washingtonpost.com/climate-solutions/2020/10/22/greensburg-kansas-wind-power-carbonemissions/?arc404=true
} 
energy goal of $20 \%$ by 2020 which was established in 2015 under Kansas Stat. Ann. §661256 et seq. [52]. The main difference between RPS and renewable goals is that while the former is mandatory or legally binding on utilities, the latter is not [77], [78], [79]. RE investment is supported by Google and Kansas City [74]. There is municipal ownership of the local utility, which works in collaboration with the community on their goal.

The previous natural disaster that left a devastating impact on the community can be considered as one driver in the community's successful RE transition. Based on the minutes of Greensburg council meeting, the need to rebuild following the natural disaster provided an opportunity for the municipal leadership to shift focus from their initial energy outlook. The transition typology pathway that is evident here is transformation, as actions and voices of regime players including policy makers, special interest and community-based groups such as Greensburg Green Town [72], [73], and other stakeholders were involved, due to landscape pressure, leading to the creation of new plans or goals for innovation.

\begin{tabular}{|c|c|c|c|c|}
\hline $\begin{array}{l}\text { Municipality, } \\
\text { Transition } \\
\text { Typology and Year }\end{array}$ & Renewable Energy Mix & $\begin{array}{l}\text { Utility Ownership \& } \\
\text { Supply Source }\end{array}$ & $\begin{array}{l}\text { City size \& Mayor's } \\
\text { Affiliation }\end{array}$ & State Legislation on RE \\
\hline $\begin{array}{l}\text { Georgetown, TX } \\
\text { De-alignment and } \\
\text { Re-alignment } \\
\text { (achieved in 2018) }\end{array}$ & $50 \%$ solar \& $50 \%$ wind. & $\begin{array}{l}\text { GUS - Municipally owned } \\
\text { utility. All supply imported } \\
\text { from EDF RE }\end{array}$ & $\begin{array}{l}\text { Population of } \\
54,898 \text { Mayor is } \\
\text { affiliated to } \\
\text { Democratic party }\end{array}$ & $\begin{array}{c}\text { Texas has } 10 \text { GW RE capacity target } \\
\text { by } 2025\end{array}$ \\
\hline $\begin{array}{l}\text { Burlington, VT } \\
\text { Technology } \\
\text { substitution } \\
\text { (achieved in 2014) }\end{array}$ & $\begin{array}{l}50 \% \text { hydro, } 30 \% \text { wood chip, } \\
20 \% \text { from solar, wind \& } \\
\text { landfill methane. }\end{array}$ & $\begin{array}{l}\text { BED - Municipally owned } \\
\text { utility. Outsource part from } \\
\text { RE retailers e.g. Hydro } \\
\text { Quebec, NYPA etc. }\end{array}$ & $\begin{array}{l}\text { Population of } \\
\text { 42,282. Democratic } \\
\text { Mayor's support }\end{array}$ & $\begin{array}{l}\text { Vermont also has renewable energy } \\
\text { standard (RES) of } 75 \% \text { RE by } 2032 \\
\text { enforceable on MOU, IOU and } \\
\text { Cooperative utility }\end{array}$ \\
\hline $\begin{array}{l}\text { Aspen, CO } \\
\text { Reconfiguration } \\
\text { (achieved in 2015) }\end{array}$ & $\begin{array}{l}53 \% \text { wind, } 46 \% \text { hydropower, } \\
\text { and } 1 \% \text { land-fill gas. }\end{array}$ & $\begin{array}{c}\text { COA Utility - Municipally } \\
\text { owned utility. Imports } 70 \% \\
\text { supply from Holy Cross } \\
\text { Energy }\end{array}$ & $\begin{array}{l}\text { Population of } 6,658 \\
\text { Mayor is politically } \\
\text { affiliated to } \\
\text { Libertarian party }\end{array}$ & $\begin{array}{l}\text { The state of Colorado has of up to } \\
20 \% \text { by } 2020 \text { which applies to all } \\
\text { utility type }\end{array}$ \\
\hline $\begin{array}{l}\text { Rock Port, MO } \\
\text { Reconfiguration } \\
\text { (achieved in 2008) }\end{array}$ & Over $125 \%$ wind energy. & $\begin{array}{l}\text { Investor owned utility } \\
\text { (public-private partnership) } \\
\text { Imports if need be }\end{array}$ & $\begin{array}{l}\text { Population of } 1,300 \\
\text { Non-partisan Mayor }\end{array}$ & $\begin{array}{l}\text { Missouri has RES established to } \\
\text { achieve } 15 \% \text { RE share by } 2021\end{array}$ \\
\hline $\begin{array}{l}\text { Greensburg, KS } \\
\text { Transformation } \\
\text { (achieved in 2013) }\end{array}$ & $\begin{array}{l}166 \% \text { RE from Greensburg } \\
\text { wind farm. Excess } 2 / 3 \text { sold as } \\
\text { REC. }\end{array}$ & $\begin{array}{c}\text { MKEC - Co-operative } \\
\text { owned utility with PPA with } \\
\text { Kansas Power Pool }\end{array}$ & $\begin{array}{l}\text { Population of } 778 \\
\text { Republican Mayor }\end{array}$ & $\begin{array}{l}\text { Kansas has renewable energy goal of } \\
\qquad 20 \% \text { by } 2020\end{array}$ \\
\hline
\end{tabular}

Figure 2-2: Driver Matrix - Comparative analysis of socio-technical actors and energy transition typology in the 5 municipalities already in 100\% RE.

\subsection{Discussion}

Most of these municipalities relied solely on fossil fuel for electricity supply prior to shifting to $100 \%$ RE [50], [61]. This is due partly to the stability of incumbent energy technologies and the sociotechnical landscape. This research finds that community members, social groups, existing energy legislation, and utility type or ownership are all critical in the transitioning of these five municipalities to $100 \%$ RE (Figure 2). These municipalities have shown resilience in achieving this feat amidst unpredictable political 
terrains, resource availability, and demographic challenges associated with small population size.

Furthermore, the research results show that these socio-technical transitions were achieved irrespective of political affiliation of their local leadership. Although two of the five local leaders who were responsible for the RE transition commitment are affiliated with the Democratic party, the study shows involvement from a mix of other political parties (Figure 2). For example, the mayor of Greenburg is affiliated with the Republican party, whose current national leadership tends to deny climate change or the need to prioritize climate change issues. Some previous scholarship suggests that political party affiliation of local leaders in U.S. with Republican party identity may hinder this transition [80] [81]. The current findings, however, though with a small sample, contradicts this suggestion, finding that $100 \%$ RE transition at U.S. grassroots levels is also evident in places with politically conservative mayors, city council managers, etc.

State level legislation such as RPS is a key factor, considering that all the states, except Kansas, of the five municipalities have it. An RPS can further strengthen previous arguments as a driver in energy transition. However, in the case of Vermont, it may be argued that the RPS cannot be considered as a driving factor because the achievement was prior to the state's RPS enactment. As policy processes (bill conceptualization, proposals, and passages) usually start much earlier than enactment, the effect of the RPS proposition could have played a role; given that the majority of U.S. states do not have RPS policies, these may be necessary but not alone sufficient for successful 100\% RE transitions.

Another observation is the role of resource availability in these municipalities to produce electricity. As critical as the availability of these energy resources are, these municipalities have been able to achieve their target in the absence of it locally. Three out of the five municipalities - Aspen, Burlington and Georgetown - import some or all their electricity from renewable energy generating utilities in proximity to meet demand. These municipalities have been able to leverage the market instrument of renewable energy credits (RECs) for renewable energy trading and credit certification. This is fostered by the utility type in these places, which is predominantly municipally owned. Greensburg and Rock Port do not engage in importation like the other three. While Greensburg is served by a cooperative owned utility, Rock Port is served by an investor owned utility. Even then, they are engaging the public in public-private partnerships to develop RE generating power plants to meet the $100 \%$ RE goal.

The role of the public, civic groups, external pressures, and clean energy advocates is invaluable to the achievement of $100 \%$ RE transitions, even or perhaps especially in places where there is less support from the top leadership. Sierra Club's campaign and activities on energy transition is gaining more attraction by local leaders. Such attraction has led to an exponential increase in the number of mayors that have signed up for $100 \% \mathrm{RE}$ transition between 2016 and 2019 [60], [62]. It thus makes this civil group an important external actor in the sociotechnical landscape and regime of the transition process. This 
group is acting as an advocacy and information provider for low-carbon electricity transition in the U.S.

From the conceptual stage as in the case of Rock Port and Greenburg to achievement and continuous supply of affordable electricity from RE resources as in the case of Georgetown, public participation is evident. Greensburg was able to bring about changes in its energy landscape as they rebuilt the city following the previous tornado. This change was the collective decision of the small but resilient members and leaders of the community. The Canary Initiative of policy makers and stakeholders in Aspen also exemplifies the roles of the public and small advocacy groups in the transition process. Energy efficiency programs and net metering for privately owned RE systems in Burlington further demonstrate the importance of the public and public engagement in energy transitions.

All of the five municipalities possess a relatively small population. Two of the municipalities, Rock Port and Greensburg, have a population that is less than 2,000. Georgetown and Burlington both have over 40,000 population, although this is also considered small in the U.S. context. More so, the two communities with the smallest populations are the ones with excess electricity generation and with a single renewable energy technology - wind turbine. While there is not much of surprise that municipalities such as Georgetown and Burlington could achieve this transition, Rock Port and Greensburg present amazing cases of communities with extremely small populations yet with capability to achieve such a feat.

In the transition process, we observe that different key actors across the three levels of MLP played a significant role in each municipality. The different roles of those key actors help identifying four pathways from Geels' framework on socio-technical transition. While Aspen and Rock Port are reconfiguration, Georgetown, Burlington and Greensburg are realignment/dealignment, technological substitution and transformation respectively. We also observed closeness between key actors in technological substitution and realignment/dealignment as defined by Geels. This brings about a thin line difference between the two typologies and need for more empirical data from the five communities to clarity.

\subsection{Conclusion and Recommendations}

This research highlights common factors and significant variables that matter in the RE transition processes of the five municipalities in the U.S. that have met the Sierra Club challenge for $100 \%$ RE. An established RPS in some of the states where these municipalities are located, indicating the importance of state legislation. RE resource availability (within or in proxy) and possibilities for hybridization of energy technologies are evident in the studied places. Locally available RE resources are a factor, however, 
municipalities and their utilities can import electrical power from neighboring RE retailers with abundant resources.

However, innovations in energy technologies, especially battery and other electrical storage, can further facilitate the sociotechnical transition. As resources in proxy are crucial to the transition process, future research should further examine the technical feasibility of achieving such transitions. This will include comprehensive year-round resource assessment to match hourly electricity demand and identification of potential relationships between cities or municipalities for RE. Average wind speed as given by the resource map, for instance, is not enough to know if granular load can be met all year-round. Technical assessment of resource and infrastructure availability is often limited by proprietary information kept by utilities reluctant share their load data or to identify the capacity of their interconnection infrastructure, but this information is necessary for a full assessment of the technical capabilities and needs for supporting RE transitions. Yet technical capabilities and the proximity to RE resources do not necessarily benefit surrounding communities. This underscores the need for further interdisciplinary analysis for which this study serves as the initial step.

The different transition typologies that these communities underwent are identified in this work, with reconfiguration being most common but without any clear emergence of one typical transition pathway for these $100 \% \mathrm{RE}$ transitions at the municipal level. The reconfiguration pathway offers an effective bottom-up and gradual approach to achievement of $100 \%$ RE transitions by allowing learning in the process of replacing the incumbent technology. This typology is the result of technological innovation fueled by development in RE technologies combined with small stakeholder advocacy for the RE transition.

$100 \%$ RE transitions in the U.S., which is stemming from municipalities and local levels, is occurring independently of the political affiliations of mayor or other types of local leadership, as demonstrated by the variety in political affiliations of local leaders in the five municipalities. What is unknown is the probability of termination of transition goals or plans in the face of changing leadership at local levels in the U.S. That, in turn, requires further research attention on the effect of leadership change within or between political parties on transition commitment and achievement. This is necessary because many other mayors have pledged to $100 \%$ RE transition [60] and it is not known if such pledges will be sustained if a new regime comes into power before the goals are achieved.

Utility ownership type is a vital factor to transitioning, as most of the municipalities have MOUs. This suggests that MOUs have the greater flexibility to transition to $100 \% \mathrm{RE}$ and could facilitate such sociotechnical change. On the other hand, IOU resistance to energy transition is evident through lobbying and political campaigns [8]. As such, other municipalities as well as scholars looking towards grassroot $100 \%$ renewable electricity must pay cognizant to the ownership type of the utility serving them. 
Civic engagement cannot be overlooked; this is especially important for the energy efficiency and conservation programs that utilities are incorporating into the $100 \% \mathrm{RE}$ transition. These variables, therefore, provide helpful parameters of consideration for future research on energy transitions in other places in the U.S. and beyond. They also demonstrate mechanisms for promoting transition pathways for $100 \% \mathrm{RE}$ at localized levels. However, our analysis could not substantiate the level of participation of the public and civil groups. It is also important to know how the research supports or differs from some theoretical framework of public participations such as [82], [83], [84], especially because public participation usually stems from grassroots involvement.

Future research may further investigate the transition process by obtaining data from the main actors and stakeholders who were involved in the process. Surveys, interviews, and focus group meetings are some of the ways to obtain direct information that may be excluded from cities' or communities' websites, news articles, and available peer-reviewed and grey article publications. Such information could help to uncover all that transpired in the process including level of community participation, setbacks and challenges that confront communities in transition.

Scholars of MLP on any other forms of socio-technical transition (e.g. 100\% clean mobility) can borrow a cue from this analysis. An in-depth case by case future work will be needed to provide a fuller explanatory framework about pressures on existing regimes, the role of other external factors and other elements of the socio-technical regime. By other elements of the regime, we refer to specificity of individuals actors along the transition process and their contributions. Municipalities and other mayors in the U.S. who are yet to achieve their $100 \%$ RE target, will find this comparative analysis very useful in knowing what to consider along the way. Lastly, other case study would facilitate further understanding of transition typologies in the U.S.

\section{Supplemental Material}

Appendix 1 - Renewable Energy Resources in U.S

a. Global Horizontal Irradiance for U.S. 


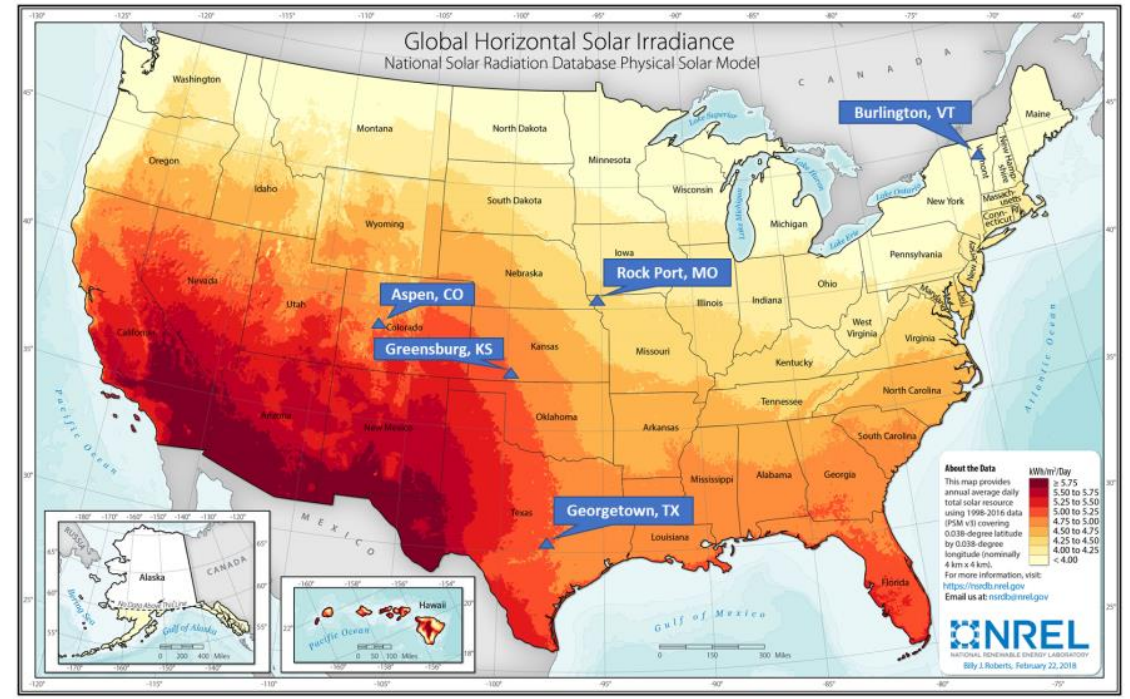

b. Wind Resource for U.S - Speed at 100m above ground level

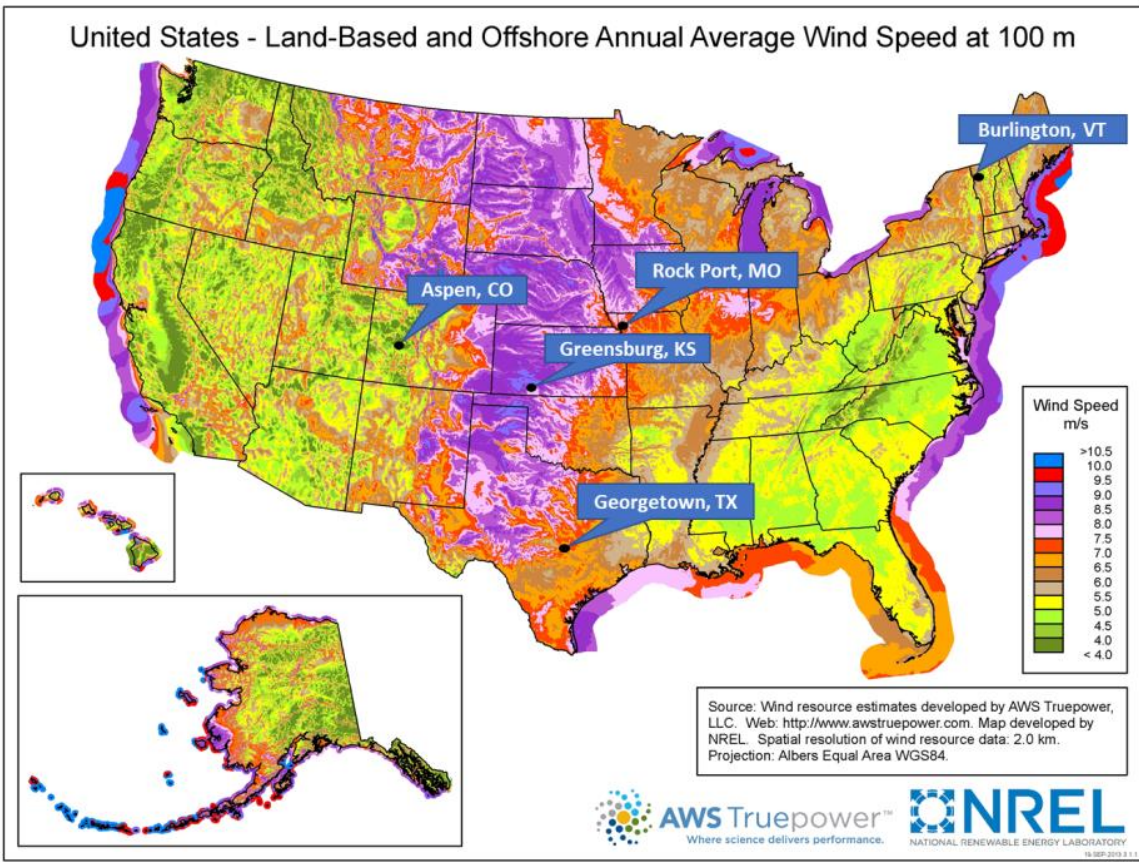

\section{c. U.S. National Hydropower Map}




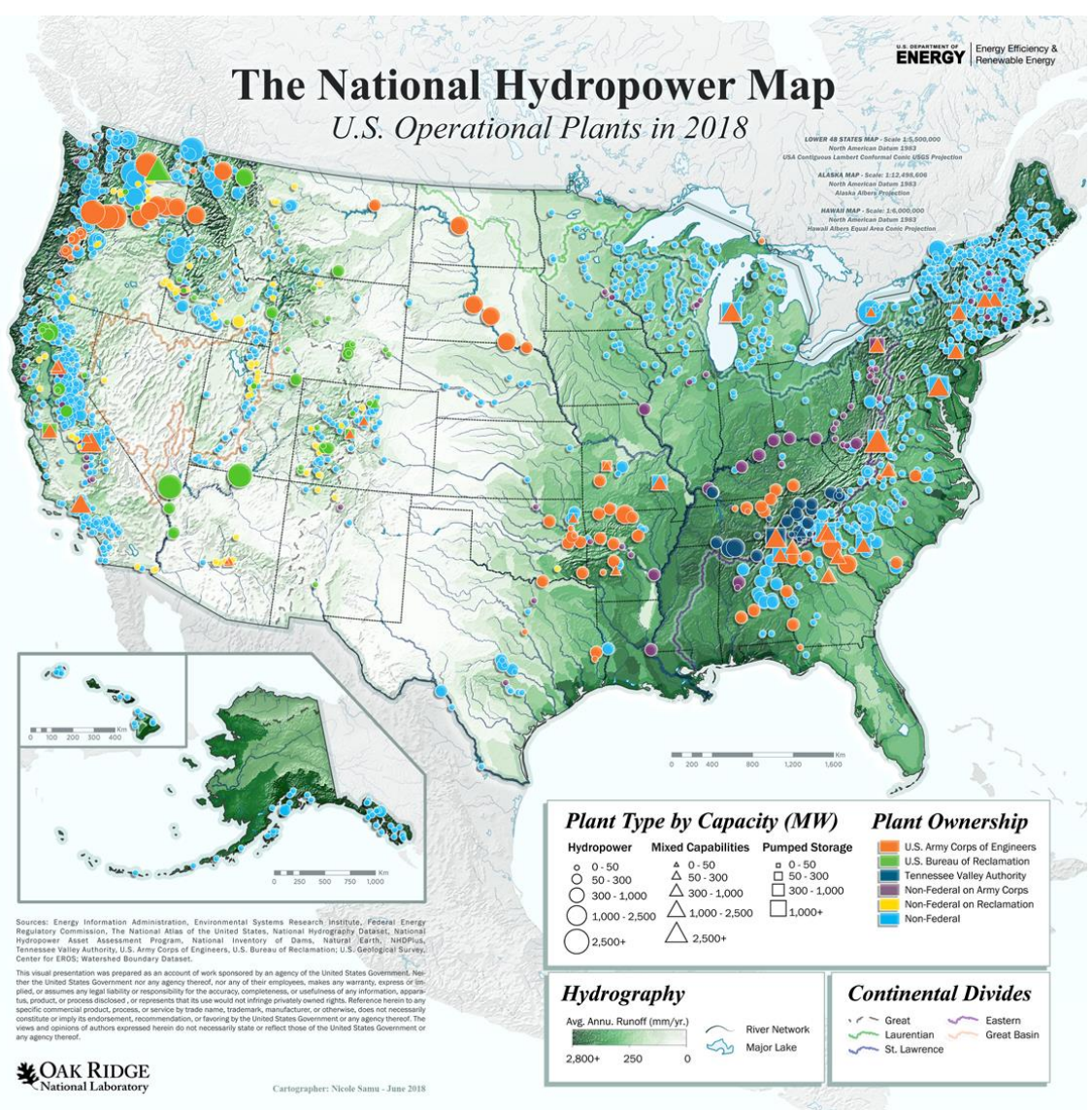

Appendix 2

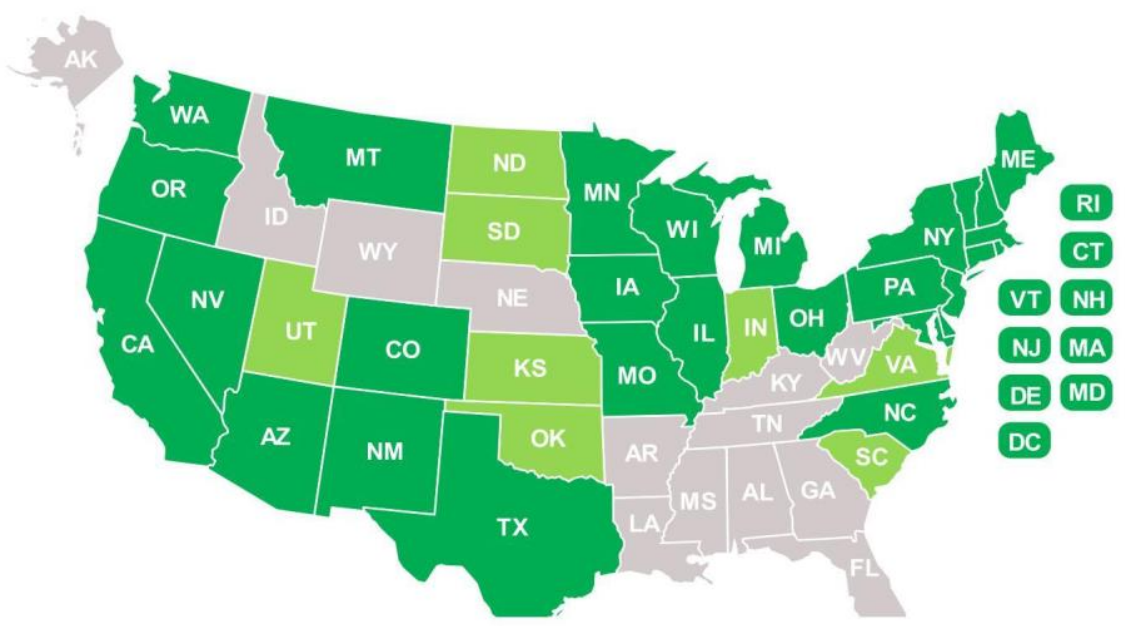

State Renewable Portfolio Standards 2018 (Source: NCSL 2018) 


\section{References}

1. Gearino, D. As Rooftop Solar Grows, What Should the Future of Net Metering Look Like? https://insideclimatenews.org/news/11062019/rooftop-solar-netmetering-rates-renewable-energy-homeowners-utility-state-law-changes-map. (2019)

2. Sierra Club-a. Ready for $100 \%$. Case Study Report. Cities Are Ready for $100 \%$ Clean Energy. https://www.sierraclub.org/ready-for-100 (Accessed 13 November 2018).

3. U.S. Climate Alliance. States United for Climate Action. https://www.usclimatealliance.org/ (Accessed 13 November 2018)

4. Martinez, H., K. DeFrancia, K. Schroder, A. Moving Towards 100\% Renewable Energy: Drivers Behind City Policies and Pledges. (2018). Google Scholar

5. Banerjee, A., Prehoda, E., Sidortsov, R., Schelly, C. Renewable, ethical? Assessing the energy justice potential of renewable electricity. In AIMS Energy 5 (5), (2017)., pp. 768-797. DOI: 10.3934/energy.2017.5.768.

6. Bunker, K., Doig, S., Hawley, K., Morris, J. Renewable Microgrids: Profiles from Islands and Remote Communities Across the Globe. Rocky Mount Institute, (2018).

7. Branker, K., Pathak, M.J.M., Pearce, J. M. A review of solar photovoltaic levelized cost of electricity. Renewable and sustainable energy reviews, 15(9), (2011), 4470-4482.

8. Prehoda, E. Pearce, J., Schelly, C. Politics to overcome barriers for renewable energy distributed generation: A case study of utility structure and regulatory regimes in Michigan. Energies, 12(4), (2019), 674.

9. Kantamneni, A., Winkler, R., Gauchia, L., Pearce, J.M. Emerging economic viability of grid defection in a northern climate using solar hybrid systems. Energy Policy. 95, (2016). pp. 378-389.

10. EIA. Annual Energy Outlook 2019 with projections to 2050 https://www.eia.gov/outlooks/aeo/pdf/aeo2019.pdf (Accessed 21 May 2019)

11. IRENA. Global Energy Transformation; https://www.irena.org//media/Files/IRENA/Agency/Publication/2018/Apr/IRENA_Report_GET_2018.p df (Accessed 11 May 2019) 
12. Shaner, M.R; Davis, S.J., Lewis, N.S., Caldeira K. Geophysical constraints on the reliability of solar and wind power in the United States. In Energy and Environ Sci. (2018)

13. Geels, Frank W.; Schot, Johan (2007): Typology of sociotechnical transition pathways. In Res. Policy 36 (3), pp. 399-417. DOI: 10.1016/j.respol.2007.01.003.

14. Burke, M. J., \& Stephens, J. C. (2018). Political power and renewable energy futures: A critical review. Energy Res. Soc. Sci., 35, 78-93.

15. Carley, S., Evans, T. P., \& Konisky, D. M. Adaptation, culture, and the energy transition in American coal country. Energy Res. Soc. Sci., 37(2018), 133-139.

16. Sierra Club-b. 100 Percent Clean Energy: The New Normal. https://www.sierraclub.org/articles/2019/05/100-percent-clean-energy-newnormal (Accessed 15 August 2019)

17. Hess, D. J., \& Gentry, H. 100\% renewable energy policies in US cities: strategies, recommendations, and implementation challenges. Sustainability: Science, Practice and Policy, 15(2019), pp.45-61.

18. Smil, Vaclav. Energy Transitions: Global and National Perspectives. Praeger. (2017)

19. Markard, J., Raven, R., \& Truffer, B. Sustainability transitions: An emerging field of research and its prospects. Res. policy, 41(2012), 955-967.

20. Köhler, J., Geels, F. W., Kern, F., Markard, J., Onsongo, E., Wieczorek, A., ... \& Fünfschilling, L. An agenda for sustainability transitions research: State of the art and future directions. Environ. Inn. Soc. Trans., 31 (2019), 1-32.

21. Geels, Frank W. Regime Resistance against Low-Carbon Transitions: Introducing Politics and Power into the Multi-Level Perspective. In Theory, Culture \& Society 31 (2014), pp. 21-40.

22. Geels, F.W. Disruption and low-carbon system transformation: Progress and new challenges in socio-technical transitions research and the Multi-Level perspective. Journal of Energy Res. Soc. Sci., 37 (2018) 224-231.

23. Bayulgen, O. (2020). Localizing the energy transition: Town-level political and socio-economic drivers of clean energy in the United States. Energy Res. Soc. Sci., 62(2020), 101376. 
24. Lee, T., Glick, M. B., \& Lee, J. H. (2020). Island energy transition: Assessing Hawaii's multi-level, policy-driven approach. Renew. Sustain. Energy Rev., 118(2020), 109500.

25. Skill, E. E. (2019). Developing, Adopting, and Executing 100\% Net-Renewable Electricity Resolutions at the Local Level. Google Scholar

26. Araújo, K. The emerging field of energy transitions: progress, challenges, and opportunities. Energy Res. Soc. Sci, 1(2014), 112-121.

27. Kern, F., and Smith, A. Restructuring energy systems for sustainability? Energy transition policy in the Netherlands. Energy policy, 36(2008), 4093-4103.

28. Bluvas, K. (2006). Distributed Generation: A Step Forward in United States Energy Policy Comment. Albany Law Review, 70 (4), 1589-1614. Google Scholar

29. Hess, D. J. Electricity Transformed: Neoliberalism and Local Energy in the United States. Antipode, 43(2011), 1056-1077.

30. Hess, D. J. The politics of niche-regime conflicts: distributed solar energy in the United States. Environ. Inn. Soc. Trans., 19(2016), 42-50.

31. Geels, F.W. (2004) Processes and patterns in transitions and system innovations: Refining the co-evolutionary multi-level perspective. Technological Forecasting \& Social Change 72 (2005) 681-696

32. Unruh, G. (2000), 'Understanding carbon lock in’, Energy Policy 28, 817-830.

33. Unruh, G. (2002): "Escaping Carbon Lock-in” Energy Policy 30. 317-325.

34. Mildenberger, M., Marlon, J. R., Howe, P. D., \& Leiserowitz, A. The spatial distribution of Republican and Democratic climate opinions at state and local scales. Clim. change, 145(2017), 539-548.

35. Carlisle, J. E., Kane, S. L., Solan, D., Bowman, M., \& Joe, J. C. Public attitudes regarding large-scale solar energy development in the US. Renew. Sustain. Energy Rev., 48(2015), 835-847.

36. Mayer, A. (2019). National energy transition, local partisanship? Elite cues, community identity, and support for clean power in the United States. Energy Res. Soc. Sci., 50(2019), 143-150.

37. Karapin, Roger. "Federalism as a Double-Edged Sword: The Slow Energy Transition in the United States." Environ. Dev. (2020): 1070496519886001. 
38. MASC. Forms and Powers of Municipal Government. An Elected Official's Guide from the Municipal Association of South Carolina.

https://www.masc.sc/SiteCollectionDocuments/Administration/Forms $\% 20$ and $\% 2$ OPowers2.pdf (Accessed 10 August 2019).

39. Moulder, E. R. Municipal form of government: Trends in structure, responsibility, and composition. The Municipal Yearbook 2008.

40. Bae, J., \& Feiock, R. Forms of government and climate change policies in US cities. Urban Studies, 50(2013), pp.776-788.

41. City Mayors. http://www.citymayors.com/mayors/us-mayors.html (Accessed 20 February 2019)

42. White House Briefings. President Donald J. Trump Is Unleashing American Energy Dominance. https://www.whitehouse.gov/briefings-statements/presidentdonald-j-trump-unleashing-american-energy-dominance/ (Accessed 22 May, 209)

43. Klass, A. B.; Wiseman, H.J. (Eds.). Energy Law: Foundation Press. (2015)

44. Wiser, R., Namovicz, C., Gielecki, M., \& Smith, R. (2007). The experience with renewable portfolio standards in the United States. Electr. J., 20(2007), 8-20.

45. Yin, $\mathrm{H}$. and Powers, N. Do state renewable portfolio standards promote in-state renewable generation? Energy Policy 38(2010). 1140-1149

46. Rihoux, B. Qualitative comparative analysis (QCA) and related systematic comparative methods: Recent advances and remaining challenges for social science research. Int. Sociol. 21(2006), 679-706.

47. Foster, C. Municipal Utilities’ Engagement with Renewable Energy-Georgetown Utility Systems. (2017) Google Scholar.

48. Motyka, M., Smith, S., Slaughter, A. and Amon, C. Renewables (em)power smart cities; Wind and solar energy best enable the goals of people-centered smart cities. Deloitte Insight. https://www2.deloitte.com/us/en/insights/industry/powerand-utilities/smart-renewable-cities-wind-solar.html (Accessed 12 September 2019)

49. Long, J., \& Kincaid, P. A Red City Goes Green: The Renewable Energy Partnership of Georgetown, Texas and Southwestern University. Sustainability: Journal of Record, 11(2018), 298-306.

50. Yang, J. Y. Is Energy Transition Occurring in the United States? A Case Study of Texas. (2019). Google Scholar 
51. Garbose, B. U.S. Renewables Portfolio Standards 2016 Annual Status Report. https://escholarship.org/content/qt0wt0q741/qt0wt0q741.pdf (Accessed 2 August 2019).

52. NCSL. State Renewable Portfolio Standards and Goals. Available online at http://www.ncsl.org/research/energy/renewable-portfolio-standards.aspx. (Accessed 2 August 2019).

53. Georgetown, Texas. Item $\mathrm{C}$ - Presentation, update, and discussion regarding the Bloomberg Philantropies Mayor's Challenge - Chris Foster. August 14, 2018 Workshop. http://georgetowntx.swagit.com/play/08152018-808 (Accessed 12 May 2019).

54. Linan, A. Georgetown won $\$ 1$ million to capture and store solar energy. Here's what happens next. Community Impact Newspaper. Georgetown.

https://communityimpact.com/austin/georgetown/citycounty/2018/10/31/georgetown-won-1-million-to-capture-and-store-solar-energyheres-what-happens-next/ (Accessed 12 May 2019).

55. The City of Burlington (2019); Office of Mayor Miro Weinberger. https://www.burlingtonvt.gov/Mayor (Accessed 15 July 2019).

56. Burlington Electric Department. https://www.burlingtonelectric.com/index.php/our-energy (Accessed 10 May 2019)

57. The Vermont Statutes Online. Title 30: Public Service, Chapter 089: Renewable Energy Programs Subchapter 001: General Provisions. https://legislature.vermont.gov/statutes/section/30/089/08004

58. Clegg, J. M. The winds of change: The political ecology of renewable energy transition in Vermont. (2013). Google Scholar.

59. NREL (2015): Reaching $100 \%$ Renewable Energy. Available online at https://www.nrel.gov/docs/fy15osti/62490.pdf (Accessed 23 November 2018).

60. City of Aspen. Renewable Energy. https://www.cityofaspen.com/1202/Renewable-Energy (Accessed 5 May 2018).

61. McLaren, J. Reaching 100\% Renewable Energy: Lessons-Learned from Aspen, Colorado. In Urban Energy Transition, (2018) pp. 525-528. Elsevier.

62. City of Aspen. https://www.cityofaspen.com/DocumentCenter/View/756/02Energy (Accessed 7 May 2019) 
63. University of Missouri Extension. Rock Port, Missouri, First 100 Percent Windpowered Community in U.S. ScienceDaily.

www.sciencedaily.com/releases/2008/07/080715165441.htm (Accessed 11 May 2019)

64. Johnson, J. Rock Port on Wind Power Map. https://www.farmprogress.com/storyrock-port-on-wind-power-map-9-16005 (Accessed 11 May 2019)

65. Hart, J. Rock Port, Missouri: This Town Runs on Wind Power, Literally. Mother Earth News. https://www.motherearthnews.com/nature-and-environment/rockport-missouri-zmaz09onzraw (Accessed 12 May 2019)

66. Moris, R. Missouri Town Is Running on Vapor - And Thriving. Environment, NPR. https://www.npr.org/templates/story/story.php?storyId=93208355 (Accessed 12 May 2019)

67. Rock Port. $100 \%$ wind powered community. http://www.rockportwind.com/ (Accessed 12 May 2019)

68. Cohen, Martin R: A Clean Energy Economy for Missouri. Analysis of the Rural Economic Development Potential of Renewable Resources. The Natural Resources Defense Council (NRDC) (NRDC Issue Paper). Available online at https://www.nrdc.org/sites/default/files/cleanmo.pdf (Accessed 11 May 2019)

69. Simpson, G. Looking beyond incentives: the role of champions in the social acceptance of residential solar energy in regional Australian communities. Local Environment, 23(2018), 127-143.

70. Greensburg, KS. 5 Ways We Put the "Green" in Greensburg. https://www.greensburgks.org/sustainability/how-we-out-the-green-in-greensburg (Accessed 9 May 2019).

71. 81.World Population Review. Greensburg Kansas 2019. http://worldpopulationreview.com/us-cities/greensburg-ks-population/ (Accessed 20 February 2019)

72. NREL. Greensburg, Kansas. A better place, greener place to live. https://www.nrel.gov/docs/fy10osti/45086.pdf

73. Stone, L. A High-Renewables Tomorrow, Today: Greensburg, Kansas. https://rmi.org/blog_2013_09_10_high_renewables_tomorrow_today_greensburg _kansas/ (Accessed 5 June 2019)

74. Newsy. How a small Kansas town rebuilt on green energy. https://www.youtube.com/watch?v=PnXnxkGAArA_(Accessed 11 May 2019) 
75. Executive Session, Greensburg Council Meeting December 17, 2007 6pm. County Meeting Facility, E. Wisconsin St.

http://www.greensburgks.org/government/agendas-minutes/2008-agendasminutes/12-1-08\%20minutes.docx/view_(Accessed 11 May 2019)

76. Mid-Kansas Electric Company, Inc. https://www.midkansaselectric.net/default.htm (Accessed 22 March 2019)

77. SEIA. 38 states plus D.C. have a Renewable Portfolio Standard. https://www.seia.org/initiatives/renewable-energy-standards (Accessed 11 May 2019)

78. Li, H., \& Yi, H. Multilevel governance and deployment of solar PV panels in US cities. Energy Policy, 69(2014), 19-27.

79. Adelaja, A., Hailu, Y. G., McKeown, C. H., Tekle, A. T. Effects of renewable energy policies on wind industry development in the US. Journal of Natural Resources Policy Research, 2(2010), 245-262.

80. Kantamneni, A. Winkler, R. And Calvert, K. Chapter 7: Incorporating Community: Opportunities and Challenges in Community-Engaged Research in "A Research Agenda for Environmental Management. Edward Elgar Publishing. (2019)

81. Cornwall, Andrea. "Unpacking 'Participation': models, meanings and practices." Community. development 43(2008): 269-283.

82. Marquart-Pyatt, S. T. and P. Petrzelka. Trust, the Democratic Process, and Involvement in a Rural Community. Rural Sociology. 73(2008): 250-274.

83. Carmichael, Jason T.; Brulle RJ. Elite cues, media coverage, and public concern: an integrated path analysis of public opinion on climate change, 2001-2013. Environ Polit 2017;26:232-52. https://doi.org/10.1080/09644016.2016.1263433.

84. Mayer A. Partisanship, politics, and the energy transition in the United States: A critical review and conceptual framework. Energy Res Soc Sci 2019;53:85-8. https://doi.org/10.1016/j.erss.2019.02.022. 


\title{
3 Achieving 100\% Renewable and Self-Sufficient Electricity in Impoverished, Rural, Northern Climates: Case Studies from Western Upper Michigan, USA
}

\author{
Adewale A. Adesanya ${ }^{1, *}$, Nelson Sommerfeldt ${ }^{2,3}$ and Joshua M. Pearce ${ }^{1,2,4}$ \\ 1. Environmental and Energy Program, Department of Social Sciences, Michigan \\ Technological University, Houghton, Michigan, U.S.A. \\ 2. Department of Material Science and Engineering and Electrical and Computer \\ Engineering, Michigan Technological University, Houghton, Michigan, U.S.A.
}

3. Department of Energy Technology, KTH Royal Institute of Technology, Stockholm, Sweden

4. School of Electrical Engineering, Aalto University, Finland

*Correspondence: adesanya@mtu.edu

\begin{abstract}
Development of $100 \%$ renewable electricity (RE) systems plays a pivotal role in ensuring climate stability. Many municipalities blessed with wealth, an educated and progressive citizenry, and large RE resources, have already reached 100\% renewable electric generation. Impoverished municipalities in unwelcoming environments both politically and climatically (e.g. northern latitudes with long, dark winter conditions) appear unable to transition to renewables. This study challenges that widespread assumption by conducting a detailed technical and economic analysis for three representative municipalities in the Western Upper Peninsula of Michigan. Each municipality is simulated with their own hourly electricity demand and climate profiles using an electrical supply system based on local wind, solar, hydropower, and battery storage. Sensitivities are run on all economic and technical variables. Results show that the transition to $100 \%$ $\mathrm{RE}$ is technically feasible and economically viable. In all baseline scenarios, the $100 \% \mathrm{RE}$ systems produced a levelized cost of electricity up to $43 \%$ less than the centralized utility rates, which are predominantly fueled by gas and coal. Current policies, however, prevent such self-sufficient systems from being deployed, which are not only detrimental to the global environment, but also aggravate the economic depression of such regions. Recommendations regarding both sociotechnical and policy pathways are provided.
\end{abstract}

Keywords: self-sufficient; renewable electricity; rural northern climate; municipalities; just transition. 


\subsection{Introduction}

Recent reports from the $25^{\text {th }}$ Conference of Parties (COP25) of the United Nations Framework Convention on Climate Change (UNFCCC) in 2019 show that global warming, which is mainly the result of greenhouse gas (GHG) emissions from fossil fuel combustion, requires immediate action to avoid impending catastrophes. This is based on previous scientific reports from the Intergovernmental Panel on Climate Change (IPCC) demonstrating that the world has about a decade to limit global warming below $2{ }^{\circ} \mathrm{C}$ to prevent the irreversible change [1] [2] [3].

To meet this target before 2030, each country is required to achieve an annual emission reduction of $7.5 \%$ from their current emission status. Although average global emissions for the year 2019 experienced about a $17 \%$ reduction in $\mathrm{CO}_{2}$ emissions at the end of first quarter of 2020 due to COVID-19, recent research has shown a rebound in countries easing out on lockdown with a corresponding surge in socioeconomic activities [4]. Achieving $7.5 \%$ reductions in emissions still requires more aggressive strategies to change the global energy system.

The largest portion of global GHG emissions comes from the combination of electricity and heat sectors. About a quarter of global total GHG are because of burning coal, oil and natural gas for generating electricity and heat [5]. About $92 \%$ of U.S. emissions from the electric power sector came from coal and natural gas in 2016 [6]. There is thus an immediate need to transition the U.S. electricity sector from the current dominant sources to clean and renewable resources.

Achieving such a transition is challenging in the face of the country's complex, inconsistent energy policies and the U.S. decision to pull out from the global climate pact. While the policy irregularities hinder definite steps towards transition at the federal level, efforts from state and local policies have been more useful. However, five municipalities in the U.S. (Aspen, CO; Rock Port, MS; Greensburg, KS; Burlington, AR and Georgetown, TX) have already transitioned to $100 \%$ RE supply for electricity [7] [8]. This transition may be replicated in many other municipalities, counties in the U.S. that are interested in switching to renewables. The achievement by each of the municipalities is arguably in part due to the technical feasibility of harnessing available energy resources.

To probe that assumption, this study investigates a challenging northern climate region. In general, many of the municipalities and counties in the northern rural part of the U.S. are facing challenges with their energy systems. For example, Upper Peninsula (UP) residents within the Upper Peninsula Power Company's (UPPCO) service territory, have $\$ 0.2350 / \mathrm{kWh}$ electricity prices [9], twice as much as the national average (Figure 1). Utilities face large costs for serving sparsely populated households creating higher distribution costs, which raise electricity costs. When coupled with the population's relatively low-income levels, and the corresponding hardship of paying electricity bills, a higher than average utility bill nonpayment is observed [10]. Thus, the main concern in 
this community is to have an electricity system that will be more flexible, affordable, and reliable.

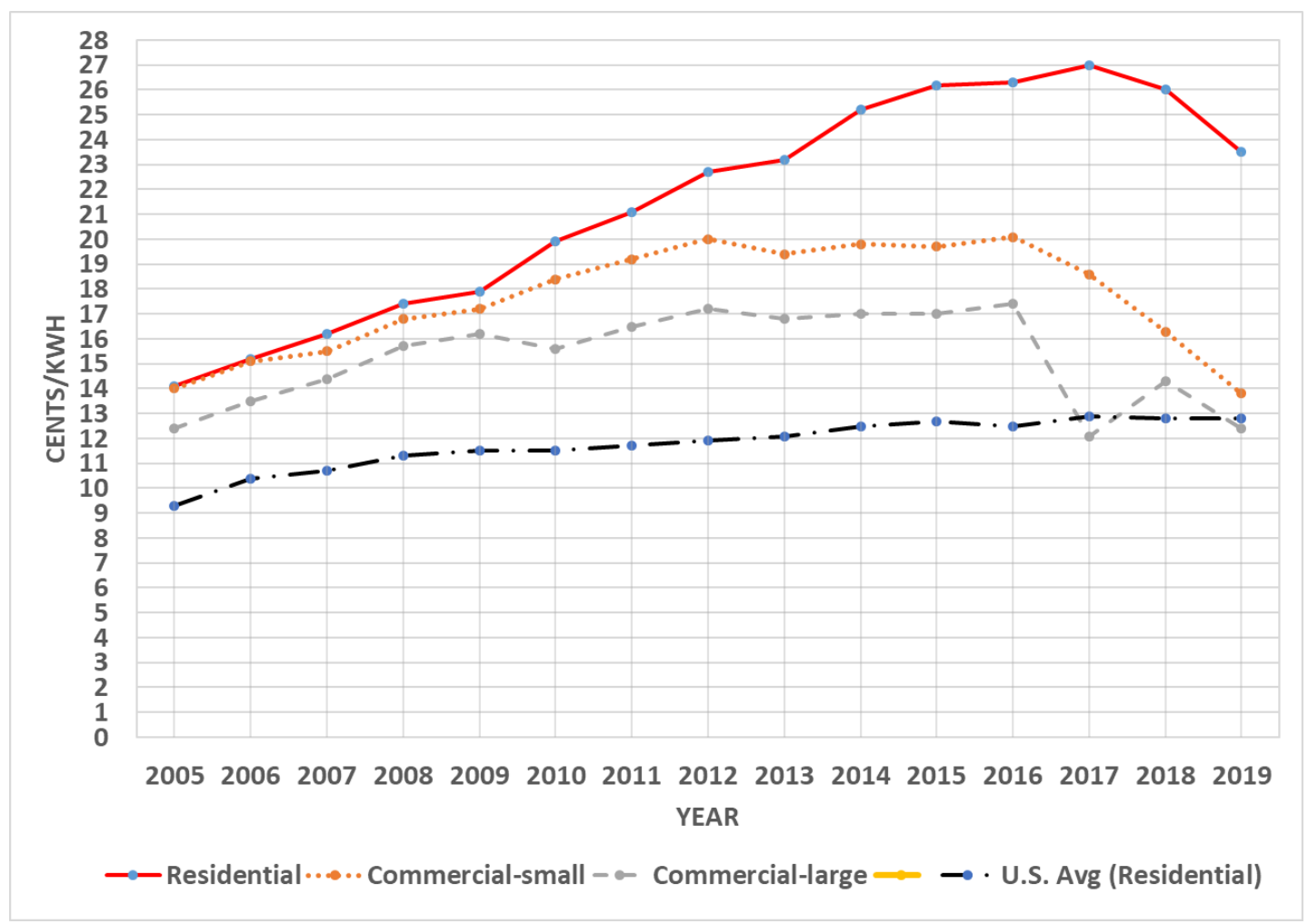

Figure 1: UPPCO's electricity price by sector and the average U.S. price from 2005-2019. Source: Author, based on MPSC data on comparison of average rates (in cents per $\mathrm{kWh}$ ) for MPSC-regulated electric utilities in Michigan [9].

Coal and natural gas are the main sources of electrical generation for the utility for serving the UP. The utility's generation mix constitutes $17.2 \%$ from hydroelectricity generation facilities, while $82.7 \%$ are purchased from Midcontinent Independent System Operator (MISO) [11]. With less RE being deployed for electricity supply by the utility, this may form an integral part of why its rate is among the highest in the U.S. Prehoda et al. [12] have found that all households would save money with deployment of customer-owned solar photovoltaic (PV) systems, yet utilities have used various techniques to minimize customer-owned distributed generation including a generation cap in UPPCO territory. In areas that can deploy RE, integration of RE is increasing, with the community of L'Anse in the western UP region adopting community solar [13] [14] [15].

There is clearly an economic case for small-scale distributed generation of RE technologies in the region, but RE may not be technically or economically viable with greater penetration rates. The objective of this study is to determine the techno-economic feasibility of $100 \%$ RE supply and sufficiency in a northern region. These regions can be 
classified as unlikely for RE transition due to extreme weather and long winters with up to eight months of snowfall, which also has effects on socioeconomic activities [16]. Hourly electricity load profiles are modeled with $100 \%$ RE supply based on local wind, solar, hydropower, and battery storage, including sensitivities on component costs, discount rates, effect of load reduction, and snow losses. The results are presented and discussed in the context of both technical and economic viability of $100 \%$ RE for northern communities.

\subsection{Background}

\subsubsection{0\% RE Transition and Concerns for Unlikely Places}

Scholars have raised concerns about the absence of some important socio-technical elements in some rural places, making them unlikely to independently achieve a renewable energy transition [17] [18]. Socially, rurality (characteristics defining rural communities) has been characterized by population loss, economic decline, and continuous poverty [17]. The U.S. rural areas have been described as small, poorer, and less progressive municipalities in the country, which are statistically modelled to be least likely to take climate action [18]. This is as different forms of capital (e.g. economic (finance), human (technical know-how), social (people or population) and natural (weather related) are presumed to be relatively inadequate to lead to RE transitions in rural places [19]. Some of the challenges faced by the rural communities are due to prior extractive activities such as mining, drilling, etc.

In addition, in northern rural communities, there are technical challenges of extreme weather conditions with long cloudy winters, and corresponding low solar penetration such as the case for the UP of Michigan, U.S [10] [16] and Nunavut, Canada [20]. The same argument holds for other rural places in the arctic region (e.g. Russia, Norway, Sweden, Finland, Greenland, Iceland, and the northern U.S). This is true of both fixed and nomadic communities in the North [21]. In such rural isolated communities with extreme cold climates there is a presumed limitation to their RE transition potential. Apart from the extreme weather, more frequent weather events such as ice and windstorms are a threat to residents of the state of Michigan under the current, centralized energy infrastructure [22].

Winkler et al. [23] describe how art can be used to invigorate some rural areas. If art is closely linked to expression of beauty and attraction to nature, then some RE infrastructure could fit into such a category. For instance, hydropower plants and the waterfalls accompanying them attracts people and tourists just like other art works [24] [25]. The same has been discussed on wind tourism [26] and solar tourism [27] particularly for rural regions using agrivoltaics [28], which is the co-location of agriculture and PV [29]. Such scenic beauty and outdoor recreation potential are drivers of population and economic growth [17]. 


\subsubsection{0\% RE Transitions and Energy Justice Concern}

Another dimension to the transition to renewable energy is concern regarding how social injustice is perpetuated in the generation and distribution of energy in rural places. This concern is rooted in interdisciplinary energy justice research. Energy justice is an emerging concept in energy discourse that considers equitable distribution of energy services as a minimum requirement of an individual in meeting basic goods of life [30] [31]. Two energy justice principles - affirmative, energy as derivative to human right to basic goods of life, and prohibitive principles, non-interference in personal rights [32], provide grounds for the discussion of energy justice in $100 \%$ RE transitions research such as this paper.

Isolated northern residents are more sensitive to energy security to meet their basic needs, cutting across electricity, heating, cooling, and mobility (transportation). In the long cold winter that usually lasts up to eight months, electricity service can be crucial for cooking, lighting and sometimes for heating. The same needs are met in the short, but warm summer with requirements for cooling rather than heating. Thus, the absence of such energy service is a threat to life, which is a fundamental right of every human [32]. High electricity costs in low-income and northern regions can challenge or interfere with the fundamental right of rural citizens, and thus requires an investigation into the potential of having clean, affordable, and reliable electrical energy. These energy justice issues are being exacerbated by the COVID-19 pandemic [33].

\subsection{Methods}

The electricity systems of three municipalities from Michigan's Upper Peninsula: Negaunee, L'Anse, and one that requests to remain anonymous, are used as a representative sampling of the Western UP (WUP). Each municipality is simulated with its own hourly electricity demand and climate profile. Electricity supply systems based on local wind, solar, hydropower, and battery storage are simulated using the Hybrid Optimization of Mixed Energy Resource Professional (HOMER Pro) software [34]. The applicability of this software spans private sector captive hybrid systems deployed by [34] [36] [37] and microgrid distributed energy systems for rural communities by [38].

The UP is rich in natural resources and today already utilizes a broad range of renewable energy technologies, including solar, wind, hydro, and biomass. In this study, only solar, wind, and hydro are investigated, which are the three leading electricity generating RE technologies globally [39] [40] due to low and falling component costs [41]. Lithium-ion batteries are the only storage technology considered in this study, given their locational flexibility. They are also increasingly available at different scales based on their various deployment for mobility and electricity at utility, commercial, and standalone scales [42] [43]

Several sensitivity analyses including component costs, discount rates, effect of load reduction, and snow losses at various tilt angles are performed to quantify the high amount 
of both short-term and long-term uncertainties. Short-term uncertainties relate to the installed costs of renewable technologies, which can change rapidly due to policies (e.g. subsidies or tariffs) or the general reduction in costs due to learning and scale. Long-term uncertainties relate to the cost of capital, energy efficiency / load reduction, and pricing in the electricity market. Further details on each technology are provided in subsequent sections.

The system diagram used for each municipality is shown in Figure 2, where each component is simulated with one representative alternative. Due to a lack of data regarding hydrological resources, hydropower is not explicitly modeled in HOMER, but represented using the grid connection. Each community has access to a proportional share of existing hydro resources, which is explained in subsection 3.7.

The communities are treated like prosumers rather than merchant energy providers, meaning that their $100 \%$ RE systems should be designed to supply their own load and not build overcapacity when it is potentially profitable to do so. To force HOMER to prioritize electricity supply to the community, grid exports are prevented in the simulations. This leads to the appropriate PV, wind, and battery capacities needed for a $100 \%$ self-sufficient community, but undervalues the sales potential of excess generation, therefore revenues from grid sales are removed from the energy cost post-process.

Cost-optimal component capacities are found using HOMER's optimization algorithm. All systems are considered to be community scale, i.e. several megawatts in capacity, which is the underlying driver of specific components and their cost assumptions. The economic lifetime of the system is 30 years, however only single-year energy simulations are run due to the use of HOMER's optimizer. The remainder of this section includes detailed boundary conditions for each component and system simulation, and a complete listing of input parameters and references can be found in Appendix A.

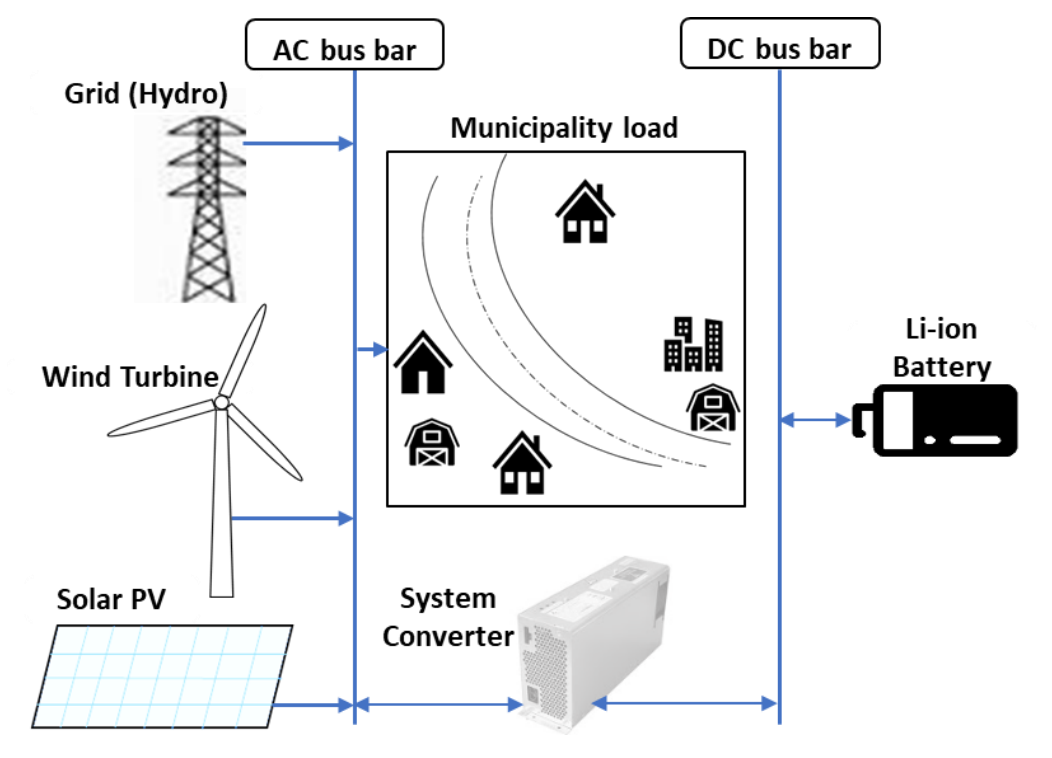


Figure 2. System diagram for simulations with hydro represented as the grid.

\subsubsection{Key Performance Indicators}

Component sizing is optimized by HOMER for minimal total net present cost $(N P C)$, described by:

$$
N P C=C_{0}+\sum_{y=1}^{L} \quad\left[\frac{C_{y}+O_{y}-R_{y}-S_{L}}{(1+d)^{y}}\right]
$$

, which discounts costs occurring in year $(y)$ with rate $(d)$ over the lifetime $(L)$ back to the present, including: initial capital expenditures to build the system $\left(C_{0}\right)$, replacement of equipment $\left(C_{y}\right)$, operational expenditures $\left(O_{y}\right)$, revenues earned from the sale of overproduction to the grid $\left(R_{y}\right)$ and salvage value of equipment that has not reached its end of useful life $\left(S_{L}\right)$.

To make NPC results relatable, costs are presented as the levelized cost of energy (LCOE), defined by:

$$
L C O E=\frac{N P C}{E_{y}} \cdot\left[\frac{d(1+d)^{y}}{(1+d)^{y}-1}\right]
$$

This form of LCOE is suitable for systems with constant annual energy generation or demand over time. HOMER has an internal LCOE calculation (labeled cost of energy, $\mathrm{COE}$ ) which uses Equation 2, and includes all generation from the system for annual electricity, including that which is sold to the grid.

For this study, grid sales are not considered relevant to the supply of the community, only an economic benefit towards reducing costs. Therefore, LCOE is calculated post-process so that annual electricity $\left(E_{y}\right)$ is limited to the community's annual demand and does not include overproduction. The bracketed portion of LCOE is the uniform capital recovery factor, applicable when annual electricity is constant over the lifetime of the system.

Economic results are also compared considering the initial capital costs. Technical results are shown using the installed capacities for solar, wind, and batteries, as well as the fraction of total generation sold to the grid, labeled here as excess generation. 


\subsubsection{Electricity Demand}

Each of the communities being simulated uses hourly electricity demand profiles from 2019 , provided by the current supplier. In the interest of anonymity, not all the communities are identified by name and specific location. However, their total population and load profiles are provided in Table 1. Figure 3 shows the distribution of loads for each location by month using standard box plots and the summation shown with a line curve. The general load patterns show higher loads in the winter except for a spike in cooling during July and August.

Table 1: Municipalities and energy load descriptions

\begin{tabular}{|l|c|c|c|c|c|}
\hline & Latitude & Longitude & Population & $\begin{array}{c}\text { Average Load } \\
\text { (MW) }\end{array}$ & $\begin{array}{c}\text { Peak Load } \\
\text { (MW) }\end{array}$ \\
\hline Negaunee & $46.4928 \mathrm{~N}$ & $87.6070 \mathrm{~W}$ & 4,547 & 2.54 & 4.09 \\
\hline L'Anse & $46.7528 \mathrm{~N}$ & $88.4480 \mathrm{~W}$ & 1,872 & 1.48 & 2.49 \\
\hline $\begin{array}{l}\text { Anonymous } \\
\text { municipality } \\
\text { in WUP }\end{array}$ & - & - & 10,005 & 9.72 & 16.3 \\
\hline
\end{tabular}

a.

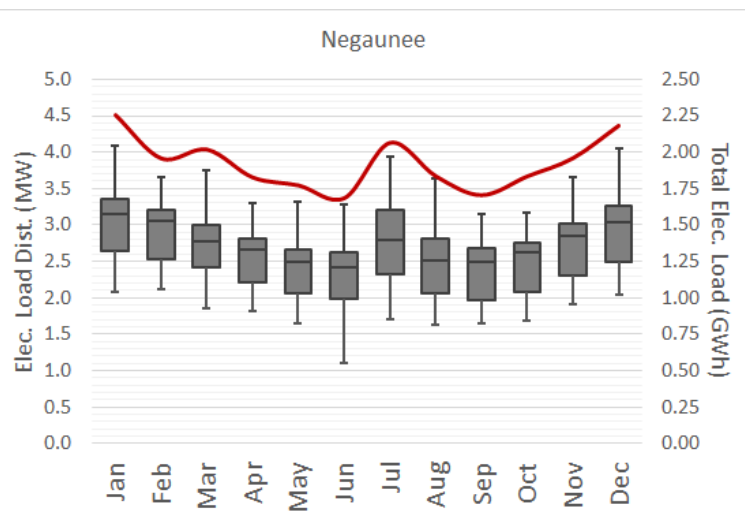


b.

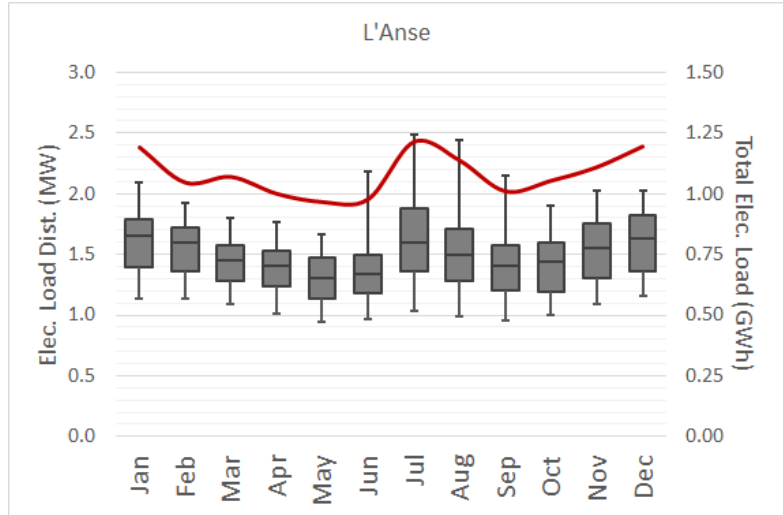

c.

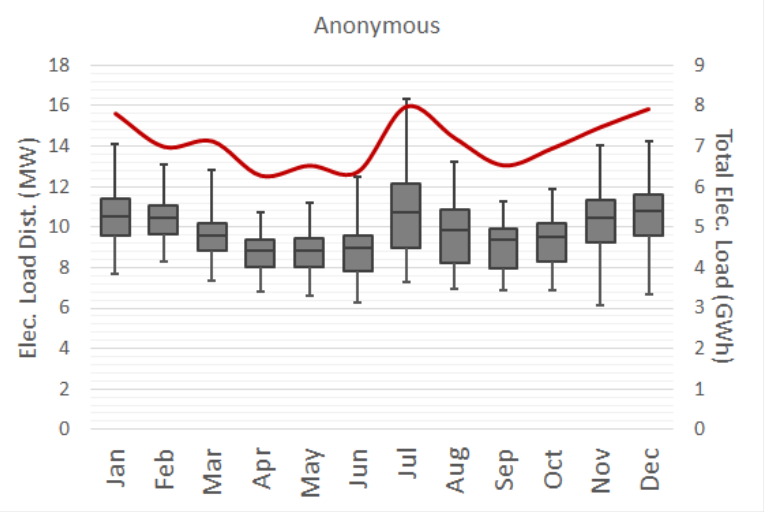

Figure 3: The three municipalities (a: Negaunee, b: L'Anse, c: Anonymous) and their load profile with average monthly consumption.

\subsubsection{Climate}

Typical meteorological year (TMY) climate data is generated using Meteonorm 7.3.1 with temperatures from 2000-2009 and radiation from 1991-2010 [44]. The latitudes and longitudes for the locations under study are given in Table 1 and the average monthly temperatures, total global horizontal irradiation (GHI) with snow losses removed, and average monthly wind speeds (at $10 \mathrm{~m}$ height) are given in Figures 4, 5, and 6, respectively. 


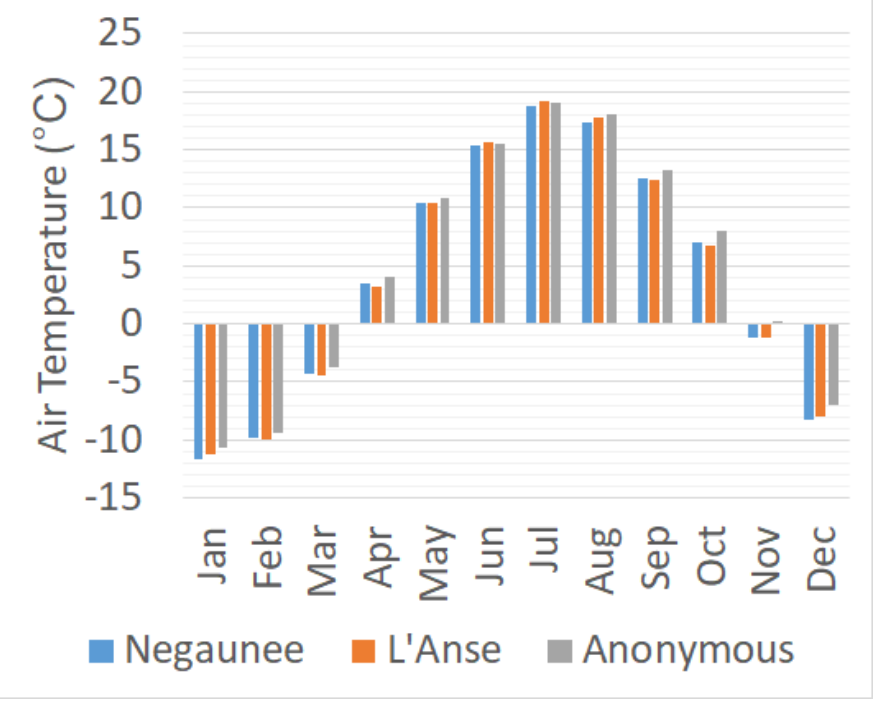

Figure 4. Average monthly air temperatures at each case study location.

The WUP has particularly high annual snowfall, causing a meaningful reduction in annual PV generation [45] [46] [47]. The accumulation and shedding of snow are a complex process that is difficult to model on an hourly basis with common weather station data [45] [47]. With detailed experimental data from a study in the WUP [46], a simplified approach is used here where snowfall is assumed to cause a fixed percentage of losses for an entire day, which are selected randomly during a month. The resulting losses for $30^{\circ}$ and $45^{\circ}$ tilts have comparable daily loss patterns to empirical measurements, and total seasonal and annual losses from unobstructed modules [46]. Given that the measurements by [46] were made from an area of the WUP with relatively high snowfall as compared to the communities studied here, these losses are considered conservative. A $60^{\circ}$ test is not included in [46], however measurements by [47] show snow losses at $60^{\circ}$ to be approximately half those at $40^{\circ}$ and therefore a similar pattern from $45^{\circ}$ to $60^{\circ}$ are applied here. The seasonal and annual losses for each location and tilt angle are given in Table 2, and monthly GHI for the $45^{\circ}$ tilt with snow losses removed is given in Figure 6. 
Table 2. Estimated seasonal and annual snow losses for each PV tilt angle in each case study community.

\begin{tabular}{|c|c|c|c|c|}
\hline \multirow{2}{*}{ Solar PV tilt angle } & $\mathbf{3 0}^{\circ}$ & $\mathbf{4 5}^{\circ}$ & $\mathbf{6 0}^{\circ}$ \\
\hline \multirow{2}{*}{ L'Anse } & Seasonal & $21.0 \%$ & $11.7 \%$ & $5.1 \%$ \\
\cline { 2 - 5 } & Annual & $10.0 \%$ & $5.6 \%$ & $2.4 \%$ \\
\hline \multirow{2}{*}{ Negaunee } & Seasonal & $21.5 \%$ & $12.0 \%$ & $5.7 \%$ \\
\cline { 2 - 5 } & Annual & $10.1 \%$ & $5.7 \%$ & $2.7 \%$ \\
\hline \multirow{2}{*}{ Anonymous } & Seasonal & $22.1 \%$ & $11.6 \%$ & $5.9 \%$ \\
\cline { 2 - 5 } & Annual & $10.6 \%$ & $5.6 \%$ & $2.8 \%$ \\
\hline
\end{tabular}

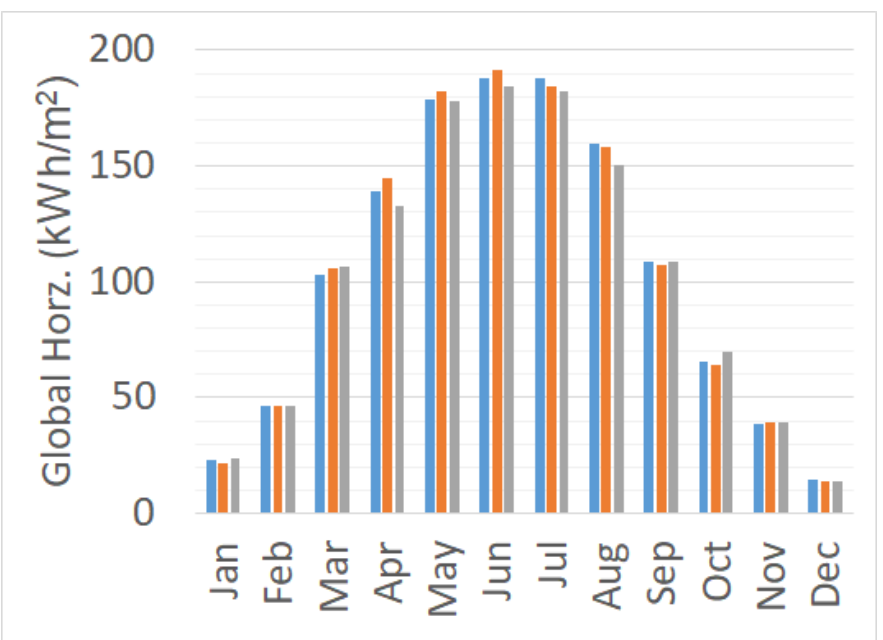

Negaunee L'Anse anonymous

Figure 5. Monthly GHI (with $45^{\circ}$ snow losses removed) at each simulated location. 
Wind speeds are highly localized due to terrain and nearby objects (i.e. forests or buildings), which leads wind farm developers to use short-term, site located measurements in early planning stages. This approach is cost prohibitive in feasibility studies and a known limitation [48]. Therefore, studies rely on measured wind speeds from nearby meteorological stations [49] [50] or more commonly synthetic time series data based on long-term historic measurements and local site conditions [51] [52] [53] [54].

Meteonorm generates synthetic data by leveraging nearby weather stations for wind speed distributions and applying these to a stochastic model in combination with the userspecified terrain (all locations in this study are "open" terrains). The sites are not specifically proposed for wind farms but are indicative of the potential for wind power in the region. As a check on the feasibility of results, wind turbine capacity factors are compared to the Heritage Garden wind farm, the first large wind facility located in the WUP [55].

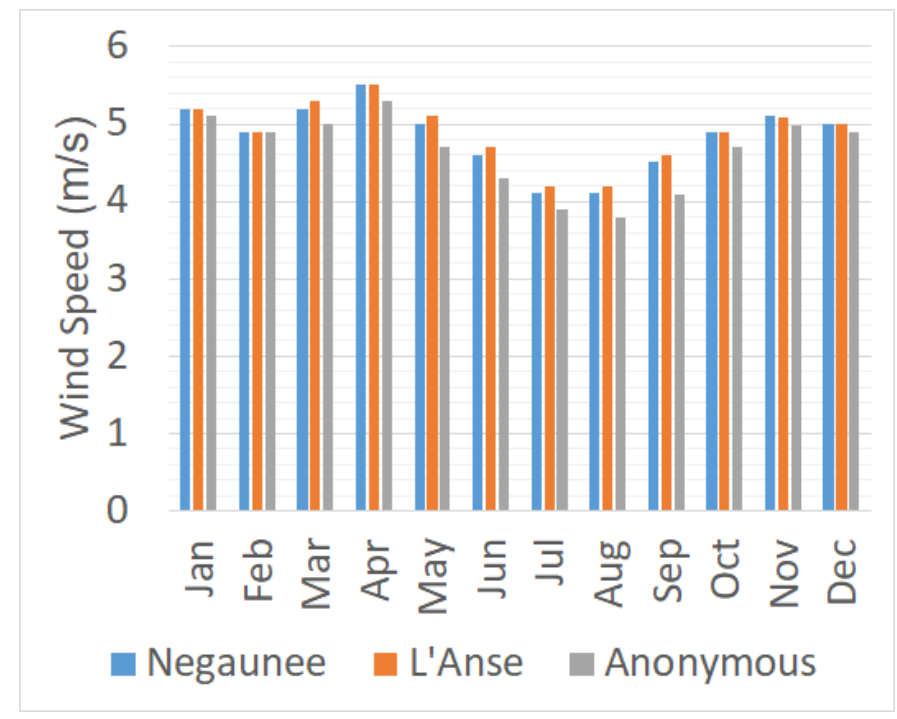

Figure 6. Average monthly wind speeds at each simulated location.

\subsubsection{Solar Photovoltaics}

The PV modules are modeled with specifications from SunPower's E20-327 [56], which has a standard test conditions efficiency of $20.4 \%$. To simplify the simulations and reduce configuration counts, the $\mathrm{PV}$ is modeled on the $\mathrm{AC}$ bus under the assumption that any community scale system will have a co-located inverter. The inverter is not explicitly modeled, rather the total system efficiency (excluding snow losses discussed above) is assumed at 85\%, which is comparable to modern installations [57] [58].

The modules are assumed to be ground mounted with a fixed orientation, positioned at $30^{\circ}$, $45^{\circ}$ and $60^{\circ}$ tilt angles and an azimuth of $0^{\circ}$ (i.e. due south). Losses due to temperature are 
included using a nominal operating cell temperature of $45^{\circ} \mathrm{C}$ and $-0.35 \% /{ }^{\circ} \mathrm{C}$ loss coefficient [59]. Since single-year simulations are used, no degradation rate is applied. Further, the selected PV module used in our model is tested to be free from potentialinduced degradation [56] Thus, degradation is taken to be $0 \%$ and not included in the simulations.

Given the target solution is a community scale, ground mounted PV system, it can be assumed that there are small changes in economies of scale relative to other uncertainties and a single specific capital cost figure is applied. The baseline installed cost is $\$ 2,000 / \mathrm{kW}_{\mathrm{p}}$, which is typical for medium sized commercial/community scale systems [60] [61] [62] [63] and is tested down to $\$ 1,200 / \mathrm{kW}_{\mathrm{p}}$ in the sensitivity analysis. The lower cost is already common in utility scale systems (i.e. $100 \mathrm{MW}_{\mathrm{p}}$ or larger) and indicative of potential developments in the near-to-mid-term for community scale systems. The low-end cost can be reached in several ways, including continued hard or soft cost declines and/or continuation of the federal investment subsidy.

Long-term system monitoring suggests PV module lifetimes of 30 or more years are possible [64] [65], so in conjunction with previous studies [60] [66] [67] [68] and the majority of project developers [69] a 30-year lifetime is used here. Annual operation and maintenance costs are assumed at $\$ 13 / \mathrm{kW}_{\mathrm{p}} /$ year and includes inspection, insurance, land, and one inverter replacement [69] [70].

\subsubsection{Wind Turbines}

Enercon wind turbine, E-82 E2 of 2MW capacity and a hub height of $85 \mathrm{~m}$ is selected [71]. A high capital cost of $\$ 1.5 / \mathrm{Wac}$ is used based on NREL reports for onshore turbines [72]. Due to falling costs of the renewable energy technologies, a five-step cost drop is modelled, giving the lowest assumed cost to $\$ 0.9 / \mathrm{Wac}$. However, the lower range is taken as an optimistic capital cost achievable in the immediate implementation scenario.

For O\&M, an upper-cost range of $\$ 36 / \mathrm{kW} /$ year is used in line with [60]. Generally, 20-25 years are used as the wind turbine lifetime [73] [74]. Recent research on lifetime extension of up to 15 years has been reported as feasible and within safety margin [75]. This assumes a wind turbine lifetime of 35 years to be possible with development in wind research and thus a 30 -year lifetime is used here.

\subsubsection{Battery Storage}

Battery plants are modeled using HOMER's idealized battery model and technical specifications from Tesla's Powerpack [76]. The base unit is $232 \mathrm{kWh}$ and $56 \mathrm{~kW}$ to provide a 4-hour duration. HOMER only allows batteries to be connected to a DC bus, and as the diagrams in Figure 2 show they are the only DC component. Therefore, the converter is considered exclusive to the battery system. Tesla lists an $89.5 \%$ AC round trip efficiency, 
which is applied at the battery in DC and a $100 \%$ conversion efficiency applied to the converter [76]. The capital and replacement costs for the converter are included with the cost of the batteries. Tesla does not publish battery lifetimes; however, 1,000-2,000 cycles are typical for lithium ion batteries [77]. A conservative 1,000 cycles are used here (232 MWh) with a float life assumed at 15 years if the cycle lifetime is not met [77].

Capital costs for lithium-ion cells and plants are falling rapidly [78] [79] and vary widely depending on type, location, and system configuration. For example, longer duration plants (i.e. 4 hours vs. 0.5 hour) have lower specific storage capacity costs $(\$ / \mathrm{kWh})$ due to savings on power conversion equipment [80]. High and low battery cost developments are tested using a linked sensitivity, with capital costs taken from 2020 and replacement costs from 2035, based on modeled cost projections from [81], and shown in Table 3. These projections capture the range of estimated cost developments from 25 previous publications, which demonstrate the considerable uncertainty around battery development [81].

Table 3. Turnkey lithium-ion battery cost sensitivities (in $\$ / \mathrm{kWh}$ ) [81]

\begin{tabular}{|l|c|c|c|}
\hline Estimate & High & Mid & Low \\
\hline Capital & 359 & 330 & 297 \\
\hline Replacement & 291 & 194 & 112 \\
\hline
\end{tabular}

\subsubsection{Existing Hydropower}

There are 27 existing hydropower facilities in Upper Michigan, consisting of both traditional reservoir and run-of-river types, and a total rated capacity of $212 \mathrm{MW}$ [55]. No new hydropower is proposed in this study; however, the existing capacity is assumed to be available in a future $100 \% \mathrm{RE}$ system and is distributed equally amongst the approximately 300,000 UP residents. Therefore, the hydro resources available for the purposes of modeling to each community is directly proportional to their population.

14 of the 27 plants are located on the Michigan/Wisconsin border and owned by utilities not primarily serving the UP. To avoid system boundary conflicts with resource allocation, only facilities that are located wholly inside Upper Michigan's borders are included, which results in a total capacity of $123 \mathrm{MW}$. Annual generation from these facilities ranges between 421 and $664 \mathrm{GWh} / \mathrm{yr}$, corresponding to capacity factors of 38.9 and $61.4 \%$, respectively [55]. It is beyond the scope of this study to model inter-year variability in renewable supply; therefore, a conservative 40\% capacity factor is used, resulting in 431 GWh/yr available for all UP residents. 
Due to a lack of access to inflow/outflow rates and reservoir sizes, hydropower as a resource is not modeled directly in HOMER meaning the potential for capacity integration with non-dispatched renewables is missing in the results. Instead, hydro is modeled as a grid connection with limits on capacity and energy supply over the year. This allows HOMER to control the amount of hydropower used without exceeding the limits of generation. The peak capacity $(\mathrm{kW})$ and annual hydro allocation $(\mathrm{GWh} / \mathrm{yr})$ for each community are listed in Table 4 . The allocation is limited by setting the minimum renewable fraction, also shown in Table 4, which is the inverse of hydro supply since the grid is always considered $0 \%$ renewable in HOMER.

Table 4. Proportions of hydropower capacity, supply and cost for each location

\begin{tabular}{|l|c|c|c|}
\hline & $\begin{array}{c}\text { Peak Capacity } \\
(\mathbf{k W})\end{array}$ & $\begin{array}{c}\text { Allocation } \\
(\mathbf{G W h} / \mathbf{y r})\end{array}$ & Minimum RF \\
\hline Negaunee & 1432 & 5.646 & $75.6 \%$ \\
\hline L'Anse & 590 & 2.325 & $82.1 \%$ \\
\hline Anonymous & 3150 & 12.417 & $85.4 \%$ \\
\hline
\end{tabular}

Based on a recent $\mathrm{UPPCO}^{3}$ integrated resource plan (IRP), the rate for the utility's hydro facility is $\$ 24.514 / \mathrm{MWh}[82]$. Thus, a rate of $\$ 0.0245 / \mathrm{kWh}$ is applied in HOMER as the grid purchase price representing available hydro.

\subsubsection{Grid Connection}

When purchasing electricity, the grid connection is limited to only represent hydropower resources within the UP, however the grid also provides an opportunity to sell excess renewable electricity generation. Like other economic sensitivities, the price which a community could sell excess power is highly uncertain, particularly in this study where the proposed systems have no local precedent. The latest MPSC approved prices for on- and off-peak sales of parallel generation for UPPCO's Primary industrial customers are 0.0349 and $0.0278 \$ / \mathrm{kWh}$, respectively [83]. As a conservative assumption, only the off-peak price is applied here.

\footnotetext{
${ }^{3}$ UPPCO's prices is used as a reference point for these utilities due to unavailability of load data from UPPCO for the model and the utility covers over half of the customers in the region. Rates in the case study are slightly lesser than UPPCO's rate.
} 
It is also important to include the cost of grid access to deliver hydropower, however it is outside the scope of this study to consider all possible regulatory or market negotiation positions for a community energy system. Therefore large, industrial customers are used as a price source given that the peak loads and annual demands of the communities are comparable to many of the heavy industrial customers in the region (e.g. paper mills, mining, manufacturing).

Capacity pricing for UPPCO's industrial customers is based on the peak demand for a given month and is separated into on- and off-peak periods [84]. The on-peak price is $\$ 6.30 / \mathrm{kW}_{\mathrm{p}} / \mathrm{mo}$ and off-peak set to $\$ 3.07 / \mathrm{kW}_{\mathrm{p}} / \mathrm{mo}$, where on-peak is considered 7:00 23:00. Finally, an annual fixed charge of $\$ 3,900$ is also applied, consistent with the current industrial pricing scheme [84].

This pricing approach is relatively simple and may not consider the complete cost of operating the regional transmission and distribution grid, however it is assumed to be adequate for a feasibility study. More detailed analysis would require a higher-level study of existing stakeholders, resources, and market structure, which is outside the scope of this work.

\subsubsection{Energy Efficiency}

Energy efficiency (EE) is an important factor in the discourse of $100 \%$ renewable electricity transitions. In achieving $100 \%$ renewable electricity, like the case in Burlington, Vermont [7], the role of EE is evident. Assumptions in a previous study on the reliability and feasibility of $100 \%$ RE study in other communities in Michigan have included EE [85], which negates/neutralizes the impact of future demand rise.

To account for potential energy efficiency and conservation, load reductions of $1.75 \%$ and $10 \%$ from the current demand are tested. In HOMER this is applied as a load reduction at the corresponding percentage at each time step. The reason for this consideration is that EE is one of the requirements by MPSC for regulated utilities' IRP on energy waste reduction (EWR), which is a medium plan to reduce existing waste both from generation and consumption by certain percent [11]. The EWR is a program targeted at energy demand side management, which utilities deploy to reduce energy demand. For instance, MPSC requested UPPCO to have an EWR of $1.75 \%$ by 2021 [11]. Also, the MPSC in the statewide energy assessment (SEA) report targets 10\% EWR to meet $35 \%$ clean energy by the year 2025 [22]. This shows how important EE is both for the utility and customers.

\subsubsection{System Level Parameters}

Load following (LF) dispatch strategy is applied for each system to optimize RE (PV and wind) production to meet demand in the day and charge battery storage for serving night 
load. Although LF is not fundamentally needed in the case of 100\% RE, HOMER requires a control strategy as a prerequisite to run simulations.

The cost of capital is highly uncertain and therefore a range of real discount rates (i.e. not including inflation) is tested. The baseline real discount rate is $2 \%$ and the highest is $8 \%$, consistent with typical market rates before the global pandemic of COVID-19 [86]. In previous research on technical modelling for small and medium enterprises in the UP, a rate of $2.66 \%$ was used [35]. A summary of the tested sensitivity parameters and their ranges is given in Table 5 .

Table 5: Summary of sensitivity parameters

\begin{tabular}{|l|c|c|c|c|}
\hline Components & Low & High & Increment & Lifetime \\
\hline $\begin{array}{l}\text { PV+inverter } \\
\text { capital cost } \\
(\$ / \mathrm{kWac})\end{array}$ & 1200 & 2000 & 200 & 30 \\
\hline $\begin{array}{l}\text { Wind turbine } \\
\text { capital cost } \\
(\$ / \mathrm{kWac})\end{array}$ & 900 & 1500 & 100 & 30 \\
\hline $\begin{array}{l}\text { Load reduction } \\
\text { via energy } \\
\text { efficiency }(\%)\end{array}$ & 1.75 & 10 & $\begin{array}{c}\mathrm{n} / \mathrm{a} \\
\text { (assumed } \\
\text { aggressive } \\
\text { EE) }\end{array}$ & - \\
\hline $\begin{array}{l}\text { PV tilt angle } \\
\text { (degrees) }\end{array}$ & 30 & 60 & 15 & - \\
\hline $\begin{array}{l}\text { Real discount } \\
\text { rate }(\%)\end{array}$ & 2 & 8 & 2 & - \\
\hline
\end{tabular}

Multi-year simulations, while available in HOMER, are not possible to combine with the optimization tool. Each community has 2700 sensitivity analyses to optimize, meaning manually sized capacities are impractical. The only boundary condition affected by this limitation here is PV degradation. With capacities found using HOMER's optimization, a test of the impact of multi-year simulations found that PV capacity would increase by 10 
to $15 \%$, increasing total cost by $1.5 \%$ to $2 \%$. This is an acceptable error considering the range of economic uncertainty captured by the tested sensitivities and shown in the results.

\subsection{Results}

A community energy project on this scale would realistically not be developed until 2025 at the earliest, because in general, it takes an average of five years for such project development. However, the base case economic scenario is defined with plausible values for the 2020 market, including a $2 \%$ real discount rate, $45^{\circ} \mathrm{PV}$ tilt angle, PV cost of $\$ 1,800 / \mathrm{kW}$, wind cost of $\$ 1,350 / \mathrm{kW}$, and medium battery cost of $\$ 330 / \mathrm{kWh}$. This makes the base case reasonably conservative, with future cost reduction potential described by the sensitivity analysis.

\subsubsection{Baseline results}

The baseline results are given in Table 6, including the cost-optimized PV, wind, and battery capacities, initial capital, and LCOE for each community. Due to the relatively nascent grid-scale battery industry and associated uncertainty in pricing, all three battery costs are shown as baseline results.

For the mid-cost battery results, the LCOE for L'Anse, Negaunee and the Anonymous municipality are $0.1813,0.1516$ and $0.2096 \$ / \mathrm{kWh}$ respectively. The prevailing residential grid price in the region is $\$ 0.2350 / \mathrm{kWh}$, therefore these LCOE values represent a $23 \%$, $35 \%$, and 14\% price reduction for L'Anse, Negaunee and Anonymous, respectively. As compared to the prevailing commercial rate of $\$ 0.1290 / \mathrm{kWh}$, these prices are $40 \%, 18 \%$, $62 \%$ higher.

Demand is met primarily with wind generation, which has both higher installed capacities as well as higher capacity factors that range from $28 \%$ to $31 \%$ as compared to $12 \%$ to $13 \%$ for PV. For L'Anse and Negaunee, approximately 50\% and 40\% (respectively) of the total generation is excess sold to the grid across the baseline. Excess occurs throughout the year but is greatest during the spring and fall seasons. Only in the Anonymous community does the cost of batteries have a notable impact on capacities, where higher costs lead to fewer batteries and more renewable generation. There is also a shift away from PV and towards wind, with higher battery costs due to the lower LCOE for wind power. This has an impact on excess generation, which increases from $41 \%$ to $46 \%$ and $62 \%$ for the low, mid, and high battery costs, respectively.

Focusing on L'Anse, the LCOE with low battery cost is $\$ 0.1582 / \mathrm{kWh}$ for $1.7 \mathrm{MW}$ of installed PV, four wind turbines totaling $8 \mathrm{MW}$ of installed capacity, and $70 \mathrm{MWh}$ of Liion battery storage. This indicates a $100 \%$ RE system could reduce energy costs by up to $33 \%$ for residential customers as compared to the current grid rate. Moving from the low to mid to high battery costs, there is a $14 \%$ increase in LCOE, meaning the savings to 
residential rates are 33\%, 23\% and 13\% for low, mid and high battery costs, respectively. For commercial customers, the lowest rate is still $23 \%$ higher than today, suggesting that if this system were implemented as is, rate design between customer groups would be a critical factor.

In Negaunee, the lowest cost solution has $\$ 0.1348 / \mathrm{kWh}$ for approximately $4.8 \mathrm{MW}$ of $\mathrm{PV}$, $10 \mathrm{MW}$, and $94 \mathrm{MWh}$ of batteries. This is $43 \%$ less than the prevailing residential rate, and only $4 \%$ higher than the commercial rate, suggesting that a rate design that saved all customers money would be feasible. Moving from the low to high cost battery systems, provides residential energy cost savings of $43 \%, 35 \%$ and $29 \%$, respectively. The results also indicate that $100 \%$ renewable electricity is more economically viable in Negaunee than the other two cases. It should be noted, however, Negaunee benefited from having a wind capacity that better fit the load profile, so there was less overproduction. This is largely a function of the large wind turbines. If future work used a generic, $1 \mathrm{~kW}$ wind turbine so that HOMER could select much more precisely the amount of wind to apply, the overproduction for each community would be closer and the LCOEs would likely be closer as well.

The third case, Anonymous, has the highest LCOE among the three municipalities, being $\$ 0.1879 / \mathrm{kWh}$ for $34.9 \mathrm{MW}$ of PV, $38 \mathrm{MW}$ wind turbine capacity, and $528 \mathrm{MWh}$ of battery at low battery costs. The highest LCOE is $\$ 0.2195 / \mathrm{kWh}$, a $17 \%$ increase over the low cost. In comparison to the prevailing residential rates from the grid, $100 \%$ renewable electricity could provide a $9 \%$ to $20 \%$ cost savings depending on battery costs.

Table 6. Optimum solutions for each battery cost in the economic base case

\begin{tabular}{|c|c|c|c|c|c|c|c|c|c|c|}
\hline \multirow{6}{*}{$\begin{array}{c}\mathrm{L} \\
\text { A } \\
\mathrm{N} \\
\mathrm{S} \\
\mathrm{E}\end{array}$} & & \multicolumn{3}{|c|}{ Low } & \multicolumn{3}{|c|}{ Mid } & \multicolumn{3}{|c|}{ High } \\
\hline & & $\begin{array}{l}\text { PV } \\
(\mathrm{M} \\
\mathrm{W})\end{array}$ & $\begin{array}{c}\text { Win } \\
\text { d } \\
(\mathrm{M} \\
\mathrm{W})\end{array}$ & $\begin{array}{c}\text { Batt } \\
\text { (MW } \\
\text { h) }\end{array}$ & $\begin{array}{l}\text { PV } \\
(\mathrm{M} \\
\mathrm{W})\end{array}$ & $\begin{array}{l}\text { Win } \\
\text { d } \\
(\mathrm{M} \\
\mathrm{W})\end{array}$ & $\begin{array}{c}\text { Batt } \\
(\mathrm{MW} \\
\mathrm{h})\end{array}$ & $\begin{array}{l}\text { PV } \\
(\mathrm{M} \\
\mathrm{W})\end{array}$ & $\begin{array}{c}\text { Win } \\
\text { d } \\
(\mathrm{M} \\
\mathrm{W})\end{array}$ & $\begin{array}{c}\text { Batt } \\
\text { (MW } \\
\text { h) }\end{array}$ \\
\hline & Capacity & 1.7 & 8 & 70 & 2.0 & 8 & 70 & 2.2 & 8 & 69 \\
\hline & $\begin{array}{l}\mathrm{LCOE} \\
(\$ / \mathrm{kWh})\end{array}$ & \multicolumn{3}{|c|}{0.1582} & \multicolumn{3}{|c|}{0.1813} & \multicolumn{3}{|c|}{0.2049} \\
\hline & $\begin{array}{l}\text { Capital } \\
(\mathrm{M} \$)\end{array}$ & \multicolumn{3}{|c|}{34.2} & \multicolumn{3}{|c|}{37.5} & \multicolumn{3}{|c|}{39.6} \\
\hline & Excess $(\%)$ & \multicolumn{3}{|c|}{49.5} & \multicolumn{3}{|c|}{50.0} & \multicolumn{3}{|c|}{50.5} \\
\hline
\end{tabular}




\begin{tabular}{|c|c|c|c|c|c|c|c|c|c|c|}
\hline \multirow{6}{*}{$\begin{array}{c}\mathrm{N} \\
\mathrm{E} \\
\mathrm{G} \\
\mathrm{A} \\
\mathrm{U} \\
\mathrm{N} \\
\mathrm{E} \\
\mathrm{E}\end{array}$} & & \multicolumn{3}{|c|}{ Low } & \multicolumn{3}{|c|}{ Mid } & \multicolumn{3}{|c|}{ High } \\
\hline & & $\begin{array}{l}\text { PV } \\
\text { (M } \\
\text { W) }\end{array}$ & $\begin{array}{c}\text { Win } \\
\text { d } \\
(\mathrm{M} \\
\mathrm{W}) \\
\end{array}$ & $\begin{array}{c}\text { Batt } \\
\text { (MW } \\
\text { h) }\end{array}$ & $\begin{array}{l}\text { PV } \\
\text { (M } \\
\text { W) }\end{array}$ & $\begin{array}{c}\text { Win } \\
\text { d } \\
(\mathrm{M} \\
\mathrm{W}) \\
\end{array}$ & $\begin{array}{c}\text { Batt } \\
\text { (MW } \\
\text { h) }\end{array}$ & $\begin{array}{l}\text { PV } \\
(\mathrm{M} \\
\mathrm{W})\end{array}$ & $\begin{array}{c}\text { Win } \\
\mathrm{d} \\
(\mathrm{M} \\
\mathrm{W}) \\
\end{array}$ & $\begin{array}{c}\text { Batt } \\
\text { (MW } \\
\text { h) }\end{array}$ \\
\hline & Capacity & 4.8 & 10 & 94 & 5.0 & 10 & 93 & 6.0 & 10 & 89 \\
\hline & $\begin{array}{l}\mathrm{LCOE} \\
(\$ / \mathrm{kWh})\end{array}$ & \multicolumn{3}{|c|}{0.1348} & \multicolumn{3}{|c|}{0.1516} & \multicolumn{3}{|c|}{0.1673} \\
\hline & $\begin{array}{l}\text { Capital } \\
(\mathrm{M} \$)\end{array}$ & \multicolumn{3}{|c|}{50.2} & \multicolumn{3}{|c|}{53.4} & \multicolumn{3}{|c|}{56.3} \\
\hline & Excess $(\%)$ & \multicolumn{3}{|c|}{38.5} & \multicolumn{3}{|c|}{38.9} & \multicolumn{3}{|c|}{40.4} \\
\hline
\end{tabular}

\begin{tabular}{|c|c|c|c|c|c|c|c|c|c|c|}
\hline \multirow{6}{*}{$\begin{array}{l}\mathrm{A} \\
\mathrm{N} \\
\mathrm{O} \\
\mathrm{N} \\
\mathrm{Y} \\
\mathrm{M} \\
\mathrm{O} \\
\mathrm{U} \\
\mathrm{S}\end{array}$} & & \multicolumn{3}{|c|}{ Low } & \multicolumn{3}{|c|}{ Mid } & \multicolumn{3}{|c|}{ High } \\
\hline & & $\begin{array}{l}\text { PV } \\
(\mathrm{M} \\
\mathrm{W})\end{array}$ & $\begin{array}{c}\text { Win } \\
\text { d } \\
(\mathrm{M} \\
\mathrm{W}) \\
\end{array}$ & $\begin{array}{c}\text { Batt } \\
\text { (MW } \\
\text { h) }\end{array}$ & $\begin{array}{l}\text { PV } \\
(\mathrm{M} \\
\mathrm{W})\end{array}$ & $\begin{array}{c}\text { Win } \\
\text { d } \\
(\mathrm{M} \\
\mathrm{W})\end{array}$ & $\begin{array}{c}\text { Batt } \\
\text { (MW } \\
\text { h) }\end{array}$ & $\begin{array}{l}\text { PV } \\
(\mathrm{M} \\
\mathrm{W})\end{array}$ & $\begin{array}{c}\text { Win } \\
\text { d } \\
(\mathrm{M} \\
\mathrm{W}) \\
\end{array}$ & $\begin{array}{c}\text { Batt } \\
\text { (MW } \\
\text { h) }\end{array}$ \\
\hline & Capacity & 34.9 & 38 & 528 & 33.0 & 44 & 510 & 26.8 & 76 & 439 \\
\hline & $\begin{array}{l}\mathrm{LCOE} \\
(\$ / \mathrm{kWh})\end{array}$ & \multicolumn{3}{|c|}{0.1879} & \multicolumn{3}{|c|}{0.2096} & \multicolumn{3}{|c|}{0.2195} \\
\hline & $\begin{array}{l}\text { Capital } \\
(\mathrm{M} \$)\end{array}$ & \multicolumn{3}{|c|}{271} & \multicolumn{3}{|c|}{287} & \multicolumn{3}{|c|}{308} \\
\hline & Excess $(\%)$ & \multicolumn{3}{|c|}{41.3} & \multicolumn{3}{|c|}{45.8} & \multicolumn{3}{|c|}{62.3} \\
\hline
\end{tabular}

\subsubsection{PV tilt angle}

At the UP's latitude, optimal PV production occurs at approximately $40^{\circ}$ [87] as the latitude is around 46 degrees for the western UP. However, system optimization considering snow increases the tilt angle. In Table 7, it can be seen that increasing the tilt angles to $45^{\circ}$ and even $60^{\circ}$ can actually reduce LCOEs. In both Negaunee and Anonymous, LCOE is reduced 
by $13 \%$ moving from a $30^{\circ}$ to $60^{\circ}$ tilt, equivalent to $\$ 0.0219 / \mathrm{kWh}$ in Negaunee and $\$ 0.0288 / \mathrm{kWh}$ in Anonymous. This is largely due to the reduction in initial capital costs, which are reduced by $10 \%$ in Negaunee and $12 \%$ in Anonymous when comparing $30^{\circ}$ to $60^{\circ}$, and the critical hours for supply occurring in winter when snow losses play a large role. Increasing the tilt angle allows snow to clear more quickly, reduces the need for batteries, thereby reducing LCOE.

L'Anse does not follow the same trends, however, with LCOE staying largely constant, battery capacities and capital costs increasing with tilt angle, and a solution without PV at $60^{\circ}$ tilt. This could be due to coincidental effects of snow losses and wind speeds and further investigation into worst-case scenarios is needed. The increased tilt angles do not always lead to less generation, as shown by the percentage of generation sold as excess to the grid. The relatively high cost of batteries is more critical to cost savings than excess sales from low cost wind and solar.

Table 7. LCOE, capacities, and excess generation for each community and PV tilt angle

\begin{tabular}{|c|c|c|c|c|c|c|c|c|c|c|}
\hline \multirow{6}{*}{$\begin{array}{l}\mathrm{L} \\
\text { A } \\
\mathrm{N} \\
\mathrm{S} \\
\mathrm{E}\end{array}$} & & \multicolumn{3}{|c|}{$30^{\circ}$ Tilt } & \multicolumn{3}{|c|}{$45^{\circ}$ Tilt } & \multicolumn{3}{|c|}{$60^{\circ}$ Tilt } \\
\hline & & $\begin{array}{l}\text { PV } \\
(\mathrm{M} \\
\mathrm{W})\end{array}$ & $\begin{array}{c}\text { Win } \\
\text { d } \\
(\mathrm{M} \\
\mathrm{W})\end{array}$ & $\begin{array}{c}\text { Batt } \\
\text { (MW } \\
\text { h) }\end{array}$ & $\begin{array}{l}\text { PV } \\
(\mathrm{M} \\
\mathrm{W})\end{array}$ & $\begin{array}{c}\text { Win } \\
\text { d } \\
(\mathrm{M} \\
\mathrm{W})\end{array}$ & $\begin{array}{c}\text { Batt } \\
\text { (MW } \\
\text { h) }\end{array}$ & $\begin{array}{l}\text { PV } \\
\text { (M } \\
\text { W) }\end{array}$ & $\begin{array}{c}\text { Win } \\
\text { d } \\
(\mathrm{M} \\
\mathrm{W})\end{array}$ & $\begin{array}{c}\text { Batt } \\
\text { (MW } \\
\text { h) }\end{array}$ \\
\hline & Capacity & 0.86 & 10 & 68.7 & 1.98 & 8 & 70.1 & 0 & 12 & 71.2 \\
\hline & $\begin{array}{l}\mathrm{LCOE} \\
(\$ / \mathrm{kWh})\end{array}$ & \multicolumn{3}{|c|}{0.1770} & \multicolumn{3}{|c|}{0.1813} & \multicolumn{3}{|c|}{0.1808} \\
\hline & $\begin{array}{l}\text { Capital } \\
(\mathrm{M} \$)\end{array}$ & \multicolumn{3}{|c|}{37.7} & \multicolumn{3}{|c|}{37.5} & \multicolumn{3}{|c|}{39.7} \\
\hline & Excess $(\%)$ & \multicolumn{3}{|c|}{56.5} & \multicolumn{3}{|c|}{50.0} & \multicolumn{3}{|c|}{62.0} \\
\hline
\end{tabular}

\begin{tabular}{|c|c|c|c|c|c|c|c|c|c|}
\hline & \multicolumn{3}{|c|}{$30^{\circ}$ Tilt } & \multicolumn{3}{|c|}{$45^{\circ}$ Tilt } & \multicolumn{3}{|c|}{$60^{\circ}$ Tilt } \\
\hline & $\begin{array}{l}\text { PV } \\
(\mathrm{M} \\
\mathrm{W})\end{array}$ & $\begin{array}{c}\text { Win } \\
\text { d } \\
(\mathrm{M} \\
\mathrm{W})\end{array}$ & $\begin{array}{c}\text { Batt } \\
\text { (MW } \\
\text { h) }\end{array}$ & $\begin{array}{l}\text { PV } \\
(\mathrm{M} \\
\mathrm{W})\end{array}$ & $\begin{array}{c}\text { Win } \\
\text { d } \\
(\mathrm{M} \\
\mathrm{W})\end{array}$ & $\begin{array}{c}\text { Batt } \\
\text { (MW } \\
\text { h) }\end{array}$ & $\begin{array}{l}\text { PV } \\
\text { (M } \\
W)\end{array}$ & $\begin{array}{c}\text { Win } \\
\text { d } \\
(\mathrm{M} \\
\mathrm{W})\end{array}$ & $\begin{array}{c}\text { Batt } \\
\text { (MW } \\
\text { h) }\end{array}$ \\
\hline Capacity & 3.38 & 12 & 108.5 & 5.95 & 10 & 93.5 & 7.77 & 10 & 79.3 \\
\hline
\end{tabular}




\begin{tabular}{|l|l|l|c|c|}
\hline $\mathrm{N}$ & $\mathrm{LCOE}$ & & & \\
$\mathrm{E}$ & $\mathrm{L}$ & 0.1649 & 0.1516 & 0.1430 \\
$\mathrm{G}$ & $(\$ / \mathrm{kWh})$ & & & \\
$\mathrm{nyyyy} \mathrm{A}$ & Capital & 58.1 & 53.4 & 52.5 \\
$\mathrm{U}$ & $(\mathrm{M} \$)$ & & & \\
$\mathrm{N}$ & & & 38.9 & 41.9 \\
$\mathrm{E}$ & Excess $(\%)$ & 43.5 & & \\
$\mathrm{E}$ & & & & \\
\hline
\end{tabular}

\begin{tabular}{|c|c|c|c|c|c|c|c|c|c|c|}
\hline \multirow{6}{*}{$\begin{array}{l}\mathrm{A} \\
\mathrm{N} \\
\mathrm{O} \\
\mathrm{N} \\
\mathrm{Y} \\
\mathrm{M} \\
\mathrm{O} \\
\mathrm{U} \\
\mathrm{S}\end{array}$} & & \multicolumn{3}{|c|}{$30^{\circ}$ Tilt } & \multicolumn{3}{|c|}{$45^{\circ}$ Tilt } & \multicolumn{3}{|c|}{$60^{\circ}$ Tilt } \\
\hline & & $\begin{array}{l}\text { PV } \\
(\mathrm{M} \\
\mathrm{W})\end{array}$ & $\begin{array}{c}\text { Win } \\
\text { d } \\
(\mathrm{M} \\
\mathrm{W}) \\
\end{array}$ & $\begin{array}{c}\text { Batt } \\
\text { (MW } \\
\text { h) }\end{array}$ & $\begin{array}{l}\text { PV } \\
\text { (M } \\
\text { W) }\end{array}$ & $\begin{array}{c}\text { Win } \\
\text { d } \\
(\mathrm{M} \\
\mathrm{W}) \\
\end{array}$ & $\begin{array}{c}\text { Batt } \\
\text { (MW } \\
\text { h) }\end{array}$ & $\begin{array}{l}\mathrm{PV} \\
(\mathrm{M} \\
\mathrm{W})\end{array}$ & $\begin{array}{c}\text { Win } \\
\mathrm{d} \\
(\mathrm{M} \\
\mathrm{W}) \\
\end{array}$ & $\begin{array}{c}\text { Batt } \\
\text { (MW } \\
\text { h) }\end{array}$ \\
\hline & Capacity & 26.6 & 52 & 539.4 & 33.0 & 44 & 510.4 & 43.8 & 32 & 416.2 \\
\hline & $\begin{array}{l}\text { LCOE } \\
(\$ / k W h) \\
\end{array}$ & \multicolumn{3}{|c|}{0.2166} & \multicolumn{3}{|c|}{0.2096} & \multicolumn{3}{|c|}{0.1878} \\
\hline & $\begin{array}{l}\text { Capital } \\
(\mathrm{M} \$)\end{array}$ & \multicolumn{3}{|c|}{296.1} & \multicolumn{3}{|c|}{287.1} & \multicolumn{3}{|c|}{259.3} \\
\hline & Excess $(\%)$ & \multicolumn{3}{|c|}{48.8} & \multicolumn{3}{|c|}{45.8} & \multicolumn{3}{|c|}{39.4} \\
\hline
\end{tabular}

\subsubsection{Sensitivity analysis}

The effects of energy efficiency, real discount rate, and equipment costs on LCOE are presented in this section. Each community is shown on its own figure, with L'Anse, Negaunee and Anonymous corresponding to Figures 7, 8, and 9, respectively.

The results are clustered primarily by discount rate on the $\mathrm{x}$-axis. Within each discount rate are clusters representing three equipment cost scenarios, Low, Mid, and High. The low scenario corresponds to PV, wind, and battery costs of $\$ 1200 / \mathrm{kW}, \$ 900 / \mathrm{kW}$, and $\$ 297 / \mathrm{kWh}$, respectively. The corresponding medium scenario is $\$ 1,600 / \mathrm{kW}, \$ 1,200 / \mathrm{kW}$, and $\$ 330 / \mathrm{kWh}$, and the high scenario is defined as $\$ 2,000 / \mathrm{kW}, \$ 1,500 / \mathrm{kW}$ and $\$ 359 / \mathrm{kWh}$. The clusters within each equipment cost scenario are for the load reductions, where business as usual (BAU) represents the existing loads, with $1.75 \%$ and $10 \%$ representing the associated reductions in annual demand. All results are shown for the design scenario with a PV tilt angle of $45^{\circ}$. 
In L'Anse and Negaunee, LCOE is relatively insensitive to load reduction within the same discount rate and equipment cost scenarios but can still be up to a $10 \%$ reduction. In absolute terms, the difference is less than $\$ 0.01 / \mathrm{kWh}$ and at most $\$ 0.02 / \mathrm{kWh}$. The patterns are more dramatic for the Anonymous community, where the $1.75 \%$ reduction can cause up to a $12 \%$, or $\$ 0.05 / \mathrm{kWh}$, increase in LCOE. This is in large part due to wind-only portfolios being selected in these cases, leading to high excess generation. Again, it is likely that more consistent trends would be present with smaller wind turbine capacities.

Within a single discount rate, however, the trend is different for load reduction scenarios. The general trend shows that up to 2 cents drop in the LCOE can be achieved, moving from BAU to $10 \%$ in both L'Anse and Negaunee. In the Anonymous municipality case, up to 6 cents drop can be observed. This is especially for higher discount rates from $4 \%$ to $8 \%$.

Moving from the low to high equipment cost scenarios, LCOE is generally increased by $17 \%$ to $20 \%$ at each step for a given load profile. The trend is less consistent in the Anonymous community, as noted above. A similar increase in relative LCOE is found moving up from the $2 \%$ discount rate, which can lead to much higher costs at the $8 \%$ rate. For instance, in the L'Anse BAU load with low components cost, corresponding LCOE increased by $71.4 \%$. A similar increment is observed for both load reduction scenarios and component cost sensitivities in the other two municipalities.

These results highlight the criticality of both equipment and financing costs given that approximately half of the sensitivities across all municipalities are below the prevailing residential rate (Res. Rate). The low-cost scenarios can be considered plausible within the next 5-7 years, which would be a reasonable development period for such projects started in 2020. If these prices were secured and financing rates remained as low as today, these municipalities could even approach the prevailing commercial rates (Com. Rate) for the region, and in the case of Negaunee actually fall below the commercial rate in the low-cost scenario. This is particularly notable given that these LCOEs are less than the $\$ 0.12 / \mathrm{kWh}$ average national residential price for electricity, shown in Figure 1. 


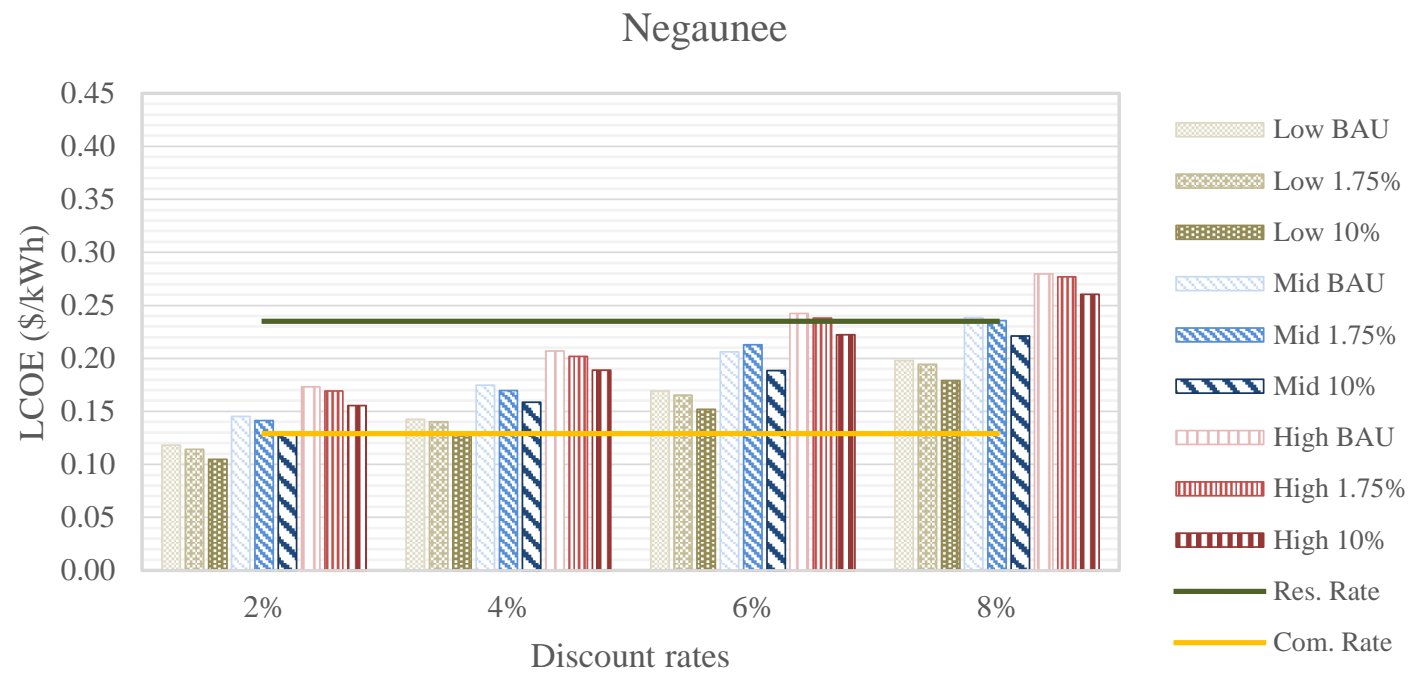

Figure 7: Sensitivity results for Negaunee with $45^{\circ}$ tilt angle, different discount rate, varying components costs, and varying average load with and without energy efficiency considerations

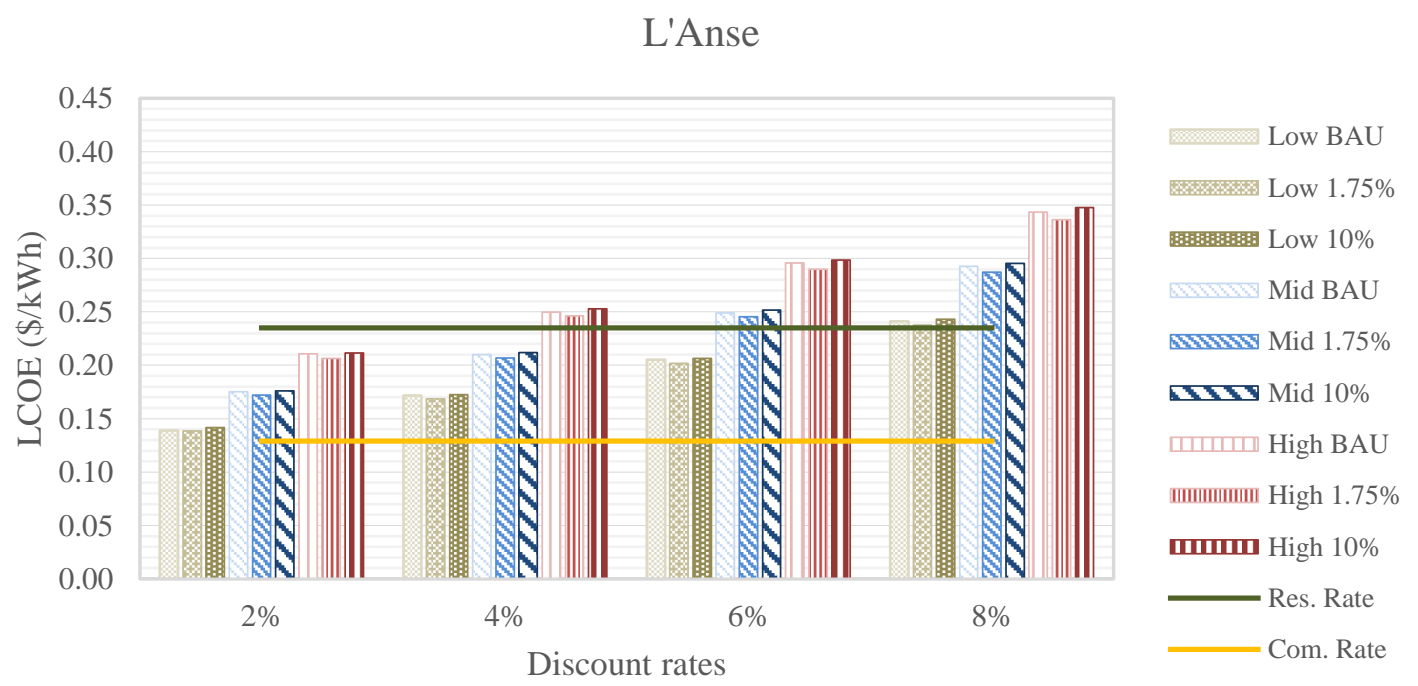

Figure 8: Sensitivity results for L'Anse with $45^{\circ}$ tilt angle, different discount rate, varying components costs, and varying average load with and without energy efficiency considerations 


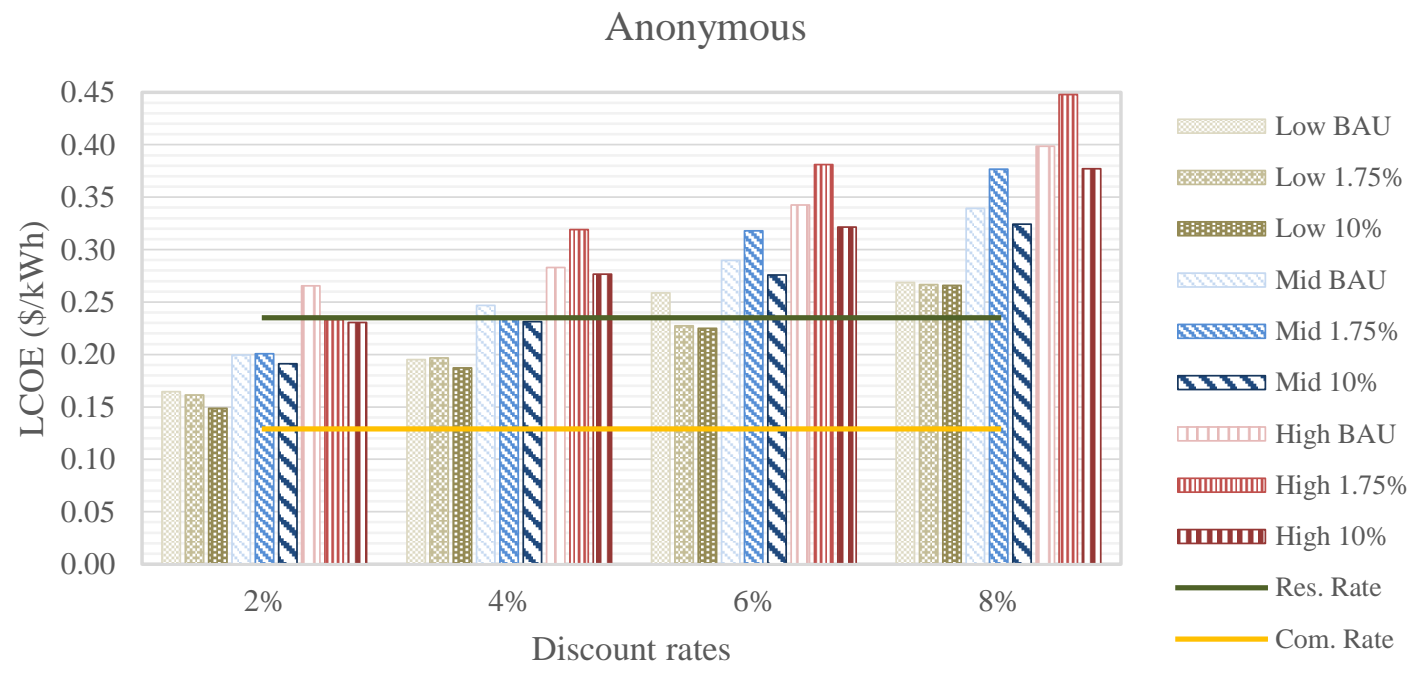

Figure 9: Sensitivity results for Anonymous with $45^{\circ}$ tilt angle, different discount rate, varying components costs, and varying average load with and without energy efficiency considerations

\subsection{Discussion}

As the research examines scenarios that exist outside of the current regulatory framework, policies to facilitate transition to $100 \%$ renewably sourced electricity are investigated to inform statewide energy policy with specific recommendations. Conditions for technical feasibility and policy implications for achieving this $100 \% \mathrm{RE}$ are discussed in this section.

\subsubsection{Feasibility and Economic Justification of $100 \%$ RE Transition}

The different scenarios and sensitivity considered in this research show routes that each municipality can take to achieve the $100 \% \mathrm{RE}$ for electricity generation. Overall, the northern rural areas can move to RE systems at costs less than the residential electricity rates already in 2020. The sensitivities show that LCOEs lower than commercial rates are plausible within the next 5 years given the ongoing cost reductions in renewable generation and battery storage, which would make $100 \% \mathrm{RE}$ an easier choice for rural UP communities. A risk to these results is the cost of financing, which has been relatively low for the past decade and is highly beneficial to renewable investments [88].

Most system solutions resulted in $40-60 \%$ of the generation not being used within the communities, highlighting the opportunities for longer-term storage, such as pumped hydro or hydrogen, and the electrification of transport [89] [90]. For instance, there is an increasing interest in pumped hydro storage from abandoned mines, which are common in the UP [91] [92]. Electric vehicle (EV) technology, sales, and charging stations are growing 
rapidly, with the expectation that EVs will have a 30\% market share in 2030 [93]. Replacing gas boilers with heat pumps can also increase renewable utilization, particularly in a cold climate where heat is the largest energy demand in buildings [94]. Electrifying all buildings will cause a considerable increase in electricity demand and can potentially lead to higher peak loads [95], however the flexibility offered by hot water tanks and building mass combined with smart controls make load shifting and peak reductions increasingly possible [96] [97] [98] [99].

From an economic perspective, increasing local utilization of renewable generation will help to reduce costs from the results presented here. Here the value of excess generation is only $\$ 0.0278 / \mathrm{kWh}$, whereas higher prices could be set if this energy was being delivered to EVs or heat pumps. From a climate perspective, shifting generation from regional gas and coal plants to local renewables will dramatically reduce emissions, much more so if transport and heating can be electrified [100] [101]. Through a bottom up approach that involves participation and support of grassroot populace, rural northern regions thus have the ability to lead in meeting $7.5 \%$ annual national emissions reduction and limiting global warming to $2{ }^{\circ} \mathrm{C}$ by transitioning to $100 \%$ renewable electricity. Perhaps most importantly such rural regions can take this leading environmental position while reducing costs.

The equal distribution of hydro resources throughout the population is a core assumption for this study and works to reduce LCOEs as compared to having no access to hydropower. However, municipalities do not currently have the ability to directly procure the UP's hydropower, only indirectly through existing utilities. The production of an entire plant's generation can be purchased exclusively for use by a single, large consumer, i.e. a manufacturing facility. Utilities located outside the region can also secure UP resources; for example, Detroit, Michigan based utility DTE will take ownership of a 72 MW wind farm in the UP for their customers in the Lower Peninsula [102]. Local renewable resources are not allocated to the residents in the current market structure they are an easily privatized, exportable product. This can be a positive economic aspect for landowners who earn rent, residents with new jobs, and communities through increased tax revenues [103] [104]. However, the opportunity cost to residents who could have had lower energy prices through municipal ownership also needs to be considered as part of a holistic and just economic development plan [105] [106].

There is also a conflict between the political boundaries of states as compared to the boundaries of utility companies and markets, as signified by the omission of hydro facilities on the Michigan/Wisconsin border. It is certainly possible to create alternative distributions of hydro resources based on various system boundaries or market designs, which will have a significant impact on the cost of energy given hydro's low marginal cost and dispatchable generation. Only $62 \%$ of the UP's hydro capacity is included in the model, meaning it is possible that more generation from plants at the Wisconsin/Michigan border could serve UP customers and reduce costs. Additionally, conservative capacity factors are assumed for the hydro plants, whereas higher capacity factors will yield lower LCOE compared to results presented here. 
While an attempt is made to maintain conservative yet plausible assumptions for both technical and economic boundary conditions, it should also be restated that the LCOEs found here are likely to be $1 \%$ to $2 \%$ higher in all cases due to the lack of PV degradation in the HOMER model. However, given the sensitivity results of section 4 , this uncertainty is relatively minor and does not alter the conclusions.

\subsubsection{Policy Implications and Future Work}

The renewable generation portfolios developed in this research assume that each community is capable of transitioning from a group of co-located customers of a single, regulated utility into a single prosumer (producer and consumer). It is important to note that under current Michigan regulations, WUP communities are unable to self-organize, form municipal utilities, and procure their own energy as only $2 \%$ of utility's average instate load on the distributed program are allowed [107]. This rule applies to only individual customers who are able to build local RE systems.

Successful transitioning of municipalities to $100 \%$ RE for electricity supply can be facilitated by state and local policies, which motivates local energy ownership and municipalization of utility [108]. Policies that have proven to be successful in the expansion of renewable electricity are combinations of renewable portfolio standard (RPS), distributed energy system and net-metering [109]. While these policies have or do exist in the state of Michigan, they are constrained by current distributed generation caps and other legislation favoring electric monopolies. For instance, Michigan's current 15\% RPS could be substantially increased after 2021 considering 14 other states in the U.S. have at least a 50\% target [110]. Policies enabling distributed renewable energy technologies to simply compete with existing utilities will give the municipalities the ability to selforganize, promote, and locally fund development of clean and affordable distributed energy resources for successful and profitable energy transition.

Concerning excess electricity produced by the system, policies to increase the adoption of electric vehicles and heating will help reduce energy waste and costs. Federal rebates already exist for both products; however, these programs are less effective in a region with low income where residents cannot make large investments [111] [112] [113]. Business models and/or market regulations that reduce the cost of energy without high upfront costs will be far more effective, as has already been demonstrated in the U.S. PV market [114] [115] [61] In addition to electricity, the need for competitive and sustainable heating is already the focus of the Michigan governor's UP-Energy Task Force [116], which is seeking alternatives to propane, and more work on the individual investment economics are needed to support specific policy initiatives.

For electric vehicles, expansive infrastructural development of charging stations is another way of using the excess generation from RE technologies. Across Michigan, EV charging sites are growing with the help of economic support from the state, including two dozen locations in Upper Michigan [117]. Stakeholders and residents will play critical roles in 
such decision-making processes. For instance, large commercial customers such as Walmart [118] can be a host to municipal EV charging stations through a carefully developed memorandum of understanding.

Since lower supply costs are achieved with a $10 \%$ reduction in average annual load, the municipalities should devise plans for aggressive energy efficiency programs. This might require changes in social practices among individuals and organizations, which can shape demand for energy resources and lead to a sustainable energy transition [119]. Examples include use of energy saving devices (EnergyStar appliances, smart / programmable thermostats, LED lighting, smart power strips, high performance HVAC upgrades), home renovations (e.g. weatherization, energy efficient windows, insulation) to reduce heating demand, and the use of motion-sensor lightening. Energy efficiency is particularly important in northern regions when the RE resources are not in abundance, due to the annual long and dark winter period.

This analysis is considered a regional feasibility study for $100 \%$ RE supply; it is not an investment analysis and does not capture all the interests and motives of the diverse set of stakeholders required to construct the simulated systems. By providing a thorough sensitivity analysis, uncertainties surrounding unknown costs are captured, which can now be utilized for future stages of development in the region. To build on this work, more detailed stakeholder analysis should be done towards the realization of $100 \%$ RE supply. These studies can test specific market structures, regulations, and business models to make relevant investment analyses for individual stakeholders.

\subsection{Conclusions}

In the light of the societal goals of environmental conservation and the energy justice concern of high energy cost, this study assesses the technical and economic feasibility for $100 \%$ renewable and self-sufficient electricity supply in three municipalities representative of northern rural areas. The results show that 100\% RE is technically feasible and economically competitive with prevailing residential rates under conservative assumptions. Barring structural barriers and the need for policy to support transition with local decision-making, $100 \% \mathrm{RE}$ is feasible and viable in WUP. If the cost declines for wind, solar, and batteries continue as expected, within the upcoming 5 to 7 years $100 \% \mathrm{RE}$ systems could have lower costs than the prevailing commercial rates.

The flexibility provided by existing hydropower is a crucial component towards the reduction of battery storage capacity and cost, therefore significant attention must be paid to equitable distribution of existing hydro usage. Today most of the hydro capacity is owned by private energy utilities, leaving residents indirect access these resources. If municipalities were able to self-organize and invest through community-based renewable energy, it could increase direct access for individual residential and commercial customers 
and lower costs. However, this scenario requires changes to Michigan's utility regulations that currently prohibit defection from electric utility monopolies.

The $100 \%$ self-sufficiency model structure used here results in high levels of excess electricity, even with large battery storage capacity. The sales price applied is commensurate with current regulations, however it is still lower than retail or wholesale market prices. If load curves could be flexibly adapted to electrify heating and transport to reduce excess sales, prices for that generation would likely increase, further improving economic conditions. Conversely, policies to encourage energy efficiency can also reduce LCOEs so long as excess generation is reduced.

Development of $100 \%$ RE can play a pivotal role in meeting the challenges of GHG emission reductions. This research has shown that such transition is technically feasible and economically viable in rural northern regions, which can improve energy justice, but require a reexamination of current energy policies that favor monopoly utilities. Further on energy justice consideration, there is a need for policy design and regulatory framework that strengthens local energy resources usage by and for the utmost benefits of local communities as well as local energy ownership.

Transitioning the electricity outlook of the region to $100 \% \mathrm{RE}$ also carries solutions to current energy crisis in the state and government's focus to ensure that residents have clean, affordable and reliable energy. This research has shown that $100 \%$ renewable electricity can achieve such a goal for the electricity concerns in the region. Thus, the UPEnergy Task force should consider results in this research as a matter of urgency that their work requires.

In general, scholarly misconceptions and ideologies about the unlikeliness of a rural region's capabilities to transition to RE requires substantial review. This is especially when such is premised on constraints that include climatic situations and technical feasibility and economic viability of such. This research, alongside previous work, has established that rurality status is not tantamount to incapability in achieving an energy transition, such as $100 \%$ renewable electricity.

The results of this study can be leveraged for future planning by the municipalities in the region as well as by research institutions studying the RE transition in northern communities for further development of $100 \% \mathrm{RE}$ scenarios in other contexts. The research results can also be relevant for governments, utilities, mayors, utilities, policy, and decision makers with interest in sustainable energy for solving local energy challenges. Other places across the globe with similar energy, climatic, and socioeconomic status, can also find this research useful. Further, community leadership and stakeholders will be able to use information from this research in making local decisions on feasibility of transition to renewable energy for electricity generation. 


\section{Acknowledgement}

The authors would like to appreciate the support of Brett Niemi and WPPI for providing annual load data of some of the municipalities and support from the Witte Endowment.

\section{Declaration of Competing Interest}

The authors declared that there is no conflict of interest.

\section{Research Funding}

This research did not receive any specific grant from funding agencies in the public, commercial, or not-for-profit sectors.

\section{Appendix A}

To maintain a concise and readable main paper, a detailed documentation of all relevant boundary conditions as they are applied in HOMER are given here. The structure follows the tab format in HOMER for convenient repeatability. Citations are given on most inputs and all critical inputs, which are also given in the main text. Inputs without citation are required for simulation but either not relevant, insignificant, and assumed, or a function of the modeling assumptions. Full context on the modeling approach is given in the main text and specific tables/chapters are referred to in this list.

\section{Components}

\section{Photovoltaics}

- SunPower E20-327 [59]

○ Nominal Efficiency: 20.4\%

- Nominal Operating Cell Temperature: $45^{\circ} \mathrm{C}$

○ Temperature Coefficient: $-0.35 \% /{ }^{\circ} \mathrm{C}$

- Electrical Bus

○ AC

- Site Specific Input

○ Derating Factor: 85\% [57] [58]

- Cost

○ Capacity: $1 \mathrm{kWp}$

○ Capital: 1200-2000 \$/kWp [60] [61] [62] [63] (See Table 5)

- Replacement: N/A

- O\&M: 13 \$/kWp/year [69] [70]

○ Lifetime: 30 years [64] [65] 
- Sizing

- HOMER Optimizer

- Advanced Settings

○ Inverter not explicitly modeled

- Orientation

- Ground Reflectance: $20 \%$

- No Tracking

- Panel Slope: $30^{\circ}, 45^{\circ}$ and $60^{\circ}$

- Panel Azimuth: $0^{\circ}$

- Temperature effects are considered, parameters given with module specifications

\section{Wind Turbines}

- Enercon E-82 E2 [71]

- Rated Capacity: 2 MW

- Site Specific Input

- Lifetime: 30 years [73] [74] [75]

- Hub Height: $85 \mathrm{~m}$

- Ambient temperature effects are considered

- Electrical Bus

$\circ \mathrm{AC}$

- Costs

- Quantity: 1 turbine

- Capital: $\$ 1.8 \mathrm{M}-\$ 3 \mathrm{M}$ per turbine [72] (See Table 5)

- Replacement: N/A

- O\&M: \$72k per turbine/year [60]

- Sizing

- HOMER Optimizer

- Advanced Properties

- Power Curve [71]

\begin{tabular}{|c|c|}
\hline Wind Speed $(\mathrm{m} / \mathrm{s})$ & Power Output $(\mathrm{kW})$ \\
\hline 1 & 0 \\
\hline 2 & 3 \\
\hline 3 & 25 \\
\hline
\end{tabular}




\begin{tabular}{|c|c|}
\hline 4 & 82 \\
\hline 5 & 174 \\
\hline 6 & 321 \\
\hline 7 & 532 \\
\hline 8 & 815 \\
\hline 9 & 1180 \\
\hline 10 & 1580 \\
\hline 11 & 1810 \\
\hline 12 & 2080 \\
\hline 13 & 2050 \\
\hline 14 & 2050 \\
\hline 15 & 2050 \\
\hline 16 & 2050 \\
\hline 17 & 2050 \\
\hline 18 & 2050 \\
\hline 19 & 2050 \\
\hline 20 & 2050 \\
\hline 21 & 2050 \\
\hline 22 & 2050 \\
\hline 23 & 2050 \\
\hline 24 & 2050 \\
\hline 25 & 2050 \\
\hline
\end{tabular}


○ Turbine Losses

- Availability Losses: 0\%

- Wake Effect Losses: 0\%

- Turbine Performance Losses: $2 \%$

- Electrical Losses. 2\%

- Environmental Losses: 0\%

- Curtailment Losses. 0\%

- Other Losses. 0\%

- Maintenance Table

- No maintenance schedule considered

\section{Battery}

- Idealized battery model w/ Tesla Powerpack [76]

- Nominal Voltage: 380V

○ Nominal Capacity: $232 \mathrm{kWh}$

- Nominal Capacity: 611 Ah

○ Round Trip Efficiency: $89.5 \%$

○ Maximum Charge Current: 152 A

○ Maximum Discharge Current: 152 A

- Cost

- Quantity: 1

- Capital: \$297-\$359 [81] (See Table 3)

○ Replacement: \$112-\$291 [81] (See Table 3)

- Lifetime

○ O\&M: \$500/unit/yr [81]

○ Years: 15 [77]

○ Throughput: 232,000 kWh [77]

- Site Specific Input

- String Size: 1

- Initial State of Charge: $100 \%$

- Minimum State of Charge: 0\%

- No minimum storage life

- No maintenance schedule considered

- Sizing

○ HOMER Optimizer

\section{Converter}


The converter is an integral part of the battery and drives the input parameters, see $\mathrm{Ch}$. 3.6 .

- Generic large, free converter (from HOMER catalog)

- Costs

- Capacity: $1 \mathrm{~kW}$

○ Capital: $\$ 0$

○ Replacement: $\$ 0$

○ O\&M: 0 \$/kW/year

- Inverter Input

- Lifetime: 15 years

○ Efficiency: $100 \%$

- Rectifier Input

○ Relative Capacity: $100 \%$

○ Efficiency: $100 \%$

- Capacity Optimization

- Search Space

- $0 \mathrm{~kW}$

- $9,999,999 \mathrm{~kW}$

\section{Grid Connection}

The grid connection in HOMER is used to represent both hydropower and the grid, see Ch. 3.7 and 3.8.

- Modeled using Scheduled Rates

- Parameters

- Sale Capacity: $0 \mathrm{~kW}$

- Annual Purchase Capacity: 590, 1432, 3150 kW (See Table 4)

○ No net metering considered

- No maximum net grid purchases considered

- Grid Extension Charges

- Grid Capital Cost: $0 \$ / \mathrm{km}$

- Distance: $0 \mathrm{~km}$

- Distributed Generation Costs

- Interconnection Charge: $\$ 0$

- Standby Charge: 3900 \$/year (represents fixed annual fees) [84]

- Rate Definition

○ Buy Price: $\$ 0.0245 / \mathrm{kWh}$ [82] (represents existing hydropower)

- Sell Price: N/A (added post-process with prices from [83])

- Prohibit grid from charging battery 
- Prohibit grid sales from battery

- Demand Rates [84]

O On Peak

- 7:00 - 23:00 on weekdays

- Price: $6.30 \$ / \mathrm{kW} / \mathrm{mo}$

○ Off Peak

- All other times of day/week

- Price: $3.07 \$ / \mathrm{kW} / \mathrm{mo}$

- For both rate periods

- No system dispatch override considered

- Reliability

○ No outages considered (100\% grid reliability)

- Emissions

- Ignored for this study

\section{Resources}

All solar, wind, and air temperatures are generated using Meteonorm 7.3.1 [44] and imported into HOMER as hourly time series profiles. To compliment the column charts shown in Chapter 3, the figures below show the distribution of values for each location by month using standard box plots (min, 25\%, median, 75\%, max). Solar also includes total irradiation per month, shown with a line curve, and for brevity is limited to only the $30^{\circ}$ tilt with snow losses. Other tilt angles have similar patterns, but with slightly higher quartiles in the winter season.

\section{Solar GHI}
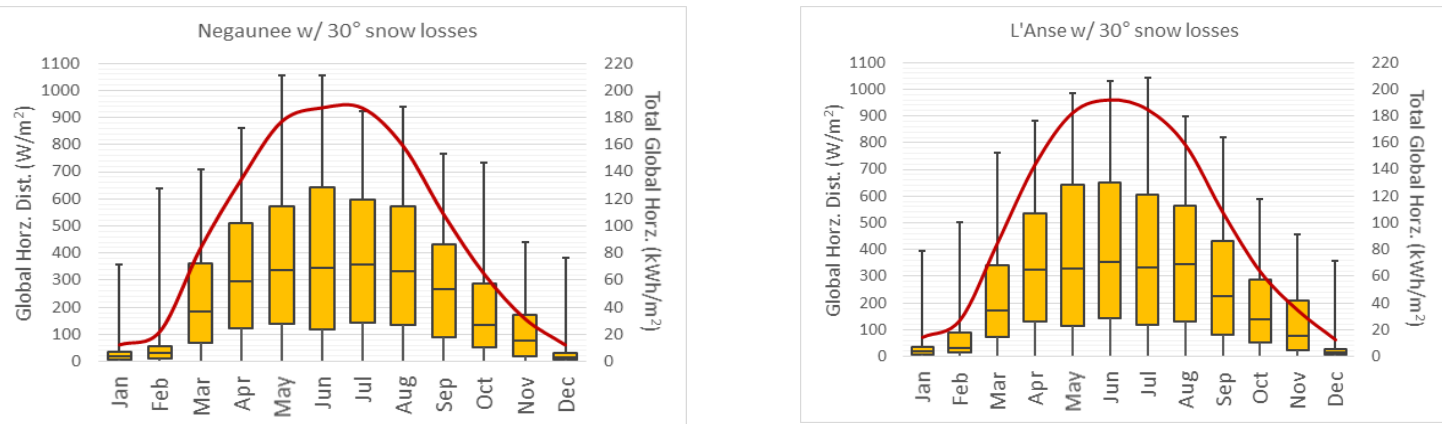


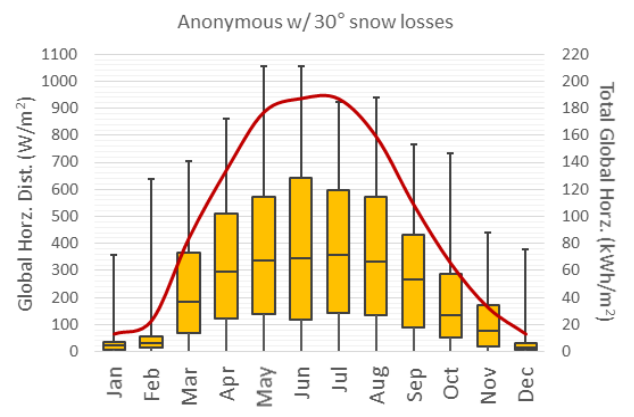




\section{Wind Speed}
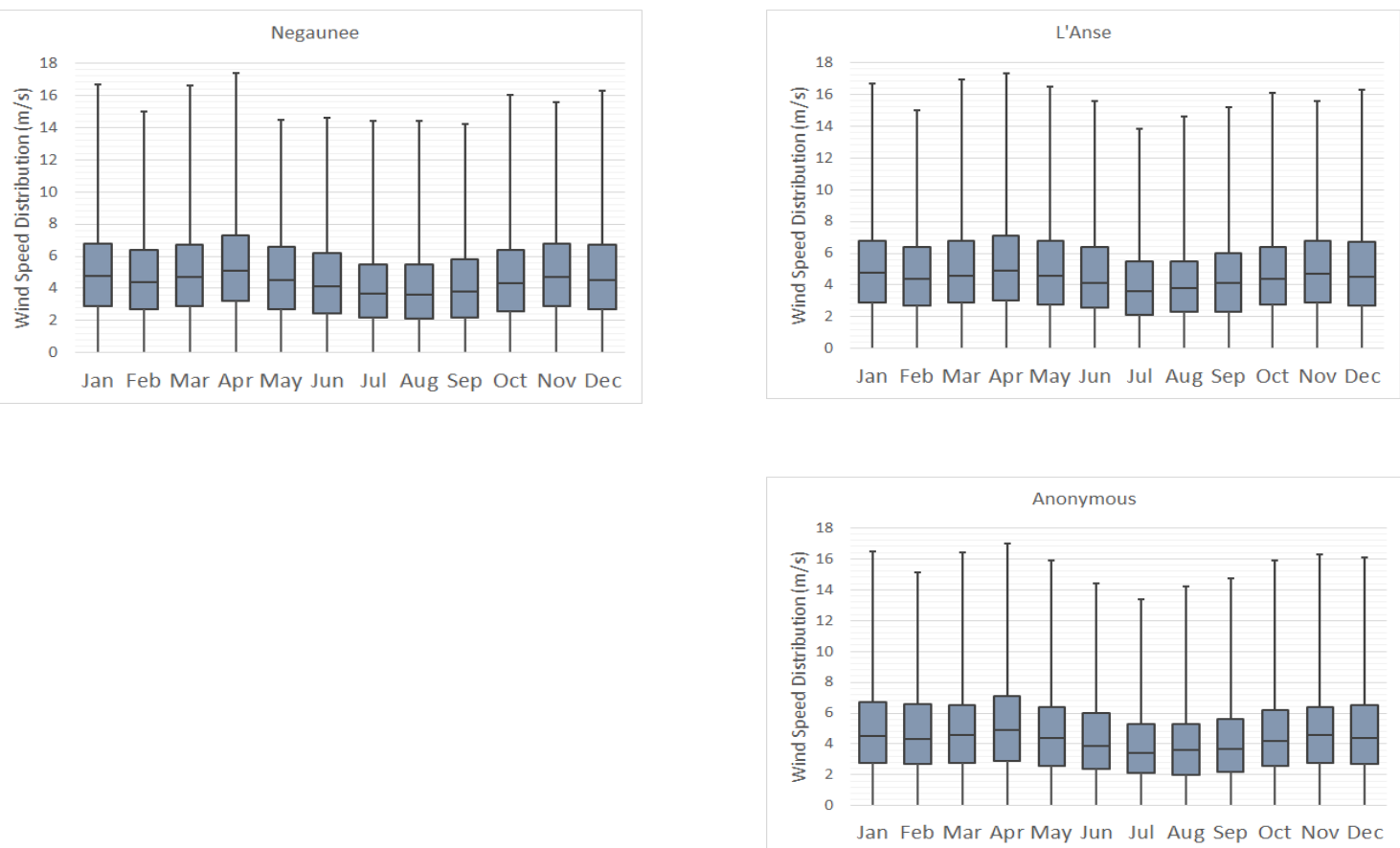

- Parameters [44]

- Altitude above sea level: 175 - $444 \mathrm{~m}$

○ Anemometer height: $10 \mathrm{~m}$

- Variation with Height

○ Wind speed profile: Logarithmic

- Surface roughness length: $0.010 \mathrm{~m}$

- Advanced Parameters not applicable due to imported time series 


\section{Air Temperature}
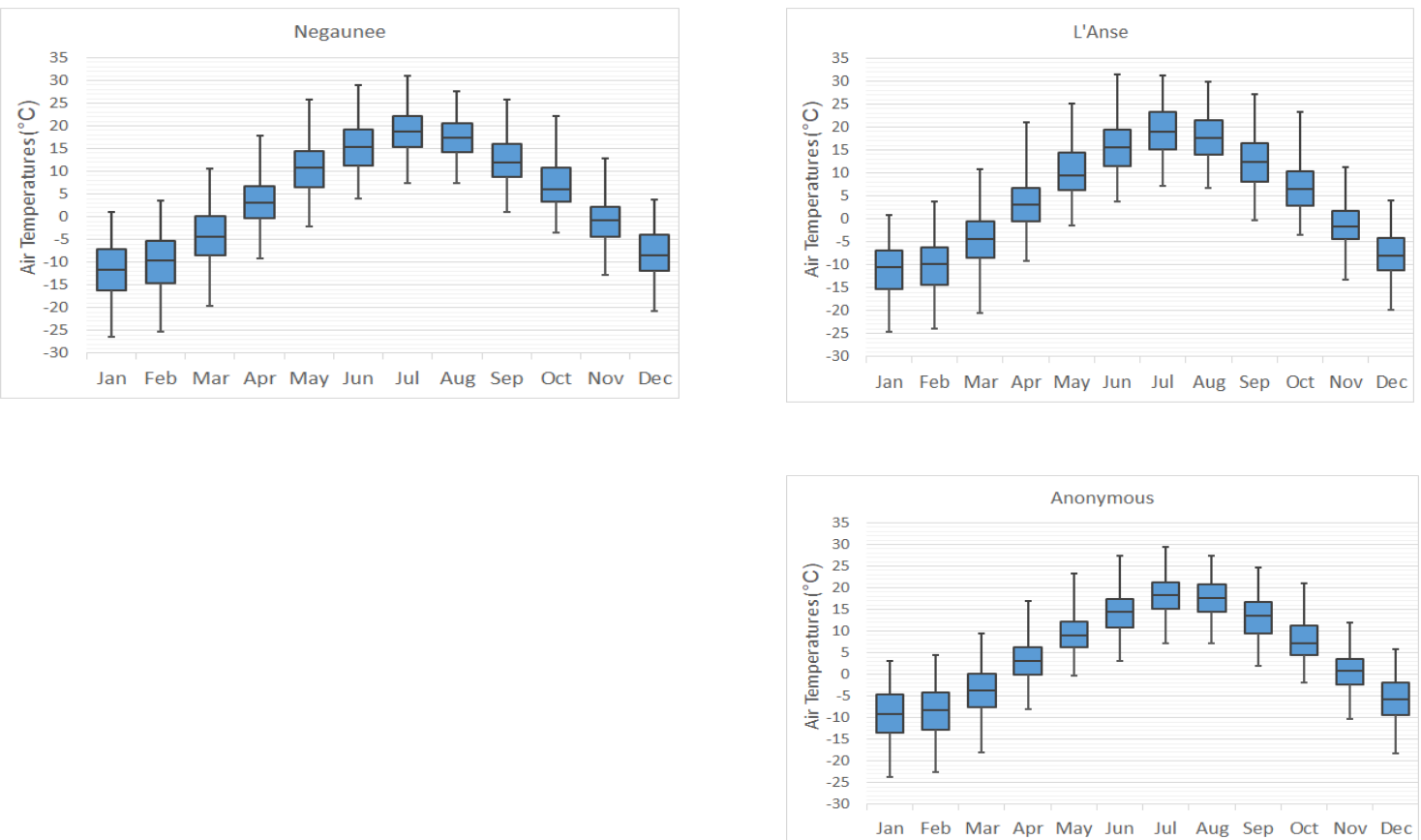

\section{Project}

\section{Economics}

- Nominal Discount Rate: 2\% - 8\% [86] (See Table 5)

- Expected Inflation Rate: 0\% (Discount rates and prices are real)

- Project Lifetime: 30 years

- System fixed capital cost: $\$ 0$

- System fixed O\&M cost: \$0/year

- Capacity shortage penalty: $\$ 0 / \mathrm{kWh}$

\section{Constraints}

- Maximum annual capacity shortage: $0 \%$

- Minimum renewable fraction: $75.6 \%, 82.1 \%, 85.4 \%$ (See Table 4)

- Operating Reserve

- As a percentage of load

- Load in current time step: $0 \%$

- Annual peak load: $0 \%$

- As a percentage of renewable output

- Solar power output: $0 \%$

- Wind power output: $0 \%$ 


\section{Emissions}

- No penalties or limits considered

\section{Optimization}

- Minutes per time step: 60

- Maximum simulations per optimization: 10,000

- System design precision: 0.0100

- NPC precision: 0.0100

- Focus factor: 50.00

- Category winners are optimized

\section{Multi-Year}

- No multi-year settings are enabled

\subsection{References}

[1] Rehfeldt M, Worrell E, Eichhammer W, Fleiter T. A review of the emission reduction potential of fuel switch towards biomass and electricity in European basic materials industry until 2030. Renew Sustain Energy Rev 2020;120:109672. https://doi.org/10.1016/j.rser.2019.109672.

[2] First J. Global Warming of 1.5 C. An IPCC Special Report on the Impacts of Global Warming of 1.5 C Above Pre-Industrial Levels and Related Global Greenhouse Gas Emission Pathways, in the Context of Strengthening the Global Response to the Thre. 2019.

[3] Intergovernmental Panel on Climate Change (IPCC). Global warming of $1.5^{\circ} \mathrm{C}$ : An IPCC special report technical summary. Glob Warm $15^{\circ} \mathrm{C}$ An IPCC Spec Rep Impacts Glob Warm $15^{\circ} \mathrm{C}$ above Pre-Industrial Levels Related Global Greenhouse Gas Emission Pathways, Context Strength Glob Response to Threat Clim Chang 2018:31-94. https://doi.org/10.1002/ejsp.

[4] Le Quéré C, Jackson RB, Jones MW, Smith AJP, Abernethy S, Andrew RM, et al. Temporary reduction in daily global CO2 emissions during the COVID-19 forced confinement. Nat Clim Change 2020;10:647-53. https://doi.org/10.1038/s41558020-0797-x.

[5] EPA. Global Greenhouse Gas Emissions Data 2019. https://www.epa.gov/ghgemissions/global-greenhouse-gas-emissions-data (accessed February 2, 2020).

[6] EIA. Power sector carbon dioxide emissions fall below transportation sector emissions 2017. https://www.eia.gov/todayinenergy/detail.php?id=34192 
(accessed February 12, 2020).

[7] Adesanya AA, Sidortsov R V., Schelly C. Act locally, transition globally: Grassroots resilience, local politics, and five municipalities in the United States with $100 \%$ renewable electricity. Energy Res Soc Sci 2020;67:101579. https://doi.org/10.1016/j.erss.2020.101579.

[8] Sierra-Club. 100 Percent Clean Energy: The New Normal. n.d. https://www.sierraclub.org/articles/2019/05/100-percent-clean-energy-new-normal (accessed August 15, 2019).

[9] MPSC. Comparison of Monthly Residential Bills * for Mpsc-Regulated Michigan Electric Utilities 2008:2008-2008.

[10] Kantamneni A, Winkler R, Gauchia L, Pearce JM. Emerging economic viability of grid defection in a northern climate using solar hybrid systems. Energy Policy 2016;95:378-89. https://doi.org/10.1016/j.enpol.2016.05.013.

[11] MPSC. Application; UPPCO IRP. Case No: U-20350. 2019.

[12] Prehoda E, Pearce JM, Schelly C. Policies to overcome barriers for renewable energy distributed generation: A case study of utility structure and regulatory regimes in Michigan. Energies 2019;12. https://doi.org/10.3390/en12040674.

[13] Prehoda E, Winkler R, Schelly C. Putting research to action: Integrating collaborative governance and community-engaged research for community solar. Soc Sci 2019;8. https://doi.org/10.3390/socsci8010011.

[14] Barnett, B., Prehoda, E. W., Kantamneni, A., Winkler, R. L., \& Schelly C. Applying transdisciplinary research to enhance low-to-moderate income households' access to community solar. In A Research Agenda for Environmental Management. Edward Elgar Publishing; 2019.

[15] Dunn, K., Jhaveri, K., Lin, K., Michalski, J., Rego B. SUN POWER: Examining the Costs and Benefits pf Community Solar in the Keweenaw Bay Region of Michigan's Upper Peninsula. University of Michigan, 2018. https://doi.org/10.1017/CBO9781107415324.004.

[16] Pettersen C, Kulie MS, Bliven LF, Merrelli AJ, Petersen WA, Wagner TJ, et al. A composite analysis of snowfall modes from four winter seasons in Marquette, Michigan. J Appl Meteorol Climatol 2020;59:103-24. https://doi.org/10.1175/JAMC-D-19-0099.1.

[17] Winkler R. Living on Lakes: Segregated Communities and Inequality in a Natural Amenity Destination. Sociol Q 2013;54:105-29. https://doi.org/10.1111/tsq.12002. 
[18] Homsy GC. Unlikely pioneers: creative climate change policymaking in smaller U.S. cities. J Environ Stud Sci 2018;8:121-31. https://doi.org/10.1007/s13412018-0483-8.

[19] Ahlborg, H., \& Hammar, L. Drivers and barriers to rural electrification in Tanzania and Mozambique-Grid-extension, off-grid, and renewable energy technologies. Renewable Energy 2014;61: 117-124.

[20] McDonald NC, Pearce JM. Community Voices: Perspectives on Renewable Energy in Nunavut. Arctic 2013;66:94-104. https://doi.org/10.14430/arctic4269.

[21] Obydenkova S V., Pearce JM. Technical viability of mobile solar photovoltaic systems for indigenous nomadic communities in northern latitudes. Renew Energy 2016;89:253-67. https://doi.org/10.1016/j.renene.2015.12.036.

[22] Talberg SA, Saari NJ, Scripps DC. Michigan Statewide Energy Assessment 2019:247.

[23] Winkler R, Oikarinen L, Simpson H, Michaelson M, Gonzalez MS. Boom, bust and beyond: Arts and sustainability in Calumet, Michigan. Sustain 2016;8. https://doi.org/10.3390/su8030284.

[24] Bagher AM, Vahid M, Mohsen M, Parvin D. Hydroelectric Energy Advantages and Disadvantages. Am J Energy Sci 2015;2:17-20.

[25] Frey GW, Linke DM. Hydropower as a renewable and sustainable energy resource meeting global energy challenges in a reasonable way. Energy Policy 2002;30:1261-5. https://doi.org/10.1016/S0301-4215(02)00086-1.

[26] Beer, M., Rybár, R., \& Kal'avský M. Renewable energy sources as an attractive element of industrial tourism. Curr Issues Tour 2018;21:2139-51.

[27] Michalena E, Tripanagnostopoulos Y. Contribution of the solar energy in the sustainable tourism development of the Mediterranean islands. Renew Energy 2010;35:667-73. https://doi.org/10.1016/j.renene.2009.08.016.

[28] Irie N, Kawahara N, Esteves AM. Sector-wide social impact scoping of agrivoltaic systems: A case study in Japan. Renew Energy 2019;139:1463-76. https://doi.org/10.1016/j.renene.2019.02.048.

[29] Dinesh H, Pearce JM. The potential of agrivoltaic systems. Renew Sustain Energy Rev 2016;54:299-308. https://doi.org/10.1016/j.rser.2015.10.024.

[30] Sovacool BK, Heffron RJ, McCauley D, Goldthau A. Energy decisions reframed as justice and ethical concerns. Nat Energy 2016;1. 
https://doi.org/10.1038/nenergy.2016.24.

[31] Heffron RJ, McCauley D, Sovacool BK. Resolving society's energy trilemma through the Energy Justice Metric. Energy Policy 2015;87:168-76. https://doi.org/10.1016/j.enpol.2015.08.033.

[32] Sidortsov, R., Heffron, R.J., Mose, T.M., Schelly, C. and Tarekegne B. In search of common ground: energy justice perspectives in global fossil fuel extraction. A Res. Agenda Environ. Manag., Edward Elgar Publishing; 2019.

[33] Brosemer K, Schelly C, Gagnon V, Arola KL, Pearce JM, Bessette D, et al. The energy crises revealed by COVID: Intersections of Indigeneity, inequity, and health. Energy Res Soc Sci 2020;68:101661. https://doi.org/10.1016/j.erss.2020.101661.

[34] Homer Energy. No Title n.d. https://www.homerenergy.com/ (accessed December 20, 2019).

[35] Peffley TB, Pearce JM. The potential for grid defection of small and medium sized enterprises using solar photovoltaic, battery and generator hybrid systems. Renew Energy 2020;148:193-204. https://doi.org/10.1016/j.renene.2019.12.039.

[36] Adesanya, A. A., \& Pearce JM. Economic viability of captive off-grid solar photovoltaic and diesel hybrid energy systems for the Nigerian private sector. Renew Sustain Energy Rev 2019. https://doi.org/https://doi.org/10.1016/j.rser.2019.109348.

[37] Adesanya AA, Schelly C. Solar PV-diesel hybrid systems for the Nigerian private sector: An impact assessment. Energy Policy 2019;132. https://doi.org/10.1016/j.enpol.2019.05.038.

[38] Weber, J. A., Gao, D. W., \& Gao T. Affordable mobile hybrid integrated renewable energy system power plant optimized using HOMER Pro. 2016 North Am. Power Symp. IEEE., 2016, p. 1-6.

[39] Banerjee A, Prehoda E, Sidortsov R, Schelly C. Renewable, ethical? Assessing the energy justice potential of renewable electricity. AIMS Energy 2017;5:768-97. https://doi.org/10.3934/energy.2017.5.768.

[40] Shaner MR, Davis SJ, Lewis NS, Caldeira K. Geophysical constraints on the reliability of solar and wind power in the United States. Energy Environ Sci 2018;11:914-25. https://doi.org/10.1039/c7ee03029k.

[41] Kroposki B, Johnson B, Zhang Y, Gevorgian V, Denholm P, Hodge BM, et al. Achieving a 100\% Renewable Grid: Operating Electric Power Systems with 
Extremely High Levels of Variable Renewable Energy. IEEE Power Energy Mag 2017;15:61-73. https://doi.org/10.1109/MPE.2016.2637122.

[42] Stan, A., M. Świerczyński, D. Stroe RT and SJA. Lithium ion battery chemistries from renewable energy storage to automotive and back-up power applications An overview,". 2014 Int. Conf. Optim. Electr. Electron. Equip. (OPTIM), Bran, 2014, p. 713-20. https://doi.org/10.1109/OPTIM.2014.6850936.

[43] Diouf B, Pode R. Potential of lithium-ion batteries in renewable energy. Renew Energy 2015;76:375-80. https://doi.org/10.1016/j.renene.2014.11.058.

[44] Remund J KS. Meteonorm 7.3.1 2018.

[45] Townsend T, Engineering BEW, Ramon S. Photovoltaics and snow : An update from two winters of measurements in the SIERRA Conference Paper in Conference Record of the IEEE Photovoltaic Specialists Conference · June 2011 2016:3231-6. https://doi.org/10.1109/PVSC.2011.6186627.

[46] Heidari N, Gwamuri J, Townsend T, Pearce JM. Impact of Snow and Ground Interference on Photovoltaic Electric System Performance. IEEE J Photovoltaics 2015;5:1680-5. https://doi.org/10.1109/JPHOTOV.2015.2466448.

[47] Andrews RW, Pollard A, Pearce JM. The effects of snowfall on solar photovoltaic performance. Sol Energy 2013;92:84-97. https://doi.org/10.1016/j.solener.2013.02.014.

[48] Khare V, Nema S, Baredar P. Solar-wind hybrid renewable energy system: A review. Renew Sustain Energy Rev 2016;58:23-33. https://doi.org/10.1016/j.rser.2015.12.223.

[49] Firtina-Ertis I, Acar C, Erturk E. Optimal sizing design of an isolated stand-alone hybrid wind-hydrogen system for a zero-energy house. Appl Energy 2020;274:115244. https://doi.org/10.1016/j.apenergy.2020.115244.

[50] Sarkar T, Bhattacharjee A, Samanta H, Bhattacharya K, Saha H. Optimal design and implementation of solar PV-wind-biogas-VRFB storage integrated smart hybrid microgrid for ensuring zero loss of power supply probability. Energy Convers Manag 2019;191:102-18. https://doi.org/10.1016/j.enconman.2019.04.025.

[51] Kalinci Y. Alternative energy scenarios for Bozcaada island, Turkey. Renew Sustain Energy Rev 2015;45:468-80. https://doi.org/10.1016/j.rser.2015.02.001.

[52] Qolipour M, Mostafaeipour A, Tousi OM. Techno-economic feasibility of a photovoltaic-wind power plant construction for electric and hydrogen production: 
A case study. Renew Sustain Energy Rev 2017;78:113-23.

https://doi.org/10.1016/j.rser.2017.04.088.

[53] Carapellucci R, Giordano L. A methodology for the synthetic generation of hourly wind speed time series based on some known aggregate input data. Appl Energy 2013;101:541-50. https://doi.org/10.1016/j.apenergy.2012.06.044.

[54] Chen J, Rabiti C. Synthetic wind speed scenarios generation for probabilistic analysis of hybrid energy systems. Energy 2017;120:507-17. https://doi.org/10.1016/j.energy.2016.11.103.

[55] EIA. U.S. States Michigan State Profile and Energy Estimates 2020. https://www.eia.gov/state/?sid=MI.

[56] SUNPOWER. SunPower® E-Series: E20-327 | E19-320 Datasheet n.d. https://us.sunpower.com/sites/default/files/media-library/data-sheets/ds-e20-series327-residential-solar-panels.pdf (accessed August 10, 2020).

[57] Van Sark WGJHM, Reich NH, Müller B, Armbruster A, Kiefer K, Reise C. Review of PV performance ratio development. World Renew Energy Forum, WREF 2012, Incl World Renew Energy Congr XII Color Renew Energy Soc Annu Conf 2012;6:4795-800.

[58] GREEN M, EMERY K, HISHIKAWA Y, WARTA W, DUNLOP E, BARKHOUSE D, et al. Solar cell efficiency tables (version 40). Ieee Trans Fuzzy Syst 2012;20:1114-29. https://doi.org/10.1002/pip.

[59] Reil F, Baumann I, Althaus J, Gebhard S. Evaluation of current standards and practices for the simulation of wind-blown sands and their applicability as accelerated ageing tests for PV modules. 2013 IEEE 39th Photovolt. Spec. Conf., IEEE; 2013, p. 1537-41. https://doi.org/10.1109/PVSC.2013.6744437.

[60] Lazard. LAZARD'S LEVELIZED COST OF STORAGE ANALYSISVERSION 5.0. n.d. https://www.lazard.com/media/451087/lazards-levelized-costof-storage-version-50-vf.pdf (accessed May 21, 2020).

[61] International Energy Agency. Trends in photovoltaic applications 2019 24nd. Report IEA PVPS T1-36:2019. 2019.

[62] Fu R, Feldman D, Margolis R. U.S. Solar Photovoltaic System Cost Benchmark: Q1 2018, NREL/TP-6A20-72399. Tech Rep NREL/TP-6A20-72399 2018.

[63] Barbose G, Naïm D. Primary authors Tracking the Sun 2019:3-52.

[64] Lopez-Garcia J, Sample T. Evolution of measured module characteristics versus 
labelled module characteristics of crystalline silicon based PV modules. Sol Energy 2018;160:252-9. https://doi.org/10.1016/j.solener.2017.12.018.

[65] Annigoni E, Virtuani A, Caccivio M, Friesen G, Chianese D, Ballif C. 35 years of photovoltaics: Analysis of the TISO-10-kW solar plant, lessons learnt in safety and performance-Part 2. Prog Photovoltaics Res Appl 2019;27:760-78. https://doi.org/10.1002/pip.3146.

[66] Brown PR, O'Sullivan FM. Spatial and temporal variation in the value of solar power across United States electricity markets. Renew Sustain Energy Rev 2020;121:109594. https://doi.org/10.1016/j.rser.2019.109594.

[67] Sommerfeldt N, Madani H. Revisiting the techno-economic analysis process for building-mounted, grid-connected solar photovoltaic systems: Part two Application. Renew Sustain Energy Rev 2017;74:1394-404. https://doi.org/10.1016/j.rser.2017.03.010.

[68] Litjens GBMA, Worrell E, van Sark WGJHM. Lowering greenhouse gas emissions in the built environment by combining ground source heat pumps, photovoltaics and battery storage. Energy Build 2018;180:51-71. https://doi.org/10.1016/j.enbuild.2018.09.026.

[69] Wiser R, Bolinger M. Benchmarking Anticipated Wind Project Lifetimes : Results from a Survey of U. S. Wind Industry Professionals 2019:1-8.

[70] Walker A. PV O \& M Cost Model and Cost 2017:1-27.

[71] Enercon. Enercon Wind Turbine - Product Overview 2015:1-19.

[72] Stehly TJ, Beiter PC. 2018 Cost of Wind Energy Review 2020:1-71. https://doi.org/10.2172/1581952.

[73] Ziegler L, Gonzalez E, Rubert T, Smolka U, Melero JJ. Lifetime extension of onshore wind turbines: A review covering Germany, Spain, Denmark, and the UK. Renew Sustain Energy Rev 2018;82:1261-71. https://doi.org/10.1016/j.rser.2017.09.100.

[74] DNV GL AS. DNVGL-ST-0437: Loads and site conditions for wind turbines. DNV GL - Stand 2016:108.

[75] Rubert T, Zorzi G, Fusiek G, Niewczas P, McMillan D, McAlorum J, et al. Wind turbine lifetime extension decision-making based on structural health monitoring. Renew Energy 2019;143:611-21. https://doi.org/10.1016/j.renene.2019.05.034.

[76] PowerPack T. Utility and Business Energy Storage Inside the Powerpack n.d. 
[77] Hu, X., Xu, L., Lin, X., \& Pecht M. Battery lifetime prognostics. Joule 2020;4:310-46.

[78] Zubi G, Dufo-López R, Carvalho M, Pasaoglu G. The lithium-ion battery: State of the art and future perspectives. Renew Sustain Energy Rev 2018;89:292-308. https://doi.org/10.1016/j.rser.2018.03.002.

[79] Nykvist B, Nilsson M. Rapidly falling costs of battery packs for electric vehicles. Nat Clim Chang 2015;5:329-32. https://doi.org/10.1038/nclimate2564.

[80] Fu R, Remo T, Margolis R, Fu R, Remo T, Margolis R. 2018 U . S . Utility-Scale Photovoltaics- Plus-Energy Storage System Costs Benchmark. Natl Renew Energy Lab 2018:32.

[81] Cole W, Frazier AW. Cost Projections for Utility- Scale Battery Storage Cost Projections for Utility- Scale Battery Storage. Natl Renew Energy Lab 2019:NREL/TP-6A20-73222.

[82] MPSC. Notice of Proposal for Decision. Case No. U-18094. 2017.

[83] UPPCO. D2. Parallel Generation - Purchase by UPPCO (Price Schedule). MPSC Vol No 8-Electric, 8th Rev Sheet No D-7220 2020. n.d.:70-1. https://www.uppco.com/wp-content/uploads/2020/05/UD2-D72.70-ParallelGeneration-Purchase-by-UPPCO-PG-4.pdf (accessed July 7, 2020).

[84] UPPCO. D2. Large Commercial \& Industrial Service (Price Schedule). MPSC Vol No 8-Electric, 6th Rev Sheet No D-2520 2020. 2020. https://www.uppco.com/wpcontent/uploads/2019/07/UD2-D25.10-Large-C-I-Cp-U.pdf (accessed July 7, 2020).

[85] Liu L, Walchale A. 100 percent Renewable Electricity Plan for Leelanau County , Michigan by 2019.

[86] Trading Economics. United States Fed Funds Rate n.d. https://tradingeconomics.com/united-states/interest-rate (accessed May 12, 2020).

[87] Calabrò E. Determining optimum tilt angles of photovoltaic panels at typical north-tropical latitudes. Renew Sustain Energy 2009;1:033104.

[88] Schmidt TS, Steffen B, Egli F, Pahle M, Tietjen O, Edenhofer O. Adverse effects of rising interest rates on sustainable energy transitions. Nat Sustain 2019;2:87985. https://doi.org/10.1038/s41893-019-0375-2.

[89] MPSC. Order Opening Docket. 2020. 
[90] Liu Z, Wen F, Ledwich G. Optimal planning of electric-vehicle charging stations in distribution systems. IEEE Trans Power Deliv 2013;28:102-10. https://doi.org/10.1109/TPWRD.2012.2223489.

[91] State of Michigan. Integrating Energy Storage into the Michigan Electric Market. n.d.

[92] City of Negaunee. Press Release - Michigan Tech and City of Negaunee explore using abandoned mines for electrical energy storage n.d.

https://cityofnegaunee.com/2019/01/24/press-release-michigan-tech-and-city-ofnegaunee-explore-using-abandoned-mines-for-electrical-energy-storage/ (accessed December 12, 2019).

[93] IEA. Global EV Outlook 2020, IEA, Paris 2020. https://www.iea.org/reports/global-ev-outlook-2020.

[94] Waite M, Modi V. Potential for increased wind-generated electricity utilization using heat pumps in urban areas. Appl Energy 2014;135:634-42. https://doi.org/10.1016/j.apenergy.2014.04.059.

[95] Fischer D, Surmann A, Lindberg KB. Impact of emerging technologies on the electricity load profile of residential areas. Energy Build 2020;208:109614. https://doi.org/10.1016/j.enbuild.2019.109614.

[96] Fischer D, Madani H. On heat pumps in smart grids: A review. Renew Sustain Energy Rev 2017;70:342-57. https://doi.org/10.1016/j.rser.2016.11.182.

[97] Vanhoudt D, Geysen D, Claessens B, Leemans F, Jespers L, Van Bael J. An actively controlled residential heat pump: Potential on peak shaving and maximization of self-consumption of renewable energy. Renew Energy 2014;63:531-43. https://doi.org/10.1016/j.renene.2013.10.021.

[98] Dar UI, Sartori I, Georges L, Novakovic V. Advanced control of heat pumps for improved flexibility of Net-ZEB towards the grid. Energy Build 2014;69:74-84. https://doi.org/10.1016/j.enbuild.2013.10.019.

[99] Psimopoulos E, Bee E, Widén J, Bales C. Techno-economic analysis of control algorithms for an exhaust air heat pump system for detached houses coupled to a photovoltaic system. Appl Energy 2019;249:355-67. https://doi.org/10.1016/j.apenergy.2019.04.080.

[100] MISO Futures. Strawman Proposal MISO Futures 2020:1-34.

[101] Steinberg D, Bielen D, Eichman J, Eurek K, Logan J, Mai T, et al. Electrification and Decarbonization: Exploring U.S. Energy Use and Greenhouse Gas Emissions 
in Scenarios with Widespread Electrification and Power Sector Decarbonization 2017:43. https://doi.org/10.2172/1372620.

[102] MPSC. MPSC approves part of DTE Electric Co.' s renewable energy plan , delays decision on future wind projects to company IRP 2019.

https://www.michigan.gov/mpsc/0,9535,7-395-93307_93313_17280-502194-,00.html (accessed July 17, 2020).

[103] Copena D, Simón X. Wind farms and payments to landowners: Opportunities for rural development for the case of Galicia. Renew Sustain Energy Rev 2018;95:3847. https://doi.org/10.1016/j.rser.2018.06.043.

[104] Saglie IL, Inderberg TH, Rognstad H. What shapes municipalities' perceptions of fairness in wind power developments? Local Environ 2020;25:147-61. https://doi.org/10.1080/13549839.2020.1712342.

[105] Macdonald C, Glass J, Creamer E. What Is the Benefit of Community Benefits? Exploring Local Perceptions of the Provision of Community Benefits from a Commercial Wind Energy Project. Scottish Geogr J 2017;133:172-91. https://doi.org/10.1080/14702541.2017.1406132.

[106] Munday M, Bristow G, Cowell R. Wind farms in rural areas: How far do community benefits from wind farms represent a local economic development opportunity? J Rural Stud 2011;27:1-12. https://doi.org/10.1016/j.jrurstud.2010.08.003.

[107] Michigan Government. MPSC approves UPPCO rate increase; most residential bills will drop. Dep License Regul Aff 2019. https://www.michigan.gov/lara/0,4601,7-154-11472-499306--,00.html (accessed August 27, 2020).

[108] Hess DJ. Coalitions, framing, and the politics of energy transitions: Local democracy and community choice in California. Energy Res Soc Sci 2019;50:3850. https://doi.org/10.1016/j.erss.2018.11.013.

[109] Adesanya AA, Schelly C. Promoting Policies for Renewable Electrification 2020:1-10. https://doi.org/10.1007/978-3-319-71057-0_50-1.

[110] National Conference of State Legislatures. State Renewable Portfolio Standards and Goals. State Renew Portf Stand Goals 2020:1-19. https://doi.org/http://dx.doi.org/10.1016/B0-12-176480-X/00529-5.

[111] Jacobsen GD. An examination of how energy efficiency incentives are distributed across income groups. Energy J 2019;40:171-98. https://doi.org/10.5547/01956574.40.6.gjac. 
[112] Zhao T, Bell L, Horner MW, Sulik J, Zhang J. Consumer responses towards home energy financial incentives: A survey-based study. Energy Policy 2012;47:291-7. https://doi.org/10.1016/j.enpol.2012.04.070.

[113] Datta S, Gulati S. Utility rebates for ENERGY STAR appliances: Are they effective? J Environ Econ Manage 2014;68:480-506. https://doi.org/10.1016/j.jeem.2014.09.003.

[114] Overholm H. Spreading the rooftop revolution: What policies enable solar-as-aservice? Energy Policy 2015;84:69-79. https://doi.org/10.1016/j.enpol.2015.04.021.

[115] Drury E, Miller M, Macal CM, Graziano DJ, Heimiller D, Ozik J, et al. The transformation of southern California's residential photovoltaics market through third-party ownership. Energy Policy 2012;42:681-90. https://doi.org/10.1016/j.enpol.2011.12.047.

[116] State of Michigan. Executive Order 2019-14 UP Energy Task Force 2019. https://content.govdelivery.com/attachments/MIEOG/2019/06/07/file_attachments/ 1226627/EO 2019-14 UP Energy Task Force .pdf.

[117] Michigan Government. EV Charger Funding Opportunities. Department Environ Gt Lakes, Energy n.d. https://www.michigan.gov/climateandenergy/0,4580,7-36485453_85455-487842--,00.html (accessed August 25, 2020).

[118] Krishnan R, Haselhuhn A, Pearce JM. Technical Solar Photovoltaic Potential of Scaled Parking Lot Canopies: A Case Study of Walmart U.S.A. J Innov Sustain RISUS ISSN 2179-3565 2017;8:104. https://doi.org/10.24212/21793565.2017v8i2p104-125.

[119] Seyfang G, Haxeltine A. Growing grassroots innovations: Exploring the role of community-based initiatives in governing sustainable energy transitions. Environ Plan C Gov Policy 2012;30:381-400. https://doi.org/10.1068/c10222. 


\title{
4 Can Michigan's Upper Peninsula Achieve Justice in Transitioning to $100 \%$ Renewable Electricity? Survey of public perceptions in Sociotechnical Change
}

\author{
Author: Adewale A. Adesanya ${ }^{1 *}$ \\ 1. Environmental and Energy Policy Program, Social Sciences Department, Michigan \\ Technological University, U.S.A. \\ * Corresponding author: adesanya@mtu.edu
}

\begin{abstract}
The cost of energy in the Western Upper Peninsula (WUP), a rural and northern part of the state of Michigan, is among the highest in the U.S. This situation has resulted in hardship for WUP residents due to exorbitant electricity bills. While interest in renewable electricity (RE) increases in the region, the unanswered questions are what factors would make WUP residents more or less supportive of a transition to $100 \%$ RE, and how does support for $100 \%$ RE transition differ between counties in the WUP? This research analyzes factors that would make residents more or less supportive of a $100 \%$ renewable electricity (RE) transition in the WUP. The research investigates public perceptions through a quantitative residents' survey $(\mathrm{N}=347)$. Using logistic regression, results show that residents' likelihood to participate in a municipality-led initiative that will reduce their consumption by $5 \%$ is statistically significant to their probability of support for wind energy development at $\mathrm{p}<$ 0.05. Further, likelihood of $100 \%$ RE transition support is very high across WUP counties, with a similar trend on project preferences. The results in this research can provide a roadmap for future community engaged planning on $100 \% \mathrm{RE}$ in various counties in the region.
\end{abstract}

Keywords: Public perception, 100\% renewable electricity, survey, energy transition

\subsection{Introduction}

As climate talk gains more traction, countries across the globe, especially the highest polluters, may be expected to make significant change to their energy systems. The type of energy technology used is central in the climate discussion, due to the variety of sources from where energy is harnessed and the associated emissions from each energy technology used. In addition, the types of energy technology used have been linked to socioeconomic and environmental outcomes of individual and community wellbeing [1] [2]. Massive deployment of alternative emerging technologies such as renewable electricity (RE) is critical to achieve the desired stability of atmospheric $\mathrm{CO}_{2}$ concentration [3] and it also offers economic benefits [2]. While these benefits appear positive to the society, public 
opinion about RE and particularly RE siting is not unilaterally supportive and some public opposition to RE can hinder its successful deployment [4] [5].

Public perceptions of RE is one of the key social dimensions in socio-technical transitions [6]. Public views on energy may be shaped by different social factors. Demographic factors such as income, environmental concern, and consumption behavior may shape public perceptions of particular energy sources. Understanding how these factors shape public support for a complete transition to RE can help in obtaining a bird's eye view of sociospatial information about its potential success. To capture the opinion of a wider range of members of the public, a designed quantitative survey possesses such capability compared to stakeholder focus groups that involve selected members of the society.

With this in mind, this research is geared toward collecting a broader perspective from residents about factors that would make them more or less likely to support a transition to $100 \% \mathrm{RE}$ in their various municipalities. Technically, 100\% RE has shown to be feasible and economically viable for residents in WUP [7]. The technical feasibility also shows more economic viability of $100 \% \mathrm{RE}$ with increased energy consumption reduction. With these in mind, it is important to investigate if WUP residents would show buy-in for such transitions with potential energy cost savings and their willingness to support municipality-led initiatives that will reduce their energy consumption. In some other research in other contexts, public attitude on support has been due to positive economic benefits in Southern California [8], while locally funded projects by private entities have received the most support in the case of Long Island [9]. As these factors cannot be generalized for all places in the U.S. due to the uniqueness of every city and state, it is important to understand if these factors can spur support or opposition in other places.

\subsubsection{Opinion of Public in Energy Transition as STST}

Sociotechnical system transitions (STST) are the combined changes in both social and material components that drive societal functions such as energy supply, communication, housing, transportation, and health care [10]. STST involves a web of elements including technology, science, user practice, culture meaning, regulation, market, infrastructure, production, and supply network [10] [11]. One conceptual framework for studying complex STST is the multilevel perspective (MLP), in which the public operates at the regime level [6] [10]. Basically, the MLP argues that interactions across multiple levels, including socio-technical landscape, socio-technical regime, and niche innovation, influence the pathways of transition [6] [12] [13]. Within this theoretical framework, the stability of new technology is partly contingent on the regime, which includes the public. Transition in the regime level, which is usually dynamically stable, occurs because of combined changes in infrastructures, policies, culture and norms [6][13]. By dynamically stable, it explains the inertia and carefulness of people to welcome new or unfamiliar system changes that might undermine their interest. In other words, technological substitution occurs in succession to increased public trust [12] [14]. 
Further, in energy system transition, understanding the role of norms, sociodemographic factors, values, and trust in the system can facilitate communication between technologists, decisionmakers, and the public [15]. To avoid neglecting the importance of public participation, social acceptance, and political feasibility, sociotechnical system transitions must be given a holistic assessment, embedded in society. The previous experience in the UK about local protest on onshore wind, failed energy savings program, unsuccessful zerocarbon home target, and smart meter roll-out are empirical examples of consequences of public neglect [13]. It is thus necessary to assess public opinion in the conceptualization of any $100 \%$ RE transition scenario.

This research attempts to answer two main questions: 1.) What factors make WUP residents more or less supportive of a transition to $100 \%$ RE? 2.) How does support for 100\% RE transition differ between counties in the WUP? The objectives are to determine factors that can contribute to support of $100 \%$ RE in WUP and to investigate similarities and differences in perceptions about $100 \%$ RE in WUP from one county to another.

\subsection{Public Perception in $100 \%$ Renewable Electricity in the U.S.}

Although there has been research on public perception and engagement on various RE in energy mix [16], not much has been done explicitly on the topic of a 100\% RE transition in the U.S. Techno-economic feasibility of $100 \%$ or nearly $100 \%$ RE transition in the U.S. have been studied by various researchers [16] [17] [18]. Previous studies have captured public and stakeholder perception on solar projects [9] [19], others studies have shown the engagement of individuals on various wind projects [20]. One of the explanations for the dearth in this research area is the relatively new concept of $100 \%$ RE in the U.S. and very few empirical case studies in that context. For instance, only five municipalities in the U.S. have been recognized for successfully transitioning to $100 \%$ RE for electricity supply [21] [22] [23] [24] [25]. These municipalities represent less than $0.003 \%$ of the total municipalities in the U.S., based on the Census Bureau in 2007 [26]. Thus, this research focuses on drawing opinions of residents from the early conceptual stage of the potential for a $100 \%$ RE transition.

The succeeding subsection uses the theoretical framework of multi-level perspective (MLP) on energy transition as socio-technical system transition (STST) as the basis for investigating public opinion. First, the demands of a 100\% RE transition and changes in consumption pattern to match available resources is discussed. Second, perceptions on the possibilities of RE in northern climates is reviewed as this relates to having resource availability for energy production to meet needs. Next, the interest of the public with respect to RE placement, project developers, and benefits from such projects is reviewed. Then the WUP in Michigan case study is introduced along the region's uniqueness, demography, and developing interest in RE. Then the methodology and hypotheses of this research are presented. The findings, discussion and conclusions follow according. 


\subsubsection{Energy Consumption Behavior and RE Transition}

Recent research reveals that the main barriers to variable or intermittent $100 \% \mathrm{RE}$ are not techno-economic, but political, cultural, and institutional challenges [16]. One example is the potential of changing consumption patterns by individuals to match available RE resources. The ability of Americans to make a connection between their consumption patterns and available energy resources, and making choices on viable alternatives, can help influence support for RE [27]. The reason for such change in behavioral pattern is because the techno-economic, social, and policy requirements in a wholly RE would be higher, compared to a mix of renewable and fossil fuel scenarios. On the technical dimension, the issue of intermittent renewable resources with the need for generation to meet base and peak loads reliably and securely is one challenge [16] [18] [28]. While the availability of storage such as batteries offers a solution to this technical challenge, its cost and economic implications pose further bottlenecks. It would be expected that if RE will displace the current fossil fuel regime, then it must provide more economic and environmental benefits for it to appeal to the people. However, the falling prices of RE technologies and battery storage [28] offer potential solutions to the economic challenges. Nonetheless, interest in energy efficiency has been growing alongside RE adoption [29] [30]. Also, energy consumption waste reduction has been the center of energy regulations [31]. It is therefore imperative that in the early stage of planning and decision-making, consideration of public interest, support, and views of individuals regarding the potential of changing their energy consumption pattern and their support for energy efficiency and waste reduction measures to reduce overall energy demand and adapt to increase use of RE is investigated as part of the potential public support for a 100\% RE transition.

Some of the themes explored in previous public opinion research regarding renewable energy development also include citing RE technologies, relationship with RE project developers, and the distribution of the benefits associated with RE development [32] [33]. In the Long Island Solar Roadmap project, for instance, input of the public was collected through a public opinion survey that asked explicitly about the relative importance of multiple factors involved in solar energy development [9]. In addition, research in Leelanau county, Michigan, finds community members' perspective of RE to be positive [34].

Considering public perceptions and preferences early in RE project development can foster support, increase public awareness, ease information sharing for better understanding, and provide opportunity to incorporate key local environmental knowledge [35]. Obtaining public support in RE development can facilitate acceptance of future implementation. On the other hand, if such a project is in conflict to the interest of the residents, it could lead to project failure [36] [37]. 


\subsubsection{Electricity Price and Environmental Concern in the Case of Michigan's Western Upper Peninsula (WUP)}

Historically, many parts of the Upper Peninsula (UP) of Michigan, U.S. have been impacted by mining activities that have left legacies of environmental degradation and damage, including impacts to the water quality of the cherished Lake Superior, the largest body of freshwater in the world [38] [39]. The legacies of mining also have economic impacts, leaving areas relatively under-resourced and with fewer opportunities for economic growth. Not only that, the cost of energy in the UP is among the highest in the whole U.S. [40]. The situation has resulted in hardship on residents of the UP region due to exorbitant electricity bills [41]. This disproportionate energy challenge in the state of Michigan has raised concerns among its residents. In response to this energy crisis, Governor Gretchen Whitmer recently appointed a Task Force to come up with viable solutions to ensure that UP residents have access to affordable, reliable, and safe energy [42].

Electricity from RE seems to be on the radar as a possible alternative solution to mitigate the existing energy challenges in the UP. In September 2020, Michigan's Governor Whitmer issued an executive directive for the state to become carbon-neutral by the year 2050, with the goal of transitioning from fossil fuel to RE [43]. The rationales for this goal, according to the directive include ensuring economic resilience, mitigation of climate change and its impact, and localizing energy provision while meeting the needs of Michiganders. Also, there has been increasing interest in RE adoption in selected parts of the UP. For instance, the Western UP Planning and Development Region (WUPPDR) has renewable energy deployment as part of its plans [44]. In 2018, WUPPDR requested the assistance of researchers from University of Michigan (UM) and Michigan Technological University (MTU) to carry out a technical and cost-benefit analysis for community solar in

the Keweenaw Bay Region [40], resulting in a community solar project [19] [40] [44] [45]. While techno-economic analysis is important in this process, the opinion of the public who are at the center of this energy development is equally germane.

WUP is a region in the northern part of Michigan, flanked by Lake Superior. WUP covers ten counties which are Baraga, Delta, Dickinson, Gogebic, Houghton, Iron, Keweenaw, Marquette, Menominee, and Ontonagon [46] [47]. The region is predominantly rural communities, with a population of 232,886 people as of 2018 [47], including 186,886 eligible voters who are at least 18 years old. Over $86 \%$ of WUP residents are high school graduates, while approximately $20 \%$ hold bachelor's degrees and higher [48]. Against this backdrop, it is important to assess the commonalities and differences across WUP while exploring social perceptions of the potential for a 100\% RE transition in the WUP.

\subsubsection{Method and Survey Design}

Investigation of residents' perception of and support for a 100\% RE transition in the WUP was conducted via survey questionnaire. The survey was distributed to residents across the 
ten WUP counties. Residents in this paper refers to individuals that live in the region for at least the past six months, including both full time or part time (seasonal or student) residents

In the face of the challenges caused by the current global pandemic of COVID19, the methodology adopted included online survey distribution. An existing survey questionnaire [9] was adapted in the design of a questionnaire to carry out an investigation of perceptions of WUP residents on 100\% RE. The redesigned questionnaire was pretested with self-selected members and non-members of the university community. This helped to know if the survey instrument can easily be completed by the public within a short time frame of fifteen minutes as well as identify potential barriers for participants to complete it. Feedback provided by these people after the pretest of the survey instrument were incorporated into the final draft of the questionnaire. Appendix 1 contains the questionnaire, which was launched on the Survey Monkey platform. In general, perception is measured by residents' support for transitioning to $100 \%$ RE sourced electricity supply.

The goal of this survey is broadly to examine the perceptions of residents in all ten WUP counties by investigating different opinions on a 100\% RE transition for electricity supply, including support for policy, project development, and participation. Specifically, it is geared towards knowing the following about WUP residents: i.) perceptions on technological options: relative support for wind and solar and the factors that influence support, ii.) support for policy mechanisms that would drive a $100 \% \mathrm{RE}$ transition, and iii.) willingness to participate, measured as willingness to engage in behavior change or to pay for RE. Table 1 shows the independent and dependent variables, which are considered in this research.

Table 1: Research variables

\begin{tabular}{|l|l|}
\hline \multicolumn{1}{|c|}{ Dependent Variables } & \multicolumn{1}{|c|}{ Independent Variables } \\
\hline \multirow{2}{*}{ Likelihood for solar energy support } & Installation option \\
\cline { 2 - 2 } & Financing model \\
\hline \multirow{2}{*}{ Likelihood for wind energy support } & Project benefits \\
\cline { 2 - 2 } & Important factors \\
\hline
\end{tabular}




\subsubsection{Sampling Frame}

The sampling framing for this research is limited to residents who can go online to complete a survey questionnaire in English. The survey was distributed online, using purposive convenience and snowball methodologies. The survey was open online for the public for 63 days in total from the period of 28 August to 29 October 2020 before the U.S. election month of November. The Survey Monkey link was emailed to contact persons at various public libraries in the WUP, with a request for publishing it on their websites and social media platforms. The same approach was taken in contacting public officials and asking them to share the link through county and city websites. The survey was also made available for residents through Facebook platforms, which were targeted to ensure a diversity of viewpoints among potential participants. These pages included local yard sale pages, Keweenaw Youth for Climate Action, Copper Country Christian School, Gogebic-Iron County Airport, Gogebic Community College, Michigan Technological University (including Halls and Departments on campus), Escanaba Upper Elementary PTO, Escanaba Area Public Schools, Baraga Area Schools, Hancock public schools, L'Anse Area Schools, West Iron District Library, Munising School Public Library, Spies Public Library, WUPPDR (email), UP Politics and Public Policy, and Keweenaw People's Movement. School contacts were requested to share the survey with parents and staff in their listserv. A follow-up email on the survey procedure was sent to Principals and contact persons from various schools in the WUP. The email provided information about the online survey and directions on how residents can complete it. A snowball approach was also deployed, where individuals were requested to share the survey with other residents within their network such as on personal Facebook, LinkedIn, Twitter timeline, and on Keweenaw Now blog. Contained in the survey was information about two participants winning a $\$ 100$ gift card in a raffle draw. Such strategy is common to increase speed of response, reduce coverage error, and lower cost of carrying out surveys [49]. Due to the snowballing approach, the frequency of share in different social media platforms could not be ascertained.

Due to the chosen sampling frame, the survey is expected to have coverage error [49]. Coverage error can be described as error resulting from exclusion of certain groups within a research study population, who may not have access to the sampling frame such as Internet, landline telephone, etc. Previous research shows that while $73 \%$ of U.S. households have access to the Internet, about $83 \%$ of adults use the internet [49]. To reduce coverage error, Marquette, Delta, and Iron counties were physically visited to distribute posters containing the information on the survey for people to participate in. Specifically, some small shops, restaurants, and bars in those places were visited and requested to help post the invitation to participate in the online survey in front of their glass windows, doors or public info boards.

The survey was designed and targeted to obtain perspectives of WUP residents. Based on the total eligible voting population of 186,886 residents in the ten WUP counties, a confidence level (C.L.) of $95 \%$ is set at confidence interval (C.I.) (error margin) of plus or 
minus $3.34 \%$. This gives the targeted sample size of voting age respondents in WUP to be 857. For each of the counties, the set C.L. and C.I. respectively $95 \%$ and $10 \%$, resulting in the following targeted sample sizes in Table 2.

Table 2: Targeted sample size for the online survey

\begin{tabular}{|c|c|c|c|}
\hline & Population (2018) & $\begin{array}{l}\text { Voting age ( } 18 \\
\text { above) }\end{array}$ & $\begin{array}{l}\text { Targeted } \\
\text { Sample size }\end{array}$ \\
\hline Baraga & 8,580 & 6,955 & 95 \\
\hline Delta & 36,395 & 28,854 & 96 \\
\hline Dickinson & 25,659 & 20,460 & 96 \\
\hline Gogebic & 15,575 & 13,085 & 95 \\
\hline Houghton & 36,335 & 27,830 & 96 \\
\hline Iron & 11,290 & 9,335 & 95 \\
\hline Keweenaw & 2,135 & 1,770 & 91 \\
\hline Marquette & 67,145 & 54,460 & 96 \\
\hline Menominee & 23,390 & 18,850 & 96 \\
\hline Ontonagon & 6,070 & 5,285 & 94 \\
\hline Total & 232,574 & 186,886 & 950 \\
\hline \multicolumn{4}{|c|}{ At $95 \%$ confidence level with a confidence interval (error margin) of $10 \%$} \\
\hline
\end{tabular}




\subsection{Results Analysis}

\subsubsection{Descriptive Statistics of Results}

A total of 351 responses were received, out of which only 327 indicated their county of residence and respondent indicated others. The result shows a large turnout in a single county. Approximately 80\% (260 people) of the respondents are from Houghton County, while the other $20 \%$ are spread across the remaining counties. Figure 1 shows the frequency distribution of respondents by county of residence. Baraga, Dickinson, and Marquette each have 15 respondents, while Baraga has 14 respondents from the survey. Due to the low response rate from all the counties aside from Houghton, subsequent analysis is done by grouping respondents into two as Houghton county and non-Houghton county. The single respondent that indicated others was added to the non-Houghton county group.

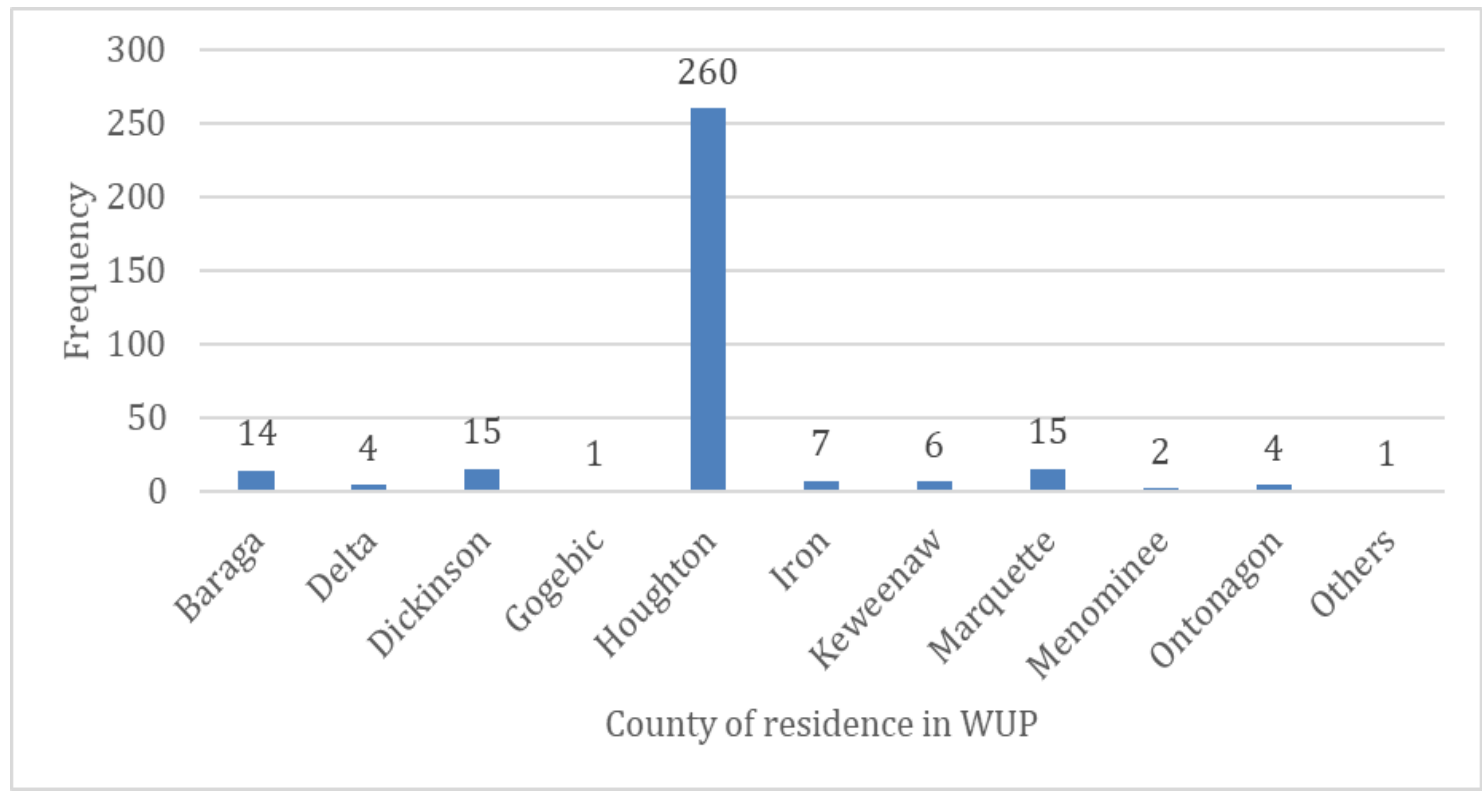

Figure 1: Frequency of participants from the nine WUP counties

\subsubsection{Knowledge of RE Technologies in WUP}

\section{RE Knowledge}

On the question about knowledge of different RE technologies for electricity generation in the WUP, results show that more than $60 \%$ of the 351 residents that responded have a little knowledge on solar and wind. In the case of knowledge of hydro where 350 responded, about 55\% indicated that they have little knowledge of the technology. Across each technology (see Figure 2, a-c), more residents indicated that they are either knowledgeable or very knowledgeable about solar and wind energy, compared to lower proportions for 
hydro. The knowledgeable rate (combination of knowledgeable and very knowledgeable) as perceived by WUP residents for each RE technology is approximately $35 \%, 28 \%$, and $25 \%$ for solar, wind, and hydro respectively. In addition, hydro is the RE technology with the least level of knowledge base among respondents.

While the overall result in this category shows low knowledge of RE across the three technologies, it does not indicate that the opinions of respondents are invalid. Rather, it means that a complementary interview of selected residents might be needed to obtain a full narrative of why each respondent selected their knowledge rate. This will help in ascertaining the veracity of their opinions for future policy and decision-making processes.

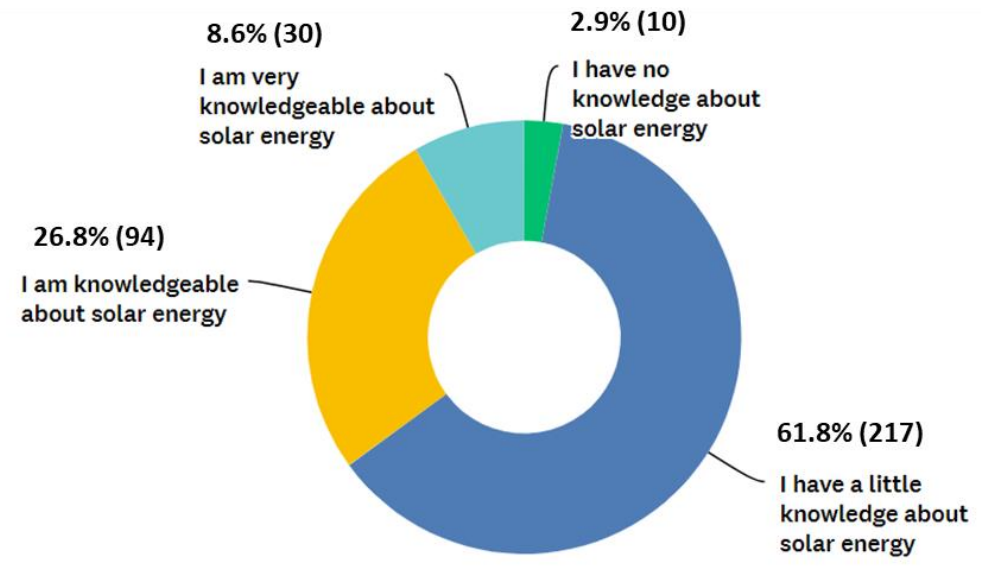

(a)

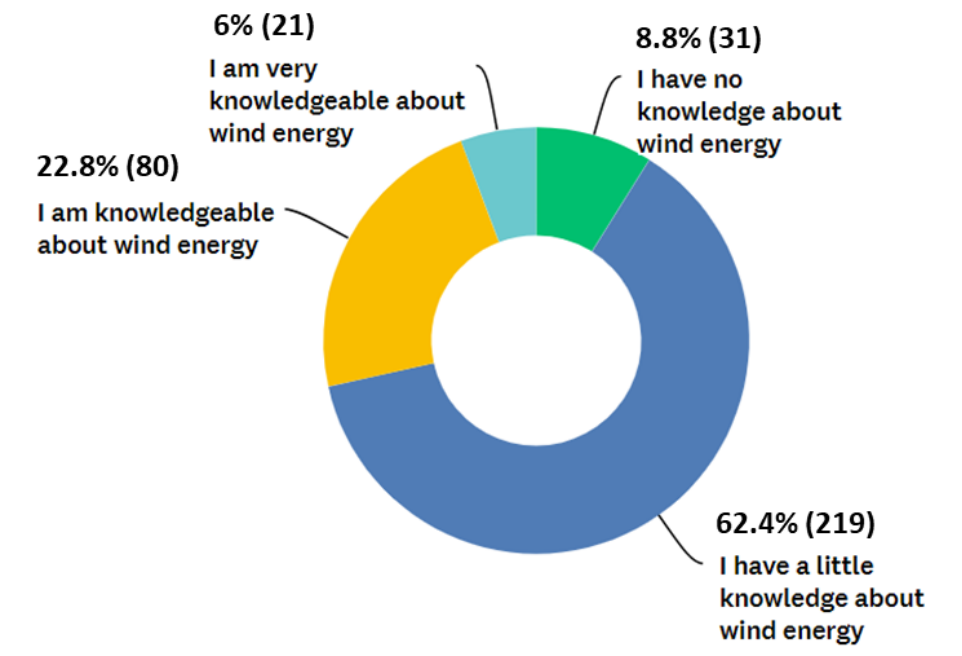

(b) 


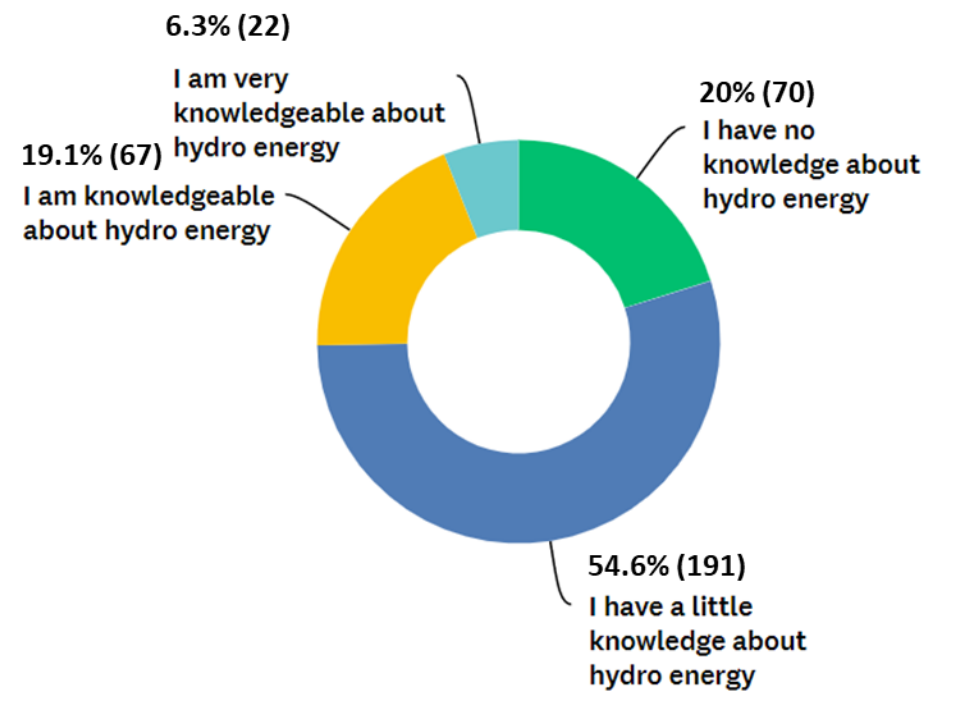

Figure 2: WUP residents' response distribution about knowledge of solar, wind, and hydro power for electricity

\section{Support for RE development}

For the support of solar and wind energy development, a comparison between responses from Houghton County and Non-Houghton Counties was made. This is due to low response rate from the remaining nine counties (aside Houghton), which produced less than 70 responses in total. In the case of Houghton County, among 258 respondents, the general distribution of responses is completely mirrored in Non-Houghton Counties. While Houghton county has approximately 78\% support for solar and 59\% support for wind, among Non-Houghton respondents, $79 \%$ are supportive of solar and $62 \%$ are supportive of wind. Table 3 below is a summary of results of frequency distributions of RE support. However, the results for both categories and the combined WUP shows high positive skewness of the data, ranging from 1.2 to 2.2 . This shows that the data is not normally distributed or non-symmetric with most of the responses tilting towards support for RE. 
Table 3: Comparison between responses in Houghton and Non-Houghton Counties on their support for solar and wind technology for electricity generation

\begin{tabular}{|l|c|c|c|c|}
\hline \multirow{2}{*}{} & \multicolumn{2}{|c|}{ Houghton County } & \multicolumn{2}{c|}{ Non-Houghton County } \\
\cline { 2 - 5 } & Solar support & Wind support & Solar support & Wind support \\
\hline Response & Percent & Percent & Percent & Percent \\
\hline Yes & 77.9 & 58.5 & 78.8 & 62.1 \\
\hline No & 5.4 & 15.5 & 7.6 & 21.2 \\
\hline Missing & 16.7 & 26 & 13.6 & 16.7 \\
\hline Total & 100 & 100 & 100 & 100 \\
\hline
\end{tabular}

\subsubsection{Demographic Analysis of Respondents}

The most represented demographic among respondents is female respondents from Houghton County, with $62 \%$ of 226 respondents that indicate their gender as being female, while $22 \%$ indicated male. The rest did not respond to this question or indicated others. In non-Houghton counties, $61 \%$ of respondents are female while $35 \%$ are male (see Figure 3 ). The income distribution observed for Houghton and combined rest of the counties in WUP (non-Houghton Counties) show similarity with the category of $\$ 0-\$ 50,000$ and $\$ 50,000-\$ 100,000$ for both being $81 \%$ and $83 \%$ respectively. The same similarity is observed with income distribution between \$100,000-\$200,000. These demographic results, especially the household income range, aligns with census data on social explorer [47] for Houghton County. In the same vein, population by household type also shows that female householder doubles that of male householder on the census data. This is an indication of non-biases in the sampling.

For Houghton County respondents, $41 \%$ of the 102 respondents indicated a Democratic political affiliation, while $38 \%$ identified as Republican. For non-Houghton counties, $41 \% \%$ of the 62 residents who answered the question also identified as Democrats, while $41 \%$ were Republican. Those that indicated "others" as their political party affiliation are $21 \%$ and $18 \%$ for the Houghton and non-Houghton Counties respectively. As observed for income distribution, there is similarity in the distribution of political party affiliation be- 
tween the two County categories. However, it is important to note that these sample sizes for both Houghton County and non-Houghton counties are not representative enough to make a general inference.

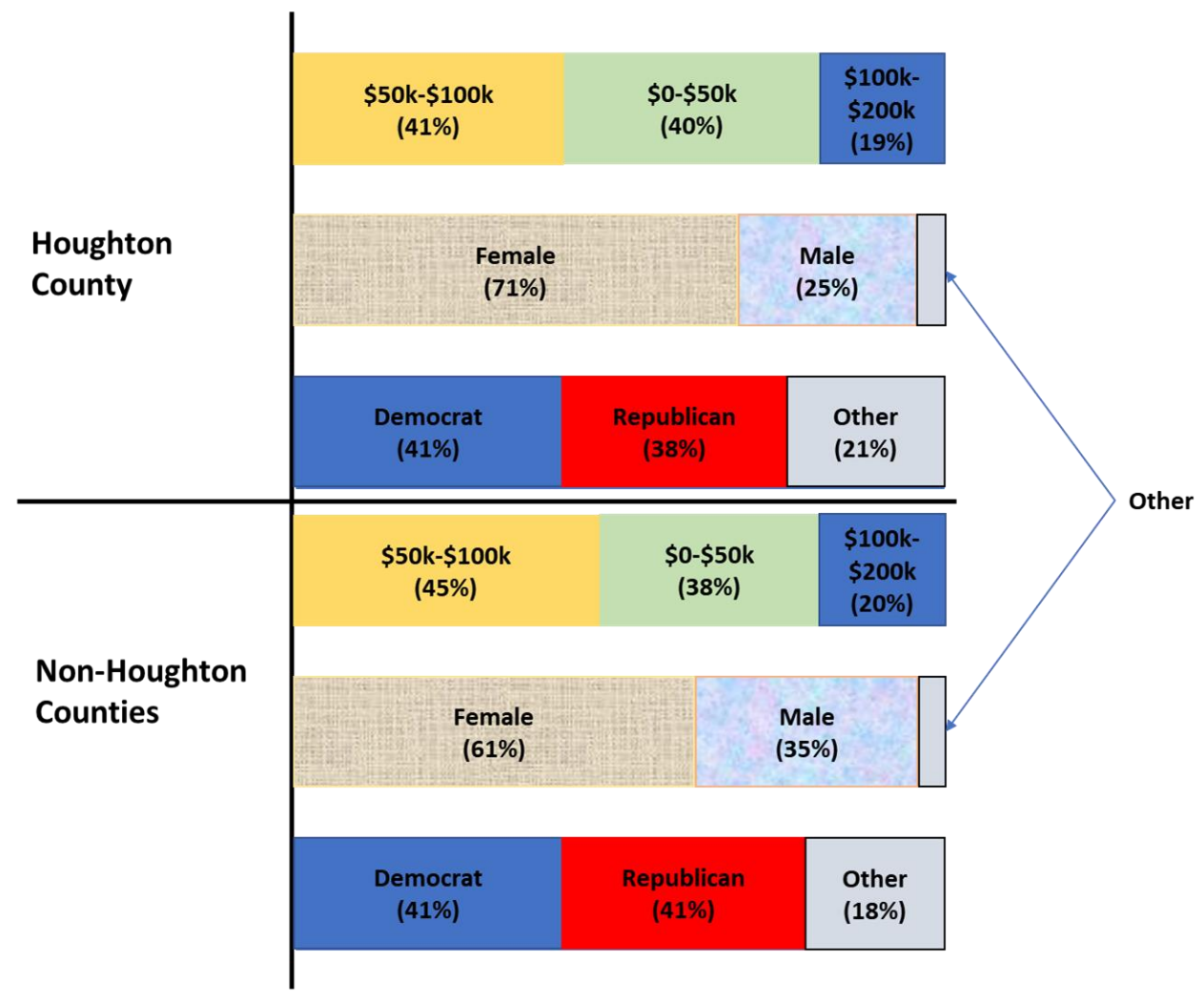

Figure 3: Demography analysis of Houghton and Non-Houghton counties' respondents

\subsubsection{Installation, Finance, and Benefit Preferences}

\section{Installation Preferences}

Another question asked in the survey relates to the kinds of RE technology installation options that residents would support and how their support would change based on visibility of the technologies (Figure $3 \mathrm{a}$ and b). The frequency of responses in each category are given as numbers in parentheses after the label on x-axis. In Houghton county, more than $80 \%$ of the respondents indicated that they would support all of the various RE installation options (see Figure 3-a), with $86 \%$ willing to support solar panels mounted in degraded land, panels on commercial or industrial rooftops, and panels that are shading parking lots or garages, and $83 \%$ indicating their likelihood to support ground mounted solar and solar technology mounted in areas earmarked for development. All these responses are regardless of whether the panels are visible or not. 
Onshore and offshore wind support are $65 \%$ and $70 \%$ respectively. Additionally, between $3 \%-9 \%$ of the respondents are willing to give more support to all these RE installation options if they are visible. On that spectrum, 9\% each are willing to support visible panels on degraded land, on commercial or industrial rooftops, and on parking lots. However, it is important to note the sharp difference between support for various solar installation options and that of wind technology. On average, the difference in percent support regardless of visibility between all solar options and wind is approximately $17 \%$. Also, the opposition to wind installation (both onshore and offshore) is almost about 6 times as much as that of solar energy, despite the former having up to $70 \%$ support.

In the case of residents in non-Houghton Counties (Figure 3-b) panels on commercial or industrial rooftops and on degraded lands have more than $90 \%$ support, higher than the results from Houghton County. Across the non-Houghton counties, there is no single response opposed to solar panels on degraded land. The same levels of lower support for onshore and offshore wind installation are observed in non-Houghton Counties as with Houghton County. The responses also have a very close similarity between both places.

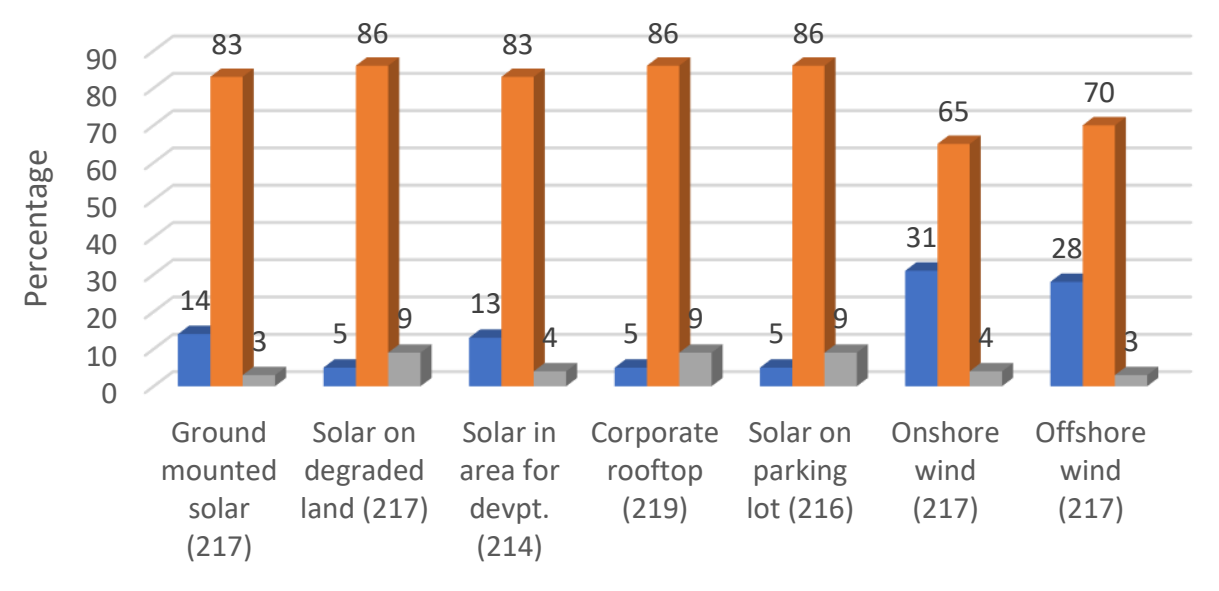

RE Installation Preferences

- Would oppose if they are visible (\%) — Would support, visible or not (\%)

Would support more if visible (\%) 


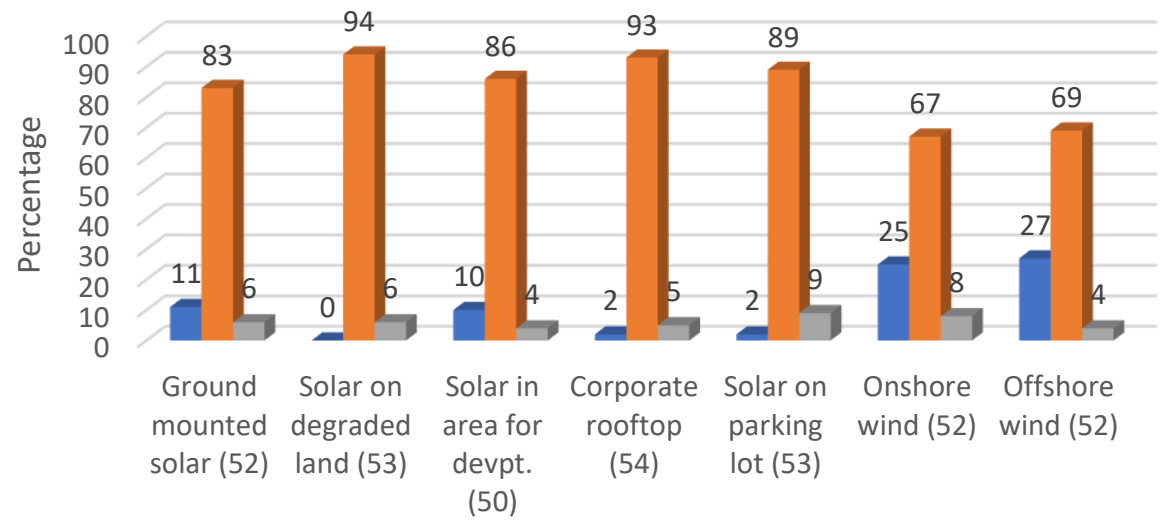

RE Installation Preferences

Would oppose if they are visible (\%) — Would support, visible or not (\%)

Would support more if visible (\%)

Figure 3: Willingness to support for various RE installation options

\section{Project Financing Preferences}

Residents responded to questions based on three predefined financing models. For model one, private developers or property owners can fund the project, own the system, and receive the return on investment. In model two, local government invest in renewable energy project with public funds and the return on investment can become part of the municipality's public funds. For the third model, a "community renewable energy" development project allows members of the community to invest in renewable electricity production that is built locally. On the issue of preferences for various RE project financing models, Table 4 represents the distribution of residents' responses from Houghton (orange color) and non-Houghton counties (blue color). The highest willingness to support rate in Houghton (combined "more like" and "most likely") is observed for privately funded projects developed as municipality renewable energy systems, where individual utility customers can elect to purchase the electricity generated, with $84 \%$ of 220 responses. In the non-Houghton Counties, publicly funded projects developed as municipality RE systems, where individual utility customers can elect to purchase the electricity generated, has the highest support, at $83 \%$. As these two financing options with the highest supporting rate are very similar, it can be inferred that municipality RE development would attract most support in WUP in general. In both Houghton and Non-Houghton, the options with the least support likelihood include privately funded projects by national or international companies for utilities' purchase. The likelihood that residents would be supportive of this project financing option is $35 \%$ and $36 \%$ for Houghton and Non-Houghton respectively.

Table 4: RE Project financing preferences 


\begin{tabular}{|c|c|c|c|c|c|}
\hline & $\begin{array}{l}\text { Do not } \\
\text { support } \\
(\%)\end{array}$ & $\begin{array}{l}\text { Less likely } \\
\text { to support } \\
(\%)\end{array}$ & $\begin{array}{l}\text { More likely } \\
\text { to support } \\
(\%)\end{array}$ & $\begin{array}{l}\text { Most likely } \\
\text { to support } \\
(\%)\end{array}$ & Total \\
\hline \multirow{2}{*}{$\begin{array}{l}\text { Public financing } \\
\text { with public fund on } \\
\text { municipal buildings }\end{array}$} & 11 & 13 & 50 & 26 & 217 \\
\hline & 11 & 25 & 36 & 28 & 56 \\
\hline \multirow{2}{*}{$\begin{array}{l}\text { Privately funded by } \\
\text { local companies for } \\
\text { local utility } \\
\text { purchase }\end{array}$} & 4 & 23 & 51 & 22 & 219 \\
\hline & 7 & 13 & 57 & 23 & 56 \\
\hline \multirow{2}{*}{$\begin{array}{l}\text { Privately funded by } \\
\text { national or } \\
\text { international } \\
\text { companies for } \\
\text { utilities }\end{array}$} & 10 & 35 & 42 & 13 & 219 \\
\hline & 11 & 36 & 38 & 16 & 56 \\
\hline \multirow{2}{*}{$\begin{array}{l}\text { Privately funded } \\
\text { municipal RE for } \\
\text { voluntary purchase }\end{array}$} & 5 & 14 & 58 & 23 & 220 \\
\hline & 5 & 13 & 55 & 27 & 56 \\
\hline \multirow{2}{*}{$\begin{array}{l}\text { Publicly funded } \\
\text { municipal RE for } \\
\text { voluntary purchase }\end{array}$} & 6 & 17 & 46 & 31 & 219 \\
\hline & 3 & 14 & 45 & 38 & 56 \\
\hline \multirow{2}{*}{$\begin{array}{l}\text { Privately funded on } \\
\text { private property for } \\
\text { owner }\end{array}$} & 7 & 20 & 48 & 25 & 220 \\
\hline & 7 & 23 & 32 & 38 & 56 \\
\hline
\end{tabular}




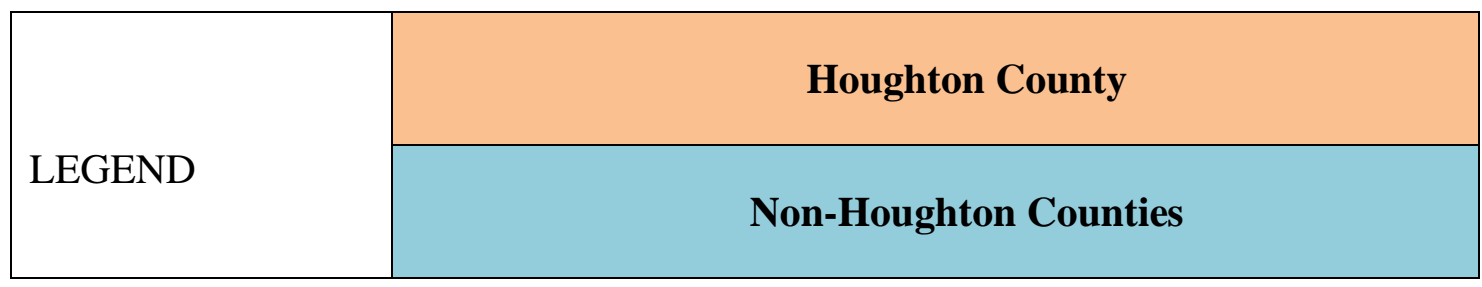

\section{Project Benefits}

Respondents were asked about what they perceive to be the benefits of RE development. On average, all the categories of project benefit have more responses showing likely support of residents (Table 5). In Houghton County, 95\% of respondents are more likely to support projects that provide jobs and other economic development benefits in their municipality and projects that provide lower electricity rates for individuals. These two benefits rank highest among all others, although the "more likely to support" rate is generally high across all the benefits for Houghton County respondents. The benefit given the lowest response of "more likely to be supported," at $61 \%$, is projects that create an increased tax base for the municipality.

In non-Houghton Counties, $91 \%$ of the 56 respondents say they are more likely to support projects that provide jobs and other economic development benefits for their municipality. As in the case of Houghton County, projects that are geared towards creating taxes for the municipality also have the lowest levels of "more likely to support," with $71 \%$ of respondents showing interest in it.

Table 5: RE Project Benefit Preference

\begin{tabular}{|l|c|c|c|c|}
\hline & $\begin{array}{l}\text { Do not } \\
\text { support (\%) }\end{array}$ & $\begin{array}{l}\text { Less likely to } \\
\text { support (\%) }\end{array}$ & $\begin{array}{l}\text { More likely to } \\
\text { support (\%) }\end{array}$ & Total \\
\hline $\begin{array}{l}\text { Project provides jobs } \\
\text { and other economic } \\
\text { development for } \\
\text { municipality }\end{array}$ & 2 & 3 & 95 & 216 \\
\cline { 2 - 5 } & 2 & 7 & 91 & 56 \\
\hline $\begin{array}{l}\text { Project provides } \\
\text { lower electricity }\end{array}$ & 2 & 3 & 95 & 215 \\
\hline
\end{tabular}




\begin{tabular}{|c|c|c|c|c|}
\hline $\begin{array}{l}\text { rates for me } \\
\text { personally }\end{array}$ & 2 & 11 & 87 & 56 \\
\hline \multirow{2}{*}{$\begin{array}{l}\text { Project is sited to } \\
\text { provide } \\
\text { supplemental } \\
\text { income for local } \\
\text { farmers in } \\
\text { municipality }\end{array}$} & 3 & 4 & 93 & 215 \\
\hline & 6 & 9 & 86 & 55 \\
\hline \multirow{2}{*}{$\begin{array}{l}\text { Project provides } \\
\text { lower electricity } \\
\text { rates to schools in } \\
\text { municipality }\end{array}$} & 2 & 6 & 92 & 198 \\
\hline & 2 & 20 & 78 & 55 \\
\hline \multirow{2}{*}{$\begin{array}{l}\text { Project developed } \\
\text { with mixed-use in } \\
\text { mind, e.g. electric } \\
\text { vehicle, rooftop } \\
\text { solar }\end{array}$} & 4 & 9 & 87 & 215 \\
\hline & 6 & 7 & 87 & 55 \\
\hline \multirow{2}{*}{$\begin{array}{l}\text { Project provides } \\
\text { personal access to } \\
\text { electricity from } \\
\text { renewable energy } \\
\text { resources }\end{array}$} & 5 & 7 & 86 & 221 \\
\hline & 7 & 11 & 82 & 56 \\
\hline \multirow{2}{*}{$\begin{array}{l}\text { Project reduces } \\
\text { GHGs emissions, } \\
\text { which contributes to } \\
\text { mitigate climate } \\
\text { change }\end{array}$} & 6 & 8 & 83 & 221 \\
\hline & 7 & 11 & 82 & 56 \\
\hline \multirow{2}{*}{$\begin{array}{l}\text { Project developed to } \\
\text { provide lower } \\
\text { electricity rate to }\end{array}$} & 6 & 11 & 83 & 215 \\
\hline & 9 & 15 & 76 & 55 \\
\hline
\end{tabular}




\begin{tabular}{|l|c|c|c|c|}
\hline $\begin{array}{l}\text { low income in } \\
\text { municipality }\end{array}$ & & & & \\
\hline $\begin{array}{l}\text { Project developed } \\
\text { instead of new fossil } \\
\text { fuel-based electricity } \\
\text { sources }\end{array}$ & 7 & 9 & 82 & 222 \\
\cline { 2 - 5 } & 9 & 14 & 77 & 56 \\
$\begin{array}{l}\text { Project creates an } \\
\text { increased tax base } \\
\text { for my municipality }\end{array}$ & 7 & 29 & 61 & 219 \\
\hline \multirow{2}{*}{\begin{tabular}{l} 
LEGEND \\
\cline { 2 - 5 }
\end{tabular}} & 9 & 20 & 71 & 56 \\
\cline { 2 - 5 } & \multicolumn{4}{|c|}{ Houghton County responses } \\
\hline
\end{tabular}

\subsubsection{Summary of Descriptive Statistics of Survey}

Support for solar energy is high and similar for Houghton and Non-Houghton Counties (> $70 \%)$, compared to wind $(<63 \%)$. Based on the response distribution in non-Houghton (other counties in WUP), more female population are expected to support RE development from solar and wind energy technologies. Such inference cannot be made of male members of the county due to high data skewness.

On installation preference, solar panels on degraded land such as landfills stands out as the most likely to be supported by residents across WUP. Project financing option with the highest support is municipally developed RE, either by private or public funding. Privately funded and owned projects by international or national companies would likely receive the most opposition in the WUP. Projects that provide jobs and other economic development benefits for the municipality and provide lower electricity rates for residents appears to be on the radar of what WUP residents would be more likely to support. This is true for both Houghton and non-Houghton Counties. 


\subsubsection{Regression Analysis of Factors Influencing Support}

Three hypotheses are drawn for this research. The hypotheses that are being tested in this research are;

H1. Support for $100 \%$ RE in WUP will be positively correlated with perceptions that RE has a positive impact on the environment

H2. Support for $100 \%$ RE will be positively correlated with perceptions that RE will result in possible reduction in electricity bill

H3. WUP residents' support for energy efficiency program to reduce electricity consumption is positively correlated with support for $100 \% \mathrm{RE}$ transition

A logistic regression was also carried out to see how much influence some of the factors have on support for each of solar and wind energy development in Houghton County. All the predictors (independent variables) are ordinal. In the case of energy consumption reduction, the Likert scale is from "I am likely to strongly oppose" to "I am likely to strongly support." The predictors are converted to binary variables by collapsing "likely to support" and "likely to strongly support" categories to equal likelihood (otherwise, Yes = 1). Then all "likely to oppose" and "likely to strongly oppose" are collapsed as unlikely (otherwise No $=0$ ), as a worst-case scenario of opposition. The model was run with individual predictors, rather than as an additive model.

Results show that in the case of support for both solar and wind, resident's consideration of fossil fuel reduction as an important factor in RE development is statistically significant at $p<.05$ (see Table 6). Also, their likelihood to participate in a municipally led initiative that would reduce their energy consumption reduction by $5 \%$ is statistically significant at $\mathrm{p}<0.05$, only in support for wind development. The probability of having support for solar energy increases by a factor of 4.092, 2.939, 3,270 and 2.486 (Beta coefficient) for importance of fossil fuel reduction, positive impact on environment, energy consumption reduction by $2 \%$, and energy consumption reduction by $5 \%$ respectively. The probability of having support for wind energy increases by a factor of 2.383 and 2.888 for importance of fossil fuel reduction and energy consumption reduction by $5 \%$ respectively. The importance of fossil fuel reduction increases this likelihood of residents' support for solar energy development by approximately $10 \%$, while consumption reduction by $5 \%$ increases the support likelihood by $18 \%$.

However, the likelihood to support solar energy development decreases with perceived importance of electricity bill reduction. The same decrease in support for solar is observed for consumption reduction by $10 \%$ and adjusting consumption to match RE. 
The Nagelkerke value, $\mathrm{R}^{2}$ for solar is approximately 0.8 , while that of wind is 0.4 . This shows that each of the independent variables are strong predictors of support for solar energy development, while being moderate for the wind energy development.

Table 6: logistic regression result

\begin{tabular}{|c|c|c|c|c|}
\hline \multirow{2}{*}{$\begin{array}{l}\text { Independent variable } \\
(\mathrm{Yes}=1, \text { No }(\text { dummy })=0)\end{array}$} & \multicolumn{2}{|c|}{ Solar $($ Yes $=1$, No $=0)$} & \multicolumn{2}{|c|}{ Wind $($ Yes $=1$, No $=0$ ) } \\
\hline & B & Sig. & B & Sig. \\
\hline $\begin{array}{l}\text { Importance of reduction in } \\
\text { electricity bill }\end{array}$ & -.886 & .918 & -1.665 & .356 \\
\hline $\begin{array}{l}\text { Importance of fossil fuel } \\
\text { reduction }\end{array}$ & 4.092 & $.027 *$ & 2.383 & $.032 *$ \\
\hline $\begin{array}{l}\text { Importance of utility } \\
\text { reputation }\end{array}$ & .320 & .970 & -.446 & .807 \\
\hline $\begin{array}{l}\text { Positive impact on } \\
\text { environment }\end{array}$ & 2.939 & .132 & .812 & .495 \\
\hline $\begin{array}{l}\text { Energy consumption } \\
\text { reduction by } 2 \%\end{array}$ & 3.270 & .226 & -.584 & .701 \\
\hline $\begin{array}{l}\text { Energy consumption } \\
\text { reduction by } 5 \%\end{array}$ & 2.486 & .386 & 2.888 & $.024 *$ \\
\hline $\begin{array}{l}\text { Energy consumption } \\
\text { reduction by } 10 \%\end{array}$ & -.503 & .780 & .490 & .561 \\
\hline $\begin{array}{l}\text { Adjusting consumption to } \\
\text { match RE }\end{array}$ & -.955 & .666 & -.688 & .527 \\
\hline Constant & -4.604 & .575 & -1.137 & .549 \\
\hline
\end{tabular}


${ }^{*} p<0.05$ Nagelkerke $\mathrm{R}^{2}=0.794$ (solar) and $\mathrm{R}^{2}=0.352$ (wind)

\subsubsection{Discussion}

Understanding the factors that will make residents more or less support 100\% RE is very important in the transition process. This is because the role of the public in terms of perceptions and acceptance is key to any sociotechnical transition [13]. Another reason is because public survey is one of the ways to garner public concern by subjecting plans and decisions to public acceptance. For instance, prior to the launching of a new product or technology to the society, universities, corporations, governments, or other organizations often sample public opinion through a survey or poll. The polls results are then put into consideration in their subsequent decision-making processes. The results from this research show that there is a positive relationship between public support for solar and wind energy development and if they consider fossil fuel reduction as an important factor in supporting such development. This positive relationship is also observed with support for energy consumption reduction by $2 \%$ and $5 \%$ to match demand with available resources.

The general low response rate across the WUP did not meet the research sample target for inferential statistics at 95\% C.L and 3.34\% margin error. While significant statistical inferences cannot be drawn for the WUP due to low response rate from the counties, analysis of results for Houghton County alone can provide a roadmap of what to expect. The reason is because the sample size obtained from the county meets the required sample size for a confidence level of $95 \%$. Houghton is the second most populous county in WUP alongside Delta county. The county also has the third highest population that are 18 years and above for participating in this research. Further, Houghton is a host to two Universities, MTU and Finlandia, as well as a community college, Gogebic Community College. These colleges employ residents from those counties in proximity as well as hosting businesses belonging to non-residents [50].

In general, the knowledge level on RE is low in both Houghton County and non-Houghton County. The perceived knowledge level obtained in the survey is presented in ranking form and in a way does not provide further information on the specific knowledge they have about each technology. A future interview of these residents can help to gauge their knowledge base on RE. Although approximately $80 \%$ of the respondents are in support of mid-to-large scale RE, there is a wide gap between support for solar and support for wind. It is, however, important to know what factors can make those in the neutral position to support or oppose these energy technologies.

With $81 \%$ of 220 respondents from Houghton County showing most support for privately funded projects as municipally owned projects, with residents having the choice to either purchase the generated electricity or not, this financing option ranks as the highest among 
others. This preference must be carefully considered in future 100\% RE planning. On the one hand, this could reflect interests in ensuring that there is a competitive energy market. On the other hand, this choice shows how residents embrace democratic processes in energy decision-making. Further, it aligns with the perspective of scholars working with the concepts of energy democracy, which is seen as a driver of a potential just energy transition to RE [51].

Beyond environmental reasons, the economic benefits of low carbon and RE technologies such as lower electricity prices may hinder resurgence of the coal industry. To gather support for $100 \%$ RE in Houghton, for instance, projects offering job opportunities and other economic benefits for residents will likely receive higher levels of support. In the same spectrum, lower electricity rates for individuals as a personal benefit and income benefits for local farmers are other factors that may attract residents' support. These three factors show the level of residents' expectations from their energy system. Therefore, projects that will most directly benefit members should be on the radar in planning for $100 \%$ RE transition in the WUP counties, especially Houghton county.

While a survey cannot replace the deeper forms of engagement such as community-based participatory research [52], it can serve as a foundation on which future energy planning in the community is built. For instance, some of the themes in the survey where likelihood of support is low can be used in building an agenda for focus group interview and discussion in future community engagement. Differences in RE technology preference for example can help in drawing important topics of deliberation with local leaders, stakeholders, and policymakers. Solar energy technology installation on corporate or industrial rooftop, which has the highest likelihood of support by residents in both Houghton and NonHoughton Counties, indicates the importance of including corporate stakeholders in future planning. While some scholars (e.g. [53]) have opined that the energy transition from coal will be easy with involvement of the community in the process, less attention is paid to the social dynamics involved in achieving such participation. Allowing public participation is to ensure that due process is followed in the planning and implementation processes. Such participation would make sure that community members or residents are given a fair share of any accompanying benefits and burdens from the RE project.

A survey of residents' perceptions can serve as a foundation to building and incorporating future public engagement. Some of the various techniques for engaging the public including survey, referenda, public hearing, negotiated rulemaking, consensus conference, citizen panel, public advisory committee, and focus groups. Common themes in opinion research from surveys of residents can be a guide for future focus groups meetings, and engagement with community members [35] [54]. The survey questionnaire and responses may therefore be useful in the preliminary stage of public recruitment for engagement in Houghton County and helps in identifying where more resources need to be directed. Other counties with lower responses would need more outreach in the future, perhaps at a postCOVID19 period when residents might be under less socioeconomic pressures that the pandemic has caused. 
The investigation of public perceptions, especially of residents and stakeholders as part of the socio-technical regime in socio-technical system transitions (STST), is a key component in the theory of socio-technical transition [13]. Understanding this perception can be combined with technical and policy analysis in leading a successful and procedurally just energy transition to RE.

\subsubsection{Conclusion}

This research shows some of the important factors that can influence WUP residents support for a $100 \%$ RE transition. Interest in positive impacts on the environment, fossil fuel reduction, and energy consumption reduction positively predict support for $100 \% \mathrm{RE}$ development. The impact of consumption reduction to meet renewable energy resources thus indicate potential for energy efficiency program acceptance in the studied area. Also, projects that lower individual electricity bills while offering other direct economic benefits for residents and possess other municipality benefits such as carpark shading and electric vehicle charging potential should be considered in the planning of RE development. Visibility of renewable energy technologies will likely not hinder public support of such a project.

While it may not be conclusive if these factors can be generalized for the whole WUP counties due to issues with the representativeness of samples, responses from Houghton County are sufficient to make inferences for the County. The online sampling frame used in this research may also present a weakness in terms of sampling bias, but this method presents the most available option for assessing public perceptions in this time of global pandemic of COVID 19, economic shutdowns, and disruptions in social economic activities. The response rate prevented the capability to conclude on how support differs from one county to another in the region. Nonetheless, the trend for Houghton County responses is similar to all responses from all the county participants, indicating that Houghton County residents do not have report different perceptions regarding support for various forms of RE and the siting and financial types that may be involved in RE development.

The survey in this research is intended to serve as a forerunner to an inclusive future participatory process for 100\% RE generation in the Western UP (WUP), a rural northern climate region in the state of Michigan. Future work should focus on increasing the response in surveying other counties in the WUP along with the questions raised in this survey to get more representative data. Such work would require ensuring that the samples are more randomly collected. Also, future community engaged research, especially with respect to $100 \%$ RE development in Houghton County and elsewhere, should leverage the analysis in this paper in drawing a roadmap for the process of community engaged explorations of a $100 \%$ RE transition.

In general, the methodology and survey instrument, which are used in this research can be scaled and adapted in studying similar places across the U.S. and in other contexts at the 
preliminary stage of just 100\% RE transition planning. As climate change discussion and the importance of STST in the electricity landscape increases, investigation of expectations and preferences of the larger public should be considered. Research on public perception in sociotechnical change such as this can be used as an integral part of public engagement. In the face of the twin climate change and current global pandemic, research approach in this paper offers a good option in gathering public perception to sociotechnical change.

\section{Appendix}

\section{Survey questionnaire for Western UP county residents (Survey Monkey)}

\section{How would you describe your current level of knowledge about each of the following renewable energy sources for electricity supply?}

\subsection{Solar energy}

I have very little knowledge about solar energy

I have a little knowledge about solar energy

I am knowledgeable about solar energy

I am very knowledgeable about solar energy

\subsection{Wind energy}

I have very little knowledge about wind energy

I have a little knowledge about wind energy

I am knowledgeable about wind energy

I am very knowledgeable about wind energy

\subsection{Hydro energy}

I have very little knowledge about hydro energy

I have a little knowledge about hydro energy

I am knowledgeable about hydro energy

I am very knowledgeable about hydro energy

2. Please indicate your level of agreement with the following: 


\begin{tabular}{|l|l|l|l|l|l|}
\hline & $\begin{array}{l}\text { Strongly } \\
\text { disagree }\end{array}$ & Disagree & Neutral & Agree & $\begin{array}{l}\text { Strongly } \\
\text { Agree }\end{array}$ \\
\hline $\begin{array}{l}\text { It is the responsibility of all } \\
\text { Americans to take action to } \\
\text { address climate change }\end{array}$ & 0 & 0 & 0 & 0 & 0 \\
\hline $\begin{array}{l}\text { Using renewable energy can } \\
\text { meaningfully address climate } \\
\text { change }\end{array}$ & 0 & 0 & 0 & 0 & 0 \\
\hline $\begin{array}{l}\text { Solar energy technology is } \\
\text { needed to meaningfully } \\
\text { address climate change }\end{array}$ & 0 & 0 & 0 & 0 & 0 \\
\hline $\begin{array}{l}\text { Wind energy technology is } \\
\text { needed to meaningfully } \\
\text { address climate change }\end{array}$ & 0 & 0 & 0 & 0 & 0 \\
\hline $\begin{array}{l}\text { Hydro energy technology is } \\
\text { needed to meaningfully } \\
\text { address climate change }\end{array}$ & 0 & 0 & 0 & 0 & 0 \\
\hline
\end{tabular}

3. Please indicate your level of agreement with the following:

\begin{tabular}{|l|l|l|l|l|l|}
\hline & $\begin{array}{l}\text { Strongly } \\
\text { disagree }\end{array}$ & Disagree & Neutral & Agree & $\begin{array}{l}\text { Strongly } \\
\text { Agree }\end{array}$ \\
\hline $\begin{array}{l}\text { I would be more likely to } \\
\text { support my municipality if I } \\
\text { knew they've invested in } \\
\text { renewable electricity }\end{array}$ & 0 & 0 & 0 & 0 & 0 \\
\hline
\end{tabular}




\begin{tabular}{|c|c|c|c|c|c|}
\hline $\begin{array}{l}\text { I think solar electricity is a } \\
\text { good investment for local } \\
\text { businesses }\end{array}$ & 0 & 0 & 0 & 0 & 0 \\
\hline $\begin{array}{l}\text { Solar electricity can } \\
\text { meaningfully contribute to } \\
\text { energy production for my } \\
\text { community }\end{array}$ & 0 & 0 & 0 & 0 & 0 \\
\hline $\begin{array}{l}\text { I think wind electricity is a } \\
\text { good investment for local } \\
\text { businesses }\end{array}$ & 0 & 0 & 0 & 0 & 0 \\
\hline $\begin{array}{l}\text { Wind electricity can } \\
\text { meaningfully contribute to } \\
\text { energy production for my } \\
\text { community }\end{array}$ & 0 & 0 & 0 & 0 & 0 \\
\hline $\begin{array}{l}\text { I think hydro electricity is a } \\
\text { good investment for local } \\
\text { businesses }\end{array}$ & 0 & 0 & 0 & 0 & 0 \\
\hline $\begin{array}{l}\text { Hydro electricity can } \\
\text { meaningfully contribute to } \\
\text { energy production for my } \\
\text { community }\end{array}$ & 0 & 0 & 0 & 0 & 0 \\
\hline $\begin{array}{l}\text { Hydro electricity is most } \\
\text { appropriate for commercial and } \\
\text { business scale settings }\end{array}$ & 0 & 0 & 0 & 0 & 0 \\
\hline
\end{tabular}

4. The following questions are about what you value when it comes to thinking about mid- to large- scale solar and wind energy development in your municipality. Generally speaking, do you support solar energy development in your community? 
YES

NO

5. When it comes to planning for $100 \%$ renewable electricity development projects in your community, please rate the following factors in terms of their importance to you:

\begin{tabular}{|c|c|c|c|c|c|}
\hline & $\begin{array}{l}\text { Not at all } \\
\text { Important }\end{array}$ & $\begin{array}{l}\text { Slightly } \\
\text { Important }\end{array}$ & $\begin{array}{l}\text { Moderately } \\
\text { Important }\end{array}$ & $\begin{array}{l}\text { Very } \\
\text { Important }\end{array}$ & $\begin{array}{l}\text { Extremely } \\
\text { Important }\end{array}$ \\
\hline $\begin{array}{l}\text { Reputation of } \\
\text { renewable energy } \\
\text { technology } \\
\text { developer }\end{array}$ & 0 & 0 & 0 & 0 & 0 \\
\hline $\begin{array}{l}\text { Reputation of my } \\
\text { utility company }\end{array}$ & 0 & 0 & 0 & 0 & 0 \\
\hline $\begin{array}{l}\text { Low cost of } \\
\text { installation }\end{array}$ & 0 & 0 & 0 & 0 & 0 \\
\hline $\begin{array}{l}\text { Reduction in my } \\
\text { electric bill }\end{array}$ & 0 & 0 & 0 & 0 & 0 \\
\hline $\begin{array}{l}\text { Positive impact on } \\
\text { the Environment }\end{array}$ & 0 & 0 & 0 & 0 & 0 \\
\hline $\begin{array}{l}\text { Leaving a positive } \\
\text { legacy for future } \\
\text { generations }\end{array}$ & 0 & 0 & 0 & 0 & 0 \\
\hline
\end{tabular}




\begin{tabular}{|l|l|l|l|l|l|}
\hline $\begin{array}{l}\text { Positive attitudes } \\
\text { towards solar } \\
\text { among my peers }\end{array}$ & 0 & 0 & 0 & 0 & 0 \\
\hline $\begin{array}{l}\text { Reduced } \\
\text { dependence on } \\
\text { imported fossil } \\
\text { fuels }\end{array}$ & 0 & 0 & 0 & 0 & 0 \\
\hline
\end{tabular}

6. According to Michigan Public Service Commission (MPSC) in its statewide energy assessment (SEA), energy efficiency is very important in ensuring resilience in grid services, limiting energy resource and electricity consumption, and leading to corresponding reduction in electricity expenses through changes in home devices (TV, refrigeration, washing machine etc.) to more efficient ones or involved in retrofitting. Energy efficiency can also facilitate meeting electricity demand with minimum renewable energy resources.

6.1 How more or less are you likely to participate in a municipality-led initiative that will reduce your electricity consumption of your home appliances by up to $10 \%$ of your current demand?

\subsubsection{Consumption reduction by $2 \%$}

More Likely

Less Likely

Not Likely

\subsubsection{Consumption reduction by $5 \%$}

More Likely

Less Likely

Not Likely

6.1.3 Consumption reduction by $10 \%$ 
More Likely

Less Likely

Not Likely

6.2 How likely are you to adjust your consumption pattern such as changing the time you perform some activities (e.g. laundry) to align with renewable electricity generation?

More Likely

Less Likely

Would support If I have more information on how it impact me

7. When it comes to renewable energy development in your county, which of the following would you identify as benefits/reasons you would support? (Please select ALL that apply)

- I believe RE technologies will provide economic benefits to me as a utility ratepayer

- I believe RE will decrease my electricity rates

- I believe RE will provide the economic benefit of jobs in my community

- I believe RE has local environmental benefits

- I believe RE has larger scale (regional to global) environmental benefits

- I believe RE has appealing or neutral aesthetic/visual impacts

- I believe RE has positive health impacts for me and/or my family

- None of the above

8. When it comes to RE development in your municipality/county, which of the following would you identify as the reasons you would not support? (Please select ALL that apply)

- I do not like the aesthetic/visual impacts of RE technologies

- I am concerned that RE technologies has negative and unacceptable health impacts 
- I am concerned that RE technologies has negative and unacceptable environmental impacts

- I am concerned that RE technologies is not a good economic investment

- I am concerned that RE development will increase my electricity rates

- I am concerned that the economic benefits of RE technologies are unfairly distributed

- I am concerned that RE will have a negative economic impact on me or my community

- None of the above

9. What kinds of renewable energy installation options would you support and how would your support change based on visibility from roads or homes in your community?

\begin{tabular}{|l|l|l|l|l|}
\hline & $\begin{array}{l}\text { Would } \\
\text { strongly } \\
\text { oppose if } \\
\text { they are } \\
\text { visible }\end{array}$ & $\begin{array}{l}\text { Would } \\
\text { oppose if } \\
\text { they are } \\
\text { visible }\end{array}$ & $\begin{array}{l}\text { Would } \\
\text { support } \\
\text { whether or } \\
\text { not they are } \\
\text { visible }\end{array}$ & $\begin{array}{l}\text { Would } \\
\text { strongly } \\
\text { support if } \\
\text { they are } \\
\text { visible }\end{array}$ \\
\hline $\begin{array}{l}\text { Ground mounted solar } \\
\text { panels }\end{array}$ & & & & \\
\hline $\begin{array}{l}\text { Ground mounted solar } \\
\text { panels on previously } \\
\text { degraded lands such as } \\
\text { landfills }\end{array}$ & & & & \\
\hline $\begin{array}{l}\text { Ground mounted solar } \\
\text { panels in areas that were } \\
\text { previously cleared for } \\
\text { development purposes }\end{array}$ & & & & \\
\hline
\end{tabular}




\begin{tabular}{|l|l|l|l|l|}
\hline $\begin{array}{l}\text { Solar panels mounted on } \\
\text { commercial or industrial } \\
\text { rooftops }\end{array}$ & & & & \\
\hline $\begin{array}{l}\text { Solar panels shading } \\
\text { parking lots and parking } \\
\text { garages }\end{array}$ & & & & \\
\hline $\begin{array}{l}\text { Onshore wind turbine } \\
\text { installation }\end{array}$ & & & & \\
\hline $\begin{array}{l}\text { Offshore wind turbine } \\
\text { installation }\end{array}$ & & & & \\
\hline
\end{tabular}

\section{Financing renewable energy development such as solar, hydro and wind can involve different financial models.}

* Private developers or property owners can fund the project, own the system, and receive the return on investment.

* Local governments can also invest in the renewable energy project with public funds and the return on investment can become part of the municipality's public funds.

* A "community renewable energy" development project allows members of the community to invest in renewable electricity production that is built locally.

If renewable energy development were to occur in your community, what kind of financial model would you prefer? Please indicate your level of support: 


\begin{tabular}{|l|l|l|l|l|}
\hline & $\begin{array}{l}\text { Do not } \\
\text { support }\end{array}$ & $\begin{array}{l}\text { Less } \\
\text { likely to } \\
\text { support }\end{array}$ & $\begin{array}{l}\text { More } \\
\text { likely to } \\
\text { support }\end{array}$ & $\begin{array}{l}\text { Most } \\
\text { likely to } \\
\text { support }\end{array}$ \\
\hline $\begin{array}{l}\text { Public financing, using public funds for } \\
\text { projects on public buildings in your } \\
\text { community }\end{array}$ & & & & \\
\hline $\begin{array}{l}\text { Privately funded projects built by local } \\
\text { companies, with the electricity } \\
\text { generated purchased by the utility }\end{array}$ & & & & \\
\hline $\begin{array}{l}\text { Privately funded projects built by } \\
\text { national or international companies, } \\
\begin{array}{l}\text { with the electricity generated purchased } \\
\text { by the utility }\end{array}\end{array}$ & & & & \\
\hline $\begin{array}{l}\text { Privately funded projects developed as } \\
\text { community renewable energy systems, } \\
\text { where individual utility customers like } \\
\text { yourself can elect to purchase the } \\
\text { electricity generated }\end{array}$ & & & & \\
\hline $\begin{array}{l}\text { Publicly funded projects developed as } \\
\text { community renewable energy systems, } \\
\text { where individual utility customers like } \\
\text { yourself can elect to purchase the } \\
\text { electricity generated }\end{array}$ & & & & \\
\hline $\begin{array}{l}\text { Privately funded projects on private } \\
\text { property, with the electricity generated } \\
\text { going primarily to the property owner. }\end{array}$ & & & & \\
\hline
\end{tabular}

11. Renewable energy (solar and wind) development projects involve a series of choices. For the choices below, please indicate which of the following you would be LESS and MORE likely to support. If solar development were to occur in your community, would these factors change your support for the project? 


\begin{tabular}{|l|l|l|l|}
\hline & $\begin{array}{l}\text { Less } \\
\text { likely to } \\
\text { support }\end{array}$ & $\begin{array}{l}\text { More } \\
\text { likely to } \\
\text { support }\end{array}$ & $\begin{array}{l}\text { Would not } \\
\text { support if ANY } \\
\text { tree removal is } \\
\text { required }\end{array}$ \\
\hline $\begin{array}{l}\text { The project is developed with mixed-use } \\
\text { in mind, for example, carport parking that } \\
\text { also has a rooftop solar system, electric } \\
\text { vehicle charging station, etc. }\end{array}$ & & & \\
\hline $\begin{array}{l}\text { The project is sited so that it provides a } \\
\text { supplemental income for farmers in my } \\
\text { municipality }\end{array}$ & & & \\
\hline $\begin{array}{l}\text { The project is designed to provide lower } \\
\text { electricity rates to low income households } \\
\text { in my community }\end{array}$ & & & \\
\hline $\begin{array}{l}\text { The project provides jobs and other forms } \\
\text { of economic development in my } \\
\text { community }\end{array}$ & & & \\
\hline $\begin{array}{l}\text { The project is designed to provide lower } \\
\text { electricity rates to schools in my } \\
\text { community }\end{array}$ & & & \\
\hline $\begin{array}{l}\text { The project provides lower electricity } \\
\text { rates for me personally }\end{array}$ & & & \\
\hline $\begin{array}{l}\text { The project provides a way for me to } \\
\text { renewable energy resources }\end{array}$ & & & \\
\hline
\end{tabular}




\begin{tabular}{|l|l|l|l|}
\hline $\begin{array}{l}\text { The project creates an increased tax base } \\
\text { for my community }\end{array}$ & & & \\
\hline $\begin{array}{l}\text { The project reduces greenhouse gas } \\
\text { emissions, which contributes to mitigating } \\
\text { climate change }\end{array}$ & & & \\
\hline $\begin{array}{l}\text { The project is developed INSTEAD of } \\
\text { putting light industrial development on } \\
\text { that site }\end{array}$ & & & \\
\hline $\begin{array}{l}\text { The project is developed INSTEAD of } \\
\text { putting a commercial building or strip } \\
\text { mall on that site }\end{array}$ & & & \\
\hline $\begin{array}{l}\text { The project is developed INSTEAD of } \\
\text { putting a new housing development on } \\
\text { that site }\end{array}$ & & & \\
\hline $\begin{array}{l}\text { The project is developed INSTEAD of } \\
\text { developing new fossil fuel based } \\
\text { electricity resources }\end{array}$ & & & \\
\hline
\end{tabular}

13. Demographic information. Please complete the following questions to provide some demographic data about yourself. Please remember that this information is completely voluntary and confidential.

\subsection{Which in Western UP county is your primary place of residence located?}

Baraga__ Delta__ Dickson_

Gogebic__ Houghton__ Iron_

Keweenaw__ Marquette__ Menominee

Ontonagon_ "Others"

\subsection{What is your age?}


$18-29$ years

30-39 years

40-49 years

50-59 years

60-69 years

70 years or older

Prefer not to answer

\subsection{What is your gender?}

Male

Female

Other

Prefer not to answer

\subsection{What is your education level?}

No high school diploma or GED

High school diploma or GED

Associates Degree

Bachelors Degree

Masters Degree

Doctoral Degree

Prefer not to answer

13.5 What is your total annual household income range?

$\$ 0$ to $\$ 50,000$

$\$ 50,000$ to $\$ 100,000$ 
$\$ 100,000$ to $\$ 200,000$

$\$ 200,000$ to $\$ 300,000$

$\$ 300,000$ to $\$ 400,000$

$\$ 400,000$ to $\$ 500,000$

Above $\$ 500,000$

Prefer not to answer

13.6 What best describes your race (choose all that apply)?

White

Black or African American

Asian

American Indian or Alaska Native

Native Hawaiian or Other Pacific Islander

Other

Prefer not to answer

\subsection{Are you Hispanic or Latino?}

No

Yes

Prefer not to answer

13.8 What is your political affiliation?

Democrat

Republican

Other 
Prefer not to answer

14. Please provide a phone number/email address that can be contacted if you won the draw for $\$ 100$ gift card

THANK YOU for taking the time to complete this survey!

\section{Acknowledgement}

Special thanks to Chelsea Schelly of MTU for helping in proofreading and providing very useful feedback for this article. I would also like to appreciate the effort of Zoe Reep, from MTU, for helping out with survey information distribution in various WUP counties. The suggestions given by Mark Rouleau (also from MTU) on statistical analysis is also appreciated.

\section{Funding}

This research is partially funded by the Great Lakes Research Center, MTU, and Michigan Indigenous Community and Anishinaabe Renewable Energy Sovereignty (MICARES) research group.

\section{References}

[1] Kumar S, Managi S. Energy price-induced and exogenous technological change: Assessing the economic and environmental outcomes. Resour Energy Econ 2009;31:334-53. https://doi.org/10.1016/j.reseneeco.2009.05.001.

[2] Goldstein A, Doblinger C, Baker E, Anadón LD. Patenting and business outcomes for cleantech startups funded by the Advanced Research Projects Agency-Energy. Nat Energy 2020;5. https://doi.org/10.1038/s41560-020-00683-8.

[3] Stephens JC, Wilson EJ, Peterson TR. Socio-Political Evaluation of Energy Deployment (SPEED): An integrated research framework analyzing energy technology deployment. Technol Forecast Soc Change 2008;75:1224-46. https://doi.org/10.1016/j.techfore.2007.12.003.

[4] Wolsink M. Invalid theory impedes our understanding: A critique on the persistence of the language of NIMBY. Trans Inst Br Geogr 2006;31:85-91. https://doi.org/10.1111/j.1475-5661.2006.00191.x.

[5] Wolsink M. Wind power and the NIMBY-myth: Institutional capacity and the limited significance of public support. Renew Energy 2000;21:49-64. https://doi.org/10.1016/S0960-1481(99)00130-5.

[6] Geels FW, Schot J. Typology of sociotechnical transition pathways. Res Policy 
2007;36:399-417. https://doi.org/10.1016/j.respol.2007.01.003.

[7] Adesanya, Adewale A.; Sommerfeldt, Nelson; Pearce JM. Achieving 100\%

Renewable and Self-Sufficient Electricity in Impoverished, Rural, Northern

Climates: Case Studies from Western Upper Michigan, USA. Under Rev 2020.

[8] Carlisle, J. E., Kane, S. L., Solan, D., \& Joe JC. Support for solar energy:

examining sense of place and utility-scale development in California. Energy Res Soc Sci 2014;3:124-130.

[9] Schelly C, Price J, Delach A, Thapaliya R, Leu K. Improving solar development policy and planning through stakeholder engagement: The Long Island Solar Roadmap Project. Electr J 2019;32:106678. https://doi.org/10.1016/j.tej.2019.106678.

[10] Geels FW, Kemp R. Dynamics in socio-technical systems: Typology of change processes and contrasting case studies. Technol Soc 2007;29:441-55. https://doi.org/10.1016/j.techsoc.2007.08.009.

[11] Geels IFW. The dynamics of transitions in socio-technical systems: A multi-level analysis of the transition pathway from horse-drawn carriages to automobiles (1860-1930). Technol Anal Strateg Manag 2005;17:445-76. https://doi.org/10.1080/09537320500357319.

[12] Geels FW. Technological Forecasting \& Social Change Micro-foundations of the multi-level perspective on socio-technical transitions : Developing a multidimensional model of agency through crossovers between social constructivism , evolutionary economics and neo- i. Technol Forecast Soc Chang 2020;152:119894. https://doi.org/10.1016/j.techfore.2019.119894.

[13] Geels FW. Energy Research \& Social Science Disruption and low-carbon system transformation : Progress and new challenges in socio-technical transitions research and the Multi-Level Perspective. Energy Res Soc Sci 2018;37:224-31. https://doi.org/10.1016/j.erss.2017.10.010.

[14] Geels FW. From sectoral systems of innovation to socio-technical systems: Insights about dynamics and change from sociology and institutional theory. Res Policy 2004;33:897-920. https://doi.org/10.1016/j.respol.2004.01.015.

[15] Boudet HS. Public perceptions of and responses to new energy technologies. Nat Energy 2019;4:446-55.

[16] Diesendorf, Mark; Elliston B. The feasibility of 100\% renewable electricity systems: A response to critics. Renew Sustain Energy Rev 2018;93:318-30.

[17] Becker S, Frew BA, Andresen GB, Zeyer T, Schramm S, Greiner M, et al. Features of a fully renewable US electricity system: Optimized mixes of wind and solar PV and transmission grid extensions. Energy 2014;72:443-58. https://doi.org/10.1016/j.energy.2014.05.067.

[18] Hart EK, Jacobson MZ. A Monte Carlo approach to generator portfolio planning and carbon emissions assessments of systems with large penetrations of variable renewables. Renew Energy 2011;36:2278-86. https://doi.org/10.1016/j.renene.2011.01.015.

[19] Prehoda E, Winkler R, Schelly C. Putting research to action: Integrating 
collaborative governance and community-engaged research for community solar. Soc Sci 2019;8. https://doi.org/10.3390/socsci8010011.

[20] Swofford J, Slattery M. Public attitudes of wind energy in Texas: Local communities in close proximity to wind farms and their effect on decision-making. Energy Policy 2010;38:2508-19. https://doi.org/10.1016/j.enpol.2009.12.046.

[21] Adesanya AA, Sidortsov R V., Schelly C. Act locally, transition globally: Grassroots resilience, local politics, and five municipalities in the United States with 100\% renewable electricity. Energy Res Soc Sci 2020;67. https://doi.org/10.1016/j.erss.2020.101579.

[22] Hess DJ, Gentry H. 100\% renewable energy policies in U.S. cities: strategies, recommendations, and implementation challenges. Sustain Sci Pract Policy 2019;15:45-61. https://doi.org/10.1080/15487733.2019.1665841.

[23] Hayley Martinez B, DeFrancia K, Schroder A. Moving Towards 100\% Renewable Energy: Drivers Behind City Policies and Pledges. 76 Th Annu Midwest Polit Sci Assoc Conf 2018.

[24] Sierra Club. 100 U.S. Cities are Committed to 100 Percent Clean, Renewable Energy | Sierra Club 2018. https://www.sierraclub.org/press-releases/2019/03/100us-cities-are-committed-100-percent-clean-renewable-energy.

[25] Sierra-Club. 100 Percent Clean Energy: The New Normal. n.d. https://www.sierraclub.org/articles/2019/05/100-percent-clean-energy-new-normal (accessed August 15, 2019).

[26] National League of Cities. Number of Municipal Governments and Population Distribution 2007. https://www.nlc.org/number-of-municipal-governmentspopulation-distribution (accessed September 26, 2020).

[27] Petrova MA. NIMBYism revisited: Public acceptance of wind energy in the United States. Wiley Interdiscip Rev Clim Chang 2013;4:575-601. https://doi.org/10.1002/wcc.250.

[28] Delucchi, Mark A.; Jacobson MZ. Providing all global energy with wind, water, and solar power, Part II: Reliability, system and transmission costs, and policies. Energy Policy 2011;39:1170-90.

[29] Rey-Hernández JM, Yousif C, Gatt D, Velasco-Gómez E, San José-Alonso J, ReyMartínez FJ. Modelling the long-term effect of climate change on a zero energy and carbon dioxide building through energy efficiency and renewables. Energy Build 2018;174:85-96. https://doi.org/10.1016/j.enbuild.2018.06.006.

[30] Elliott D. Energy efficiency and renewables. Energy Environ 2004;15:1099-105. https://doi.org/10.1260/0958305043026636.

[31] MPSC. MPSC approves part of DTE Electric Co.' s renewable energy plan, delays decision on future wind projects to company IRP 2019. https://www.michigan.gov/mpsc/0,9535,7-395-93307_93313_17280-502194-,00.html (accessed July 17, 2020).

[32] Devine-Wright P, Howes Y. Disruption to place attachment and the protection of restorative environments: A wind energy case study. J Environ Psychol 2010;30:271-80. https://doi.org/10.1016/j.jenvp.2010.01.008. 
[33] Haggett C. Understanding public responses to offsore wind power. Energy Policy 2011;39:503-10.

[34] Liu L, Walchale A. 100 percent Renewable Electricity Plan for Leelanau County, Michigan by 2019.

[35] Jami AAN, Walsh PR. The role of public participation in identifying stakeholder synergies in wind power project development: The case study of Ontario, Canada. Renew Energy 2014;68:194-202. https://doi.org/10.1016/j.renene.2014.02.004.

[36] Ikejemba, E. C., Schuur, P. C., Van Hillegersberg, J., \& Mpuan PB. Failures \& generic recommendations towards the sustainable management of renewable energy projects in Sub-Saharan Africa (Part 2 of 2). ,. Renew Energy 2017;113:639-47.

[37] Enevoldsen, P., \& Sovacool BK. Examining the social acceptance of wind energy: Practical guidelines for onshore wind project development in France. Renew Sustain Energy Rev 2016;53:178-84.

[38] Winkler R, Oikarinen L, Simpson H, Michaelson M, Gonzalez MS. Boom, bust and beyond: Arts and sustainability in Calumet, Michigan. Sustain 2016;8. https://doi.org/10.3390/su8030284.

[39] Winkler R. Living on Lakes: Segregated Communities and Inequality in a Natural Amenity Destination. Sociol Q 2013;54:105-29. https://doi.org/10.1111/tsq.12002.

[40] Dunn, K., Jhaveri, K., Lin, K., Michalski, J., Rego B. SUN POWER: Examining the Costs and Benefits pf Community Solar in the Keweenaw Bay Region of Michigan's Upper Peninsula. University of Michigan, 2018. https://doi.org/10.1017/CBO9781107415324.004.

[41] Prehoda E, Pearce JM, Schelly C. Policies to overcome barriers for renewable energy distributed generation: A case study of utility structure and regulatory regimes in Michigan. Energies 2019;12. https://doi.org/10.3390/en12040674.

[42] State of Michigan. Executive Order 2019-14 UP Energy Task Force 2019. https://content.govdelivery.com/attachments/MIEOG/2019/06/07/file_attachments/ 1226627/EO 2019-14 UP Energy Task Force .pdf.

[43] State of Michigan. State of Michigan Executive Directive; No.2020-10; Re: Building a Carbon Neutral Michigan. 2020.

[44] Western Upper Peninsula Planning \& Development Region. Community Solar Planning 2017. https://www.wuppdr.org/regional-planning/community-solarplanning/ (accessed September 1, 2019).

[45] Barnett, B., Prehoda, E. W., Kantamneni, A., Winkler, R. L., \& Schelly C. Applying transdisciplinary research to enhance low-to-moderate income households' access to community solar. In A Research Agenda for Environmental Management. Edward Elgar Publishing; 2019.

[46] Glisa. Western Upper Michigan 2020. http://glisa.umich.edu/division/mi01 (accessed April 17, 2020).

[47] Social Explorer. U.S. Census n.d. https://www.socialexplorer.com/profiles/essential-report/houghton-countymichigan.html (accessed March 21, 2020). 
[48] Ferrarini, Tawni Hunt, Cohodas SM. Community and Economic Profiles for Michigan 's Upper Peninsula. 2015.

[49] Dillman, Don A., Jolene D. Smyth and LMC. Internet, phone, mail, and mixedmode surveys: the tailored design method. John Wiley \& Sons; 2014.

[50] Backon MR, Foltz P. CITY OF HOUGHTON 2019.

[51] Burke MJ, Stephens JC. Political power and renewable energy futures: A critical review. Energy Res Soc Sci 2018;35:78-93. https://doi.org/10.1016/j.erss.2017.10.018.

[52] Kantamneni, A., Winkler, R. L., \& Calvert K (2019). Incorporating community: opportunities and challenges in community engaged research. A Res. Agenda Environ. Manag., Edward Elgar Publishing.; 2019.

[53] Carley S, Evans TP, Konisky DM. Energy Research \& Social Science Adaptation , culture, and the energy transition in American coal country. Energy Res Soc Sci 2018;37:133-9. https://doi.org/10.1016/j.erss.2017.10.007.

[54] State of Victoria D of S and E. Effective Engagement: building relationships with community and other stakeholders; Book 3 the engagement toolkit. Melbourne: The Community Engagement Network, Resource and Regional Services Division; 2005. https://doi.org/10.1057/9781137412942.0034. 


\title{
5 Promoting Policies for Renewable Electrification
}

\author{
Adewale Aremu Adesanya and Chelsea Schelly. Environmental and Energy Policy \\ Program, Department of Social Sciences, Michigan Technological University, Houghton, \\ Michigan, U.S.A.
}

\subsection{Definition}

Promoting policies for renewable electricity provides insights into ways to advance energy and climate policies that promote the provision of clean, affordable, and reliable electricity while simultaneously promoting social justice. It builds upon the concept of Sustainable Development Goal 7 (SDG 7) as set up by the United Nations. Some current and future policy pathways are considered as potential tools to promote renewable electricity adoption at different scales.

\subsection{Introduction}

Policy serves as one of the important platforms and channels for many societal changes. In the same vein, the global quest for renewable electricity for sustainable development cannot thrive in the absence of local, state, national and transnational policies that can promote it. This is evident from the lingering problematic human activities contributing to climate change, which has seen a spectrum of reactions across the world. For instance, the call for immediate action on climate change by the Intergovernmental Panel on Climate Change (IPCC) dates as far back as 1995 based on robust scientific evidence on the impending danger (Unruh 2000). However, about three decades later, nothing significant has been done to mitigate this change and its effect through strong policies supporting a transition from carbon-based technologies.

This assertion is evident with the recent call (or renewed call) for immediate action during the 25th conference of the parties (COP25) in Madrid, Spain in 2019 (European Commission 2019; World Federation of Engineering Organizations 2019). If the current scientific claim is true that the world has until 2030 to limit global warming below 2 degrees, then the world may not survive another three decades under the current energy scenario. Deliberate actions at multiple levels of governments is necessary for combating climate change to avoid the impending global catastrophe.

At a global level, inconsistent policies to expedite climate change mitigation has been a major setback. The world has seen diverse policy tools deployed by different countries to make small but incremental success towards transitioning from a carbon dominated energy system to a less carbon intensive energy regime. Some of the most common policies for promoting renewable electrification include renewable portfolio standards (RPS), netmetering, feed in tariffs (FiT) and implementation of distribution generation (DG). 
Commendably, these policies have been instrumental to the small but incremental success towards achieving renewable electrification.

This paper reviews different policies that have been instrumental to the adoption of renewable electricity. Section Two gives a brief background on one of the seventeen sustainable development goals (SDG) of the United Nations; specifically, SDG7 and its interconnection with renewable electrification is presented. Section Three provides some short definitions and an analysis of policies used to promote renewable electricity in many global countries based on existing literature. Policy mechanisms, including market, regulation, and incentives are presented in section Four, while a summary of this review is presented in the concluding section Five.

\subsection{Sustainable Development and Renewable Electrification}

The United Nations (UN) is playing a leading role to steer the world toward the path of sustainable development. One example is the agenda 7 of the Sustainable Development Goals (SDG7), targeted at ensuring access to affordable, reliable, sustainable, and modern energy for everyone (United Nations). SDG7 is one of the seventeen agenda goals that was set by the UN Member States in 2015 as an urgent call for global actions towards sustainable development. Country adoption of the SDG7 is also geared toward simultaneous reduction of carbon dioxide $\left(\mathrm{CO}_{2}\right)$ emission and global warming.

A recent report from the International Energy Agency (IEA) reveals stagnation in global $\mathrm{CO}_{2}$ emissions in the year 2019, relative to year 2018, while economic growth increased by 3\% for this time (IEA 2020; MIT Technology Review 2020). The cause of these emissions according to the report is partly due to a rise in the share of renewables in U.S. and EU electricity consumption. Meanwhile, the U.S. is one of the biggest emitters of $\mathrm{CO} 2$ in the world due to its highly carbon-based economy. The U.S. and part of the EU accounts for approximately 70 percent of carbon build up in the atmosphere (Sovacool et al. 2016). Achieving such emission stagnation under the current scenario, which is dominated by coal, oil, and natural gas power plants, is an indication that much more can be achieved through policy that promotes renewable electrification, both in high-income and lowincome country contexts.

The energy transition to renewable energy for electricity supply is one reputable way to achieve sustainable development goal seven (SDG7) for access to clean, affordable energy. Heating and electricity sector's share in global emissions is 25 percent, representing the highest contributions (EPA-a 2019). The energy transition from fossil fuel towards renewable energy (RE) is increasing in energy policy agenda, aimed at low-carbon future (Koirala et al. 2016). RE includes solar, wind, hydro, geothermal, and recently battery storage, among others. For instance, solar energy, with its zero-emission energy 
production, noiseless property, and global application, offers one viable solution to the challenges of reducing GHG emission in combating global warming (Moosavian et al. 2013). The proliferation of these technologies is subject to current and future policy design.

One of the complexities of having the right energy policy framework is because of its double-edged requirements. While in some places more energy is needed for emancipating socioeconomic situations of the people, less energy is needed in other places to reduce climate impact (Sovacool et al. 2016). Thus, the onus lies with promoting the right policy that is unique to each context in promoting access to modern, affordable and clean electricity.

\subsection{Sustainable Electrification and Energy Justice Nexus}

Sustainability, as defined by Robert et al. (2012), entails meeting present society's needs without depriving the future generations' ability to replicate the same. The implicit objective in that definition is to ensure inter-generational equity and justice in access to resources and livelihood. In the context of justice and equity in energy resource access and use, the emerging concept of energy justice has provided a good platform for such discourse (Sovacool et al. 2016; Heffron et al. 2015; Sovacool et al. 2014).

To encourage social justice through energy justice, transitioning to sustainable energy resources for electrical energy services is one option. There are eight frameworks of energy for decision-making as given by Sovacool and Dworkin (2015). The frameworks are availability, affordability, intergenerational and intragenerational equity, responsibility, sustainability, good governance, and due process. Their description of availability is that which relates to having guaranteed sufficient energy resources when needed at different scales (local, national and regional). This is the most basic element of their energy justice framework. Affordability includes having energy prices that do not burden consumers or disallowed them from utilizing other essentials of life.

In both intergenerational and intragenerational equity frameworks, all people, born and unborn, possess the right to fairly access energy services. More so, the damage caused by today's energy generation and consumption is expected to affect the functioning of future generation. The responsibility and sustainability frameworks stipulate that all entities take accountability for the protection of nature and the environment including the sources of energy; they are targeted towards limiting energy resource depletion. The remaining two energy justice frameworks of Sovacool and Dworkin (2015), good governance and the due process, are premised on equity in access to quality information as well as fairness of participation in energy decision making processes.

These eight energy justice frameworks clearly show the intersectionality of what SDG7 is geared towards achieving. This is also evident in many renewable energy policies across the globe, especially in increasing energy access, making energy more affordable, and 
tackling associated environmental and climate change challenges. In addition, evolving policies for sustainable electrification are drawing on more local participation in decisionmaking processes.

The more individuals and local communities have control in energy decision-making, the better they are able to draw up solutions that align with their needs. This can enhance community energy sovereignty, allowing people to internalize energy problems and solutions. Schelly at al. (2020) describes energy sovereignty as one of the missing links to electricity decarbonization policies, which fosters community and individual level decisions about energy system adoption. The authors argue that this concept is embedded in human rights. There is thus some overlap in energy justice, policies to promote renewable electrification, and energy sovereignty with regards to the importance of local decision-making participation.

\subsection{Most Effective Renewable Energy Policies}

Unruh (2002) identifies three policy approaches to disrupting the current carbon-based energy system as 1) treating emissions and leaving the systems as is (end of pipe), 2) modifying selected components and processes but allowing existing architecture (continuous), and 3) complete overhauling of the system, discontinuous (transition or transformation). The combination of the first two approaches appears more common, especially as climate change and fossil fuel technologies are concerned. Nation states are still very much reluctant to adopt an energy system that entirely replaces the incumbents, which are carbon based. In the U.S., two policy approaches that are geared towards supporting renewable energy deployment are the 2015 Clean Power Plan (CPP) and the Clean Air Act (CAA) (Wiseman and Osofsky 2016).

The CPP is one of the environmental regulations at federal level in the U.S. geared towards limiting $\mathrm{CO}_{2}$ emission as a voluntary commitment to the 2015 Paris Agreement (Wiseman and Osofsky 2016). The CPP, which integrates states and regional cooperative action on emissions, aimed at achieving 68 percent $\mathrm{CO}_{2}$ emission reduction of 2005 levels through transition from coal-based technologies to RE and natural gas (Wiseman and Osofsky 2016). While the CPP, which is an example of discontinuous policy approach, is geared towards technology substitution, the CAA is an empirical case for a continuous approach, targeted at ensuring installations of pollutant removal technology in power plants already in use.

In this section, some common policies that have been used to promote renewable electricity are reviewed. These include distributed generation implementation, net-metering policies, feed-in tariffs (FiT), renewable portfolio standard (RPS), and renewable energy credit (REC) (Moosavian et al. 2013). Others include subsidies, and tax exemptions, which are some of the ways that RE is being promoted. In the U.S., some other state environmental laws applicable to the electricity sector include $\mathrm{CO}_{2}$ emission performance standards, 
energy efficiency (EE) policies, and state bans on new coal fired generation, and (Klass and Wiseman 2017).

\subsubsection{Distributed Generation}

Distributed generation is described as technology that generates electricity in proximity to or at the same location of downstream users (Prehoda et al. 2019). Distributed energy systems are increasing in the global energy system, especially through smart grids systems and enhancement of local energy control (Koirala et al. 2016). Challenges with utility scaled conventional energy such as thermal power plants from natural gas, coal, etc., is the demand for water resources required to produce steam for turbine and generate electricity as well as proximity to fuel delivery infrastructures, e.g. railroad and pipeline (Klass and Wiseman 2017). The use of water resources does not only compete with water usage by the people but also creates potential for release of toxic substances to the water bodies where the power plants are sited. Water impacts is just one of many reasons why renewable energy systems employed through implementation of distributed generation are desirable when compared to the incumbent energy regime dominated by fossil fuel use.

Some factors that contribute to the evolution of DG are increasing concern about climate change, constraints on new transmission line construction, increasing demand for reliable electricity, electricity market liberalization, and development of suitable technologies for the purpose (Pepermans et al. 2003). These technologies, such as RE, have the flexibility of being deployed at different scales. Distributed energy systems are synonymous to distributed power and so, decentralization of energy systems leads to decentralized politics and power in society (Burke and Stephens 2018). Such power is related to the ability of the people to make choices from among the many alternatives. This potentially leads to competitive electricity markets and by implication, lower electricity prices. More so, DG has been known to foster energy ownership. The case of Germany, with customers owning more than 50 percent of DG through RE, is one example (Anaya and Pollitt 2015)

Despite the numerous potential benefits of DG, certain challenges arise. One of such is the excessive proliferation of DG could suffer high financial cost and environmental issues from emission of numerous generators (Pepermans et al. 2003). These burdens are however, only related to DG with conventional power plants as reported by the authors. RE power plants are therefore positioned to be more advantageous and desirable in this regard. On that note, more policy design for DG with RE resources would better promote renewable electricity. Developing countries, where energy ownership and access are very low would need more strategic policies for DG.

\subsubsection{Net-metering}

Net-metering is a simple accounting system that is used to incentivize energy "prosumers" (Schelly et al. 2017). Prosumer is a term used to describe individuals that generate 
electricity, both for self-use and sales of excess to the grid (Schelly et al. 2017), facilitated by distributed generation policy (CRS Report, 2019). This policy is a major driver of solar PV technology adoption because it provides economic benefits for investment. Not less than 40 U.S. states deploy net-metering to support "prosumers" with distributed generation ranging from $10 \mathrm{~kW}$ to MW of electricity (Klass and Wiseman 2017) with about two million customer subscribers as of 2018 (CRS Report 2019).

The working principle of net-metering, which is widely used in North America and some European countries, allows utilization of a bi-directional meter that reads and records inflow and outflow of energy (Poullikkas and Kourtis 2013). This allows prosumer's excess electricity generation to be purchased by the grid operator or electric utility. Payment for prosumer's excess electricity is usually done based on a benchmarked wholesale electricity price (Jacobs and Sovacool 2012).

Although this policy is not without some challenges, most can be resolved with further enabling policies. Lack of transparency within the net metering compensation schemes provided by electric utilities has been reported as one limitation to correct compensation for distributed generation with the net-metering (Schelly et al. 2017). This can hinder widespread adoption of such programs and its benefits for customers interested in electric generation participation. Information is very key for investment capital intensive RE technology. In the context of the U.S., Schelly et al. (2017) reveals that net-metering, which is expected to be a one-to-one exchange between utility and prosumers as an incentive to DG development, is not reflected in existing policy. The inconsistency in net-metering policy is across many states in the U.S.

Further, there has been uproar that net-metering policies create overpayments to customers. The argument is that customers generating and selling to the grid at retail rates is in excess to some associated cost that the utility rates covers, including maintenance, building, and transmission and distribution system operation costs (CRS Report 2019). However, some other alternative compensations provided in that report, shows that DG would still be more economically attractive with lessened compensation through net-metering, especially if payments are based on combination of avoided cost (only cost of production) and value of solar (social cost of energy, e.g. emissions savings).

\subsubsection{Feed-in Tariff}

A feed-in tariff (FiT) is defined as a scheme that provides a guaranteed premium price and return on investment for renewable electricity producers in a country through purchase obligation on their grid operators (Poullikkas and Kourtis 2013). The main difference with net-metering and FiT is that while the formal usually applies to individual persons with grid connection to low capacity energy generators, the latter applies most to larger corporate renewable energy generators or facilities. A RE qualifying facility may include wind, solar, small hydro, and sometimes biomass. Mandatory electricity purchases from an 
independent power producer gives assurance to investors and can encourage both local and foreign energy investments.

In many countries, a FiT has been very significant in promoting renewable energy. In Germany, for instance, where more than 50 percent of the total RE portfolio is owned by citizens and local farmers, FiT has served as a stimulus (Koirala et al. 2016). Priority dispatch for renewable electricity producers, also known as erneuerbare energie gezets (EEG), characterized the country's FiT program. In other countries such as Nigeria, FiT policy serves as a barrier breaker towards full utilization of RE resources for power generation (Adesanya and Schelly 2019).

One of the challenges of FiT is that its success is largely contingent on a high degree of investment security (Jacobs and Sovacool 2012). High investment security is a catalyst for every investor and the absence of that can turn them off. Countries with weak economic policies or unstable political systems might experience a lack of RE investors committing to such capital intensive RE projects. This can undermine the adoption of FiT due to its design of long-term cost recovery. The German EEG has also been criticized for being an impediment to future development of more cost-effective RE addition due to early excessive lock-in of high cost RE with FiT guarantee (Frondel et al. 2009). In other countries like the U.S., FiT has been phased out and replaced with net-metering.

\subsubsection{Renewable Portfolio Standards (RPS)}

RPS policies allow state governments to set a minimum renewable energy target for regulated electric utilities under a specified time period. The RPS has arisen as a primary policy mechanism for promoting RE development in the US, especially given the lack of federal government legislation (Thombs and Jorgenson 2020; Davis 2015). Drivers of RPS adoption include liberal government ideology, higher income, RPS policy diffusion among states in proximity, RE potential, energy market deregulation, RE production, and availability of RE interest groups and associations (Thombs and Jorgenson 2020).

Over 30 U.S. states have adopted this policy (Zhou and Solomon, 2020; NCSL, 2020) and it has been a good alternative to the lack of federal government policy on tackling climate change. Another interesting observation is that all the municipalities where 100 percent renewable electricity have been achieved are from states with a RPS. These municipalities are Aspen, Colorado; Burlington, Vermont; Georgetown, Texas; Greensburg, Kansas and Rock Port, Missouri, U.S. (Adesanya et al. 2020). Reference to this 100 percent renewable electricity is not intended to assert causality, but a correlational relationship between RPS and renewable electrification.

The case of some states without RPS reveals potential setbacks of depending on state initiative for electricity decarbonization (Davis 2015). As RPS represent RE share in electricity which is usually set towards a specified year in future, such may be relaxed 
afterwards due to changes in state's political leadership. Another potential setback with RPS is the possibility of adopting states and their utilities to see the target as a ceiling rather than a baseline. Zhou and Solomon (2020) in their research find that low renewable energy resources could have negative impact on beyond RPS compliance. Nonetheless, state RPS is a significant policy tool for promoting electricity from renewable resources in countries without comprehensive national energy policies. Thus, offering an easy way to achieve the SDG7.

\subsubsection{Renewable Energy Credits}

One of the ways in which regulated utilities can meet the requirements of a state RPS is through renewable energy credits (RECs). RECs are tradable certificates, usable in the market purchase of electricity from RE resources (EPA-b, 2019; Michigan Legislation). This policy tool is based on the understanding that while an electric utility may have technical challenges with generating electricity from local RE resources, the utility can purchase from another in proximity for a credit. Apart from enabling utilities to meet their RE targets, RECs also foster a symbiotic relationship among energy producers.

RECs policies are not a common policy in most countries, especially low-income countries. An argument for this is perhaps their richness in renewable energy resources such as solar, wind, hydro, and geothermal. Adapting the policy can make the $100 \%$ renewable electricity goal in any of these countries or regions very viable to attain. A country well-endowed with RE energy resources can invest massively in it and sell their excess electricity production to neighboring countries for credit. It can also serve as a strategy for achieving Nationally Determined Contributions (NDCs) and foster partnerships for green energy with countries in proximity.

\subsection{Policy mechanisms}

\subsubsection{Market Mechanism}

In a perfect market, information on true prices of commodities and services is a key feature. Many energy markets are manipulated due to asymmetric supports, e.g. subsidized oil and gas. Subsidy removal would provide a market-based level playing ground for both RE and fossil fuel even without incorporation of externalities in their prices. This will unmask the true prices of electricity generation. From the lens of energy transitions, Geels (2018) argues that price and/or performance improvements could facilitate incumbent technologies being overthrown by the new ones.

Carbon pricing is another market mechanism that can create an imbalance in continuous investment in conventional fuel power plants in support of RE. For instance, solar's share of electricity has been found to increase by $2.4 \%$ in some countries with availability of carbon pricing mechanism than for those without (Best and Burke 2018). In the same 
research, wind also increases by $5.2 \%$ with carbon pricing. However, the case is slightly different when viewed in the European Union context. There, solar thermal's share of energy only increases by $1.9 \%$ with existing aggregate solar policy support, while wind does not show any relationship (Best and Burke 2018). Rather than carbon pricing, financial capital availability for producers is the crucial factor to wind technology's share contributing to electricity in this region.

\subsubsection{Regulation}

Regulatory mechanisms, also popularly known as "command-and-control" mechanisms, involves rules prohibiting certain use of technologies. Such rules are often deployed in circumstances when other mechanisms did not yield effective compliance to certain government tenets or goals. In the face of the urgency requirement for climate change, regulation of carbon-based energy technology offers potential potency. Some regulation can be complex and difficult for energy producers to meet, leading to their gradual phase out. An example is enforcing that electricity producers include all the social cost of energy produced in their integrative resources planning processes.

Unruh (2000) argues that "rational corrective policy actions in the face of climate change would include removal of pervasive subsidies and internalization of environmental externalities arising from fossil fuel use" (pg. 817). Internalization of externalities is defined as the process of ensuring that all public and private unpaid benefits or costs are incorporated into the prices of goods and services that are produced (Eidelwein et al. 2018). While subsidy removal might be relatively easy, based on past initiatives, internalizing environmental externalities appears to be more complex, requiring higher levels of technical, social, political, and economic strategies. For instance, how will a utility generating with coal power plants incorporate the social cost of acid rain and climate change? Will such cost cover the local community that they serve or across their borders to cover all impacts including those that are global? This thus presents a complex situation and government policy on internalizing externalities would foster more proliferation of clean and affordable renewable electricity.

Further, there are different arguments regarding the negative economic impacts when policies that defund and discourage perpetual consumption of fossil fuel for energy services are put into place. One such impact is the stranded assets from current global energy infrastructures, worth trillions of dollars, due to fossil fuel providing more than two-thirds of world's energy needs (Seto et al. 2016). However, Unruh (2019) submits that greater stranded assets, which include all other infrastructures and the entire human society, abound much more. Continuous support to fossil fuel and failure to discontinue heavy reliance on electricity from coal, oil, and gas, places the earth at a higher risk. By implication, a thorough cost and benefit analysis of continuous funding or defunding for the current energy system will provide a more thorough analysis of economic impacts. 
Another mechanism for promoting renewable electricity is through incentives. Incentives act as a support system to different actors in the RE industry and not only RE producers. An example is investment incentives such as capital grants, tax credits, tax incentives and low or no interest loans, which were widely used in the early emergence of RE in the 1980s and 1990s (Jacobs and Sovacool 2012). In Nigeria, other incentives to promote renewable energy include tax holidays for RE technologies, such as component manufacturing by local industries and importers (Adesanya 2017). One reason may be the differences in policy across the EU region. Denmark, for instance, which has the highest wind energy use per capita, had a robust energy policy mix such as investment subsidies, taxes on energy and pollution, and a financial guarantee (Best and Burke 2018).

\subsection{Summary and Conclusion}

The world has seen diverse policies that have been instrumental to the promotion of RE adoption going by the review in the preceding sections. Specifically, for renewable electrification, distributed generation implementation, feed in tariffs, net-metering, and renewable portfolio standards have been identified. These policies are widely used both in high income and low-income country contexts. They can drive the SDG7 goals for access to modern, clean, and affordable electricity by 2030 as set by the UN. Although these policies are not without their weaknesses, they remain the most potent for promoting the renewable energy transition. Also, the combination of policy mechanisms such as market mechanisms, regulation, and incentives can further strengthen the transition to renewable electricity supply across the globe.

For the future, electrical energy systems that conform to the sustainable development goals (SDGs) of the United Nations must be just and socially, economically, and environmentally sustainable. To promote social justice, the UN established a correlation between decisions made on energy and climate policies and actions regarding the current energy system. Policy designs for moving energy systems toward 100\% RE that is just and that reduces social power differentials will align with the frameworks of energy justice. Eight energy justice frameworks have been identified - availability, affordability, intergenerational and intragenerational equity, responsibility, sustainability, good governance, and due process. These involve equitable sharing of burdens and benefits from the energy system, recognizing energy services as a basic good and right of the people, following due process in development of such systems, and recognizing the vulnerable people (present and future generations) and mitigating the negative impacts that energy systems have on the most vulnerable among us. Such policy considerations would cut across local, state, and national scales.

Local communities are also well placed to identify local needs, take proper initiative, and lead grassroots action toward sustainable development and climate policy making processes. Community RE planning through distributed generation policy is an example. Community participation in preliminary energy decision-making processes can facilitate 
grassroots input and due process in energy policy making. Such participation can provide understanding of specific concerns and priorities regarding energy and climate. This is because while community energy may be a viable solution in one place, net-metering for individual prosumers in the community may be preferred in another. In other words, there is no one size fits all solution for all communities without their engagement, even those from the same country or state. This is because of the heterogeneity of needs and goals from one community to another.

Locally, participation of individuals and communities in decentralized, distributed generation (DG) and RE technologies can facilitate transition to $100 \%$ RE. First, such participation is a way of sending signals to the government on social acceptance of flexible carbon neutral technologies. Second, it is also an indication of avoiding being entrenched

in carbon lock-in. Thus, when more individuals and communities show support and participate in energy policies on DG, the more the increment in RE adoption, transitioning away from carbon locked in situation.

At the state level, making strategic energy policies that feature integration of flexible and short time energy technologies can be very helpful. By flexibility, this implies state support for investment in energy systems based on current demand, and then gradually ramping up to cater to future demand growth. This approach is contrary to the conventional approach of building coal power plants big enough to meet both current and future growth in energy demand. For instance, the average lifetime of this power plant is about fifty years (Erickson et al. 2015) and big enough to meet large demand. Meanwhile, the ability to scale energy technologies such as solar PV can facilitate meeting such flexibility requirements.

Stricter national policies and regulations on carbon can provide viability to increase RE. A level playing ground for energy markets with subsidy removal can provide the true costs of different energy systems. This cost will include environmental and social costs of producing electricity. From that cost, nation states can begin to strategically develop policies to promote energy systems that are economically, socially, and environmentally sustainable.

\section{References}

Adesanya, Adewale. (2017). Impact assessment of Nigerian private sector investment on captive power generation from solar pv-diesel hybrid system. Research gate

Adesanya, A. A., \& Schelly, C. (2019). Solar PV-diesel hybrid systems for the Nigerian private sector: An impact assessment. Energy Policy, 132, 196-207.

Adesanya, A. A., Sidortsov, R. \& Schelly, C. (2020). Act locally, transition globally: Grassroots resilience, local politics, and five municipalities in the United States with 100\% renewable electricity. Energy Research \& Social Science, 67, 101579. 
Anaya, K. L., \& Pollitt, M. G. (2015). Integrating distributed generation: Regulation and trends in three leading countries. Energy Policy, 85, 475-486.

Best, R., \& Burke, P. J. (2018). Adoption of solar and wind energy: The roles of carbon pricing and aggregate policy support. Energy Policy, 118, 404-417.

CRS Report (2019). Net-Metering: In Brief. https://fas.org/sgp/crs/misc/R46010.pdf

Davis, S. (2015). Renewable electricity generation and transmission expansion: a federal, state or regional approach? The Electricity Journal, 28(4), 28-35.

Eidelwein, F., Collatto, D. C., Rodrigues, L. H., Lacerda, D. P., \& Piran, F. S. (2018). Internalization of environmental externalities: Development of a method for elaborating the statement of economic and environmental results. Journal of Cleaner Production, 170, 1316-1327.

EPA-a (2019). Global Greenhouse Gas Emissions Data. https://www.epa.gov/ghgemissions/global-greenhouse-gas-emissions-data

EPA-b (2019). Green Power Partnership; Renewable Energy Credits (RECs) https://www.epa.gov/greenpower/renewable-energy-certificates-recs (Accessed 1 June 2020)

Erickson, P., Kartha, S., Lazarus, M., \& Tempest, K. (2015). Assessing carbon lock-in. Environmental Research Letters, 10(8), 084023.

European Commission (2019). COP25 climate change conference - Questions and Answers. https://ec.europa.eu/commission/presscorner/detail/en/qanda_19_6650 (Accessed 10 February 2020)

Frondel, M., Ritter, N., Schmidt, C. M., \& Vance, C. (2010). Economic impacts from the promotion of renewable energy technologies: The German experience. Energy Policy, 38(8), 4048-4056.

Heffron, R. J., McCauley, D., \& Sovacool, B. K. (2015). Resolving society's energy trilemma through the Energy Justice Metric. Energy Policy, 87, 168-176.

IEA (2020). Global CO2 emissions in 2019. https://www.iea.org/articles/global-co2emissions-in-2019

Jacobs, D., \& Sovacool, B. K. (2012). 1.06-Feed-In Tariffs and Other Support Mechanisms for Solar PV Promotion. Comprehensive Renewable Energy, 1, 73-109.

Klass, A., \& Wiseman, H. (2016). Energy Law. West Academic. Electricity chapters only. Please identify the most applicable chapters and sections to your learning goals. 
Koirala, B. P., Koliou, E., Friege, J., Hakvoort, R. A., \& Herder, P. M. (2016). Energetic communities for community energy: A review of key issues and trends shaping integrated community energy systems. Renewable and Sustainable Energy Reviews, 56, 722-744.

Michigan Legislation. Clean and renewable energy and energy waste reduction act Act 295 of 2008.

http://www.legislature.mi.gov/\%28S\%28zovnn1an1tdvcy55sp04phbe\%29\%29/document s/mcl/pdf/mcl-Act-295-of-2008.pdf

MIT Technology Review (2020). Climate Change. Global carbon dioxide emissions were flat last year, even as the economy grew

https://www.technologyreview.com/f/615182/global-carbon-dioxide-emissions-were-flatlast-year-even-as-the-economy-grew/?et_rid=505248737\&et_cid=3207864

Moosavian, S. M., Rahim, N. A., Selvaraj, J., \& Solangi, K. H. (2013). Energy policy to promote photovoltaic generation. Renewable and Sustainable Energy Reviews, 25, 44-58.

NCSL (2020). State Renewable Portfolio Standards and Goals.

https://www.ncsl.org/research/energy/renewable-portfolio-standards.aspx

Pepermans, G., Driesen, J., Haeseldonckx, D., Belmans, R., \& D'haeseleer, W. (2005). Distributed generation: definition, benefits and issues. Energy policy, 33(6), 787-798.

Poullikkas, A., Kourtis, G., \& Hadjipaschalis, I. (2013). A review of net metering mechanism for electricity renewable energy sources. International Journal of Energy \& Environment, 4(6).

Prehoda, E., Pearce, J. M., \& Schelly, C. (2019). Policies to Overcome Barriers for Renewable Energy Distributed Generation: A Case Study of Utility Structure and Regulatory Regimes in Michigan. Energies, 12(4), 674.

https://doi.org/10.3390/en12040674

Prince Albert 2 of Monaco Foundation (2019). As the COP25 opens, HSH Prince Albert II of Monaco Urges World Leaders to Take Immediate Action to Address Ocean Crisis 02/12/2019. https://www.fpa2.org/news-6908.html (Accessed 10 February 2020)

Robert, K. W., Parris, T. M., \& Leiserowitz, A. A. (2005). What is sustainable development? Goals, indicators, values, and practice. Environment: science and policy for sustainable development, 47(3), 8-21.

Schelly, C., Louie, E. P., \& Pearce, J. M. (2017). Examining interconnection and net metering policy for distributed generation in the United States. Renewable Energy Focus, $22,10-19$. 
Schelly, C., Bessette, D., Brosemer, K., Gagnon, V., Arola, K. L., Fiss, A., ... \& Halvorsen, K. E. (2020). Energy policy for energy sovereignty: Can policy tools enhance energy sovereignty? Solar Energy, 205, 109-112.

Seto, K. C., Davis, S. J., Mitchell, R. B., Stokes, E. C., Unruh, G., \& Ürge-Vorsatz, D. (2016). Carbon lock-in: types, causes, and policy implications. Annual Review of Environment and Resources, 41, 425-452.

Sovacool, B. K., Heffron, R. J., McCauley, D., \& Goldthau, A. (2016). Energy decisions reframed as justice and ethical concerns. Nature Energy, 1(5), 16024.

Sovacool, B. K., \& Dworkin, M. H. (2015). Energy justice: Conceptual insights and practical applications. Applied Energy, 142, 435-444.

Sovacool, B. K., Sidortsov, R. V., \& Jones, B. R. (2014). Chapter 2: Deciphering energy justice and injustice in Energy security, equality and justice. Routledge.

Thombs, R. P., \& Jorgenson, A. K. (2020). The political economy of renewable portfolio standards in the United States. Energy Research \& Social Science, 62, 101379.

United Nations. Sustainable Development Goals.

https://sustainabledevelopment.un.org/sdgs

Unruh, G. (2000). ‘Understanding carbon lock in', Energy Policy 28, 817-830

Unruh, G. (2002). “Escaping Carbon Lock-in” Energy Policy 30. 317-325.

Unruh, G. C. (2019). The Real Stranded Assets of Carbon Lock-In. One Earth, 1(4), 399401.

Wiseman, H. J., \& Osofsky, H. M. (2016). Regional Energy Governance and US Carbon Emissions. Ecology LQ, 43, 143.

Zhou, S., \& Solomon, B. D. (2020). Do renewable portfolio standards in the United States stunt renewable electricity development beyond mandatory targets? Energy Policy, 140, 111377. 


\section{Overall Research Conclusion and Contribution}

\subsection{Conclusion}

This dissertation has identified pathways that can be taken for successful just energy transition to $100 \%$ renewable electricity. The answers to the overall research questions have been provided on the technical, policy, and perceptual pathways, barriers, and opportunities for just transition to $100 \%$ renewable electricity in the U.S., at states and local level. $100 \%$ RE transition is technically feasible with the available renewable resources. The feasibility of a wholly renewable electricity is also economically viable. However, the economic viability is contingent on extended use of the electricity generated to other purposes such as electric heating and electric vehicle deployment. The techno-economic feasibility also depends upon policies and programs (such as energy efficiency) programs can also improve this viability. The RE transition can align with prohibitive justice principles with its cost not interfering in an individual's ability to meet other basic good, and with procedural justice principle by engaging the public in the process. The summary and conclusion from this dissertation are presented in this section.

This conclusion section starts with the highlights of important approaches, which are taken in the research process to ensure successful study of the STST. Since all innovations in sociotechnical transition leverages on existing knowledge, the importance of approach to know production is discussed in this dissertation.

\subsubsection{Positionality and Trust in Research Design}

In just transition research design, it is very essential that researchers are mindful of social issues such as systemic or personal biases that can complicate the process of untangling the inherent complexity in the STST process. This is to ensure fairness in the future planning and decision-making process. In other words, the approach of researchers in their investigations in producing useful information for the public and decision-makers is very important. The approach requires some level of sensitivity on the part of researchers to carefully observe how their social, cultural, economic, and political influences make or mar the output of their research. There are some social factors that can influence research, especially when it involves participation members in the community. These factors include researcher's positionality, and the issue of trust in the research process from the angle of community members or residents.

Positionality in research is a concept that recognizes how a researcher's position, experiences, biological, or social attributes in the society may influence the methodology and or results of a research (Moser, 2008; Corlett and Mavin, 2018). Positionality includes gender, race, and whether the researcher is a recognized member of the community. Scenarios created by positionality are capable of hampering or facilitating a research process, especially when the research involves some interaction with the public as a person 
of color (Bourke, 2014). It is important for researchers to be more conscious of how they can positively or negatively influence research processes. Such social consciousness in research is embedded in the concept of positionality.

On the flip side, trust from residents is another related factor that can affect researchers in obtaining public opinion. The ability to have sufficient input from the public in a social process is built upon established trusts and beliefs. Conducting research in a place where researchers are perceived as foreigners can lead to little or no trust in the process and so can hamper successful exchange of ideas, information, and opinion. The ripple effect is inability to achieve productive work that will benefit society. An example of this is public attitudes toward some large-scale solar energy in Southwest, U.S. (Carlisle et al, 2015) and wind energy in Texas (Swofford and Slattery, 2010) development as a result of the community's lack of trust on project developers and lack of public trust in the process. It is therefore important to note how positionality and trust was deployed and their impact on the research design and results in this dissertation.

Due to the underlying racial issues in the public domain, the author's positionality was put into consideration in the poster distribution activity described in chapter four, to achieve wider public participation and more data collection. As a black researcher with a different accent from that of Americans, and conducting empirical research in white dominated area, the author recognizes that his positionality could hamper attention, and participation of racially sensitive individuals. The research outlined in chapters three and four occurred during the spring and summer of 2020, a time of escalating racial violence and protest. Invariably, the author considered that his positionality could stand as a barrier to participation of some specific set of residents in the region and increase coverage error. Absence of the approach could lead to skewness of data collection and unfair conclusion

As such, the author employed voluntary service of a white female American colleague to lead conversations with residents in public places that were approached during the distribution of survey posters. For instance, various restaurants, small shops, and bars in the downtown at Marquette, Escanaba, and Iron Mountain were visited for the distribution of posters. Commuters at various parks in the visited areas were also approached and given the survey information poster after brief conversations. Visits to main grocery stores such as Walmart and Meijer in the WUP counties was also done to distribute posters. However, the authorities of these grocery stores did not allow the activity of such distribution within their premises or properties.

In addition, due to the ongoing COVID 19 pandemics, the author perceived that it might be hard to get the attention of people to participate in a survey. Another consideration was the author's limited contacts with residents in the region. Thus, residents who are in the author's network, including the same civic organizations, and have larger connections within the region were requested to share the survey questionnaire link. This was very influential as the largest percentage of respondents came from the county where the author resides and has the most established social network within the WUP region. 
Another way that the author's positionality was considered was in collection of real-time hourly energy data from utilities, which were used in modelling and simulation of $100 \%$ renewable electricity systems in the three municipalities. The author leveraged trust that existed between certain members of the university community and the larger community to request the needed data. As a researcher that is relatively new in the region, and with relatively less interaction with utilities in the region, load data were collected through local networks and referral to stakeholders and the relevant decision-makers within the local utilities.

\subsubsection{Conclusion Based on Research Results}

This dissertation has established that successful STST such as that of $100 \%$ RE is contingent on various factors and interactions between actors. Within the theoretical framework of MLP, individual factors that matter for this transition to occur have been identified. Specifically, the pathway to achieving a just $100 \%$ RE will involve assessing minimum required resource availability, further development in RE technologies, technical energy systems design, strong social or residents' consent and positive attitudes towards RE development, changes in energy landscape, changes in behavioral pattern of energy consumption, and enabling policies for municipalities to self-organized. All these factors are not in isolation, rather, they all interact and are embedded in one another to lead to change in the energy system in any geographical area.

\subsubsection{Minimum Renewable Energy Resources}

Results from this dissertation have clearly shown that there are sufficient RE resources available for a transition to $100 \% \mathrm{RE}$, even in the geographically unlikely climate of the northern, rural, snowy Upper Peninsula. The synthetic wind potentials generated from meteonorm in the resource assessment, shows ample availability of such in the WUP areas studied. The $100 \%$ RE model also shows a large percentage of wind in the renewable fraction, making it an important technology to consider in the transition planning. Solar energy also possesses a complementing resource for the region, despite the extreme weather situation in the region. While it is not self-sufficient to meet year-round electricity demand without wind, its technical design must consider optimum tilt angle for cost effective energy production. Tilt angle of $45^{\circ}$ has proven to be a viable design option in the preliminary technical feasibility study. However, both the wind and solar energy technologies output must be supported by energy storage systems such as battery and hydro. Existing hydropower capacity in WUP can drive down electricity prices from renewables if they are channeled to serve the region.

In all, the combination of these technologies with their fallen prices can offer lower electricity cost (or LCOE) than what residents pay for the current utility rates, under various policy and program designs applicable to the state of Michigan. The low energy cost achieved from simulation also aligns with factors that will spur residents' support for such. 
The importance of electric bill reduction for individual resident and municipal schools was identified as an important consideration for resident support for RE in the survey that was conducted. It is perhaps an indication of how residents are wary of exorbitant electricity prices in the region that have affected their personal expenses. By implication and extension, prohibitive justice can be achieved with lower cost renewable energy resources for electricity supply.

\subsubsection{People and Community Centered Energy Transition}

One of the assumptions in this dissertation in the techno-economic feasibility of $100 \% \mathrm{RE}$ is co-location and installation of the energy technologies. The resident survey research also shows that there will be high support for renewable electricity development in the WUP counties, especially in Houghton county, with the use of available land or space for such development. As these technologies will take ample space, the support from local landowners, farmers, residents, and municipality leaders will be very key for a successful transition process. While support from residents who are landowners or farmers can facilitate access to usable land for wind and solar farm development, a buy-in from municipality leaders can facilitate access to municipally owned land and properties. More so, municipality leaders can lead in referendums to support such energy development in their locality (Klass and Wiseman, 2017).

WUP residents have clearly identified what matters most to them in supporting RE development in their locality, which include ability to voluntarily purchase electricity from RE generation, installation of solar on degraded land and corporate rooftop, and importance of fossil fuel reduction among others with lesser priorities. Local leaders, policy makers, utility regulators, and other stakeholders would need to consider residents' interest in leaving behind a positive future legacy. This can facilitate achieving intergenerational justice in the development of energy systems. Local communities and residents in the WUP also seem well placed to identify local needs, take proper initiative, and lead grassroots action toward sustainable development and climate policy making processes. This is evident in their responses to supporting energy efficiency programs in matching their energy demands with available resources. Residents' participation at the county level in the preliminary decision-making process through the survey on energy and climate is essential in having a sense of general concerns and priorities. While this is valid for WUP residents based on this research, supporting factors may be different in other places. In other words, there is no one size fits all solution for all communities without their engagement, even those from the same country or state. This is because of heterogeneity of needs and goals from one community to another.

\subsubsection{Just Energy Transition Factors}

Energy systems that would conform to the sustainable development goals (SDGs) of the United Nations must be just and socially, economically, and environmentally sustainable. 
To promote social justice, there is a clear correlation between it and decisions made regarding energy and climate policies and actions regarding current energy systems. Policy designs to promote a transition in energy systems such as the transition to $100 \%$ RE that would be just and reduce social and power differentials would consider the three lenses of social justice. This includes equitable sharing of burdens and benefits from the system, recognizing energy service as basic good and right of the people, and following due process in development of such systems and recognizing the vulnerability from the potential impacts. Such policy considerations would cut across local, state, and national scales.

At the state level, making strategic energy policies that feature integration of flexible and short time energy technologies can be very helpful. By flexibility, this implies state support for investment in energy systems based on current demand and then gradually ramping up to cater for future demand growth. This approach is contrary to the conventional government's support for the building of magnificent coal power plants for instance, big enough to meet both current and future growth in energy demand. For instance, the average lifetime of a coal-fired power plant is about fifty years (Erickson et al., 2015) and big enough to meet a very large demand. Meanwhile, the scalability of energy technologies such as solar photovoltaic can meet such flexibility requirements, providing energy at the scale and source needed (Schumacher, 1986).

Policies to encourage this transition include distributed generation and community energy development. Distributed generation and community energy development encourages the participation of the people who will use the electrical energy produced, allowing democratic governance of community energy systems. Democratic energy governance may reduce power differential in the society by allowing inclusivity in the decision-making processes. On the other hand, it is capable of limiting monotonous power from centralized entities in the society.

\subsubsection{Policy Implications and Future Work}

\subsubsection{Policy on Municipalization of Utility}

In addition to the sets of policies highlighted in Chapter 5, another salient policy area to facilitate a $100 \% \mathrm{RE}$ transition is the support for municipalization of utilities (MOUs). It is evident that the inability of communities in the WUP region to self-organize and produce their own electricity can be a setback in achieving renewable energy transition in the absence of interest from existing investor owned utilities (IOUs). One of the reasons for this is because local government policies usually require MOUs to purchase from renewable sources (Martinot et al, 2005; Hess, 2011). In the face of such local policies, municipalities may not be subject to state based or utility caps that can limit the extents of RE generation. Argument has also been made that municipal utilities are leaders in promoting energy efficiency and renewable energy as they often have greater renewable energy in their portfolio than the private counterpart (Bluvas, 2006; Hess, 2013; Homsy 
2015). This is perhaps because locally made and implemented public policies, especially on energy, have been more effective in advancing energy conservation and transition to renewable resources (Brunner, 1979). In other words, municipal utilities have been argued to be flexible towards renewable energy transition and various requests of local community members (Beck and Martinot, 2016; Homsy 2015; 2018).

Another reason is the variability in energy cost between IOU and the MOUs. Variability in energy cost in the U.S. has been associated with the type of utilities (Homsy, 2015). By variability, this research refers to how high or low electric prices are with respect to utilities providing the service. This in one way is an indication of competition driven by who is in control of the utility, either it is profit or nonprofit based and policy for regulation. Competitive electricity market is the one where no single electricity company has monopolistic or dominant market power on provision of retail electric services (Martinot et al, 2005; Bluvas, 2006). This implies the presence of a combination of various types of utilities operating in a geographical location to provide services to the people. Joskow (2005) argues that competition in the US electric power sector has been hampered due to definitive U.S. electric policy.

Garcia Sanchez (2006) in her research argues that public utilities allow for direct public management which is void the bureaucracy observed with private ownership. Homsy (2015) also agrees with this idea in his research analysis while discussing local control of utilities in the U.S. The ability of the public to have direct influence on the decision making process on energy matters that affect their lives, is made possible with the establishment of MOUs. With this possibility to influence decisions, communities and counties who believe in and are concerned about climate change are empowered to take local actions through their local governments or leaders.

In principle, it is easier for MOUs to establish DG with RE than IOUs. This is because state and local governments have the authority to establish DG in the U.S. (CRS Report, 2019). Also, local governments are mostly saddled with greater responsibilities in each state (except for a few like Florida, Washington, Wisconsin and Wyoming but with some local influence) to make ultimate approval of power plant siting (Klass and Wiseman, 2017). IOUs on the other hand require a longer process for DG system establishment, especially needing permission for power plant siting which encroaches on lands of community members.

Figure 1 below shows the DG set-up procedure for MOUs (represented in green bracket) compared to IOUs DG set-up procedure in Michigan. While MOUs require seamless procedure in about two steps of local government referendum, that of IOUs is quite complex. IOUs are subject to approval from the public service utilities, followed by from MISO's and then local government. MISO represents a midcontinental integrated systems operator and it is one of the regional transmission operators (RTOs) in the U.S. (Klass and Wiseman, 2017; Wiseman and Osofsky, 2016). Policy that enables municipalities self- 
organize and form MOUs can thus facilitate public participation, energy ownership and RE transition.

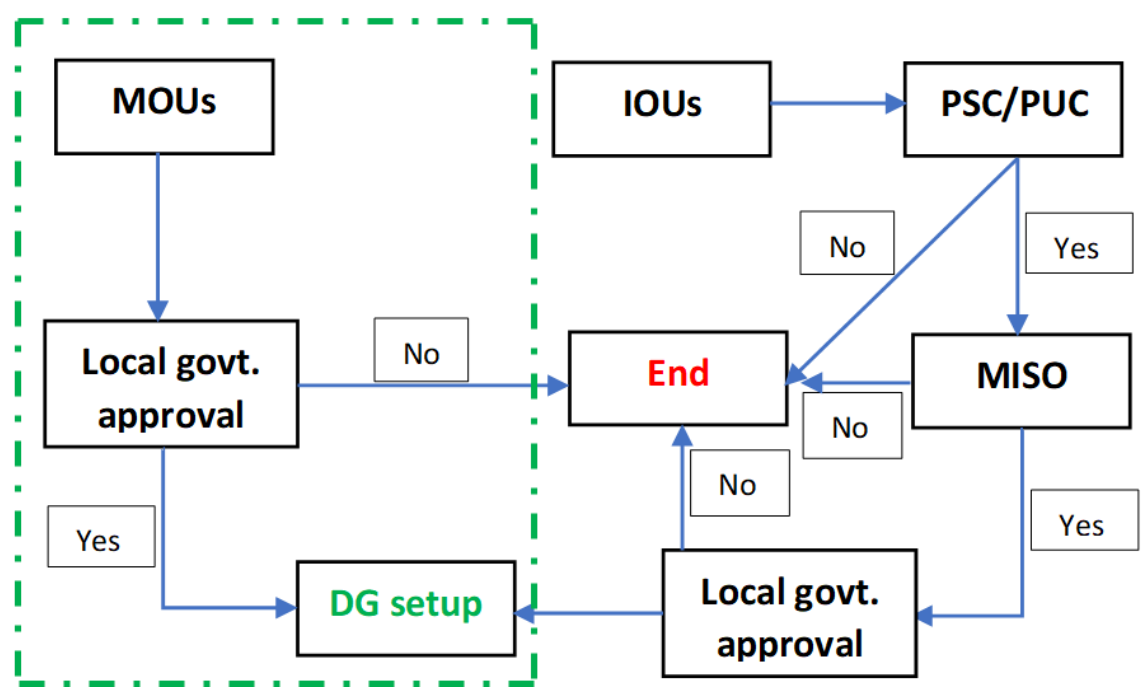

Figure 1: Empirical electricity generating plant siting and DG set-up flow chart for both MOUs and IOUs in State of Michigan (Source: developed from Klass and Wiseman, 2017)

\subsubsection{Future Work on Community Engagement}

There is a need for more robust community engagement like community-based participatory research (CBPR) to obtain full qualitative reports from stakeholders on those questions asked (see for example, the Michigan Indigenous Community and Anishinaabe Renewable Energy Sovereignty or MICARES project). Public perceptions from the survey can be used in developing a meaningful agenda for discussion on what matters to citizens of the region. Community energy is an example of energy democracy, leading to public ownership, energy sovereignty, and control of energy infrastructure (Krupa et al, 2015; Prehoda et al, 2019). These features are especially for CBPR. The core principles and values of this typology are participatory, cooperative, and equitable partnership, colearning, development and sustainability, empowerment, implementation intervention and social recognition (Shalowitz et al, 2009). This makes CBPR the best process for community engagement in energy decision making, delivering power to the people.

Locally, participation of individuals and communities in decentralized, distributed generation (DG) and renewable energy technologies can facilitate gradual transitions to $100 \%$ RE. First, such participation is a way of sending a signal to the government on the social acceptance of flexible carbon neutral technologies. Second, it is also an indication of avoiding being entrenched in possible future carbon lock-in. In other words, the more the buy-in from individuals and communities into energy policies on DG, the less impactful 
the lock-in will be with incremental transitioning from the current carbon locked-in situation.

Planning social change, especially that of grassroots energy system transitions in a rural community, requires recruiting and retaining residents as participants with a sense of identity, belonging, purpose and community (Seyfang and Haxeltine, 2010; Flint et al., 2008). Communities can be very instrumental to RE development. However, their capabilities are often undermined due to misconceptions on their rurality, fostered by social and political constructs. Flora and Flora (2013) argue that rurality is a stereotypical labelling, often perpetuated by government for administrative and political purposes. Thus, there is a need for paradigm shift on how rural places are perceived with respect to their abilities and capabilities.

\subsubsection{Future Work on Regional Wide 100\% RE Feasibility Assessment}

Due to data limitations, the technical feasibility only covers three municipalities and their various residents. While the results are only valid for these case study, future research is needed to assess the whole WUP region. One of the important factors involved in investigating the region as a whole is the possible energy resource differentials as the technical feasibility study of the three municipalities have shown. While some places are more endowed with annual wind energy resources, others could have more solar influx. Also, a municipality with more RE resources may have lesser energy demand. For instance, Delta, Houghton, and Marquette are the most populous counties in the region, but the best wind and solar resources may be in Keweenaw County with a population that is about onesixth of Marquette's.

Collective regional energy transition planning may therefore offer more economically beneficial solutions with intermunicipal sharing of resources. In addition to sources of potential energy generation, space is another capital that can be shared to achieve a common goal in the region. A region with distinct municipalities can have local leaders form coalition to take advantage of the economy of co-locating RE technology installation.

\subsection{Contributions}

The main contributions of this dissertation to scholarship on energy transition are in two categories. The first major contribution is expansion of the concept of STST and MLP on $100 \%$ renewable electricity transition. The second major contribution is justice consideration in STST. This dissertation also shows global relevance to the emerging advocacy of justice in the adoption of RE.

\subsubsection{STST and MLP Expansion to Just 100\% RE Context}


First, this dissertation contributes to the expansion of understanding of MLP framework, especially in the context of $100 \%$ RE transitions. The dissertation identifies the specific transition typology involved in each of the five municipalities that have achieved $100 \%$ renewable electricity and accounts for the factors that contributed to these successful energy transitions. Such identification is necessary for further recognition of factors to take note of in other U.S. municipalities, cities, and states for possible replication of achieving $100 \%$ RE transitions. Also, the results from the WUP case study in this dissertation can be used as reference points for the analysis of other regional multi-level actors' roles in $100 \%$ RE transitions, both within the state of Michigan and other states in the country.

The other contribution to the knowledge of MLP is the introduction of the justice component to the framework. While the MLP theory considers interactions of various actors (internal and external) in the transition processes and pathways, less connection is made between the framework and social justice. The use of the foundational approach to energy justice in the dissertation (technical feasibility and public perception chapters) can inform consideration for justice in $100 \% \mathrm{RE}$ transitions. Other applied justice considerations in the STST integration of energy democracy and sovereignty.

\subsubsection{Transdisciplinary Approach to Just 100\% RE Transition}

The second category of contributions from this dissertation is the development of transdisciplinary approach to $100 \% \mathrm{RE}$ transition. This first involves looking at justice through the lens of the sustainable development goals (SDGs) of the United Nations. Specifically, SDG 7 on affordable and clean energy is used as a bridging gap between STST and justice through the discussion of energy democracy and sovereignty. A second aspect of the transdisciplinary contribution category is the collaboration with external stakeholders and partners in the STST research. Apart from the interdisciplinarity in methodology of the research, utilities in the region had their input in the research process leading to understanding of pathways to achieving $100 \% \mathrm{RE}$.

\subsubsection{Process Flowchart for Transdisciplinary Energy Transition}

Lastly but not the least, a research process flowchart is provided (Figure 2) to help in replicating this type of research in any other contexts. This is because one of the yardsticks of knowledge provision and academic scholarship is replicating results from existing works. For future scholarship or community-based planning (in sequel to formation of community participants), idea conceptualization on energy transition starts the process. The next stage involves reflecting on the current energy system to identify embedded problems in the system as well as its effect on the society. This should lead to the third stage of asking various questions of research, geared towards solving those identified societal problems relating to energy and the environment. Simultaneously, there is a need to inquire about places that have had similar problems and analyze identifiable common factors of success. 


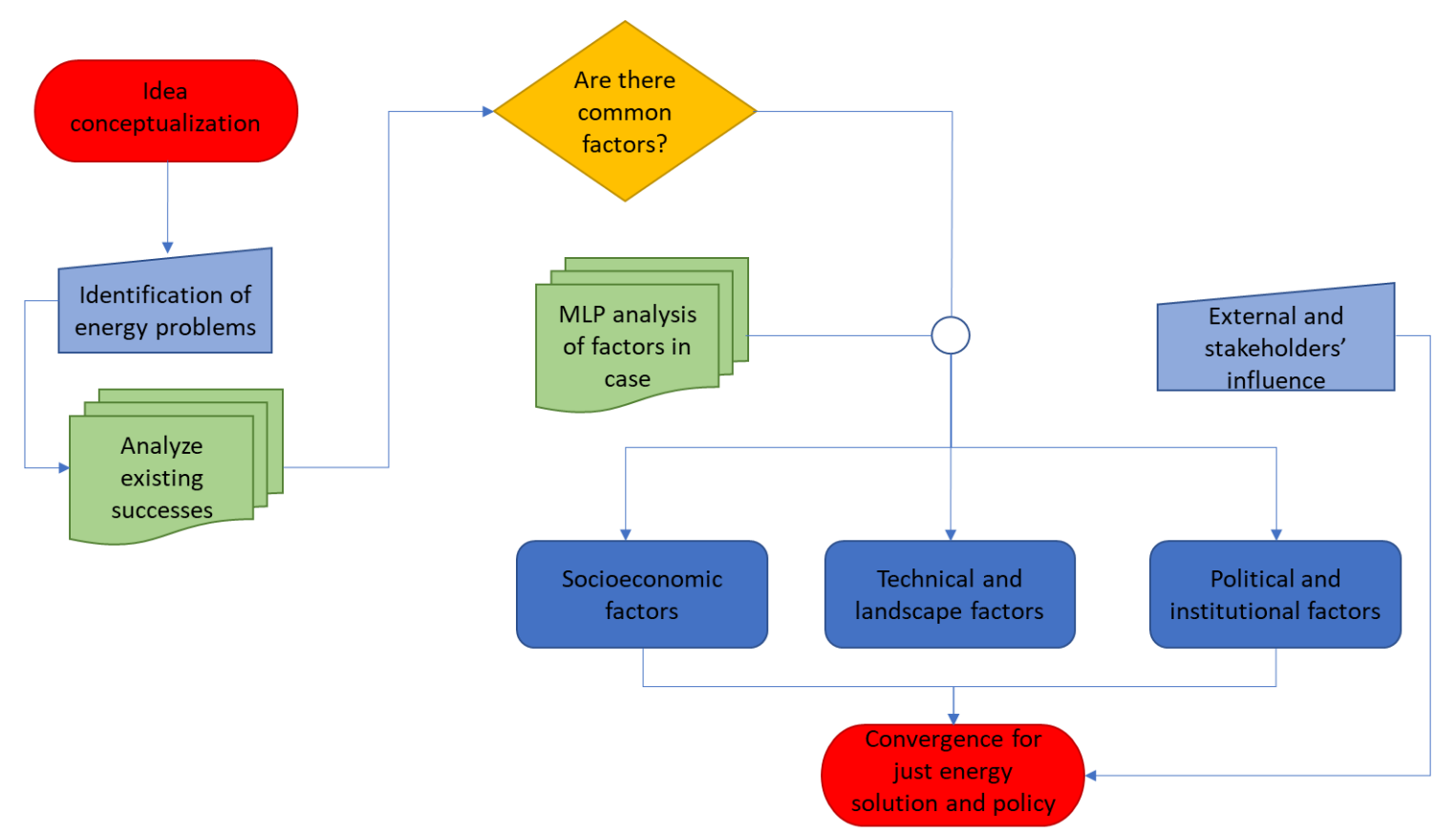

Figure 2: Process and flowchart of transdisciplinary analysis of 100\% RE pathway

Further analysis of the factors is then required, to decipher the multi-level actors across social, economic, technological, political, policy, and institutional landscape, and how they interact at different stages. This iterative process is hypothetically the most time consuming and requires interdisciplinary effort. In addition, contributions from external or industrial stakeholders to model solutions (technical, social and policy) that will encompass real life data and assumptions.

Finally, to achieve just transition to $100 \%$ RE, the technical pathway will involve energy mix of wind, solar, battery storage, and existing hydro power plants. To ensure the most economically viable scenario, the energy system will require consideration for some socioeconomic factors such as reduction in energy consumption and business models with low interest rates like the current bank rate. In addition, extended and alternative social use of electricity that is generated from $100 \%$ RE to meet other needs is required. This extended use includes electric heating, pumped hydro, and electric vehicle charging. By implication, the system to ensure the alternative energy usage will also need to be developed. The viable scenario thus shows the embedded roles of social and technical factors. Savings from the transition to $100 \%$ RE can facilitate a prohibitive principle of energy justice as savings by residents from energy cost with RE can be assigned to meeting other needs. Collection of public perception and putting them into consideration in future planning can help achieve procedural justice principles. More so, the transition process must incorporate the viewpoint and contributions of local representatives, local decision-makers, policymakers, and stakeholders in the planning process. Such convergence is a major prerequisite to achieving just transition to $100 \%$ RE. 
One of the potential barriers to the $100 \% \mathrm{RE}$ is absence of policies that allow municipalities in WUP from self-organizing, ownership of energy systems, and control of municipalities. Some utility policies like utilities capping customers in distributed generation to $1 \%$ also pose a potential barrier. While the current utility type does not favor $100 \%$ RE, growing interest of grassroots and regional agencies like WUPPDR on RE offers potential opportunities for the STST in the energy system. Appendices 1 and 2 provide a summary of key findings from the technical feasibility research and public perception on $100 \% \mathrm{RE}$ respectively. The appendices are provided to give a comprehensive snapshot of what these research entails for easy public readership.

\section{Appendices}

\section{One-page summary: Achieving $100 \%$ Renewable and Self- Sufficient Electricity in Impoverished, Rural, Northern Climates: Case Studies from Upper Michigan, USA}

\section{Main research objective}

This research is geared towards assessing the technical feasibility and economic viability of $100 \%$ renewable electricity in three Western UP municipalities: L'Anse, Negaunee, and Anonymous. The Anonymous municipality is a collaborator in the project that preferred to have their identity undisclosed.

\section{Methodology}

The approach to this study is energy systems modelling and simulation, involving the RE technology component of solar PV, wind turbine, existing hydro power plant in WUP, and battery storage. HOMER Pro a state-of-the-art microgrid energy system modelling software, developed by NREL for Homer Energy. A year hourly load data (for 2019), provided by utility for each of the municipalities was used in the simulation. The key performance index of the $100 \%$ RE was given as a levelized cost of energy (LCOE). In simple terms, LCOE is the average net present cost (net cost minus net revenue) per $\mathrm{kWh}$ of electrical generation by all the power plants over their lifespan. For this research, the lifespan of solar PV and wind turbine are 30 years.

\section{Main Findings from Research}

○ $100 \%$ RE transition is technically feasible, despite the climate situation in the WUP

- $100 \%$ RE can offer up to $43 \%$ less LCOE (under the conservative baseline scenarios) than the current centralized utility rates, which are predominantly fueled by gas and coal. With the sensitivity, $100 \%$ RE can offer up to $52 \%$ less 
LCOE. Sensitivity is the consideration of other uncertainties such as energy efficiency, battery prices, and falling component costs. This presents a case for the prohibitive justice principle.

- LCOEs that are lower than commercial rates are plausible within the next 5 years, given the falling cost of RE generation and battery storage.

- Current economic viability is hinged on ability to sell and utilize excess production for other needs such as electric heating (instead of propane), pumped hydro, electric vehicle (charging), etc.

- Ability of communities or municipalities to self-organized to produce and sell their electricity is important and can facilitate the 100\% RE transition scenario

- Energy efficiency also proved to be a major cost driver

\section{Recommendation for future action}

It is recommended to ensure the most economically viable scenario, the $100 \%$ RE system will require consideration for some socioeconomic factors such as reduction in energy consumption and business models with low interest rates like the current bank rate. In addition, extended and alternative social use of electricity that is generated from $100 \%$ $\mathrm{RE}$ to meet other needs is required. This extended use includes electric heating, pumped hydro, and electric vehicle charging. Future work on assessment of $100 \% \mathrm{RE}$ in the whole WUP municipalities will be needed - with data from Transmission System Operators (TSO) or all the utilities in the region.

\section{One-page summary: How can Michigan's Western UP Achieve Just transition to $100 \%$ Renewable Electricity? Survey of public perception in Sociotechnical Change}

\section{Main Objective}

The main objective of this research is to capture and analyze broader perspectives from residents about factors that would make them to be more or less supportive of a transition to a $100 \%$ RE in their counties. Specifically, it is geared towards assessing factors that correlate with residents' support for a transition to $100 \% \mathrm{RE}$ and how support for such transition differs between counties in the WUP.

\section{Methodology}

Survey of WUP residents was carried out, using a survey instrument adapted from previous research on public perceptions of solar development. The survey, after being 
pretested by members and non-members of the MTU community, was launched online for residents' participation for 60 days. Questions asked in the survey include demographic information; residents' knowledge level about each of solar, wind, and hydro resources for electricity supply; level of agreement with various questions on climate change, the use of RE, RE investment in the community, and its contribution based on individual perception; support for mid-to-large RE development; residents' rating of factors that should be important in 100\% RE planning; likelihood to support energy consumption reduction to meet available resources; RE technology installation options and their visibility preferences; RE project financing options and preferences; and project development options and how it will change their support.

\section{Main Findings from Research}

$>$ There is a positive relationship between public support for RE (both solar and wind) development and if residents consider fossil fuel reduction as an important factor in the support for such development.

$>$ Although, approximately $80 \%$ of the respondents are in support of mid-to-large scale RE, there is a wide gap between support for solar and support for wind.

$>$ It is most likely that installation of RE infrastructures would not have significant opposition if they are visible to residents

$>$ Residents' consideration of the impact of consumption reduction to meet renewable energy resources as an important factor shows a potential for their acceptance of energy efficiency programs.

$>$ While a survey cannot replace the deeper forms of engagement such as communitybased participatory research (CBPR), it can serve as a foundation for community engagement in energy planning

\section{$\underline{\text { Recommendation for future action }}$}

First, it is strongly recommended that actionable decisions should not be made by local leaders, policymakers, or interest parties solely on the results of this survey without a CBPR. Results from this research is only intended to serve as the foundation for ensuring that due procedure is followed in gathering broader perception of residents on $100 \%$ RE. Second, the result from this research offers useful information that can be leveraged for future decision-making processes by involving public engagement.

\section{Reference}

Beck, F., \& Martinot, E. (2016). Renewable energy policies and barriers. Google Scholar

Bluvas, K. (2006). Distributed Generation: A Step Forward in United States Energy Policy Comment. Albany Law Review, 70(4), 1589-1614. Retrieved from https://heinonline.org/HOL/P?h=hein.journals/albany70\&i=1603 
Bourke, B. (2014). Positionality: Reflecting on the research process. Qualitative Report, 19(33).

Brunner, R. D. (1979). Decentralized energy policies. Policy Studies Review Annual, 4, 331. Google Scholar

Carlisle, J. E., Kane, S. L., Solan, D., Bowman, M., \& Joe, J. C. (2015). Public attitudes regarding large-scale solar energy development in the US. Renewable and Sustainable Energy Reviews, 48, 835-847.

Corlett, S., \& Mavin, S. (2018). Reflexivity and researcher positionality. The SAGE handbook of qualitative business and management research methods, 377-399.

CRS Report (2019). Net-Metering: In Brief. https://fas.org/sgp/crs/misc/R46010.pdf

Flint, C. G., Luloff, A. E., \& Finley, J. C. (2008). Where is "community" in communitybased forestry?. Society and Natural Resources, 21(6), 526-537.

Flora, C. B., \& Flora, J. L. (2013). Rural Communities: Legacy and change. Boulder, CO: Westview Press.

García-Sánchez, I. M. (2006). Efficiency measurement in Spanish local government: the case of municipal water services. Review of Policy Research, 23(2), 355-372.

Hess, D. J. (2011). Electricity Transformed: Neoliberalism and Local Energy in the United States. Antipode, 43(4), 1056-1077. https://doi.org/10.1111/j.14678330.2010.00842.x

Homsy, G. C. (2015). Powering sustainability: Municipal utilities and local government policymaking. Environment and Planning C: Government and Policy, 34(6), 1076-1094. https://doi.org/10.1177/0263774X15596530

Homsy, G. C. (2018). Capacity, sustainability, and the community benefits of municipal utility ownership in the United States. Journal of Economic Policy Reform, 1-18.

Joskow, P. L. (2005). Transmission policy in the United States. utilities Policy, 13(2), 95115 .

Klass, A., \& Wiseman, H. (2017). Energy Law. West Academic.

Krupa, Joel, Lindsay Galbraith and SB. "Participatory and multi-level governance: applications to Aboriginal renewable energy projects." Local Environ 2015;20:81-101.

Martinot, E., Wiser, R., \& Hamrin, J. (2005). Renewable energy policies and markets in the United States. Center for Resource Solutions. 
Moser, S. (2008). Personality: a new positionality?. Area, 40(3), 383-392.

Prehoda, E., Pearce, J. M., \& Schelly, C. (2019). Policies to overcome barriers for renewable energy distributed generation: A Case study of utility structure and regulatory regimes in Michigan. Energies, 12(4), 674.

Schumacher, E. F. (1986). Small is beautiful. Rowohlt.

Seyfang, G., \& Haxeltine, A. (2010). Growing grassroots innovations: Exploring the role of community-based social movements for sustainable energy transitions (No. 10-08).

CSERGE working paper EDM.

Shalowitz, M. U., Isacco, A., Barquin, N., Clark-Kauffman, E., Delger, P., Nelson, D., Quinn, A., \& Wagenaar, K. A. (2009). Community-based participatory research: a review of the literature with strategies for community engagement. Journal of Developmental \& Behavioral Pediatrics, 30(4), 350-361.

Swofford J, Slattery M. Public attitudes of wind energy in Texas: Local communities in close proximity to wind farms and their effect on decision-making. Energy Policy 2010;38:2508-19. https://doi.org/10.1016/j.enpol.2009.12.046.

Wiseman, H. J., \& Osofsky, H. M. (2016). Regional Energy Governance and US Carbon Emissions. Ecology LQ, 43, 143. 